\title{
モUSES
}

science for a changing world

Evaluation of Intake Efficiencies and Associated Sediment-Concentration Errors in US D-77 Bag-Type and US D-96-Type Depth-Integrating Suspended-Sediment Samplers

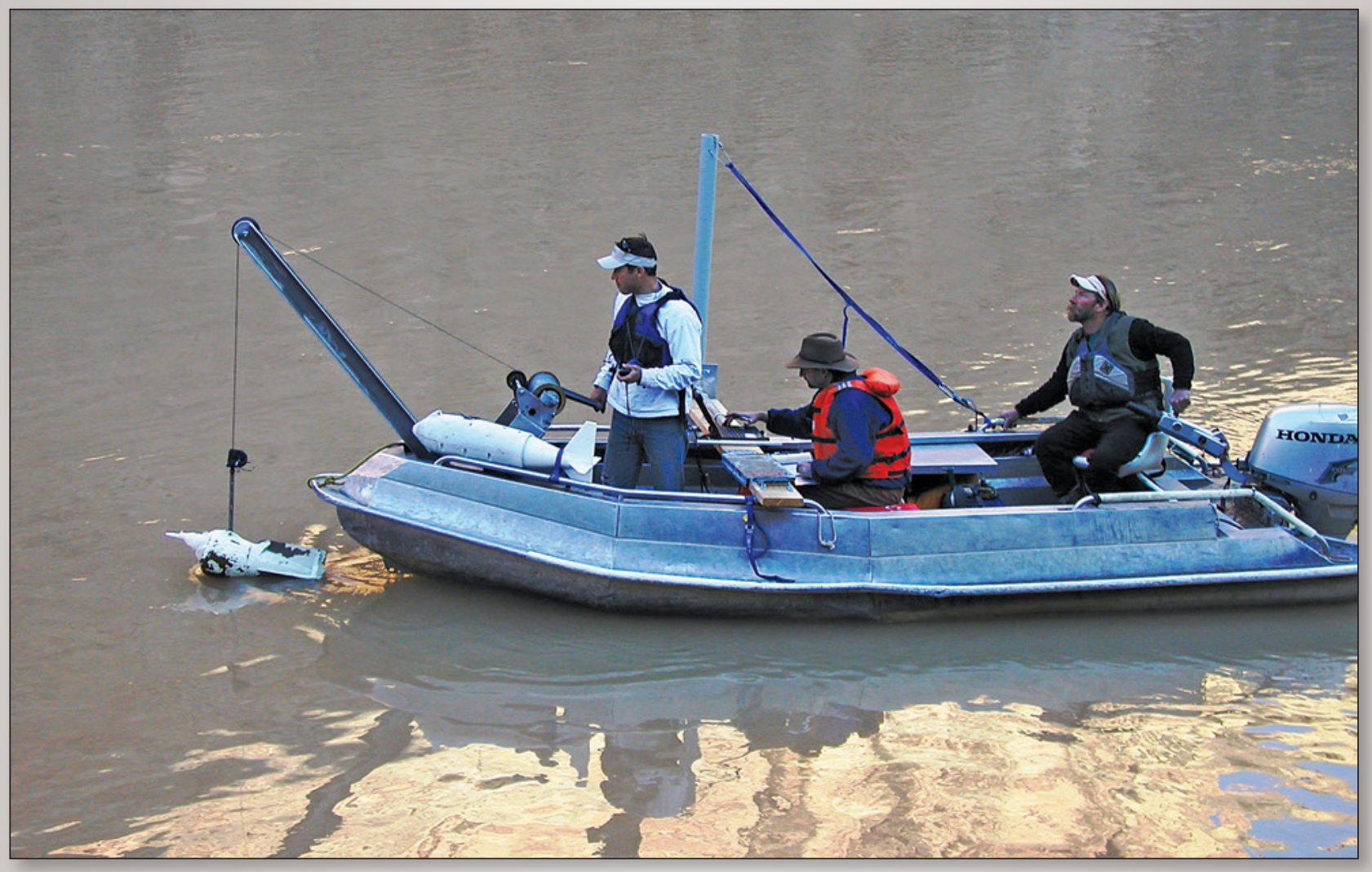

Scientific Investigations Report 2012-5208 
Cover: Photograph showing typical setup of the sampling vessel used to collect depthintegrated suspended-sediment samples with either the US D-77 bag-type (suspended from crane) or the US D-96-type (resting on gunwale) suspended-sediment samplers. An acoustic Doppler current profiler (ADCP), deployed off of the gray vertical boom on the starboard side of the vessel, is used to collect velocity data concurrent with the operation of both suspended-sediment samplers. 


\section{Evaluation of Intake Efficiencies and Associated Sediment-Concentration Errors in US D-77 Bag-Type and US D-96-Type Depth-Integrating Suspended-Sediment Samplers}

By Thomas A. Sabol and David J. Topping

Scientific Investigations Report 2012-5208 


\title{
U.S. Department of the Interior SALLY JEWEL, Secretary
}

\section{U.S. Geological Survey Suzette M. Kimball, Acting Director}

\author{
U.S. Geological Survey, Reston, Virginia: 2013
}

For more information on the USGS - the Federal source for science about the Earth, its natural and living resources, natural hazards, and the environment, visit http://www.usgs.gov or call 1-888-ASK-USGS.

For an overview of USGS information products, including maps, imagery, and publications, visit http://www.usgs.gov/pubprod.

To order this and other USGS information products, visit http://store.usgs.gov.

Any use of trade, firm, or product names is for descriptive purposes only and does not imply endorsement by the U.S. Government.

Although this information product, for the most part, is in the public domain, it also may contain copyrighted materials as noted in the text. Permission to reproduce copyrighted items must be secured from the copyright owner.

Suggested citation:

Sabol, T.A., and Topping, D.J., 2013, Evaluation of intake efficiencies and associated sediment-concentration errors in US D-77 bag-type and US D-96-type depth-integrating suspended-sediment samplers: U.S. Geological Survey Scientific Investigations Report 2012-5208, 88 p., http://dx.doi.org/10.3133/sir20125208.

ISSN 2328-0328 (online) 


\section{Contents}

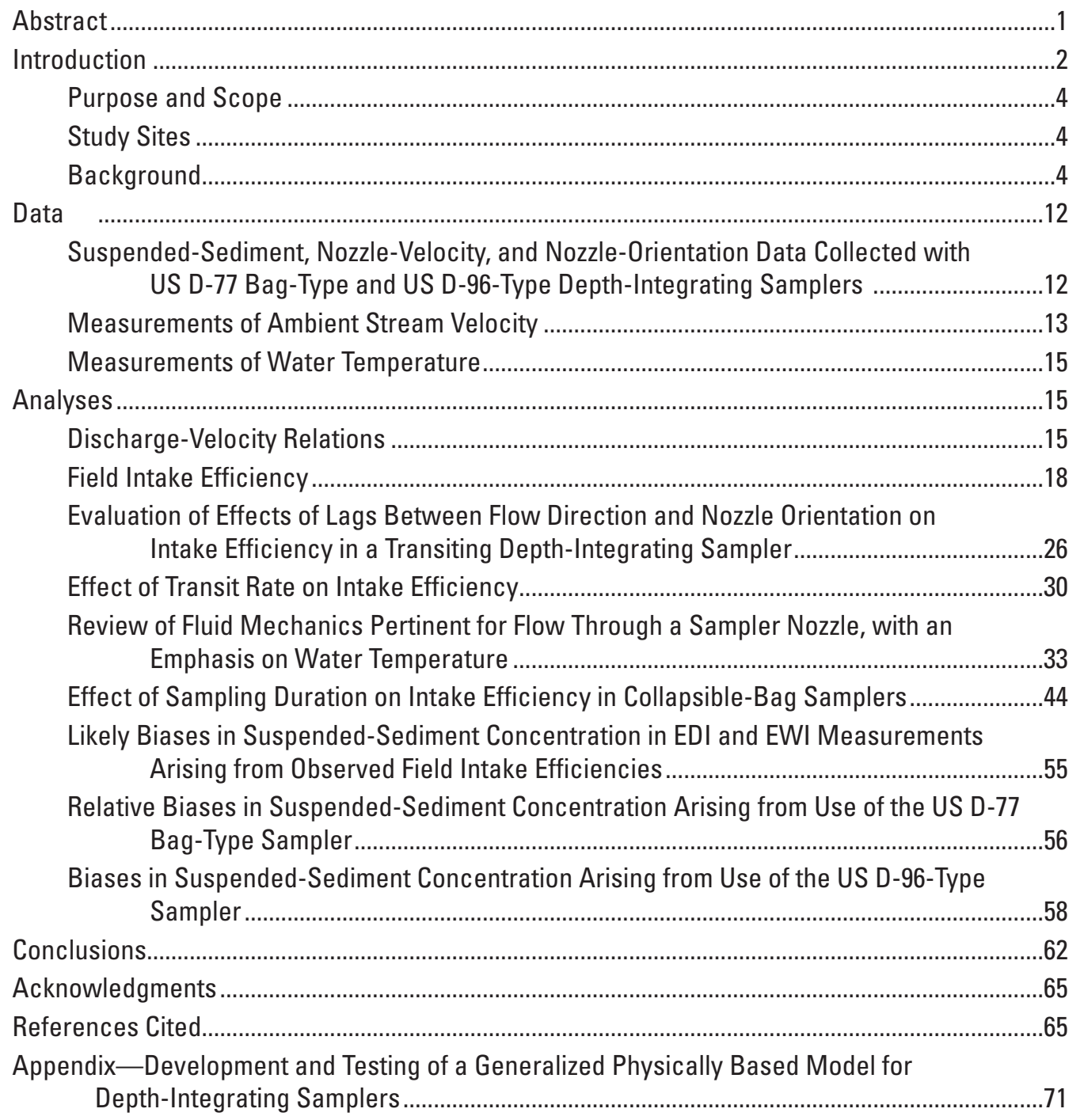




\section{Figures}

1. Map of the Colorado River in Marble and Grand Canyons showing the location of the six cross-sections at the three study sites where suspended-sediment samplers were deployed

2. Graphs showing shape of each tagline and cableway cross-section where data were collected in this study

3. Diagrams illustrating effects of isokinetic, sub-isokinetic, and super-isokinetic sampling on the measured concentration of sand-size sediment

4. Graph showing effect of intake efficiency on errors in suspended-sediment concentration for 0.06-millimeter $(\mathrm{mm}), 0.15-\mathrm{mm}$, and 0.45 - $\mathrm{mm}$ diameter sediment

5. Plots showing intake efficiency of the US D-77 bag-type and US D-96 samplers plotted as a function of ambient stream velocity in flume tests and flume and tow tests

6. Photograph showing manned, motorized, boat equipped for the simultaneous collection of velocity-profile data and either US D-96 type or US D-77 bag-type suspended-sediment data at the 30-mile and 61-mile study sites

7. Plots showing comparison between subsets of the field intake efficiency $\left(\mathrm{IE}_{\text {field }}\right)$ calculated at each EWI (equal-width increment) sampling vertical along tagline $B$ at the 30-mile study site and tagline $C$ at the 61 -mile study site using two methods to calculate $\mathrm{IE}_{\text {field }}$

8. Plots showing field intake efficiency within the operating ranges of the US D-77 bag-type and the US D-96-type depth-integrating suspended-sediment samplers at all individual sampling verticals along the cross-sections at 30-mile tagline $A, 30$-mile tagline $B, 61$-mile tagline $A$, 61-mile tagline $B, 61$-mile tagline $\mathrm{C}$, and the 87-mile cableway

9. Plots showing comparisons between laboratory-determined intake efficiencies of either the US D-77 bag-type sampler in flume tests or the US D-96-type sampler in flume and tow tests with the field intake efficiencies of these two types of samplers at all individual sampling verticals along the cross-sections at 30-mile tagline $A, 30$-mile tagline $B, 61$-mile tagline $A, 61$-mile tagline $B, 61$-mile tagline $C$, and the 87-mile cableway .

10. Plots showing relations between ambient stream velocity and nozzle velocity associated with depth-integrated samples collected using $1 / 4$ - and 5/16-inch nozzles on US D-77 bag-type and US D-96-type samplers at individual verticals along the cross-sections at 30 -mile tagline $A, 30$-mile tagline $B$, 61-mile tagline $A, 61$-mile tagline $B, 61$-mile tagline $C$, and the 87-mile cableway

11. Plots showing relative change in horizontal flow direction between different 1.2-foot depth bins along simulated upward and downward transits of depth-integrating suspended-sediment samplers plotted as a function of depthand time-averaged ambient stream velocity

12. Plots showing relation between the oblique angle of flow approaching the nozzle entrance and the apparent area of the nozzle entrance for the US D-96-A1 depth-integrating suspended-sediment sampler 


\section{Figures-Continued}

13. Plots showing effect of transit rate on the field intake efficiency of the US D-96-A1 sampler at sampling verticals along the cross-sections at 30-mile tagline $B$ and 61 -mile tagline $C$

14. Graphs showing measured and modeled intake efficiencies of a US D-43 sampler with nozzles that have entrance diameters of $1 / 8$ inch, $3 / 16$ inch, and $1 / 4$ inch at an ambient stream velocity of $3.5 \mathrm{ft} / \mathrm{s}$ and measured and modeled intake efficiencies of a US D-96 sampler with a nozzle with an entrance diameter of 3/16 inch at an ambient stream velocity of $3.7 \mathrm{ft} / \mathrm{s}$

15. Graph showing relations between ambient stream velocity and the velocity of water through nozzles on US D-43 samplers at water temperatures of 0 and 19.4 Celsius

16. Graphs showing modeled and measured intake efficiencies plotted as a function of ambient stream velocity for the US D-96 sampler using the $3 / 16$-inch development nozzle, the $3 / 16$-inch standard nozzle, the $1 / 4$-inch development nozzle, the $1 / 4$-inch standard nozzle, the $5 / 16$-inch development nozzle, and the $5 / 16$-inch standard nozzle

17. Plots showing comparison of US D-96 intake efficiencies obtained during river tests in the Mississippi River near Vicksburg, Mississippi, and the temperature-corrected field-determined intake efficiencies for all samples collected within the operating range of the US D-96-type depth-integrating suspended-sediment samplers at 30-mile tagline $A, 30$-mile tagline $B, 61$-mile tagline $A, 61$-mile tagline $B, 61$-mile tagline $C$, and 87-mile cableway

18. Graphs showing comparisons of modeled intake efficiencies for the US D-96 sampler using different diameter nozzles with two different taper depths

19. Graphs showing comparisons of the predicted errors in 0.15 -millimeter suspended-sand concentration associated with the modeled intake efficiencies in figure 18 for the US D-96 sampler using nozzles with three different entrance diameters and two taper depths

20. Plots showing effect of sampling duration on intake efficiency measured in flume tests of collapsible-bag samplers

21. Plots showing velocity-binned intake efficiency plotted as a function of sampling duration for the US D-77 bag-type sampler using 1/4-inch nozzles and using a 5/16-inch nozzles at all six cross-sections at all three study sites

22. Plots showing velocity-binned intake efficiency plotted as a function of sampling duration for the US D-96-type sampler using 1/4-inch nozzles and using 5/16-inch nozzles at all six cross-sections at all three study sites

23. Plots showing comparison of US D-96 intake efficiencies in river tests on the Mississippi River near Vicksburg, Mississippi, with the temperature-corrected US D-96 intake efficiencies in the Colorado River for sampling durations of $\leq 30$ seconds at 30-mile tagline $A, 30$-mile tagline $B, 61$-mile tagline $A, 61$-mile tagline $B, 61$-mile tagline $C$, and 87-mile cableway

24. Plot of relative intake efficiencies between US D-77 bag-type and US D-96-type depth-integrating suspended-sediment samplers deployed at all cross-sections at all study sites 


\section{Figures-Continued}

25. Graphs showing US D-77 bag-type to US D-96-type sampler relative bias in measured suspended-sediment concentration at 30-mile tagline $A, 30$-mile tagline $B, 61$-mile tagline $A, 61$-mile tagline $B, 61$-mile tagline $C$, and the 87 -mile cableway

26. Plots showing relations between sampling duration and intake efficiency for paired comparisons among the US D-96-A1 collapsible-bag sampler, the US D-74 rigid-container sampler, and the US D-77 rigid-container (bottle) sampler along 61 -mile cross-section $\mathrm{C}$ at tagline station 318 feet and along the 87-mile cross-section at cableway station 158 feet

27. Graphs showing biases in the concentration of each size class of suspended sediment measured with the US D-96-A1 collapsible-bag sampler; measured biases are compared with those predicted on the basis of the 1940s Federal Interagency Sedimentation Project (FISP) laboratory experiments

\section{Tables}

1. Discharge-velocity relations at each sampling vertical along each cross-section at each study site

2. Composite field intake efficiencies and associated predicted likely biases in suspended-sediment concentration in three size classes 


\section{Conversion Factors}

Inch/Pound to SI

\begin{tabular}{lcl}
\hline \multicolumn{1}{c}{ Multiply } & By & \multicolumn{1}{c}{ To obtain } \\
\hline foot (ft) & Length & \\
mile (mi) & 0.3048 & meter $(\mathrm{m})$ \\
& 1.609 & kilometer $(\mathrm{km})$ \\
\hline ounce, fluid (fl. oz) & Volume & \\
pint (pt) & 0.02957 & liter (L) \\
quart (qt) & 0.4732 & liter (L) \\
gallon (gal) & 0.9464 & liter (L) \\
\hline & 3.785 & liter $(\mathrm{L})$ \\
\hline foot per second (ft/s) & Flow rate & meter per second $(\mathrm{m} / \mathrm{s})$ \\
cubic foot per second (ft $\left.{ }^{3} / \mathrm{s}\right)$ & 0.3048 & cubic meter per second $\left(\mathrm{m}^{3} / \mathrm{s}\right)$ \\
\hline & 0.02832 & gram $(\mathrm{g})$ \\
\hline ounce, avoirdupois $(\mathrm{oz})$ & Mass & \\
\hline
\end{tabular}

SI to Inch/Pound

\begin{tabular}{lcl}
\multicolumn{1}{c}{ Multiply } & By & \multicolumn{1}{c}{ To obtain } \\
\hline meter $(\mathrm{m})$ & Length & foot $(\mathrm{ft})$ \\
kilometer $(\mathrm{km})$ & 3.281 & mile (mi) \\
\hline & 0.6214 & \\
\hline liter $(\mathrm{L})$ & Volume & ounce, fluid (fl. oz) \\
liter (L) & 33.82 & pint $(\mathrm{pt})$ \\
liter $(\mathrm{L})$ & 2.113 & quart $(\mathrm{qt})$ \\
liter $(\mathrm{L})$ & 1.057 & gallon $(\mathrm{gal})$ \\
\hline & 0.2642 & \\
\hline meter per second $(\mathrm{m} / \mathrm{s})$ & Flow rate & foot per second $(\mathrm{ft} / \mathrm{s})$ \\
cubic meter per second $\left(\mathrm{m}^{3} / \mathrm{s}\right)$ & 3.281 & cubic foot per second $(\mathrm{ft} / \mathrm{s})$ \\
\hline & 35.31 & ounce, avoirdupois $(\mathrm{oz})$ \\
\hline gram $(\mathrm{g})$ & Mass & \\
\hline
\end{tabular}

Temperature in degrees Celsius $\left({ }^{\circ} \mathrm{C}\right)$ may be converted to degrees Fahrenheit $\left({ }^{\circ} \mathrm{F}\right)$ as follows:

$$
{ }^{\circ} \mathrm{F}=\left(1.8 x^{\circ} \mathrm{C}\right)+32
$$


viii

This page is intentionally left blank. 


\title{
Evaluation of Intake Efficiencies and Associated Sediment-Concentration Errors in US D-77 Bag-Type and US D-96-Type Depth-Integrating Suspended-Sediment Samplers
}

\author{
By Thomas A. Sabol and David J. Topping
}

\section{Abstract}

Accurate measurements of suspended-sediment concentration require suspended-sediment samplers to operate isokinetically, within an intake-efficiency range of $1.0 \pm 0.10$, where intake efficiency is defined as the ratio of the velocity of the water through the sampler intake to the local ambient stream velocity. Local ambient stream velocity is defined as the velocity of the water in the river at the location of the nozzle, unaffected by the presence of the sampler. Results from Federal Interagency Sedimentation Project (FISP) laboratory experiments published in the early 1940s show that when the intake efficiency is less than 1.0, suspended-sediment samplers tend to oversample sediment relative to water, leading to potentially large positive biases in suspended-sediment concentration that are positively correlated with grain size. Conversely, these experiments show that, when the intake efficiency is greater than 1.0, suspended-sediment samplers tend to undersample sediment relative to water, leading to smaller negative biases in suspended-sediment concentration that become slightly more negative as grain size increases.

The majority of FISP sampler development and testing since the early 1990s has been conducted under highly uniform flow conditions via flume and slack-water tow tests, with relatively little work conducted under the greater levels of turbulence that exist in actual rivers. Additionally, all of this recent work has been focused on the hydraulic characteristics and intake efficiencies of these samplers, with no field investigations conducted on the accuracy of the suspended-sediment data collected with these samplers. When depth-integrating suspended-sediment samplers are deployed under the more nonuniform and turbulent conditions that exist in rivers, multiple factors may contribute to departures from isokinetic sampling, thus introducing errors into the suspended-sediment data collected by these samplers that may not be predictable on the basis of flume and tow tests alone.

This study has three interrelated goals. First, the intake efficiencies of the older US D-77 bag-type and newer, FISP-approved US D-96-type ${ }^{1}$ depth-integrating suspended-sediment samplers are evaluated at multiple cross-sections under a range of actual-river conditions. The intake efficiencies measured in these actual-river tests are then compared to those previously measured in flume and tow tests. Second, other physical effects, mainly water temperature and the duration of sampling at a vertical, are examined to determine whether these effects can help explain observed differences in intake efficiency both between the two types of samplers and between the laboratory and field tests. Third, the signs and magnitudes of the likely errors in suspendedsand concentration in measurements made with both types of samplers are predicted based the intake efficiencies of these two types of depth-integrating samplers. Using the relative difference in isokinetic sampling observed between the US D-77 bag-type and D-96-type samplers during river tests, measured differences in suspended-sediment concentration in a variety of size classes were evaluated between paired equal-discharge-increment (EDI) and equal-width-increment (EWI) measurements made with these two types of samplers to determine whether these differences in concentration are consistent with the differences in concentrations expected on the basis of the 1940s FISP laboratory experiments. In addition, sequential single-vertical depth-integrated samples were collected (concurrent with velocity measurements) with the US D-96-type bag sampler and two different rigidcontainer samplers to evaluate whether the predicted errors in suspended-sand concentrations measured with the US D-96type sampler are consistent with those expected on the basis of the 1940s FISP laboratory experiments.

\footnotetext{
${ }^{1}$ For the purpose of this study, both the US D-96 and the US D-96-A1 sampler (Davis, 2005) are herein referred to as the US D-96-type sampler.
} 
Results from our study indicate that the intake efficiency of the US D-96-type sampler is superior to that of the US D-77 bag-type sampler under actual-river conditions, with overall performance of the US D-96-type sampler being closer to, yet still typically below, the FISP-acceptable range of isokinetic operation. These results are in contrast to the results from FISP-conducted flume tests that showed that both the US D-77 bag-type and US D-96-type samplers sampled isokinetically in the laboratory. Results from our study indicate that the single largest problem with the behavior of both the US D-77 bag-type and the US D-96-type samplers under actual-river conditions is that both samplers are prone to large time-dependent decreases in intake efficiency as sampling duration increases. In the case of the US D-96-type sampler, this problem may be at least partially overcome by shortening the duration of sampling (or, instead, perhaps by a simple design improvement); in the case of the US D-77 bag-type sampler, although shortening the sampling duration improves the intake efficiency, it does not bring it into agreement with the FISP-accepted range of isokinetic operation.

The predicted errors in suspended-sand concentration in EDI or EWI measurements made with the US-96-type sampler are much smaller than those associated with EDI or EWI measurements made with the US D-77 bag-type sampler, especially when the results are corrected for the effects of water temperature and sampling duration. The bias in the concentration in each size class measured using the US D-77 bag-type relative to the concentration measured using the US D-96-type sampler behaves in a manner consistent with that expected on the basis of the observed differences in intake efficiency between the two samplers in conjunction with the results from the 1940s FISP laboratory experiments. In addition, the bias in the concentration in each size class measured using the US D-96-type sampler relative to the concentration measured using the truly isokinetic rigid-container samplers is in excellent agreement with that predicted on the basis of the 1940s FISP laboratory experiments. Because suspended-sediment samplers can respond differently between laboratory and field conditions, actual-river tests such as those in this study should be conducted when models of suspended-sediment samplers are changed from one type to another during the course of long-term monitoring programs. Otherwise, potential large differences in the suspended-sediment data collected by different types of samplers would lead to large step changes in sediment loads that may be misinterpreted as real, when, in fact, they are associated with the change in suspended-sediment sampling equipment.

\footnotetext{
${ }^{2}$ These results are for sampler nozzles that are oriented upstream within about 30 degrees of the streamlines (that is, the standard nozzle orientation on FISP depth-integrating samplers). As shown in FISP (1941) and Winterstein and Stefan (1983), the results are very different when the nozzles are oriented more obliquely or perpendicular to the streamlines.
}

\section{Introduction}

Traditionally, the U.S. Geological Survey (USGS) has used depth-integrating samplers to collect velocity-weighted samples for use in determining concentrations and grain-size distributions of suspended sediment in river cross-sections (Edwards and Glysson, 1999; Nolan and others, 2005; Gray and others, 2008). The fundamental requirement for the proper collection of suspended-sediment data with a depth-integrating sampler is the isokinetic operation of the sampler, in which the water-sediment mixture enters the sampler nozzle at the local ambient stream velocity. In this usage, "local ambient stream velocity" is defined as the velocity of the water in the river at the location of the nozzle, unaffected by the presence of the sampler. Laboratory experiments performed by the Federal Interagency Sedimentation Project (FISP) published in the early 1940s show that when the water-sediment mixture enters a sampler nozzle at a rate lower than the local ambient stream velocity, suspended-sediment samplers tend to oversample sediment because of the greater inertia of the particles of sand-sized sediment relative to the water, thus leading to positive biases in suspended-sediment concentrations that are positively correlated with grain size (FISP, 1941a) ${ }^{2}$. Conversely, these same experiments show, by virtue of the same inertial effects, that when the water-sediment mixture enters a sampler nozzle at a rate higher than the local ambient stream velocity, suspended-sediment samplers tend to undersample sediment. This undersampling leads to negative biases in suspended-sediment concentrations that are also positively correlated with grain size; these biases become more negative as grain size increases.

The replacement of the rigid-container sampler container with a collapsible bag in the design of the bag-type depth-integrating suspended-sediment samplers developed by the FISP in the 1980s and 1990s represents the most radical design change in suspended-sediment sampling equipment since the original development of isokinetic rigid-container depth-integrating samplers in the 1940s (FISP, 1940a, 1941a, 1952, 2003; Szalona, 1982; Davis, 2001, 2005a; McGregor, 2006). Unlike during the design of the original rigid-container depth-integrating samplers, however, far less testing occurred during the development of the bag-type depth-integrating samplers. Depth-integrating, suspended-sediment samplers are intended for use in rivers and streams where flow conditions are typically more turbulent and variable than those in laboratory flumes or those experienced by samplers towed in a lake by a boat. Although these samplers are meant to be used to sample suspended sediment in rivers, the 
majority of recent sampler development and testing has been conducted via flume and slack-water towing tests (Szalona, 1982; McGregor, 2000a, 2000b, 2006; Davis, 2005a; FISP, 2003), with relatively little work occurring in actual rivers under actual sampling conditions (Allen and Petersen, 1981; Davis, 2001). Of the seven FISP depth-integrating suspended-sediment samplers developed since 1980, only the US D-96-type depth-integrating sampler received any river testing of intake efficiency (Davis, 2001). Furthermore, all recent FISP sampler development and testing has been focused on the hydraulic characteristics and intake efficiencies of these samplers, with no work conducted on the accuracy of the suspended-sediment data collected with these samplers (Szalona, 1982; McGregor, 2000a, 2000b, 2006; Davis, 2001, 2005a; FISP, 1979, 2003). Because the flow in actual-river settings is more nonuniform and turbulent than the flow in either laboratory flumes or lakes, there is no guarantee that samplers tested only under these relatively uniform conditions will sample isokinetically under actual-river conditions (for example, Pickering, 1983; and Yorke and Ward, 1998). The early development and testing of FISP rigid-container suspended-sediment samplers included extensive laboratory and river tests of both hydraulic and suspended-sediment sampling behavior, with intercomparisons between different types of suspended-sediment samplers in a variety of rivers (Benedict, 1944; FISP, 1944, 1951, 1952, 1957). However, because recent collapsible-bag-type sampler development has not included the field evaluation of the suspendedsediment sampling behavior through intercomparison with different types of suspended-sediment samplers, there is no guarantee that the suspended-sediment data collected with newly developed bag-type suspended-sediment samplers is (1) consistent with the suspended-sediment data collected with the older rigid-container suspended-sediment samplers on which field tests of suspended-sediment sampling behavior were conducted by the FISP, let alone (2) accurate. Because sediment-sampling tests were not conducted during the development of the new bag-type of suspended-sediment samplers, there is a risk that step changes in sediment loads may be introduced when changes in sampler type are made during the course of long-term monitoring programs.

To monitor sediment transport in the Colorado River in Marble and Grand Canyons, a long-term suspended-sediment monitoring program was initiated by the USGS - Grand Canyon Monitoring and Research Center (GCMRC) in 1999 (Rubin and others, 2002). This program initially consisted of suspended-sediment measurements made at least once per day at several stations along the Colorado River, and later expanded to five stations using a combination of depth-integrating suspended-sediment samplers and newer pump, laser, and acoustic surrogate technologies (Melis and others, 2003; Topping and others, 2004, 2006, 2007, 2010; Griffiths and others, 2012). The initial depth-integrating suspended-sediment sampler chosen for this program was the US D-77 bag-type sampler developed and tested by Szalona (1982). The configuration used was that in figure $2-2 A$ in Webb and Radtke (1998). Szalona (1982) showed that the US D-77 bag-type sampler sampled isokinetically in flume experiments, and therefore the inference was that this sampler should collect accurate suspended-sediment data, although no river tests on either intake efficiency or sediment-sampling behavior had been conducted. In response to observed problems with the deployment of the US D-77 bag-type sampler in rivers (Pickering, 1983; Boning, 1992; Webb and Radtke, 1998; Yorke and Ward, 1998; Sorenson, 2002), the USGS Office of Water Quality, in concurrence with the Office of Surface Water, recommended the phaseout of this sampler in 2002 (Sorenson, 2002). In response, the USGS-GCMRC replaced the US D-77 bag-type sampler with the FISP approved US D-96-type collapsible-bag sampler for use in the USGS-GCMRC monitoring program on the Colorado River in Marble and Grand Canyons (Davis, 2001). Upon phaseout of the US D-77 bag-type sampler in this program, either the US D-96-A1 (comparable in weight to that of the US D-77 bag-type sampler) or the heavier US D-96 was used, depending on flow conditions. During this change in sampler type, a negative step change was detected in the measured suspended-sand concentrations. Initial side-by-side sampler comparisons conducted on the Colorado River during this change in sampler type indicated that, under the same flow and sediment conditions, the US D-77 bag-type sampler collected samples with higher measured concentrations of suspended sand than did the US D-96-type sampler. This difference in sediment-sampling behavior was observed despite the fact that both samplers were previously found to sample isokinetically in flumes (Szalona, 1982; Davis, 2001). As a result, the study described in this report was initiated to evaluate whether the intake efficiencies of these two types of samplers were different under actual-river conditions, and whether such potential differences in intake efficiency could explain the differences in the suspended-sediment data collected by the two types of samplers. In addition, the effects of water temperature, lags between changes in flow direction and nozzle orientation, and transit rates were examined to determine whether these effects could help explain observed differences in intake efficiency between the two types of samplers and between the laboratory and field tests. 


\section{Purpose and Scope}

The purpose and scope of this report is to describe and analyze the data collected (between 1999 and 2011) to address the following three goals:

1. To compute intake efficiencies of the US D-77 bag-type and US D-96-type samplers over a range of actual-river conditions and compare these field intake efficiencies with those measured in the laboratory,

2. To evaluate whether the potential effects of water temperature, sampling duration, transit rates, and lags between changes in flow direction and nozzle orientation could help explain observed differences in intake efficiency between the two types of samplers and between the laboratory and river tests, and

3. To compute and verify whether any errors in suspended-sand concentration measured by the US D-77 bag-type and D-96-type samplers (computed on the basis of the intake efficiencies of these two types of depth-integrating samplers) are consistent with the errors in concentration expected based on 1940s FISP laboratory experiments.

Data used in this study were collected between 1999 and 2011 at six cross-sections on the Colorado River within Grand Canyon National Park (GCNP). For the purpose of this study, data collected with either the US D-96 or the US D-96-A1 are herein referred to as US D-96-type. Because the only difference between the two is weight, isokinetic operation of both samplers is the same when deployed within their specific operating ranges (Davis, 2001; FISP, 2003). Therefore, in this study, differentiating specific data collected with either a US D-96 or a US D-96-A1 is unnecessary.

\section{Study Sites}

The study area is the Colorado River in Marble and Grand Canyons within GCNP. By longstanding convention, locations along the Colorado River in GCNP are referenced to river miles. Marble Canyon extends from river mile 0 to the mouth of the Little Colorado River near river mile 62; Grand Canyon extends from the mouth of the Little Colorado River to the Grand Wash Cliffs near river mile 277. Data evaluated in this study were collected at six cross-section locations (figs. 1, 2):

1. Two cross-sections on the Colorado River at USGS-GCMRC river miles 30.0 and 30.3 near the USGS-GCMRC river-mile 30 sediment station, herein referred to as 30-mile tagline $\mathrm{A}$ and 30-mile tagline $\mathrm{B}$, respectively;
2. Two cross-sections on the Colorado River at USGSGCMRC river miles 60.7 and 61.0 upstream from the decommissioned USGS Colorado River above Little Colorado River near Desert View, Arizona, gaging station (09383100), herein referred to as 61-mile tagline A and 61-mile tagline B, respectively;

3. The cross-section at USGS-GCMRC river mile 61.5 at the former location of the measurement cableway at the decommissioned USGS Colorado River above Little Colorado River near Desert View, Arizona, gaging station (09383100), herein referred to as 61-mile tagline C; and

4. The cross-section at USGS-GCMRC river mile 88.0 at the measurement cableway at Colorado River near Grand Canyon, Arizona, gaging station (09402500), herein referred to as the 87-mile cableway.

This last cross-section was deemed especially appropriate for this study because it was the location of the FISP suspended-sediment sampler river tests published in Benedict (1944) and FISP $(1944,1957)$. Orthorectified aerial photographs showing the detailed locations of each of these cross-sections at the three study sites are provided in Topping and others (2011).

\section{Background}

The depth-integrating samplers used in this study were all designed, calibrated, and tested by the Federal Interagency Sedimentation Project (FISP). The FISP was established in 1939 to address the lack of standardization in sediment-sampling equipment and techniques (Skinner, 1989). Initial FISP efforts focused on understanding hydraulic and mechanical aspects of sediment sampling with regard to measurement and analysis of suspended-sediment, bedload sediment, and bed material (FISP, 1940a, 1940b, 1941a, 1941b, 1941c, 1952; Davis, 2005b). Currently, FISP evaluates and develops standardized calibrated equipment and methods for analysis of water quality, sediment characteristics, and sediment transport in surface waters (accessed October 27, 2011, at http://water.usgs.gov/fisp/ background.html). Although extensive field testing of depthintegrating samplers in rivers occurred in the 1940s and 1950s to evaluate both intake efficiency and suspended-sediment data (Benedict, 1944; FISP, 1944, 1951, 1952, 1954, 1957), few field tests have been conducted and published since then to evaluate how suspended-sediment data are affected by the sampling behavior of suspended-sediment samplers in actual river settings (for example, see Allen and Petersen, 1981). Multiple Federal and State agencies, foreign countries, and companies in the private sector use FISP-designed and approved equipment. 

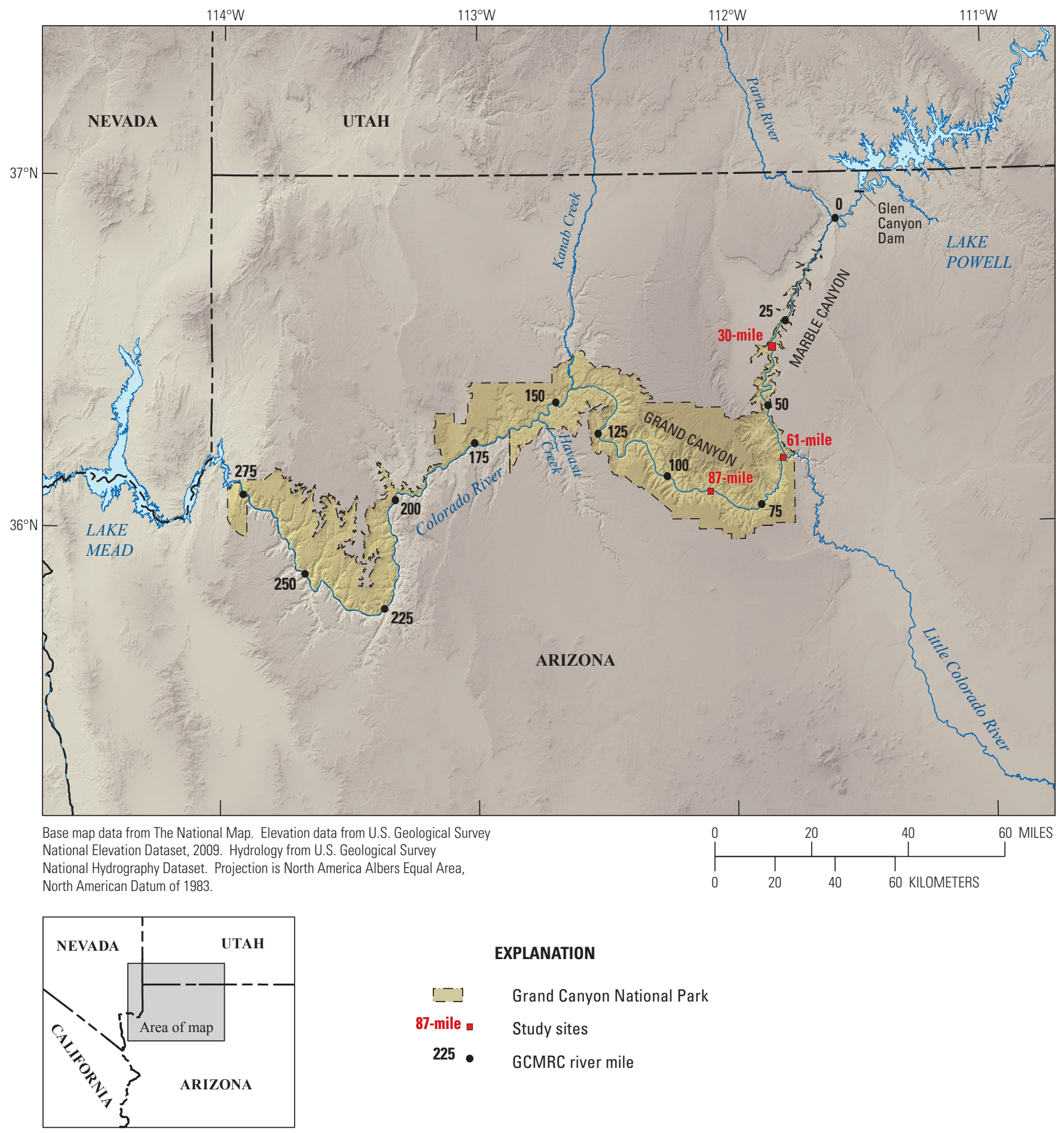

Figure 1. Map of the Colorado River in Marble and Grand Canyons showing the location of the six cross-sections at the three study sites where suspended-sediment samplers were deployed. ["30-mile" indicates location of taglines A and B at the river mile 30 sediment station, "61-mile" indicates location of taglines A, B, and C near the former location of the USGS Colorado River above Little Colorado River near Desert View, Arizona, gaging station (09383100), and "87-mile" indicates the location of the measurement cableway at the USGS Colorado River near Grand Canyon, Arizona, gaging station (09402500).] 


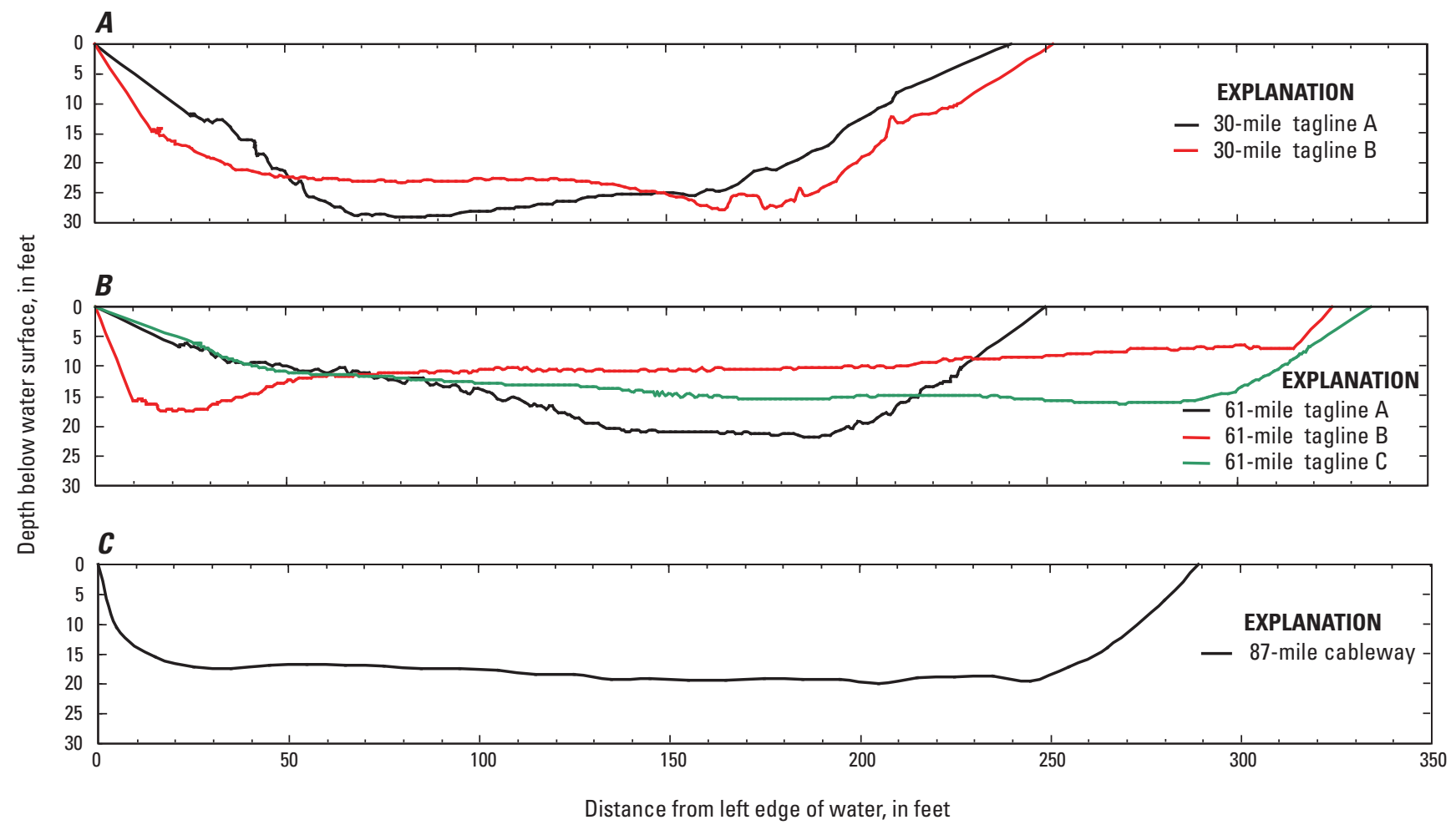

Figure 2. Graphs showing shape of each tagline and cableway cross-section where data were collected in this study. Values are extrapolated from acoustic Doppler current profiler (ADCP) data at measured discharges of $(A) 13,900,(B) 12,500$, and $(C) 15,000$ cubic feet per second at the $(A)$ 30-mile, $(B)$ 61-mile, and $(C)$ 87-mile study sites, respectively.

Isokinetic depth-integrating suspended-sediment samplers are designed to continuously collect a sample of the water-sediment mixture at the ambient stream velocity at the location of the sampler nozzle while transiting a sampling vertical in either the equal-discharge-increment (EDI) or equalwidth-increment (EWI) methods (FISP, 1952; Edwards and Glysson, 1999; Nolan and others, 2005; Gray and others, 2008). FISP-designed suspended-sediment samplers are calibrated in a flume over a narrow range of water temperatures to ensure that the velocity of the water-sediment mixture entering the nozzle is within 10 percent of the local ambient stream velocity throughout the sampler's operating range, resulting in an intake efficiency of 1.0 \pm 0.10 (Davis, 2001; Gray and others, 2008). Suspended-sediment samplers are deemed to be isokinetic when they meet this criterion; as recently as the official phaseout of the US D-77 bag-type sampler in 2002, the historically acceptable range in intake efficiency associated with isokinetic depth-integrating, suspended-sediment samplers was $1.0 \pm 0.15$ (Szalona, 1982; Yorke and Ward, 1998). Isokinetic sampling is important because non-isokinetic operation of suspendedsediment samplers can result in either positive or negative biases in suspended-sediment concentrations that are correlated with grain size (Edwards and Glysson, 1999; FISP, 1941a).
The measure of isokinetic sampling, indicated by intake efficiency (IE), is defined as:

$$
\mathrm{IE}=\frac{V_{\mathrm{n}}}{V},
$$

where

$$
\begin{gathered}
V_{\mathrm{n}} \text { is the instantaneous velocity of the water- } \\
\text { sediment mixture moving through the } \\
\text { nozzle into the sample container, and } \\
V \quad \text { is the instantaneous ambient stream velocity } \\
\text { at the location of the sampler-nozzle intake, } \\
\text { unaffected by the presence of the sampler. }
\end{gathered}
$$

Because it is impossible to measure instantaneous values of $V_{\mathrm{n}}$ when using depth-integrating samplers in the field, $V_{\mathrm{n}}$ in this study is replaced by $\bar{V}_{\mathrm{n}}$, that is, the velocity of the watersediment mixture moving through the nozzle averaged over the time a depth-integrating sampler is deployed at a vertical, and $V$ in this study is replaced by $\bar{V}$, that is, the time- and depth-averaged ambient stream velocity at a vertical. To maintain USGS convention, all velocities in this paper are reported in units of feet per second (ft/s). 
Non-isokinetic operation (fig. 3) of suspended-sediment samplers can result in either positive or negative biases in measured suspended-sediment concentrations, under standard nozzle orientations with the sampler intake pointed upstream within about 30 degrees of the streamlines (FISP, 1941a;
Winterstein and Stefan, 1983; Edwards and Glysson, 1999). As intake efficiency decreases from unity, the magnitude of the positive bias in suspended-sediment concentration increases because the sediment has greater inertia than the water (fig. 4). Because larger particles have greater inertia
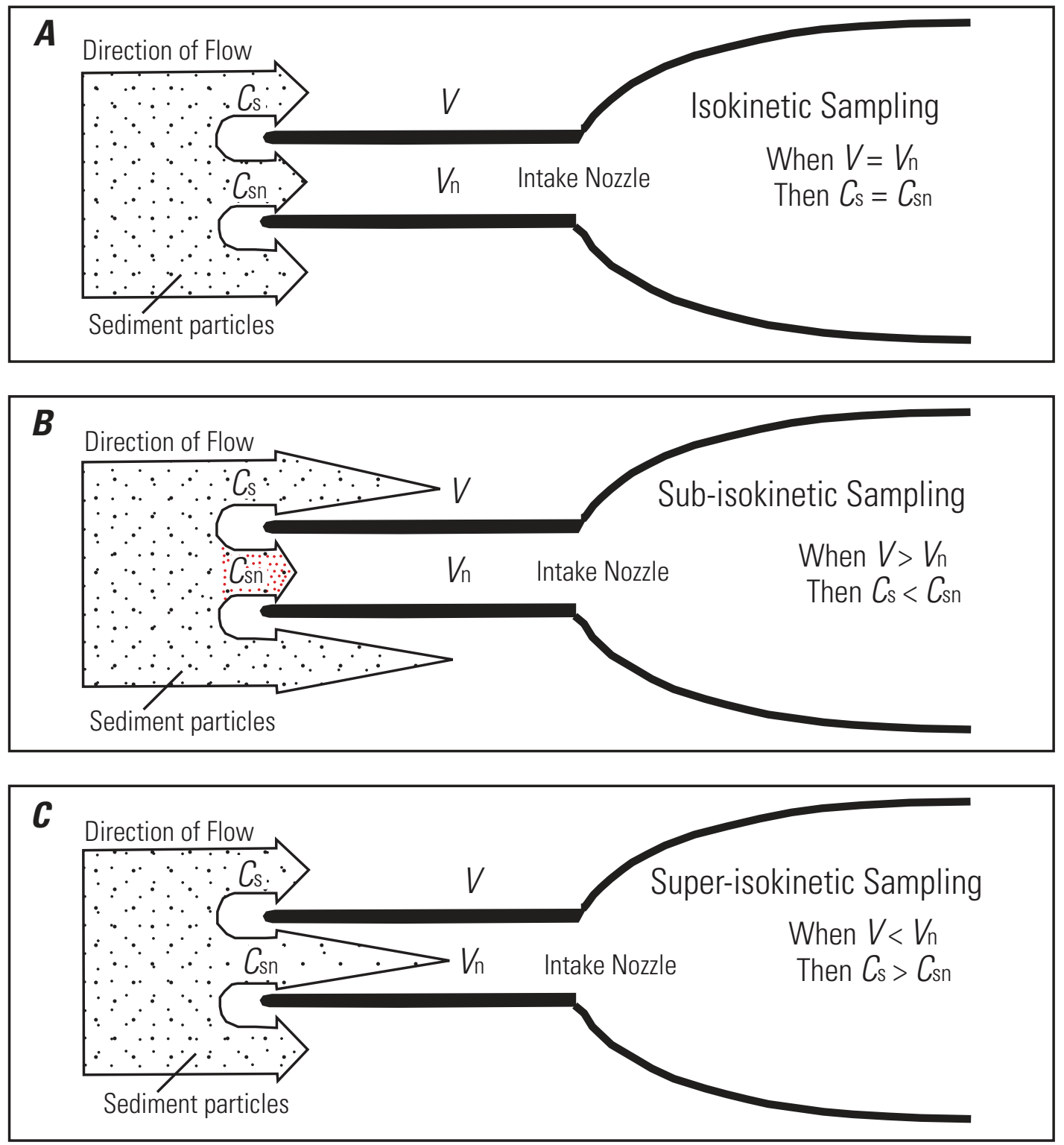

Modified from Edwards and Glysson (1999).

Figure 3. Diagrams illustrating effects of $(A)$ isokinetic, $(B)$ sub-isokinetic, and $(C)$ super-isokinetic sampling on the measured concentration of sand-size sediment $(>0.0625$ millimeter in diameter), where $V$ is the instantaneous ambient stream velocity at the location of the sampler-nozzle intake, unaffected by the presence of the sampler, $V_{n}$ is the instantaneous velocity of the water-sediment mixture moving through the nozzle into the sample container, $C_{s}$ is the instantaneous ambient suspended-sediment concentration at the location of the sampler-nozzle intake, unaffected by the presence of the sampler, and $C_{\mathrm{sn}}$ is the instantaneous suspended-sediment concentration moving through the nozzle into the sample container. 
than smaller particles, intake efficiencies less than 1 lead to positive biases in suspended-sediment concentrations that are positively correlated with grain size. As a result of the same inertial effects, when intake efficiency increases above unity, the magnitude of the bias in sediment concentration becomes more negative as grain size increases (fig. 4). The rate of increase in the positive bias in suspended-sediment concentration with either decreasing intake efficiency (below unity) or increasing grain size is much larger than the rate of increase in the negative bias in suspended-sediment concentration with either increasing intake efficiency (above unity) or increasing grain size. Therefore, greater potential for large absolute-value errors in sediment concentration exists when intake efficiencies are less than 1 , rather than greater than 1 .

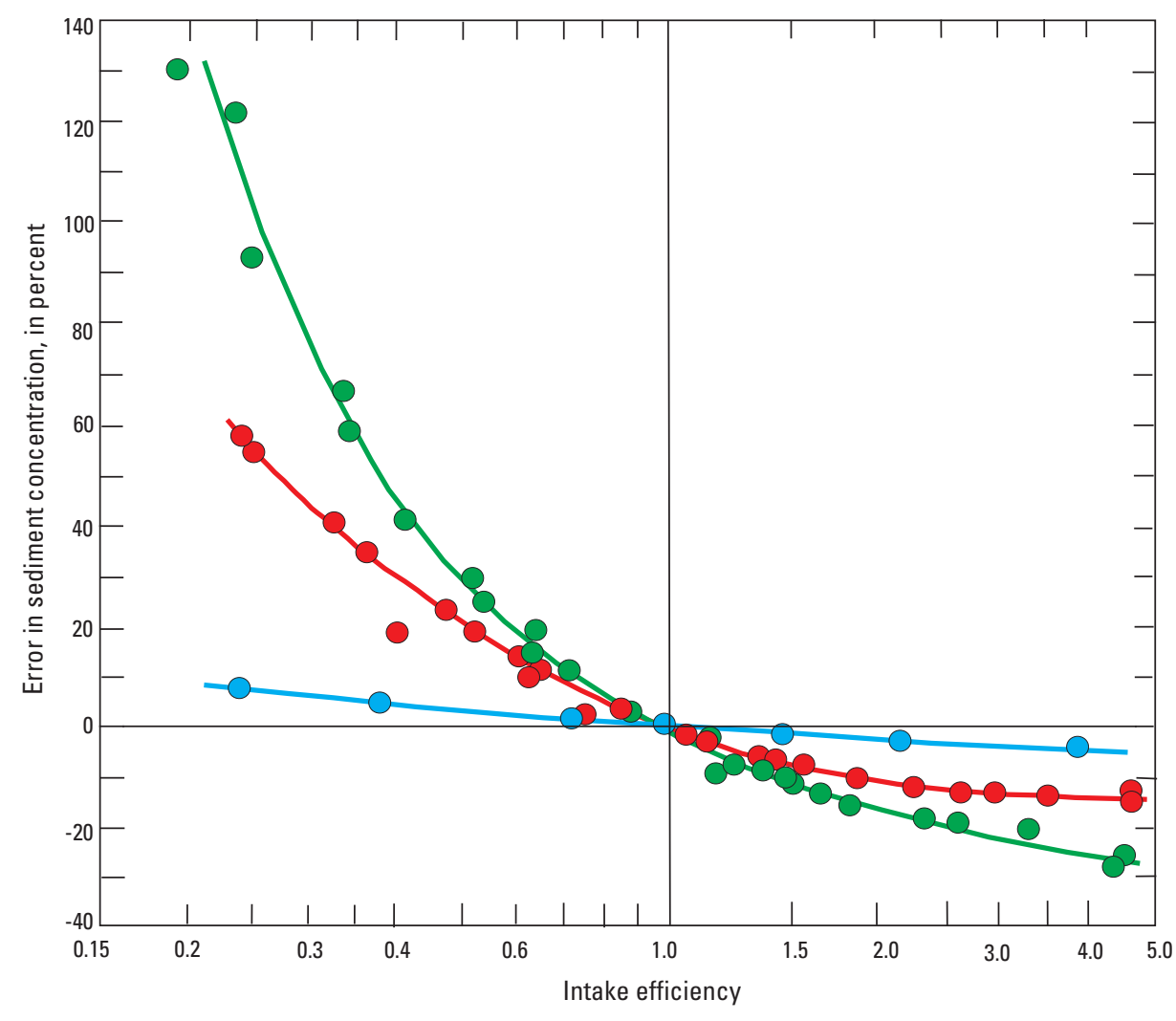

EXPLANATION

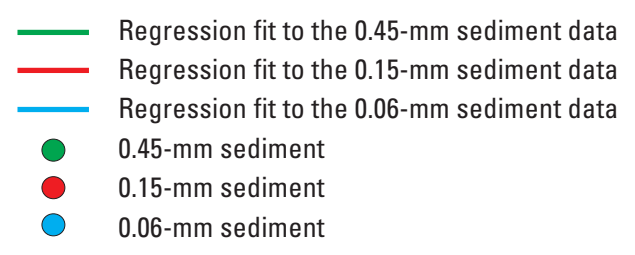

Figure 4. Graph showing effect of intake efficiency on errors in suspended-sediment concentration for 0.06-millimeter ( $\mathrm{mm}), 0.15-\mathrm{mm}$, and 0.45-mm diameter sediment. Data collected using the 1/4-inch standard nozzle at a stream velocity of 5 feet per second. Relations in graph are applicable for data collected with both the 1/4-inch and the 5/16-inch nozzles; figure modified from Report 5, Federal Interagency Sedimentation Project (FISP, 1941a, fig. 32). 
The original development of collapsible-bag depth-integrating samplers occurred because the depths of many rivers exceeded the deployment depth limits of standard rigid-container depth-integrating samplers (Szalona, 1982); the concept of the collapsible-bag depth-integrating sampler was first described by FISP (1952, p. 100-101). The air in the sample container (that is, bottle) of a rigid-container depth-integrating sampler is at atmospheric pressure when the sampler enters the water at a sampling vertical. As the sampler is lowered through the water column toward the bed, the pressure in the sample container increases hydrostatically resulting in compression of the trapped air. Proper sampling with rigid-container depth-integrating samplers requires that this pressure-driven decrease in the volume of air in the sample container be offset during the downward transit by a volume of water-sediment mixture, entering the sampler container through the nozzle isokinetically, that is equal to or greater than the volume needed to instantaneously compress the air in the container and balance the external hydrostatic head. If the water-sediment mixture enters the nozzle at a rate lower than that required to equalize the pressure of the air trapped in the sample container with the hydrostatic pressure, a pressure-driven inrush of additional water through both the nozzle and the sampler air exhaust will occur. If the water enters the nozzle at a rate higher than that required to equalize the pressure of the air trapped in the sample container with the hydrostatic pressure, some of the trapped air will simply escape through the sampler air exhaust. Because of this pressure-equalization constraint, the depth limit of a rigid-container depth-integrating sampler is set by the volume of the sample container (FISP, 1952; Edwards and Glysson, 1999). To allow depth-integrating samplers to be used in rivers with greater depths, Szalona (1982) adapted the US D-77 collapsible bag-type sampler from the US D-77 rigid-container sampler using commercially available plastic food-storage bags. Because the sample container of a collapsible bag-type sampler can freely contract as pressure increases, no pressure-driven inrush will occur in such a sampler. As a result, the maximum allowable transit rate of a collapsible bag-type sampler is not reduced as a function of increasing sample container size (as is the case with rigid-container samplers), thus allowing bag-type samplers to be operated to greater depths so long as the transit rates do not exceed the theoretical approach-angle limits of $\sim 40$ percent of the ambient stream velocity (FISP, 1952, 1954; Szalona, 1982; Edwards and Glysson, 1999; Davis, 2001).

Flume tests conducted during the development of the US D-77 bag-type sampler and flume and tow tests conducted during the development of the US D-96-type sampler show that both of these samplers can sample isokinetically under the uniform flow conditions (with relatively low levels of turbulence) that exist in these types of tests (fig. 5; Szalona, 1982; Davis, 2001). Szalona's (1982) flume tests determined that the US D-77 bag-type can sample at intake efficiencies (IEs) of $1 \pm 0.15$ over a velocity range of 1.5 to $6.6 \mathrm{ft} / \mathrm{s}$, depending on the configuration of the sampler. Flume and tow tests performed during sampler development verified the isokinetic operation ( $\mathrm{IE}=1 \pm 0.10)$ of the US D-96 sampler between 2 and $15 \mathrm{ft} / \mathrm{s}$ in these highly controlled uniform sampling environments (Davis, 2001). Throughout the development of the US D-77 bag-type sampler no tests in actual rivers occurred; however, 22 river tests performed during development of the US D-96 sampler indicated that it sampled at intake efficiencies of $1 \pm 0.15$ over a velocity range of 2 to $6.7 \mathrm{ft} / \mathrm{s}$ (Davis, 2001). Of these 22 tests, the results of 15 were within the tighter $\mathrm{IE}=1 \pm 0.10$ range under which FISP samplers are now deemed to be isokinetic (Davis, 2001). Details of the respective US D-77 bag-type and US D-96 sampler development processes are further discussed in Szalona (1982) and Davis (2001).

During the deployment of depth-integrating samplers under the more nonuniform, more turbulent, and deeper conditions that exist in rivers, factors not apparent in the flume and tow tests may contribute to departures from isokinetic sampling and, as a result, introduce biases into the velocity-weighted, suspended-sediment concentration data collected. During the years following the development of the US D-77 bag-type sampler in 1982, it became apparent to many workers that, regardless of its performance in flume tests, this sampler did not perform well in actual-river settings (Pickering, 1983; Boning, 1992; Webb and Radtke, 1998; Yorke and Ward, 1998; Davis, 2001, 2005b, 2006; Sorenson, 2002; FISP, 2003). The US D-96 collapsible-bag sampler, and later the US D-96-A1 collapsible-bag sampler, were both developed in response to the US D-77 bag-type sampler's documented limited range of isokinetic operation, instability at high flows, and general unreliability when used in actual rivers (Davis, 2001, 2005b, 2006; FISP, 2003). Physical factors affecting all samplers in actual rivers that may result in departures from isokinetic sampling not necessarily observed in flume and tow tests include (1) larger ranges in depth, (2) greater levels of turbulence, (3) the fact that rivers are boundary-layer "shear flows" unlike the flows affecting samplers in tow and towed-transit tests, (4) larger ranges in water temperature, and (5) the presence of suspended sediment in the water. Some of the effects of these physical factors have been the focus of previous research (for example, the effects of greater river depths on drift angle) and are beyond the scope of this report. 


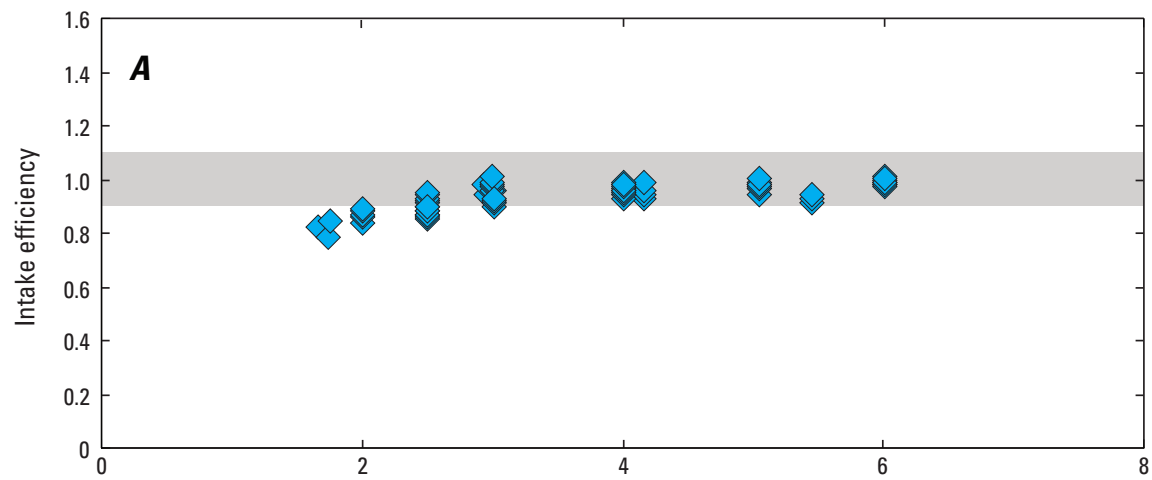

EXPLANATION

US D-77 bag-type flume tests $1 / 4$-in. and 5/16-in. nozzles

US D-96 type flume and tow tests $1 / 4$-in. and $5 / 16$-in. nozzles

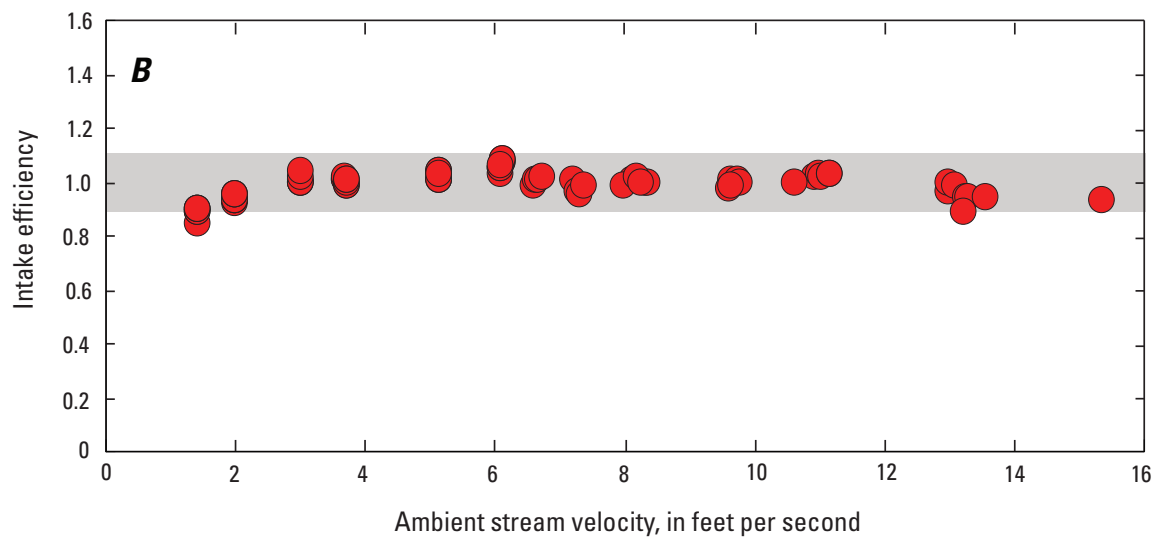

Figure 5. Plots showing intake efficiency of $(A)$ the US D-77 bag-type and $(B)$ US D-96 samplers plotted as a function of ambient stream velocity in flume tests $(A)$ and flume and tow tests $(B)$. US D-77 bag-type sampler data from Szalona (1982) and B.E. Davis (U.S. Geological Survey, written commun., 2009); US-D96 sampler data from Davis (2001). Shaded area represents range in intake efficiency $(1.0 \pm 0.10)$ considered to be isokinetic. The minimum operational stream velocities and temperatures of both the US D-77 bag-type and the US D-96 type samplers are 3 feet per second at 7 degrees Celsius $\left({ }^{\circ} \mathrm{C}\right)$ for the US D-77 bag-type and 3 feet per second at $4^{\circ} \mathrm{C}$ for the US D-96 type (Webb and Radtke, 1998; Lane and others, 2003).

In addition to the above factors, bag-type samplers are affected in rivers by the following physical factor that does not affect rigid-container samplers; this factor arises as a result of the initial flooding and subsequent purging of water from the sampler cavity in a bag-type sampler after submergence. Proper sampling with a bag-type depth-integrating sampler requires the free exchange of air and water between the sampler cavity housing the bag and the river while the sampler is in motion transiting a sampling vertical. As a bag-type sampler is lowered to the bed and subsequently raised through the water column, water quickly floods the sampler cavity through vent holes located near the bottom of the sampler body as trapped air escapes through a vent hole or holes located near the top of the sampler body. In the final version of the US D-77 bag-type sampler designed by Szalona (1982), flooding of the sampler cavity occurred within 5 seconds of submergence; in measurements made during 2010 on the Colorado River over a range of ambient stream velocities, flooding of the sampler cavity in a US D-96-type sampler occurred over 5-6 seconds. After all air is expelled from the sampler cavity, water must then be able to exit the sampler cavity at the same rate that water fills the bag through the nozzle isokinetically (Szalona, 1982; Davis, 2001, 2005a). However, as shown by measurements reported in Szalona (1982) and Davis (2001), this process does not occur in reality where the rate at which water exits a sampler cavity decreases over time, leading to intake efficiencies in bag-type samplers that decrease over time. This behavior is unlike that of rigidcontainer samplers, in which intake efficiency is not time dependent so long as these samplers are operated within their limits to avoid pressure-driven inrush.

Beginning with Szalona (1982) and reiterated by both Davis (2001, 2005a) and McGregor (2006), the standard assumption has been that, for a bag-type sampler to sample isokinetically, it is advantageous for the sampler cavity to flood quickly, within seconds, upon submergence. The basis for this assumption is that it is physically impossible for water to exit a sampler cavity as fast as air. This physical impossibility arises because when air is present in the sampler cavity, the additional force of buoyancy helps to drive the air out of the cavity. Therefore, it is impossible to design a bag-type sampler that will sample isokinetically with both air and water in the sampler cavity. A bag-type sampler designed to sample isokinetically when most of the volume in the 
sampler cavity is composed of air would sample at much lower intake efficiencies once the cavity was flooded; a bagtype sampler designed to sample isokinetically after the cavity was flooded would sample at intake efficiencies much greater than 1 while the sampler cavity was still mostly filled with air. Because the air in a sampler cavity must be replaced with water, it is best if this exchange happens as quickly as possible so that a sampler can be designed to sample isokinetically after the cavity has been flooded.

However, analysis of laboratory data presented in Szalona (1982) and Davis (2001) suggests that it is not possible to design a bag-type sampler that has intake efficiencies that do not decrease over time, even after the cavity has been flooded. In fact, as a filling bag occupies more of the volume in a sampler cavity, it becomes progressively more difficult for the filling bag to displace the water in the cavity and purge this displaced water through the vent holes. This arises because (1) the effect of wall friction on the water flowing in the sampler cavity around the bag increases as the space in the sampler cavity around the filling bag decreases in effective diameter and (2) the bag will tend to progressively block more vent holes as it fills. As described below, the first of these two processes results in an additional head loss, not present in rigid-container samplers, that increases over time as the filling bag occupies progressively more of the sampler cavity. Analysis of the laboratory data in Szalona (1982, figs. 4, 5) indicates that the intake efficiency of a US D-77 bag-type sampler decreased by $\sim 30$ percent as the sampling duration increased from $\sim 5$ to $\sim 60$ seconds. Most of this decrease in intake efficiency occurred after flooding of the sampler cavity; Szalona reported that the cavity in this earlier version of the US D-77 bag-type sampler flooded over $\sim 27$ seconds, not the $\sim 5$ seconds of his final design.

Experiments conducted during the development of the US D-96 sampler showed results with similar trends to those reported by Szalona (1982). Analysis of the laboratory data in Davis $(2001$, figs. 6, 7) indicates that the intake efficiency of a US D-96 sampler decreased by $\sim 30$ percent as the sampling duration increased from 20 seconds to 175 seconds at an ambient stream velocity of $2 \mathrm{ft} / \mathrm{s}$. At a higher ambient stream velocity of $5 \mathrm{ft} / \mathrm{s}$, however, the intake efficiency of a US D-96 sampler decreased by only $\sim 8$ percent as the sampling duration increased from 14 seconds to 84 seconds. On the basis of our measurements in the Colorado River, flooding of the US D-96 sampler in Davis' experiments likely occurred within 5-6 seconds. Davis (2001) attempted to compensate for the time-dependent effect on intake efficiency by drilling a 1/16-inch-diameter pressure-equalization hole between the top of the nozzle holder and the cavity for the US D-96 sampler; this pressure-equalization hole was subsequently included in the design of the US D-99 and US DH-2 samplers (Davis, 2005a; McGregor, 2006). Without the pressure-equalization hole, the intake efficiency of the US D-96 sampler decreased from 0.94 to 0.65 when the sampling duration increased from $\sim 30$ to $\sim 180$ seconds at an ambient stream velocity of $2 \mathrm{ft} / \mathrm{s}$. After inclusion of the pressure-equalization hole, the intake efficiency of the US D-96 sampler decreased from 1.21 to 0.91 when the sampling duration increased from $\sim 20$ to $\sim 180$ seconds at an ambient stream velocity of $2 \mathrm{ft} / \mathrm{s}$. Although inclusion of the pressure-equalization hole greatly increased the intake efficiency by likely allowing an avenue for the escape of the small amount of air trapped inside the nozzle holder and bag, it did not reduce the rate of decrease in intake efficiency. In fact, on the basis of Davis (2001, fig. 7), inclusion of the pressure-equalization hole may have actually increased the initial rate of decrease in intake efficiency; with the pressure-equalization hole, the intake efficiency decreased by $\sim 20$ percent over the first $\sim 80$ seconds of sampling.

As indicated in the previous discussion, intake efficiencies in bag-type samplers are time dependent and depend strongly on (1) rapid flooding of the sampler cavity and (2) subsequent purging of the water from the cavity at the same rate that water fills the bag through the sampler nozzle isokinetically. Because of these dependencies, the design of the vent holes in bag-type samplers is crucial to maintaining isokinetic sampling over typical sampling durations. As first observed by Szalona (1982), Davis (2001, 2005a) reported that both the locations and diameters of vent holes and the presence or absence of vent-hole flow deflectors greatly influenced intake efficiency (Davis, 2001, fig. 6; 2005a, table 1). Both Szalona (1982) and Davis (2001, 2005a) found that the greatest decrease in intake efficiency over time occurred with either no venting or with the top vent hole reduced in diameter. Szalona (1982) found that the intake efficiency of the US D-77 bag-type sampler decreased to $\sim 0.5$ when the upper vent hole was partially plugged; Davis (2001) found that the intake efficiency of the US D-96 sampler decreased to $\sim 0.64$ with no venting. Davis (2005a) also observed that intake efficiencies could be as low as 0.38 when no upper vent hole was present in the US DH-2 sampler preventing the escape of air from the sampler cavity. In the development of the US D-96 sampler, Davis (2001) found that intake efficiencies closest to unity were maintained when the upper and lower vent holes both had cast flow deflectors and were located on the top and bottom of the widest parts of the sampler body. The Venturi effect arising from the acceleration of flow around the sampler body results in negative dynamic pressure between the location of the sampler nozzle and the locations of the vent holes on the widest parts of the sampler body; this slight reduction in pressure aids in the evacuation of both air and water from the sampler cavity. In addition to these two vent holes, in the latest FISP approved designs of both the US D-96 and the US D-96-A1 samplers, an additional vent-hole slot is located on the bottom at the rear of the sampler cavity where the tail fin attaches to the sampler body (Davis, 2001; FISP, 2003). In the development of the US DH-2 sampler, Davis (2005a) found that intake efficiencies closest to unity were maintained when the upper vent hole was located on top of the widest part of the sampler body, and had a diameter larger than the two lower vent holes, and had a flow deflector. 


\section{Data}

\section{Suspended-Sediment, Nozzle-Velocity, and Nozzle-Orientation Data Collected with US D-77 Bag-Type and US D-96-Type Depth-Integrating Samplers}

Between 1999 and 2011, suspended-sediment data were collected using US D-77 bag-type (Szalona, 1982) and US D-96-type (Davis, 2001; FISP, 2003) depth-integrating, suspended-sediment, collapsible-bag samplers at six cross-sections located at three study sites on the Colorado River (figs. 2, 3). These data were collected using either the EDI or EWI method (Edwards and Glysson, 1999; Nolan and others, 2005), depending on the study site. The velocity-weighted suspended-sediment data collected using the EDI and EWI methods are equivalent within error when sufficient verticals are sampled (Edwards and Glysson, 1999; Topping and others, 2011). In the EDI method, a river cross-section is divided into increments of equal discharge; in the EWI method, a river cross-section is divided into increments of equal width. With both the EDI and EWI methods, depth-integrated samples were collected at the vertical located at the center of every discharge- or width-based increment (Edwards and Glysson, 1999). Uniform transit rate of the sampler at all verticals is required to collect velocity-weighted suspended-sediment data with the EWI method. While using the EWI method, a US VTP-99 electronic metronome was used to maintain uniform transit rates (FISP, [n.d.]a). During this study, both noncomposited data, where the sample collected at each vertical is processed separately in the laboratory, and field-composited EWI data were collected. The EDI sampling method does not require a uniform transit rate among all sampling centroids to collect velocity-weighted concentration data, and the transit rate between any upward or downward transit at a given centroid may vary; however, the rate during any individual downward transit from the water surface to the streambed or upward transit from the streambed to the water surface must be uniform, and the sample volume collected at each vertical must be equivalent if the sample is composited in the field. Deployment configuration of the US D-77 bagtype sampler followed that described in figure 2-2A in Webb and Radtke (1998); deployment configuration of the US D-96-type sampler followed those described in both the FISP US D-96 operating instructions (FISP, [n.d.]b, c) and Lane and others (2003). Data were collected with each sampler using both 1/4- and 5/16-inch-diameter nozzles ${ }^{3}$. During the course of this study, 1,645 EDI or EWI measurements were made using the US D-77 bag-type sampler and 413 EDI or EWI measurements were made using the US D-96-type sampler. Beginning in 2003, paired US D-96-A1 and US D-77 bag-type, suspended-sediment samples were collected under a wide range of flow conditions to evaluate potential biases in suspended-sediment concentrations measured using the US D-77 bag-type sampler relative to those measured using the US D-96-A1 sampler. These 160 sequential paired measurements were made at all six cross-sections among the three study sites.

At the 87-mile study site, samplers were deployed from a cableway, using the EDI method. At the other sampling cross-sections located at the 30-mile and 61-mile study sites, samplers were deployed from manned, motorized, aluminum, V-shaped-hull boats (see photograph on cover and fig. 6) held stationary under a Kevlar tagline at each vertical, using the EWI method. Before January 2005, some EWI measurements at the 30-mile and 61-mile study sites were made using the same field protocols from different types of boats. A depth sounding was first taken at each sampling vertical prior to sample collection to prevent the sampler from impacting the bed and causing possible bed contamination of the sample. To allow calculation of $\bar{V}_{\mathrm{n}}$, that is, the velocity of the water-sediment mixture moving through the nozzle averaged over the time a depth-integrating sampler is deployed at a vertical, a stopwatch was used to measure sampling duration at each vertical, and the sample volume collected at each vertical was recorded. Samples were analyzed for suspended-sediment concentrations and grain-size distributions at the USGS-GCMRC sediment laboratory in Flagstaff, Arizona, using standard USGS methods (Guy, 1969; Knott and others, 1992, 1993) augmented for grain-size analysis by dry-sieve-calibrated laser-diffraction methods described in Topping and others $(2010,2011)$. The USGS-GCMRC sediment laboratory participates in the national Sediment Laboratory Quality Assurance (SLQA) Project to ensure the accuracy, quality, and reliability of the laboratory analyses (Yorke, 1998).

In addition to the above suspended-sediment dataset, measurements were made using a US D-96-A1 sampler to evaluate the importance of lags between changes in flow direction and nozzle orientation. This additional dataset was collected because a depth-integrating sampler deployed under turbulent flow conditions may always be adjusting its orientation to changing flow directions as it transits a sampling vertical. These measurements on the rates of nozzle reorientation were made from a tethered boat in the Colorado River by first (1) lowering the sampler into the flow just below the water surface and allowing the nozzle orientation

\footnotetext{
${ }^{3}$ Throughout this report, nozzles are referred to with respect to their entrance diameters. As discussed below, the rear of most sampler nozzles are internally tapered to reduce frictional losses, hence the mean inside diameter of a nozzle is slightly larger than the entrance diameter.
} 


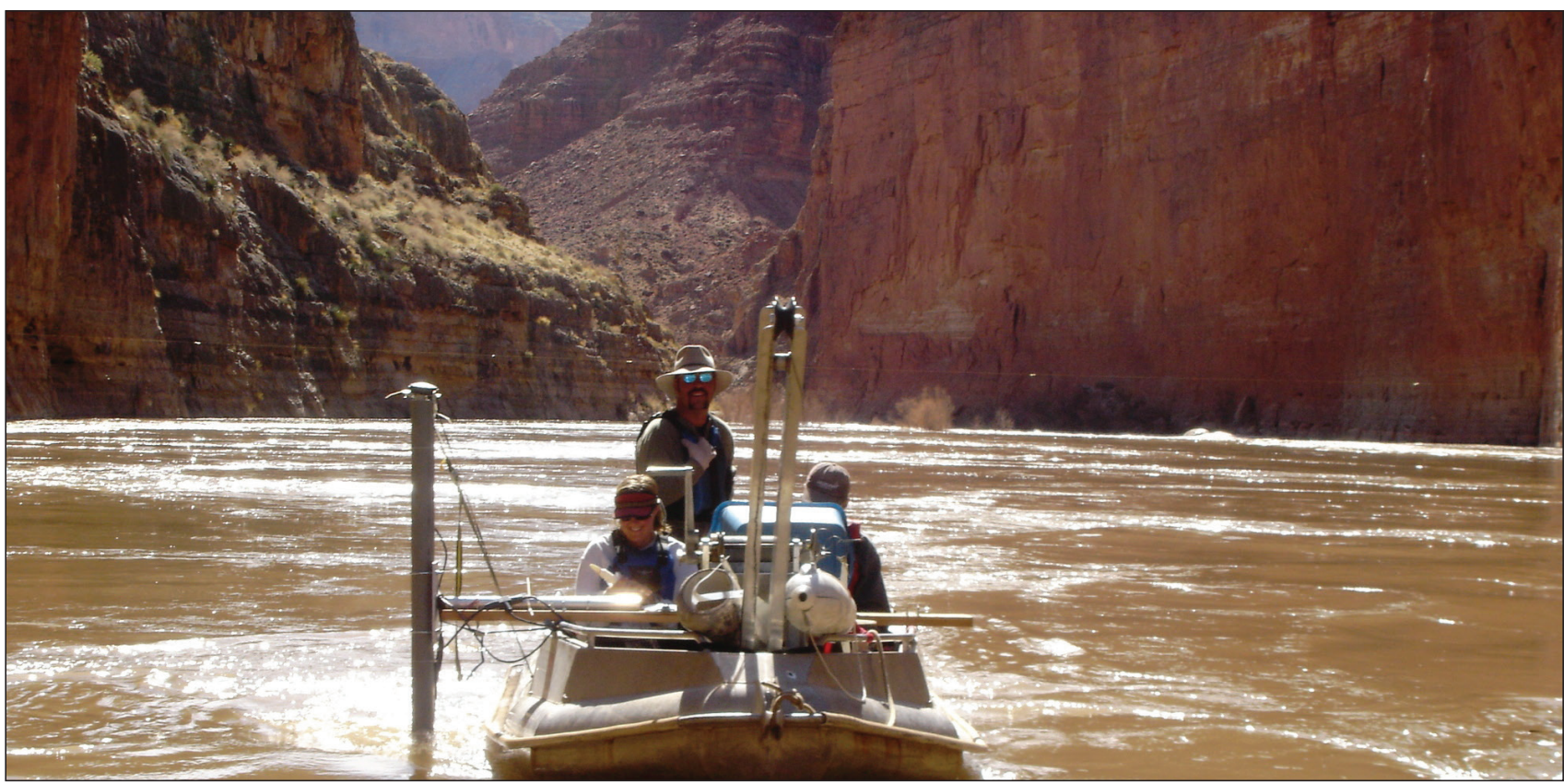

Figure 6. Photograph showing manned, motorized, boat equipped for the simultaneous collection of velocity-profile data and either US D-96 type or US D-77 bag-type suspended-sediment data at the 30-mile and 61-mile study sites. Downstream view of boat in the middle of the Colorado River near the tagline B cross-section at the 30-mile study site (Kevlar tagline visible behind boat). Acoustic-Doppler current profiler (ADCP) mounted at base of vertical pipe on starboard side of boat (left side of photograph). US D-77 bag-type and US D-96-A1 samplers are resting on gunwale near crane on bow.

to equilibrate with the flow direction, that is, point upstream parallel to the streamlines, (2) rotating the sampler so that the nozzle is oriented a specified number of degrees from this direction using a boat-mounted swing arm protractor, and then (3) measuring the time required for the sampler to reorient with the nozzle pointing upstream. These measurements were made nine times at orientations of 45, 30, 20, and 10 degrees from the upstream direction. At an ambient stream velocity of $\sim 3 \mathrm{ft} / \mathrm{s}$, results show that the US D-96-A1 takes an average of $2.9,2.5,1.6$, and 1.2 seconds to achieve re-equilibration with the flow direction for orientations of 45, 30, 20, and 10 degrees from the upstream direction, respectively.

\section{Measurements of Ambient Stream Velocity}

Acoustic-Doppler current profilers (ADCP, RD Instruments Workhorse Rio Grande, 600 kHz; Workhorse Monitor, 600/1200 kHz; Workhorse Sentinel, 300 kHz) were used to collect velocity-profile data at the five 30-mile and 61-mile study-site cross-sections, and Price AA mechanical current meters were deployed using the two-point method to collect velocity-profile data at the cableway cross-section at the 87-mile study site. Quality control and error analyses were conducted on these velocity data to ensure that curves fit to these data accurately reflected the time- and depth-averaged ambient stream velocity, $\bar{V}$, encountered by the depth-integrating suspended-sediment samplers at each vertical. The methods used in this study to constrain the ambient stream velocity at each sampling vertical are at least as accurate as those used in previous river tests of depth-integrating samplers (for example Benedict, 1944; FISP, 1944,1951, 1952; Davis, 2001). Extensive analyses by Mueller $(2002,2003)$ and Oberg and Mueller (2007) show that velocities and discharges measured using ADCPs compare well with reference velocities and discharges measured using mechanical current-meter methods in both field and laboratory settings, with no statistical biases evident. Across a wide range of riverine test settings, Mueller $(2002,2003)$ and Oberg and Mueller (2007), demonstrate that ADCP streamflow data, collected from both manned and tethered boats, are both accurate within 5 percent and unbiased when compared to reference values, thus ensuring the consistency of results with standard USGS techniques. Based on their findings, it is concluded that the uncertainties associated with mean ambient stream velocities, measured by ADCPs in this study and used to compute intake efficiencies in equation 1 , are unbiased and accurate within 5 percent. 
ADCPs were mounted on the side of motorized, aluminum, V-shaped-hull boats (see photograph on cover and fig. 6), with the transducers oriented downward and typically submerged an average of $1.1 \mathrm{ft}$ below the water surface. Per the Configuration and Measurement Wizards of WinRiver and WinRiver II, ADCPs were programmed to collect data using Water Modes 1 and 12, with bin sizes ranging from 0.82 to $1.64 \mathrm{ft}$. Blanking distance was held constant at $0.82 \mathrm{ft}$. Details of ADCP configuration settings and best practices can be found at RD Instruments, Inc., (accessed October 27, 2011, at http://www.rdinstruments.com) and from OSW Hydroacoustics (accessed October 27, 2011, at http:// hydroacoustics.usgs.gov/index.shtml).

Moving-boat ADCP deployment requires that the relative position of the instrument in the river be known. Typically, this is determined by using either a Global Positioning System (GPS) or the bottom-track pings from the ADCP. Combinations of high velocities, high concentrations of suspended sediment, and bed-load transport can affect the Doppler shift of the bottom-track ping, leading to a measurement error known as "moving bed" (Mueller and Wagner, 2009). Under such moving bed conditions, GPS is typically used on other rivers to establish the relative position of the instrument. Incomplete GPS coverage at the study sites, however, necessitated local referencing of the ADCP position, relative to the location of the EWI verticals along the tagline cross-section at each study site, when moving-bed conditions rendered the bottom-track ping unreliable during the collection of stationary velocity data. Local referencing made it possible to use the raw unbiased velocity data collected when moving bed conditions were present.

During the collection of stationary time- and depth-averaged velocity data, a professional technical boat operator visually maintained the position of the manned, motorized, nontethered boat underneath the tagline at each EWI vertical along the tagline cross-section. Previous work conducted at the 61-mile tagline $\mathrm{C}$ and 30-mile tagline $\mathrm{B}$ cross-sections demonstrated that this technique of maintaining fixed positions relative to the location of the EWI verticals along the tagline typically produces small variations in boat motion within \pm 3 to $6 \mathrm{ft}$, with total distances traveled of less than $3 \mathrm{ft}$ and, therefore, is an unlikely source of bias in velocity measurements (Gartner and Ganju, 2007). Although streamflow conditions during ADCP data collection were commonly unsteady as a result of upstream dam-regulated fluctuations in discharge, the effect of unsteady flow on ADCP velocity data used in this study is minimal. Analysis of ADCP data collected at 61-mile tagline $\mathrm{C}$ throughout this study demonstrates this minimal effect; data show that the average rate of change in time- and depth-averaged velocity is $0.002 \mathrm{ft} / \mathrm{s}$ for each minute of ADCP velocity data collected during unsteady fluctuating flows.

In an effort to guarantee the usefulness of all velocity data collected, regardless if moving bed conditions were present or not, the position of the ADCP relative to the location of EWI sampling verticals along each tagline were continuously documented. At all 30-mile and 61-mile study-site cross-sections, velocity data were collected with the ADCP using two methods, which were compared to ensure internal consistency within the dataset. Stationary, time- and depth-averaged velocity data were collected at EWI sampling verticals with the ADCP, using methods described by Mueller and Wagner (2009) and Gartner and Ganju (2007). Stationary velocity data were analyzed for moving-bed conditions and corrected to remove any low bias with the Stationary Moving-Bed Analysis software v4.2 (accessed October 27, 2011, at http://hydroacoustics.usgs.gov/movingboat/SMBA1. shtml). The resulting time- and depth-averaged velocity data were then used in the calculation of intake efficiency and velocity-discharge relations at each of the sampling locations.

ADCP transect data from moving-boat discharge measurements at each cross-section were analyzed to develop estimates of surrogate time- and depth-averaged stationary velocity data from transient transect data at each sampling vertical. During discharge measurements (Mueller and Wagner, 2009), direct comparisons between the position of the ADCP under the tagline relative to the EWI sampling locations, and the ensembles collected by the ADCP, were used to flag ensembles corresponding to the location of sampling verticals throughout each transient transect. Using percent difference comparisons performed between data from sequential back-to-back stationary velocity measurements and averaged moving-boat discharge-measurement transects, it was determined that during moving-boat discharge-measurement transects, an average of five ensembles around each EWI sampling vertical provided the best velocity surrogate (difference of only \pm 4 percent) for time-averaged, stationary-velocity data collected at the EWI vertical. Discharge during the sequential collection of data for the comparison between these two methods varied less than 1 percent. Surrogate values of time- and depth-averaged velocities using this approach were determined only in the absence of moving bed conditions. Using both of these methods resulted in a much larger dataset of ambient stream velocities to use in the analyses of the field intake efficiencies of the US D-77 bag-type and US D-96-type samplers.

At the 87-mile study site, velocities were measured using a Price AA current meter typically deployed using the two-point method at two elevations, 0.2 and 0.8 of the distance from the water surface to the streambed, at 25-30 verticals along the cableway cross-section during the collection of 64 standard USGS discharge measurements using the midsection method (Rantz and others, 1982); these measurements were made by the USGS Arizona Water Science Center. Analysis of depth-averaged velocity and discharge data at this site indicates that data collected with the Price AA current meter are identical to those collected with an ADCP; that is, no bias exists between the data collected with these two methods (G. Fisk, USGS, oral commun., 2010). 


\section{Measurements of Water Temperature}

During collection of the suspended-sediment data, water temperatures were measured at 15 -minute intervals using Onset Computer Corporation HOBO water-temperature sensors and YSI 6920 multiparameter sondes. These instruments are permanently deployed at each study site (Voichick and Wright, 2007; Griffiths and others, 2012). Using this dataset, water temperatures were interpolated to the exact time associated with the temporal midpoint of each EDI or EWI suspended-sediment measurement along each cross-section.

\section{Analyses}

\section{Discharge-Velocity Relations}

As defined in equation 1, quantification of intake efficiency is dependent on the ability to constrain $V_{\mathrm{n}}$, the instantaneous velocity moving through the nozzle, and $V$, the instantaneous ambient stream velocity at the locus of the sampler-nozzle intake unaffected by the presence of the sampler. As previously discussed, because $V_{\mathrm{n}}$ cannot be measured during the field deployment of depth-integrating samplers, a time average of $V_{\mathrm{n}}$, that is $\bar{V}_{\mathrm{n}}$, must be used in calculating field intake efficiency. $\bar{V}_{\mathrm{n}}$ is the velocity of the water-sediment mixture moving through the nozzle averaged over the time a depth-integrating sampler is deployed at a vertical. At any given vertical, $\bar{V}_{\mathrm{n}}$ is calculated using the inside diameter of the nozzle entrance, the duration the depth-integrating sampler is collecting a sample, and the sampled volume. Because a time-averaged quantity is used in the numerator of equation 1 , it is necessary to use data averaged over the same interval for the ambientstream-velocity term, $V$, in the denominator of equation 1 when calculating field intake efficiency. As a result, $V$ in equation 1 is replaced in this study by $\bar{V}$, that is, the time- and depth-averaged ambient stream velocity at a vertical. Making these substitutions in equation 1 leads to

$$
\mathrm{IE}_{\text {field }}=\frac{\bar{V}_{\mathrm{n}}}{\bar{V}}
$$

where

$$
\begin{aligned}
& \mathrm{IE}_{\text {field }} \text { is the field-determined intake efficiency of a } \\
& \text { depth-integrating sampler. }
\end{aligned}
$$

Equation 2 is the same relation used to calculate intake efficiency in early FISP river tests of depth-integrating samplers (Benedict, 1944; FISP, 1944, 1951).

Calculation of $\mathrm{IE}_{\text {field }}$ requires measurement of $\bar{V}$ across the entire range of discharge encountered at each sampling vertical in an EDI or EWI measurement. Because it is not always possible to measure $\bar{V}$ at the same time that a suspended-sediment sample is collected at a given vertical, $\bar{V}$ in equation 2 was evaluated using relations developed between the discharge of the river through the cross-section and the time- and depth-averaged velocities measured at each vertical in the cross-section. The accuracies of these relations were then evaluated using limited measurements of time- and depth-averaged velocity measured concurrently with the collection of suspended-sediment data to ensure that no bias or substantial error was introduced into calculations of $\mathrm{IE}_{\text {field }}$ using the discharge-velocity relations. Discharge $(Q)$-velocity $(\bar{V})$ relations, table 1 , were developed for each EWI sampling vertical at the 30-mile and 61-mile tagline cross-sections by regressing both the time- and depthaveraged ADCP velocity data and the surrogate time- and depth-averaged ADCP velocity data against 15 -minuteinterval discharge data (Griffiths and others, 2012). At the 87-mile study site cableway cross-section, values of timeand depth-averaged velocity were extracted for each EDI centroid from 64 discharge measurements made with Price AA current meters deployed using the midsection method (Rantz and others, 1982). These time- and depth-averaged Price AA velocity data were regressed on discharge to develop velocity-discharge relations for each EDI sampling vertical at this study site (table 1). The form of the discharge-velocity relations presented in table 1 is

$$
\bar{V}=b+m_{1} Q+m_{2} Q^{2},
$$

where

$b$ is the $\bar{V}$-intercept,

$m_{1}$ is the coefficient associated with $Q$, and

$m_{2}$ is the coefficient associated with $Q^{2}$ for 12 of the 52 sampling verticals where a second-order polynomial regression provides a statistically significant better fit than a linear regression.

The weighted $R^{2}$-value for all statistically significant relations (at the 0.05 critical level of significance) between $Q$ and $\bar{V}$ used in this study is 0.92 . The relative mean absolute errors in $\bar{V}$ calculated using these relations relative to measurements of $\bar{V}$ are shown in table 1 . 
Table 1. Discharge-velocity relations at each sampling vertical along each cross-section at each study site.

[Measurements of the time- and depth-averaged ambient stream velocity, $\bar{V}$, were obtained using various ADCPs, except at the 87-mile study site, where $\bar{V}$ was computed using Price AA current-meter data. Verticals are numbered from left to right across each cross section. RMAE, relative mean absolute error in $\bar{V}$ predicted by the discharge-velocity relation. Study site and cross-section: RM30A, tagline cross-section A at the 30-mile study site; RM30B, tagline crosssection B at the 30-mile study site; RM61A, tagline cross-section A at the 61-mile study site; RM61B, tagline cross-section B at the 61-mile study site; RM61C, tagline cross-section C at the 61-mile study site; RM87, cableway cross-section at the 87-mile study site. $\boldsymbol{n}$ indicates number of measurements in each regression; $\boldsymbol{p}$ indicates level at which regression is significant; $\boldsymbol{Q}_{\min }$ and $\boldsymbol{Q}_{\max }$ indicate minimum and maximum discharges of water, respectively, at which

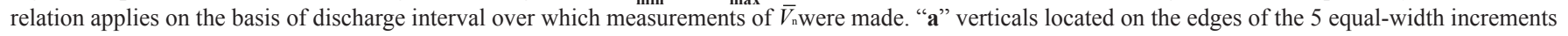
normally sampled; "2004" indicates verticals that were located at slightly different stations along 61-mile tagline C cross-section during November 2004.

Abbreviations: $\mathrm{ft}^{3} / \mathrm{s}$, cubic feet per second; <, less than]

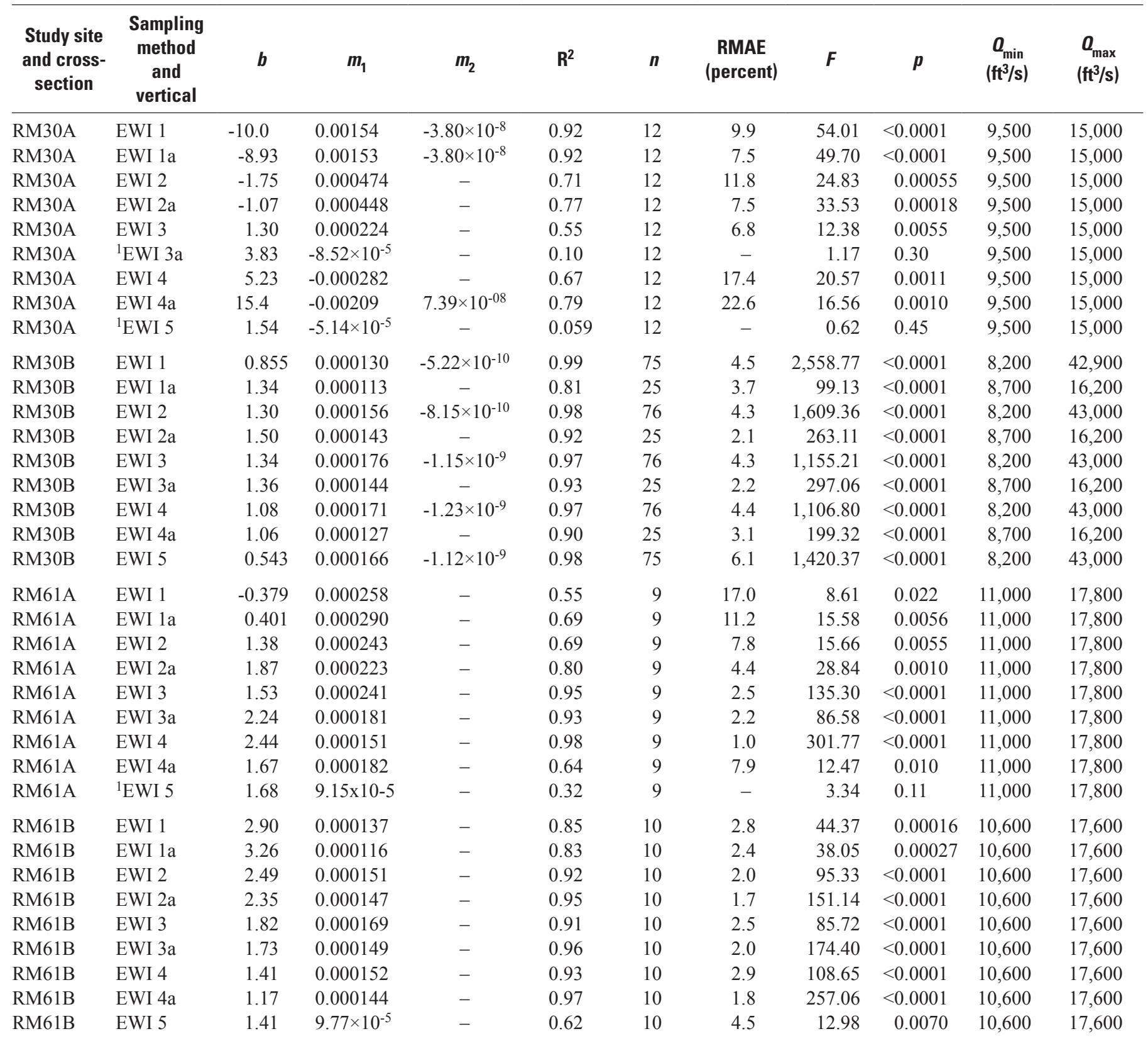


Table 1. Discharge-velocity relations at each sampling vertical along each cross-section at each study site.-Continued

[Measurements of the time- and depth-averaged ambient stream velocity, $\bar{V}$, were obtained using various ADCPs, except at the 87-mile study site, where $\bar{V}$ was computed using Price AA current-meter data. Verticals are numbered from left to right across each cross section. RMAE, relative mean absolute error in $\bar{V}$ predicted by the discharge-velocity relation. Study site and cross-section: RM30A, tagline cross-section A at the 30-mile study site; RM30B, tagline crosssection B at the 30-mile study site; RM61A, tagline cross-section A at the 61-mile study site; RM61B, tagline cross-section B at the 61-mile study site; RM61C, tagline cross-section $\mathrm{C}$ at the 61-mile study site; RM87, cableway cross-section at the 87-mile study site. $\boldsymbol{n}$ indicates number of measurements in each regression; $\boldsymbol{p}$ indicates level at which regression is significant; $\boldsymbol{Q}_{\min }$ and $\boldsymbol{Q}_{\max }$ indicate minimum and maximum discharges of water, respectively, at which relation applies on the basis of discharge interval over which measurements of $\bar{V}_{\mathrm{n}}$ were made. "a" verticals located on the edges of the 5 equal-width increments normally sampled; "2004" indicates verticals that were located at slightly different stations along 61-mile tagline C cross-section during November 2004. Abbreviations: $\mathrm{ft}^{3} / \mathrm{s}$, cubic feet per second; $<$, less than]

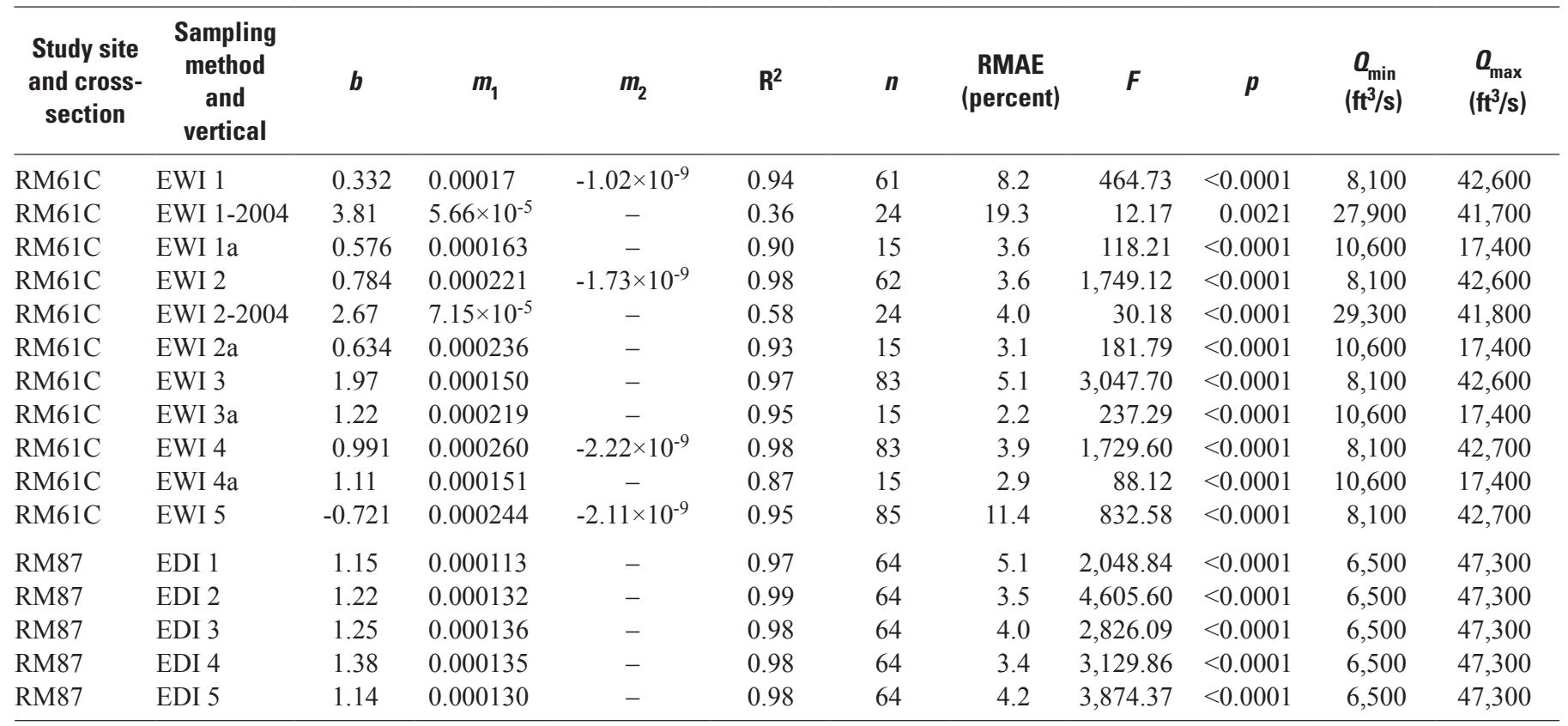

${ }^{1}$ Regression between $\bar{V}$ and $Q$ not significant at the 0.05 critical level; data best explained by mean velocity over $Q_{\min }$ to $Q_{\max }$ range in discharge.

Accurate calculation of the field intake efficiency (eqn. 2) at each sampling vertical depends on the accurate calculation of ${ }^{-}$using the discharge-velocity relations in table 1 . Evaluation of the accuracy of $\bar{V}$ calculated by this method was therefore conducted through comparison of the $Q-\bar{V}$ relation-predicted values of $\bar{V}$ with those determined by direct measurements of $\bar{V}$ made at a vertical concurrently with the collection of suspended-sediment data. At the 30-mile tagline $\mathrm{B}$ and 61-mile tagline $\mathrm{C}$ cross-sections, both the ADCP, and either the US D-77 bag-type or the US D-96-type sampler, were simultaneously deployed from a boat at EWI sampling verticals to collect concurrent depth-integrated suspended-sediment data and stationary time- and depth-averaged velocity data (photograph on cover, fig. 6); average horizontal offset between the ADCP and the sampler was approximately $5 \mathrm{ft}$ during deployment. These data, 184 observations at the 30-mile tagline B cross-section and 97 observations at the 61-mile tagline $\mathrm{C}$

\footnotetext{
${ }^{4}$ The two subscripts associated with the $F$ value indicate the degrees of freedom associated with the numerator of the $F$ value, and the degrees of freedom associated with the denominator of the $F$ value, respectively. $p$ indicates level of significance associated with each $F$ value.
}

cross-section, allow direct comparisons to be made at the sampling verticals between the $\mathrm{IE}_{\text {field }}$ calculated using the $\bar{V}$ from the $Q-\bar{V}$-relation with the $\mathrm{IE}_{\text {field }}$ calculated using directly measured values of $\bar{V}$ (fig. 7). $F$-tests comparing the variance around multiple or single linear regressions (Griffiths, 1967, p. 453-455) show no significant difference, at the 0.05 critical level, between the values of $\mathrm{IE}_{\text {field }}$ calculated at the 30-mile tagline $\mathrm{B}$ cross-section (fig. $7 A$ ) for the US D-96-type sampler $\left(F_{1,184}=1.48, p=0.226\right)^{4}$ or the US D-77 bag-type sampler $\left(F_{1,176}=0.390, p=\right.$ 0.533 ) when either $\bar{V}$ from the concurrent ADCP velocity data or $\bar{V}$ from the discharge-velocity relation is used in equation 2. Likewise, these tests also indicate that no significant difference exists between the values of $\mathrm{IE}_{\text {field }}$ calculated at the 61-mile tagline $\mathrm{C}$ cross-section (fig. 7B) for the US D-96-type sampler $\left(F_{1,86}=0.038, p=0.845\right)$ or the US D-77 bag-type sampler $\left(F_{1,100}=0.314, p=0.575\right)$ when either $\bar{V}$ from the concurrent ADCP velocity data or $\bar{V}$ from the discharge-velocity relation is used in equation 2 . 


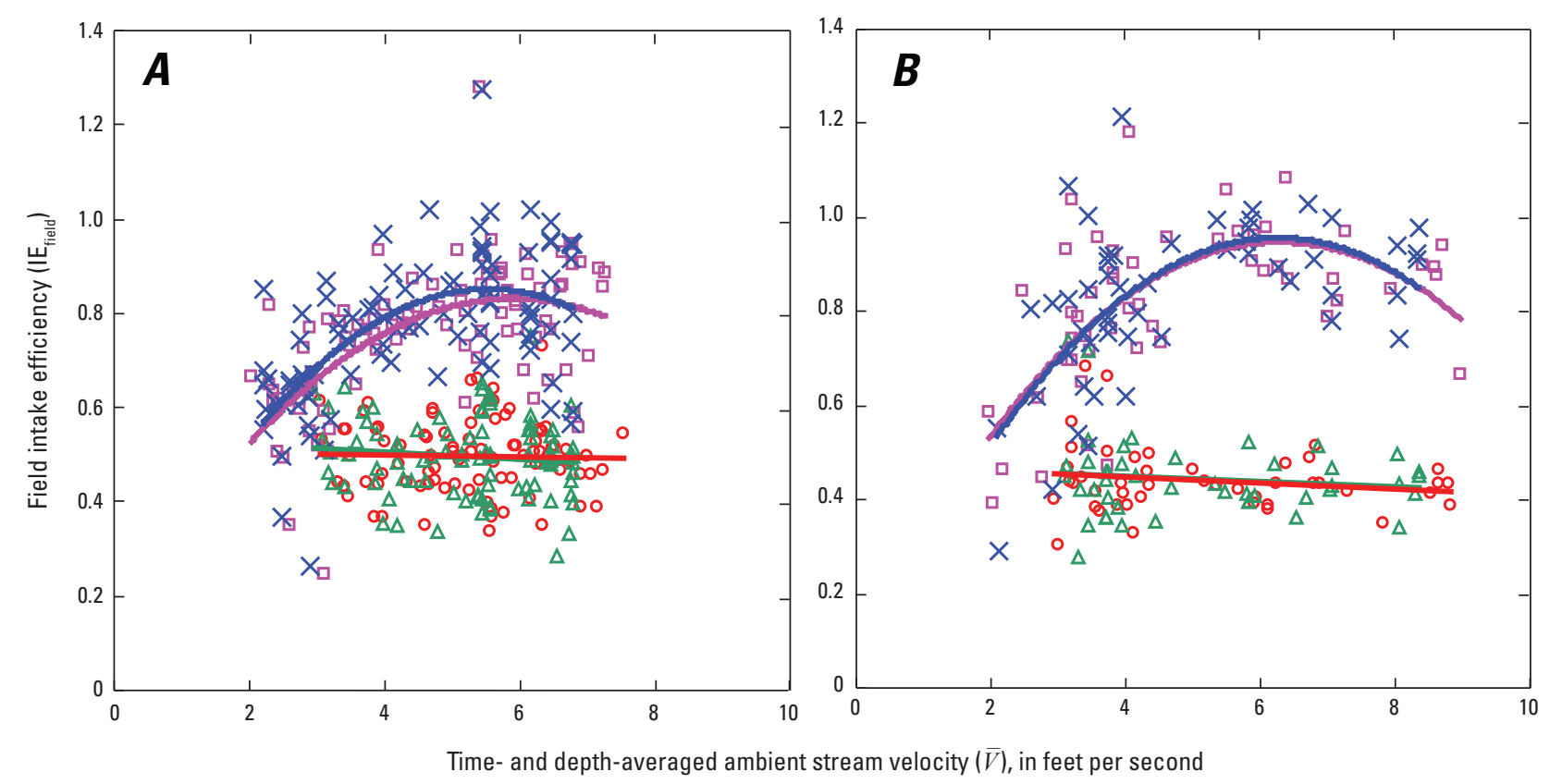

\title{
EXPLANATION
}

\author{
US D-77 bag-type sampler, $\bar{V}$ component of $\mathrm{IE}_{\text {field }}$ from \\ $\rightarrow \quad$ Stationary concurrent ADCP measurements, line is best fit linear regression \\ $\triangle \quad$ Discharge-velocity relations developed for each sampling vertical, line is best fit linear regression \\ US D-96-type sampler, $\bar{V}$ component of $\mathrm{IE}_{\text {field }}$ from \\ $\because-\quad$ Stationary concurrent ADCP measurements, curve is best fit $2^{\text {nd }}$ order polynominal regression \\ * Discharge-velocity relations developed for each sampling vertical, curve is best fit $2^{\text {nd }}$ order polynominal regression
}

Figure 7. Plots showing comparison between subsets of the field intake efficiency $\left(\mathrm{IE}_{\text {field }}\right)$ calculated at each EWI (equal-width increment) sampling vertical along $(A)$ tagline $B$ at the 30 -mile study site and $(B)$ tagline $C$ at the 61 -mile study site using two methods to calculate $\mathrm{IE}_{\text {field: }}$ (1) the method where $\bar{V}$ was determined from stationary ADCP measurements conducted concurrently with the deployment of either the US D-77 bag-type or the US D-96-type samplers at a vertical or (2) the method where $\bar{V}$ was calculated using the discharge-velocity relations developed for each sampling vertical. Even though linear regressions were required and used in all Griffiths' (1967) F-test analyses, second-order-polynomial nonlinear regressions are shown for the US D-96-type-sampler data because they provide a statistically significant better fit than linear regressions for these data.

In addition to the $F$-tests, a Relative Mean Absolute Error (RMAE) of 5.85 percent $(n=281)$ was computed for all $\mathrm{IE}_{\text {field }}$ observations, from data collected using both the US D-77 bag-type and US D-96-type samplers at both the 30-mile tagline $\mathrm{B}$ and 61-mile tagline $\mathrm{C}$ cross-sections, when comparing "measured" $\mathrm{IE}_{\text {field }}$ calculated using a $\bar{V}$ that was directly measured by the ADCP during sample collection and “modeled" $\mathrm{IE}_{\text {field }}$ calculated using a $\bar{V}$ that was calculated from the discharge-velocity relation at each sampling vertical. These results therefore indicate that the discharge-velocityrelation method for determining $\bar{V}$ at each EWI sampling vertical yields field intake efficiencies that are sufficiently accurate for the analyses conducted in this study. 


\section{Field Intake Efficiency}

Large differences exist between intake efficiencies measured in the laboratory and those measured in the field, especially for the US D-77 bag-type sampler. Depth-integrating samplers are designed for use in the field and not in the laboratory. Therefore, once the sampler development and testing phase has been concluded in a controlled laboratory environment, the field-determined intake efficiencies and sediment-concentration data are the ultimate measure of sampler performance. Differences between laboratory- and field-determined intake efficiencies may arise from: (1) differences that exist between the laboratory and tow-test environment and the environment in actual rivers, and (2) differences in bag-type sampler behavior between when a sampler is held stationary and when a sampler is transiting a sampling vertical. Compared to the relatively uniform flow conditions in laboratory flumes and the uniform nonturbulent conditions in tow tests, rivers have a much larger range in depth, much greater levels of turbulence, and larger ranges in temperature. In addition, rivers are boundary-layer shear flows and the flows experienced by samplers in tow and towed-transit tests are not. Furthermore, samplers are generally held stationary in the vertical dimension in flume and tow tests, whereas they are always in motion when deployed in actual rivers. Although this difference in sampler motion may not matter in tests of rigid-container depth-integrating samplers ${ }^{5}$, it may result in large differences in intake efficiencies measured for bag-type depth-integrating samplers. This is because changes in the maximum rate at which water can be purged from the sampler cavity while the sampler is in motion may prevent the bag from filling at the rate required for isokinetic sampling, resulting in reduced intake efficiencies. In addition, because rivers are shear flows, the dynamic pressures at the tops and bottoms of a bag-type sampler (where the vent holes are located) will be slightly different than these dynamic pressures would be in a towed-transit test in a lake (where the flow velocity at the top and bottom of the sampler body would be equal). Thus, the rate at which water can exit the sampler cavity when in motion transiting in a river could be different than the rates observed in flumes, in tow tests, or when in motion in towed-transit tests.

Field intake efficiencies were calculated using equation 2 for the US D-77 bag-type and US D-96-type samplers at each sampled vertical in each cross-section at the three study sites on the Colorado River in Marble and Grand Canyons (fig. 8). At all six cross-sections among all three study sites, the field intake efficiency of the US D-96-type sampler is much closer to isokinetic unity than it is for the US D-77 bag-type sampler, with overall performance of the US D-96-type sampler

\footnotetext{
${ }^{5}$ This is true so long as the transit rates are low enough to prevent pressuredriven inrush during sampler descent.
}

being much closer to the FISP-acceptable range of isokinetic operation, especially when a 1/4-inch nozzle is used at time-and depth-averaged ambient stream velocities in excess of about $3 \mathrm{ft} / \mathrm{s}$ (fig. 8). All data in figure 8 were collected within the operational limits of the samplers and at transit rates less than 40 percent of the time- and depth-averaged ambient stream velocity. The minimum operational stream velocities and temperatures of both the US D-77 bag-type and the US D-96 type samplers are $3 \mathrm{ft} / \mathrm{s}$ at $7^{\circ} \mathrm{C}$ for the US D-77 bag-type and $2 \mathrm{ft} / \mathrm{s}$ at $4^{\circ} \mathrm{C}$ for the US D-96 type (Webb and Radtke, 1998; Lane and others, 2003). Unlike in the flume tests shown in figure 5 , where mean intake efficiency is close to unity over most of the operating range, the mean field intake efficiency of the US D-77 bag-type sampler in the river tests in figure 8 is only about 0.4 to 0.6 over the entire range of ambient stream velocity (fig. 9). As shown in the following sections, these extremely low field intake efficiencies likely arise from an inability of the filling bag to displace the water in the flooded sampler cavity at the rate required for isokinetic sampling as the filling bag progressively occupies more of the volume of the sampler cavity. In contrast to the US D-77 bag-type sampler, the observed differences in intake efficiency of the US D-96-type sampler between the flume and tow tests in figure 5 and the river tests in figure 8 are less substantial (fig. 9), and they may be partially explained on the basis of differences in water temperature between the warm-water flume, tow, and towed-transit tests, and the water temperature in the cold-water river tests (as described below). However, the field intake efficiencies of the US D-96-type sampler can be much lower than expected on the basis of differences in water temperature alone and, as in the case of the US D-77 bag-type sampler, likely also arise from an inability of the filling bag to displace the water in the flooded sampler cavity at the rate required for isokinetic sampling as the filling bag progressively occupies more of the volume of the sampler cavity (as analyzed below).

The greater variance in the field intake efficiencies than in the laboratory intake efficiencies for the US D-77 bag-type and US D-96-type samplers (fig. 9) likely reflects (1) the greater variability in flow conditions in rivers compared to in flumes and in tow tests, and (2) the fact that the bag-type depth-integrating samplers are always in motion (transiting verticals) in the river tests but are held stationary (in the vertical dimension) in flume and tow tests. The comparatively small variance (approximately \pm 5 percent) in the laboratory intake efficiencies in figure 9 can almost be entirely explained by the tolerance limits on machining the sampler nozzles (Davis, 2001). Dimensional tolerances in the machining process of $\pm 1 / 32,000$-inch can result in up to 5 percent variation in intake efficiency (B.E. Davis, USGS, written commun., July 7, 2009). Additionally, inconsistencies among nozzles in the smoothness of the inside machined bore can cause variations in intake efficiency (Davis, 2001). 


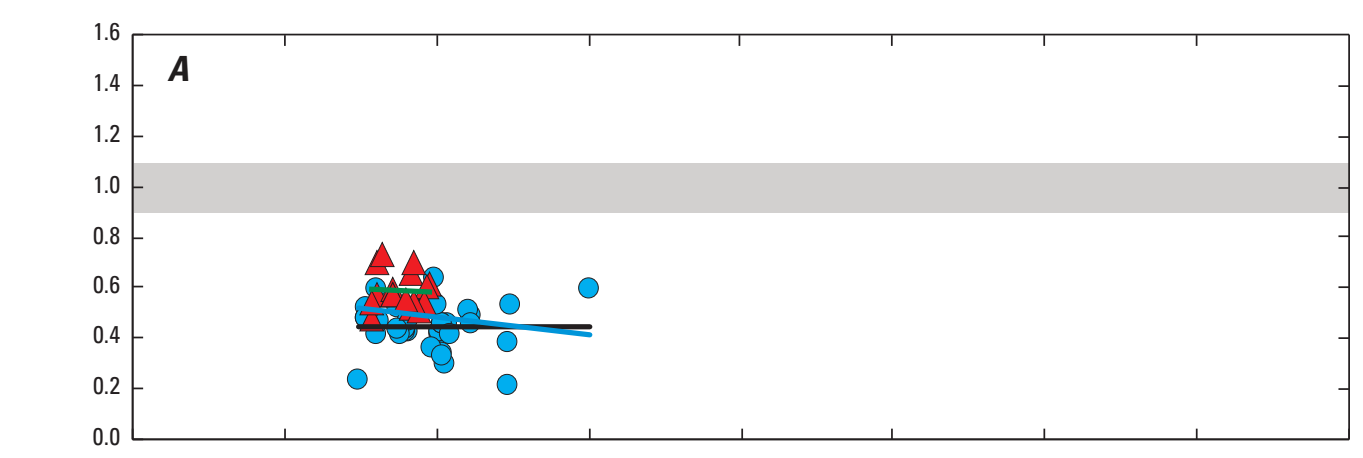

\section{EXPLANATION}
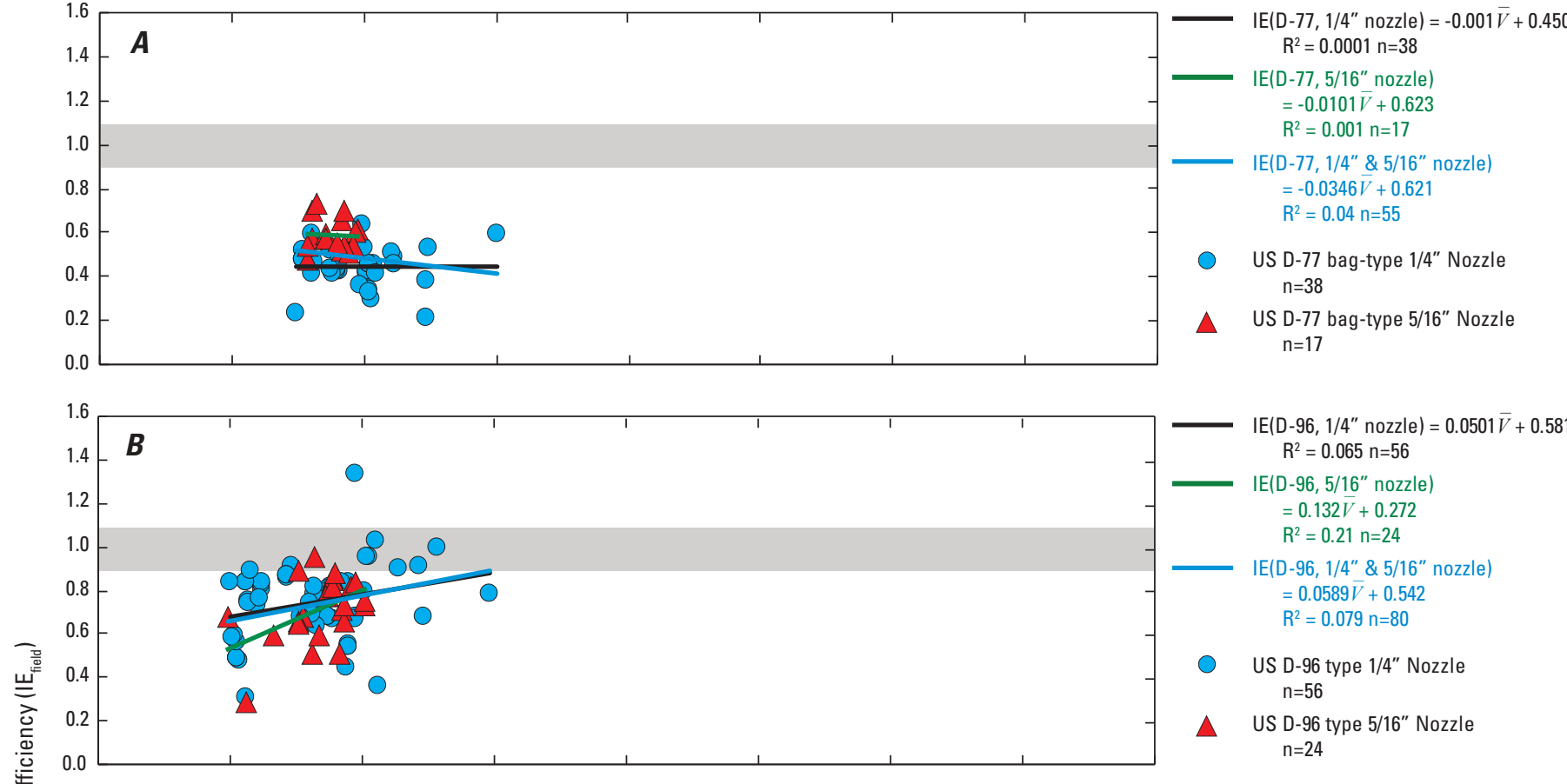
IE $\left(\mathrm{D}-96,1 / 4^{\prime \prime}\right.$ nozzle $)=0.0501 \bar{V}+0.581$ $R^{2}=0.065 n=56$
IE(D-96, 5/16" nozzle) $=0.132 \bar{V}+0.272$ $\mathrm{R}^{2}=0.21 \mathrm{n}=24$

IE(D-96, 1/4" \& 5/16" nozzle) $=0.0589 \bar{V}+0.542$ $R^{2}=0.079 n=80$

US D-96 type 1/4" Nozzle $\mathrm{n}=56$

A US D-96 type 5/16" Nozzle $\mathrm{n}=24$

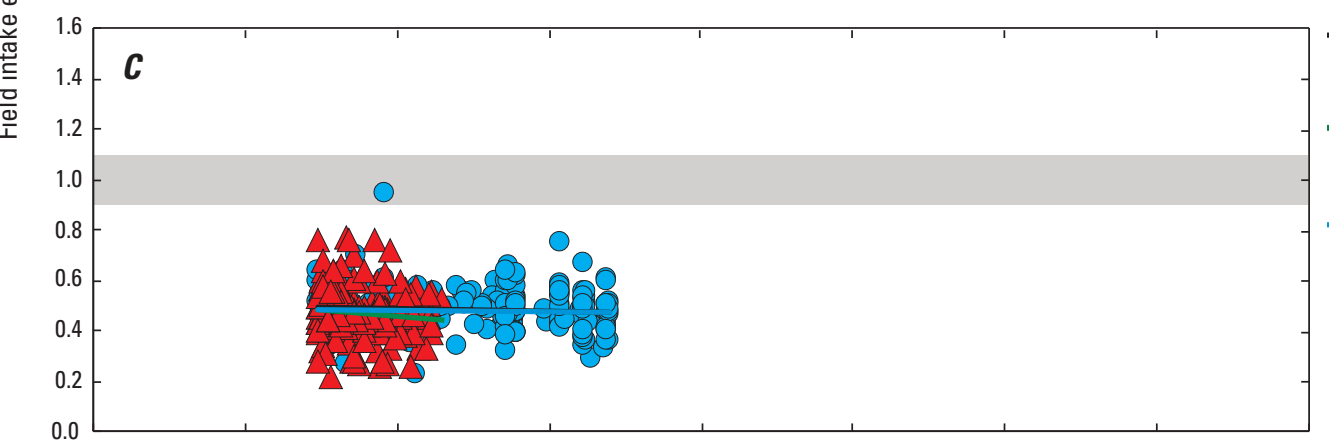

IE(D-77, 1/4" nozzle) $=-0.0043 \bar{V}+0.5058$ $R^{2}=0.0044 n=203$

IE(D-77, 5/16" nozzle) $=-0.0267 V+0.5637$ $R^{2}=0.014 n=215$

IE(D-77, 1/4" \& 5/16" nozzle) $=-0.0006 \bar{V}+0.4799$ $R^{2}=7.0 \times 10^{-05} \mathrm{n}=418$

US D-77 bag-type 1/4" Nozzle $\mathrm{n}=203$

A US D-77 bag-type 5/16" Nozzle $\mathrm{n}=215$

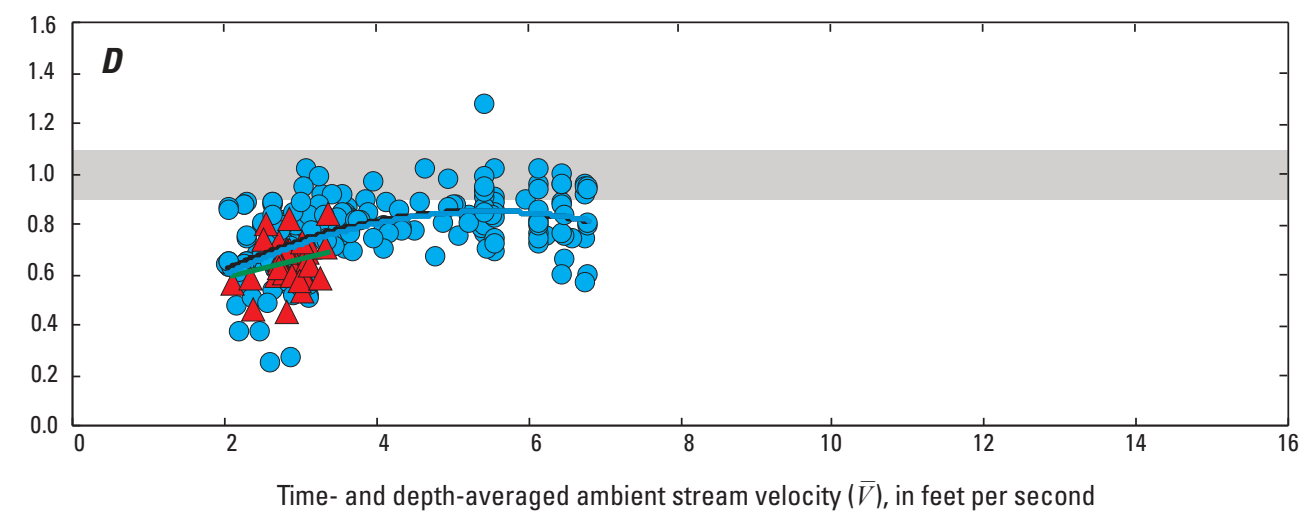

IE(D-96, 1/4" nozzle) $=-0.0204 \bar{V}^{2}+0.220 \bar{V}+0.257$ $R^{2}=0.24 n=220$

IE(D-96, 5/16" nozzle) $=0.0739 \bar{V}+0.435$ $R^{2}=0.051 n=37$

IE(D-96, 1/4" \& 5/16" nozzle) $=-0.0206 V^{2}+0.227 V+0.226$ $R^{2}=0.27 n=257$

US D-96 type 1/4" Nozzle $\mathrm{n}=220$

US D-96 type 5/16" Nozzle $\mathrm{n}=37$

Figure 8. Plots showing field intake efficiency within the operating ranges of the US D-77 bag-type and the US D-96-type depthintegrating suspended-sediment samplers at all individual sampling verticals along the cross-sections at $(A, B) 30$-mile tagline $A,(C, D)$ 30-mile tagline $B,(E, F) 61$-mile tagline $A,(G, H) 61$-mile tagline $B,(I, J) 61$-mile tagline $C$, and $(K, L)$ the 87-mile cableway. Best-fit linear or second-order-polynomial regressions between the time- and depth-averaged ambient stream velocity and field intake efficiency are shown for data collected with either $1 / 4$-inch or 5/16-inch nozzles and both $1 / 4$-inch and 5/16-inch nozzles. 

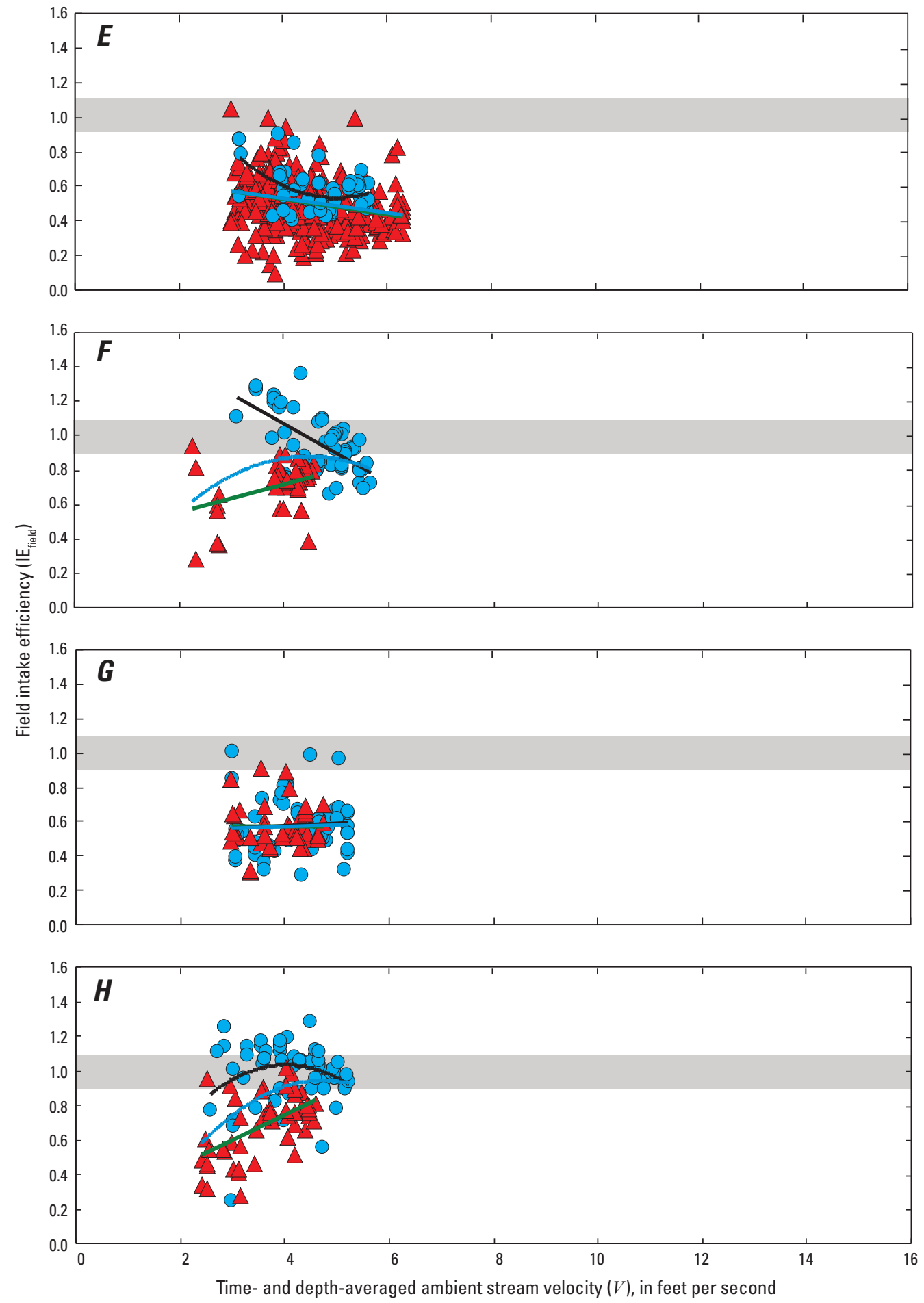

Figure 8.-Continued

\section{EXPLANATION}

IE $(D-77,1 / 4 "$ nozzle $)=$ $0.0677 V^{2}-0.68 V+2.24$ $R^{2}=0.25 n=62$

IE(D-77, 5/16" nozzle) $=-0.0437 \bar{V}+0.699$ $\mathrm{R}^{2}=0.061 \mathrm{n}=353$

IE(D-77, 1/4" \& 5/16" nozzle) $=-0.0411 \mathrm{~V}+0.698$

$R^{2}=0.054 n=415$

- US D-77 bag-type $1 / 4$ " Nozzle $\mathrm{n}=62$

A US D-77 bag-type 5/16" Nozzle $\mathrm{n}=353$

IE $\left(\mathrm{D}-96,1 / 4^{\prime \prime}\right.$ nozzle $)=-0.172 \bar{V}+1.76$ $R^{2}=0.42 n=62$

IE(D-96, 5/16" nozzle) $=0.0793 \bar{V}+0.400$ $\mathrm{R}^{2}=0.13 \mathrm{n}=40$

IE(D-96, 1/4" \& 5/16" nozzle) $=-0.0527 V^{2}+0.471 V-0.172$ $R^{2}=0.070 n=102$

US D-96 type 1/4" Nozzle $\mathrm{n}=62$

US D-96 type 5/16" Nozzle $\mathrm{n}=40$

IE(D-77, 1/4" nozzle) $=0.0117 \bar{V}+0.5279$ $\mathrm{R}^{2}=0.0027 \mathrm{n}=69$

IE(D-77, 5/16" nozzle) $=0.0004 \mathrm{~V}+0.5696$ $R^{2}=4 E-06 n=44$

IE(D-77, 1/4" \& 5/16" nozzle) $=0.0091 \bar{V}+0.5377$ $R^{2}=0.0018 n=113$

- US D-77 bag-type 1/4" Nozzle $\mathrm{n}=69$

$\Delta$ US D-77 bag-type 5/16" Nozzle $\mathrm{n}=44$

IE(D-96, 1/4" nozzle) $=-0.0798 \mathrm{~V}^{2}+0.6435 \mathrm{~V}-0.2636$ $\mathrm{R}^{2}=0.0631 \mathrm{n}=73$

IE(D-96, 5/16" nozzle) $=0.146 \bar{V}+0.1611$ $\mathrm{R}^{2}=0.3136 \mathrm{n}=52$

IE(D-96, 1/4" \& 5/16" nozzle) $=-0.0674 V^{2}+0.6377 V-0.5655$ $R^{2}=0.2035 n=125$

- US D-96 type 1/4" Nozzle $\mathrm{n}=73$

US D-96 type 5/16" Nozzle $\mathrm{n}=52$ 


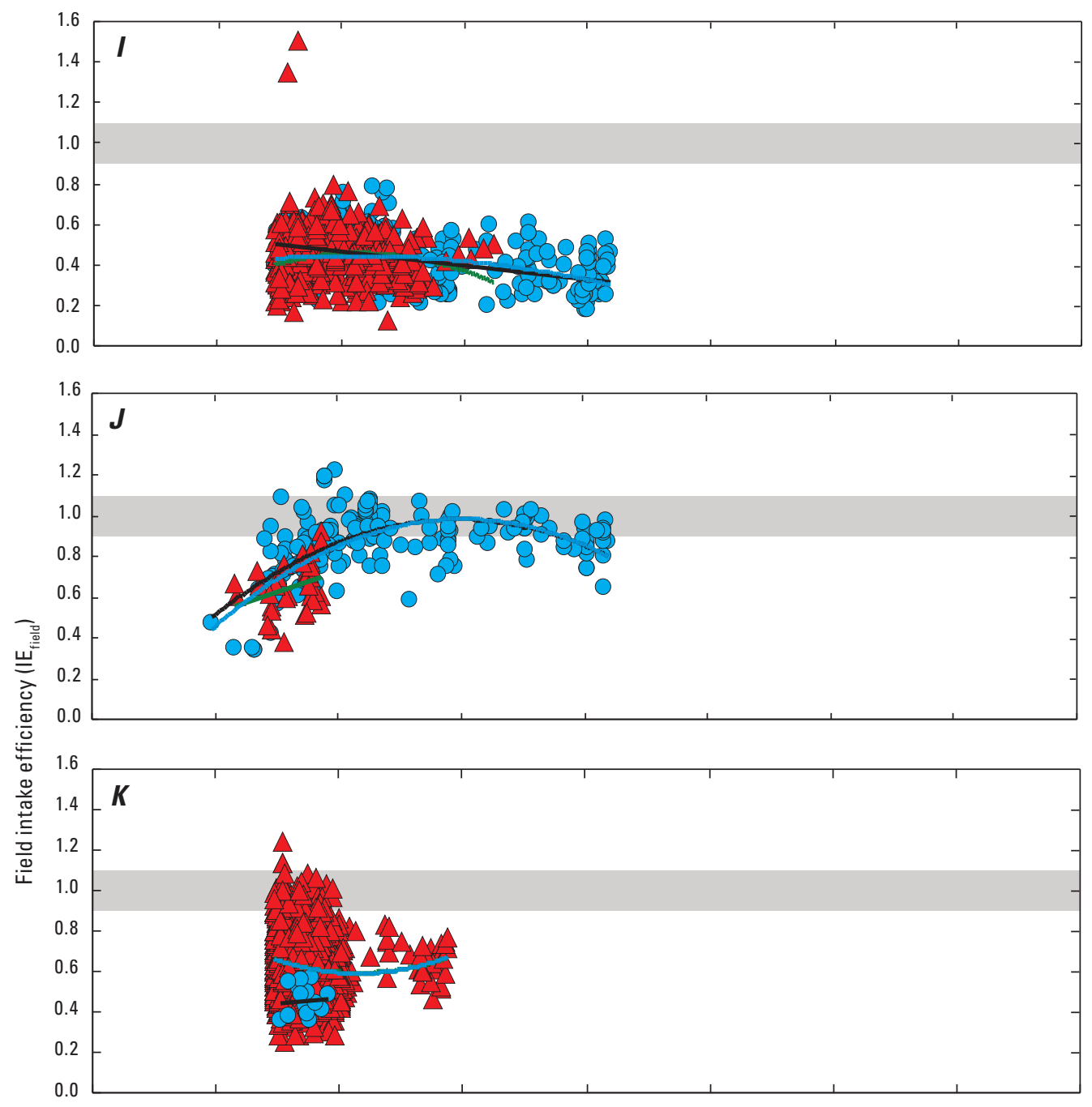

\section{EXPLANATION}

IE(D-77, 1/4" nozzle $)=-0.0333 \bar{V}+0.597$ $\mathrm{R}^{2}=0.19 \mathrm{n}=255$

IE(D-77, 5/16" nozzle)

$=-0.0301 \bar{V}^{2}+0.259 \bar{V}-0.100$ $R^{2}=0.023 n=547$

IE(D-77, 1/4" \& 5/16" nozzle) $=-0.0081 \bar{V}^{2}+0.0682 \bar{V}+0.300$ $R^{2}=0.06 n=802$

US D-77 bag-type $1 / 4 "$ Nozzle $\mathrm{n}=255$

A US D-77 bag-type 5/16" Nozzle $\mathrm{n}=547$

IE $(D-96,1 / 4 "$ nozzle $)=$ $-0.0303 \bar{V}^{2}+0.361 \bar{V}-0.0897$ $\mathrm{R}^{2}=0.34 \mathrm{n}=202$

IE(D-96, 5/16" nozzle) $=0.102 \bar{V}+0.322$ $\mathrm{R}^{2}=0.11 \mathrm{n}=35$

— IE(D-96, 1/4" \& 5/16" nozzle) $=-0.0327 \bar{V}^{2}+0.393 \bar{V}-0.199$ $R^{2}=0.40 n=237$

- US D-96 type $1 / 4$ " Nozzle $\mathrm{n}=202$

- US D-96 type 5/16" Nozzle $\mathrm{n}=35$

- IE(D-77, 1/4" nozzle) $=0.0226 \mathrm{~V}+0.378$ $R^{2}=0.005 n=15$

— IE(D-77, 5/16" nozzle) $=0.0366 \bar{V}^{2}-0.315 \bar{V}+1.27$ $R^{2}=0.015 n=1969$

_ IE(D-77, 1/4"\& \&/16" nozzle) $=0.0376 \bar{V}^{2}-0.323 \bar{V}+1.29$ $R^{2}=0.016 n=1984$

- US D-77 bag-type $1 / 4$ " Nozzle $\mathrm{n}=15$

$\Delta$ US D-77 bag-type 5/16" Nozzle $\mathrm{n}=1969$

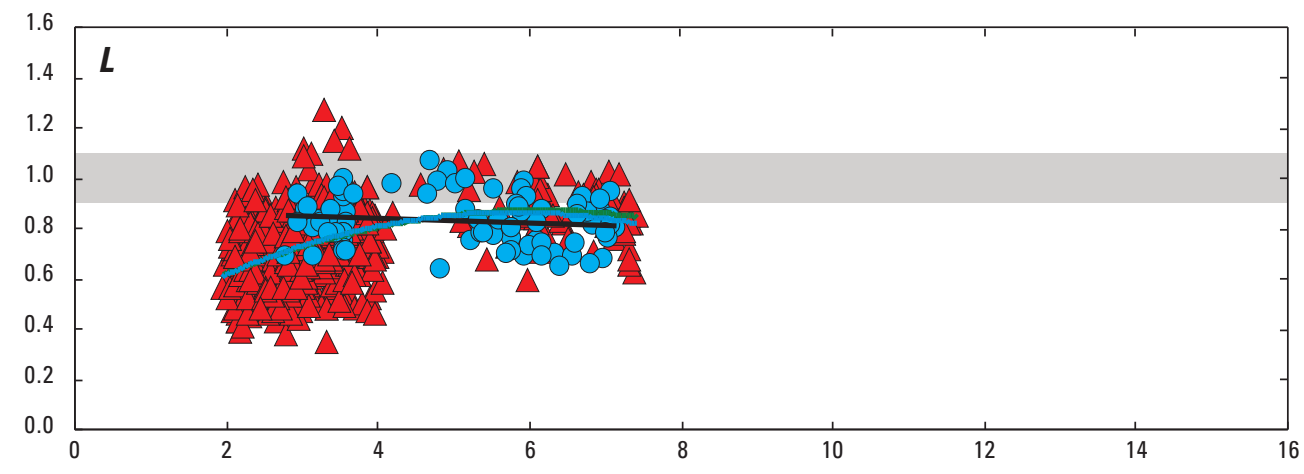

IE(D-96, 1/4" nozzle) $=-0.0091 \bar{V}+0.878$ $R^{2}=0.018 n=88$

— IE(D-96, 5/16" nozzle) $=-0.015 \bar{V}^{2}+0.183 \bar{V}+0.312$ $\mathrm{R}^{2}=0.195 \mathrm{n}=1069$

IE(D-96, 1/4" \& 5/16" nozzle) $=-0.0171 \bar{V}^{2}+0.198 \bar{V}+0.289$ $R^{2}=0.206 n=1157$

- US D-96 type $1 / 4$ " Nozzle $\mathrm{n}=88$

U US D-96 type 5/16" Nozzle $\mathrm{n}=1069$

Figure 8.-Continued 


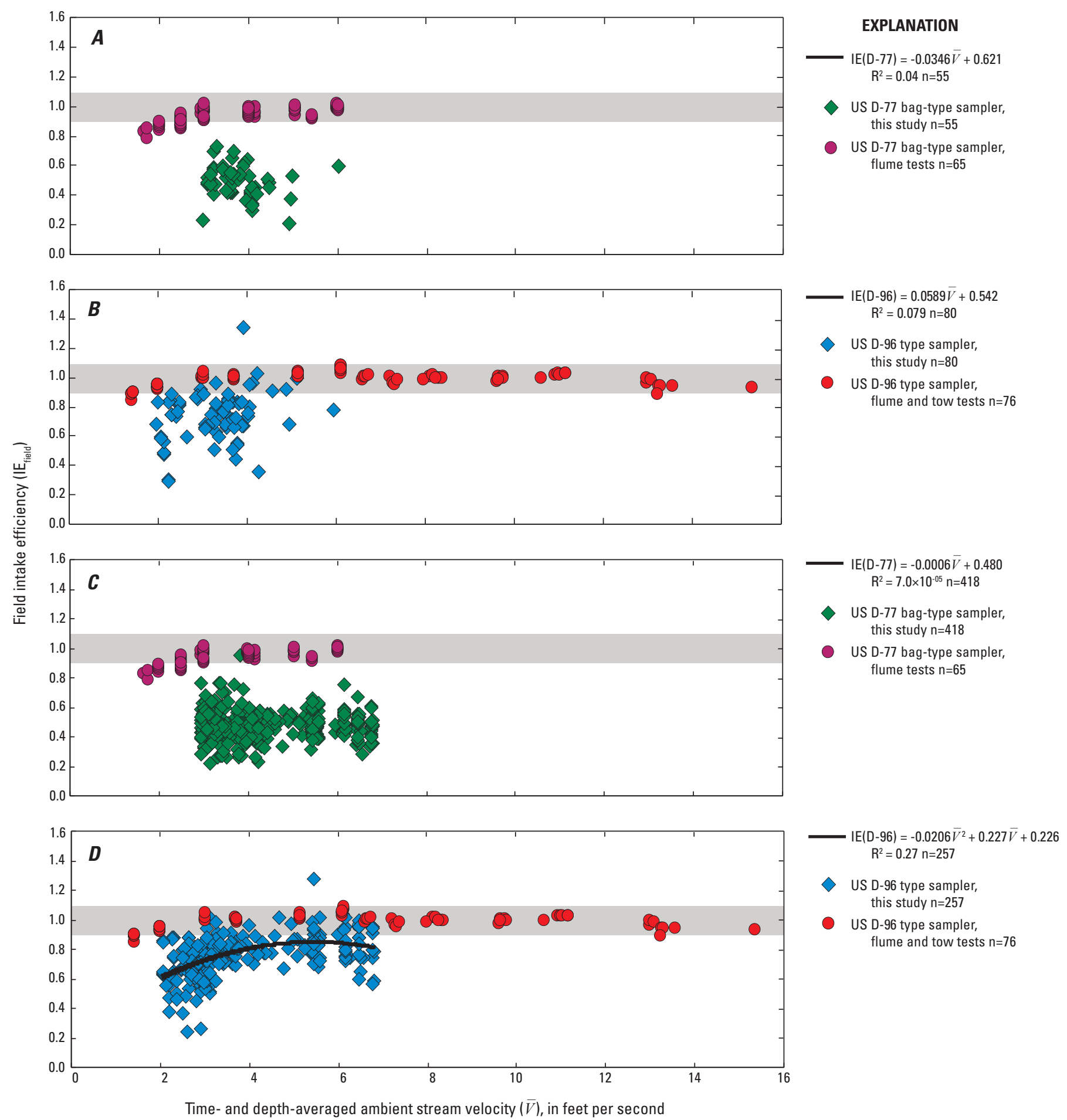

Figure 9. Plots showing comparisons between laboratory-determined intake efficiencies of either the US D-77 bag-type sampler in flume tests (fig. 5A) or the US D-96-type sampler in flume and tow tests (fig. $5 B$ ) with the field intake efficiencies of these two types of samplers (fig. 8) at all individual sampling verticals along the cross-sections at $(A, B) 30$-mile tagline $A,(C, D) 30$-mile tagline $B,(E, F)$ 61-mile tagline $A,(G, H)$ 61-mile tagline $B,(I, J) 61$-mile tagline $C,(K, L)$ and the 87-mile cableway. Best-fit linear or second-orderpolynomial regressions between the time- and depth-averaged ambient stream velocity and intake efficiency are shown for field data collected with both $1 / 4$-inch and 5/16-inch nozzles. 


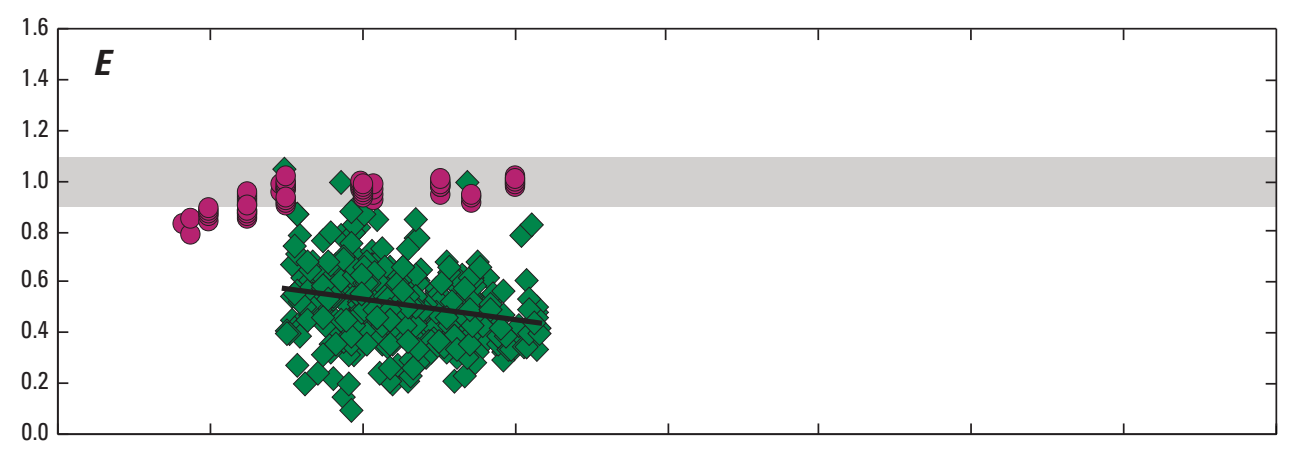

\section{EXPLANATION}

IE $(D-77)=-0.0411 \bar{V}+0.698$ $\mathrm{R}^{2}=0.054 \mathrm{n}=415$

US D-77 bag-type sampler, this study $n=415$

US D-77 bag-type sampler, flume tests $n=65$
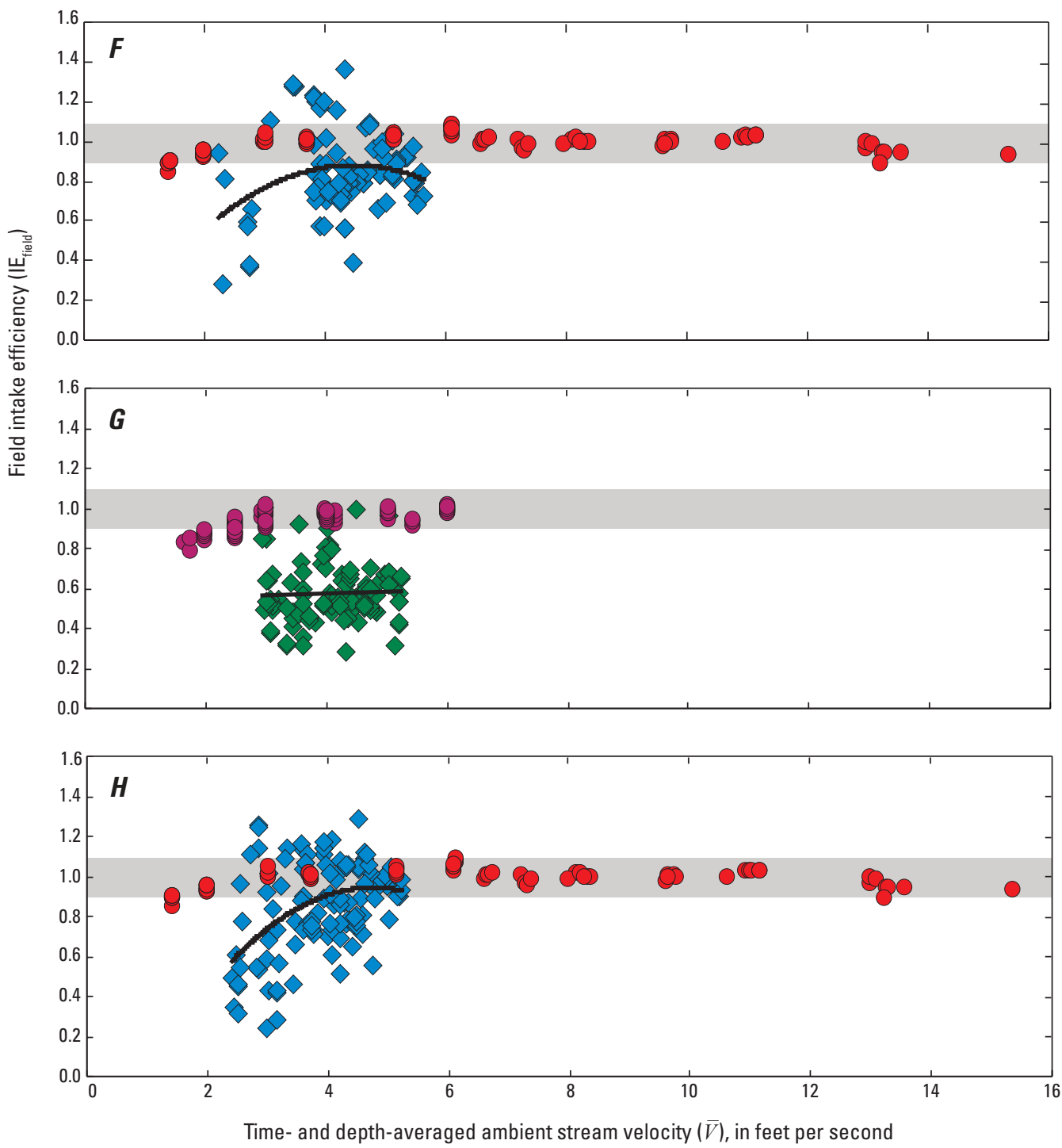

$\mathrm{IE}(\mathrm{D}-96)=-0.0674 \bar{V}^{2}+0.638 \bar{V}-0.566$ $R^{2}=0.20 n=125$

US D-96 type sampler, this study $n=125$

- US D-96 type sampler, flume and tow tests $n=76$

Figure 9.-Continued 


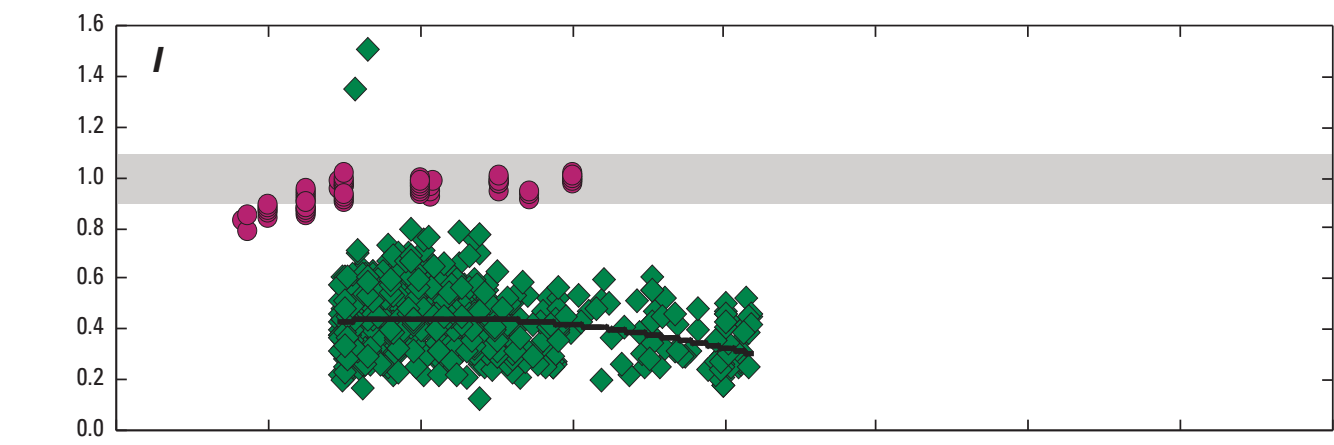

\section{EXPLANATION}

IE $(\mathrm{D}-77)=-0.0081 \bar{V}^{2}+0.0682 \bar{V}+0.300$ $\mathrm{R}^{2}=0.06 \mathrm{n}=802$

US D-77 bag-type sampler, this study $n=802$

US D-77 bag-type sampler, flume tests $n=65$
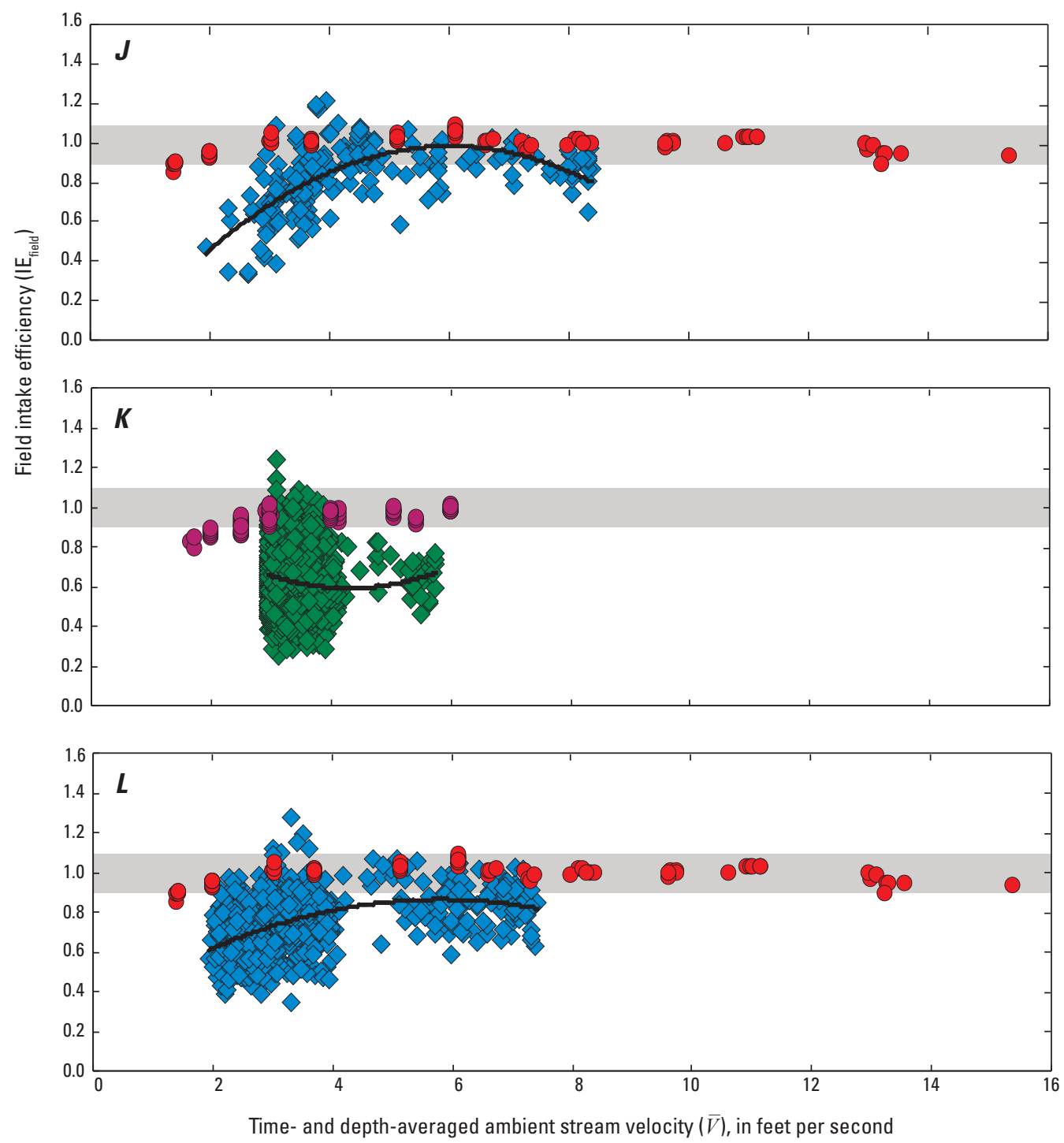

$\mathrm{IE}(\mathrm{D}-96)=-0.0171 \bar{V}^{2}+0.198 \bar{V}+0.289$ $\mathrm{R}^{2}=0.21 \mathrm{n}=1157$

US D-96 type sampler, this study $n=1157$

US D-96 type sampler, flume and tow tests $n=76$

Figure 9.-Continued 
FISP (1941a) and Davis (2001) concluded that the diameter of the nozzle entrance had comparatively little effect upon the accuracy of the samples collected, at least when nozzles larger than about 3/16-inch diameter were used. To test whether this result also applied to our dataset, analyses were conducted to test whether the field intake efficiencies associated with samples collected with different diameter nozzles could be shown to come from the same population. These analyses (Griffiths, 1967, p. 453-455) tested whether a single linear regression fit to a composite of all data collected with both 1/4- and 5/16-inch diameter nozzles or linear regressions individually fit to data collected with either 1/4- or 5/16-inch diameter nozzles best described the relations between ambient stream velocity, $\bar{V}$, and nozzle velocity, $\bar{V}_{\text {n }}$ (fig. 10). Analysis of the data in this manner, using nozzle velocity instead of intake efficiency as the dependent variable, allows better detection of any influence of nozzle entrance diameter on intake efficiency because this type of analysis removes the intercorrelation between ambient stream velocity and intake efficiency ${ }^{6}$. Intercorrelation between independent and dependent variables affects the structure of the variance in the dependent variable, potentially affecting the ability to detect differences between dependent variables derived from different populations. These analyses were conducted separately among data collected using the US D-77 bagtype sampler, among data collected using the US D-96-type sampler, and among data from both the US D-77 bag-type and US D-96-type datasets at each of the six cross sections among the three study sites. As found by FISP (1941a) and Davis (2001), samples collected with different diameter nozzles were determined to be from identical populations when using the US D-77 bag-type sampler at 30-mile tagline $\mathrm{B}$ and 61-mile tagline $\mathrm{B}$, and when using the US D-96-type sampler at 30-mile tagline A. In contrast, in all other cases, analysis of our field data indicates a slight but significant discrepancy among the relations between $\bar{V}$ and $\bar{V}_{\mathrm{n}}$, when samples are collected with 1/4-inch and 5/16-inch diameter nozzles. However, because this significant discrepancy in intake efficiency is extremely small, data collected with different diameter nozzles are combined at each cross section in all subsequent analyses. When significant at the 0.05 critical level, either best-fit linear or second-orderpolynomial regressions are therefore used to characterize these data in subsequent analyses, depending on whether a second-order-polynomial regression provides a better fit than a linear regression.

\footnotetext{
${ }^{6}$ Because ambient stream velocity is in the denominator of the definition of intake efficiency (equation 1), the independent and dependent variables are intercorrelated when intake efficiency is plotted as a function of ambient stream velocity.
}

\section{Evaluation of Effects of Lags Between Flow Direction and Nozzle Orientation on Intake Efficiency in a Transiting Depth-Integrating Sampler}

Isokinetic operation of the US series of depth-integrating samplers requires that the intake nozzle must point into the approaching stream flow. In rivers, where FISP samplers are intended for use, turbulence can cause considerable fluctuations in flow direction as a sampler transits a sampling vertical. FISP (1952) used trigonometric re-analysis of flume-test data from FISP (1941a) to evaluate the effects of differences between nozzle and velocity-vector orientation on intake efficiency and the associated errors in suspendedsediment concentration. Results show that, at likely nozzle orientations in a river, the angle at which flow approaches the nozzle entrance has minimal effects on error in concentration, with approximately only \pm 2 percent error occurring as the nozzle orientation approaches 20 to 30 degrees from the upstream direction (FISP, 1952). Subsequent experiments using 1/4-inch diameter nozzles independent of samplers in the flume at the St. Anthony Falls Hydraulic Laboratory confirmed this result (Winterstein and Stefan, 1983).

To address the potential effect of turbulent conditions creating lags between flow direction and sampler nozzle orientation, and the potential resultant effects on field intake efficiencies, we investigated whether the rate of nozzle reorientation to observed changes in flow direction experienced by a transiting depth-integrating sampler at a vertical was sufficient to keep the nozzle oriented within 30 degrees of the upstream flow direction (FISP, 1941a; Winterstein and Stefan, 1983). This analysis was conducted using the previously described measurements of nozzle-reorientation rates for the D-96-A1 sampler in combination with numerical simulations of a depthintegrating sampler transiting through turbulent flow. For this analysis, depth-binned ADCP data collected in the Colorado River at the 30-mile and 61-mile study sites were first analyzed to evaluate the relative change in horizontal velocity azimuth between successive depth bins (average depth-bin size $1.2 \mathrm{ft}$ ) likely experienced by a depth-integrating sampler transiting a vertical. In the numerical simulations, the transit rate of the depth-integrating sampler is adjusted as a function of ambient stream velocity such that the transit rate of the sampler never exceeds the FISP-specified maximum transit rate of 40 percent of the ambient stream velocity. 

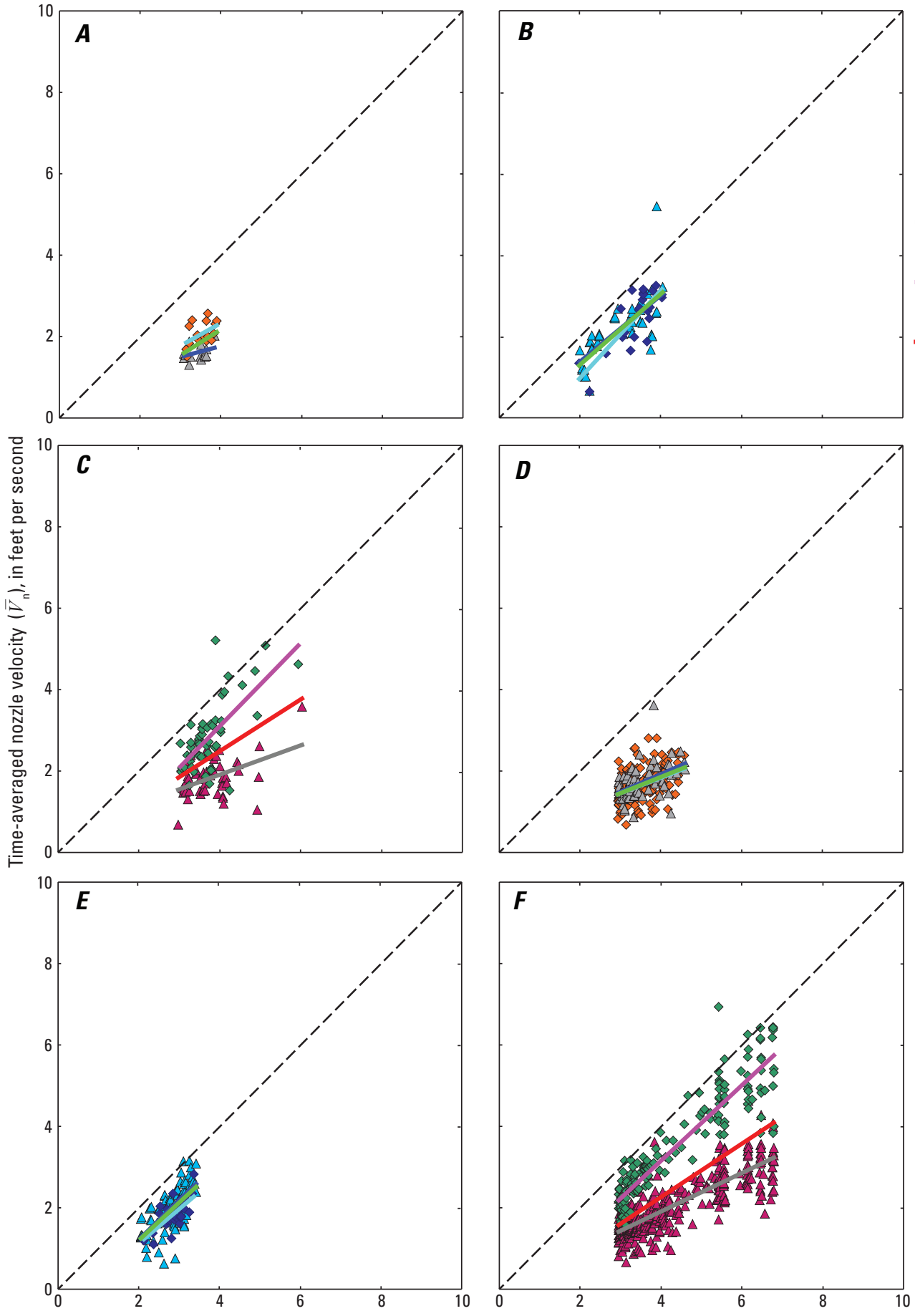

Time- and depth-averaged ambient stream velocity $(\bar{V})$, in feet per second

Figure 10. Plots showing relations between ambient stream velocity, $\bar{V}$, and nozzle velocity, $\bar{V}_{n}$, associated with depth-integrated samples collected using 1/4- and 5/16-inch nozzles on US D-77 bag-type and US D-96-type samplers at individual verticals along the cross-sections at $(A-C) 30$-mile tagline $A,(D-F)$ 30-mile tagline $B,(G-l) 61$-mile tagline $A,(J-L) 61$-mile tagline $B,(M-0) 61$-mile tagline $C$, and $(P-R)$ the 87-mile cableway. 

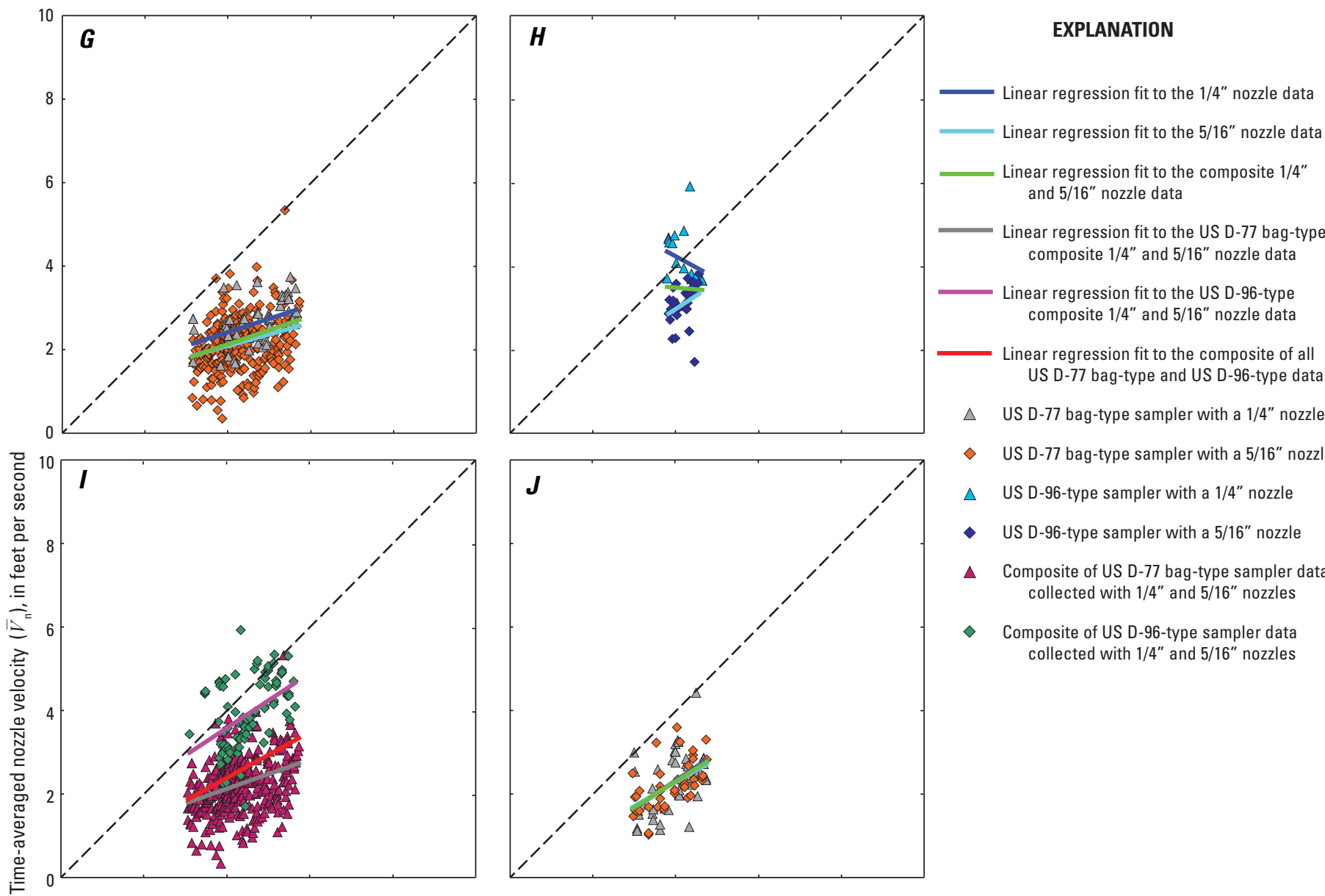

Linear regression fit to the US D-77 bag-type
composite $1 / 4^{\prime \prime}$ and $5 / 16^{\prime \prime}$ nozzle data
Linear regression fit to the US D-96-type
composite $1 / 4^{\prime \prime}$ and $5 / 16^{\prime \prime}$ nozzle data
Linear regression fit to the composite of all
US D-77 bag-type and US D-96-type data
$\Delta \quad$ US D-77 bag-type sampler with a $1 / 44^{\prime \prime}$ nozzle
$-\quad$ US D-77 bag-type sampler with a $5 / 16^{\prime \prime}$ nozzle
$\Delta \quad$ US D-96-type sampler with a $1 / 4 "$ nozzle
- US D-96-type sampler with a $5 / 16 "$ nozzle

- Composite of US D-77 bag-type sampler data
collected with $1 / 4^{\prime \prime}$ and $5 / 16^{\prime \prime}$ nozzles

- Composite of US D-96-type sampler data collected with $1 / 4 "$ and $5 / 16 "$ nozzles
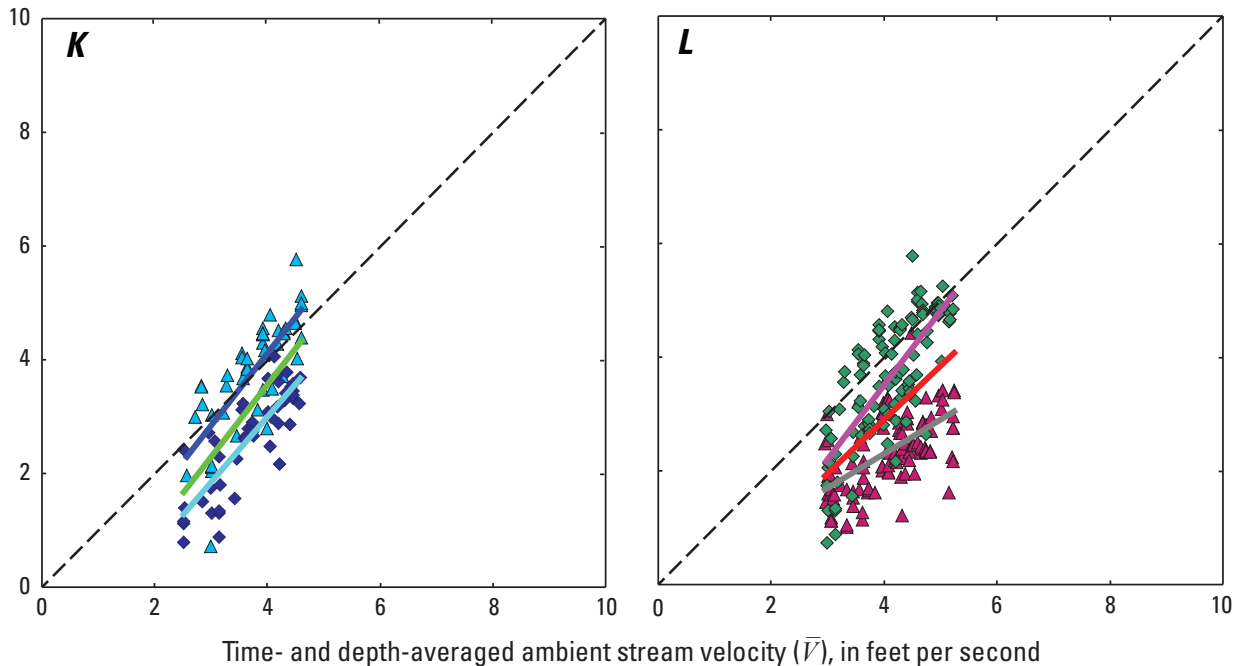

Figure 10.-Continued 

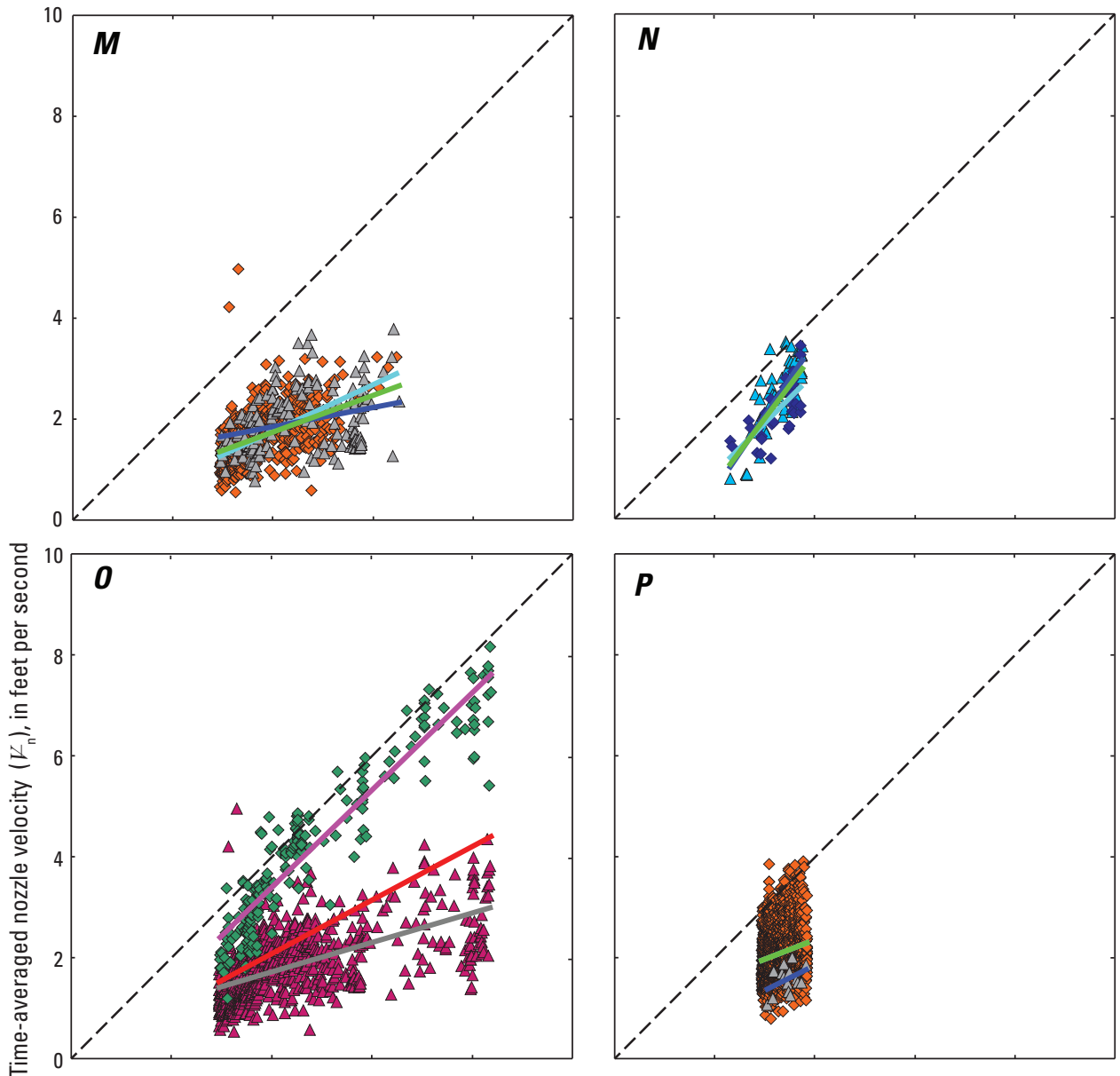

EXPLANATION

Linear regression fit to the $1 / 4$ " nozzle data

Linear regression fit to the $5 / 16$ " nozzle data

Linear regression fit to the composite 1/4" and $5 / 16 "$ nozzle data

Linear regression fit to the US D-77 bag-type composite $1 / 4 "$ and $5 / 16 "$ nozzle data

Linear regression fit to the US D-96-type composite $1 / 4 "$ and $5 / 16$ " nozzle data

Linear regression fit to the composite of all US D-77 bag-type and US D-96-type data

$\Delta \quad$ US D-77 bag-type sampler with a $1 / 4$ " nozzle

- US D-77 bag-type sampler with a 5/16" nozzle

$\Delta \quad$ US D-96-type sampler with a 1/4" nozzle

- US D-96-type sampler with a 5/16" nozzle

- Composite of US D-77 bag-type sampler data collected with $1 / 4$ " and $5 / 16$ " nozzles

- Composite of US D-96-type sampler data collected with $1 / 4$ " and $5 / 16$ " nozzles
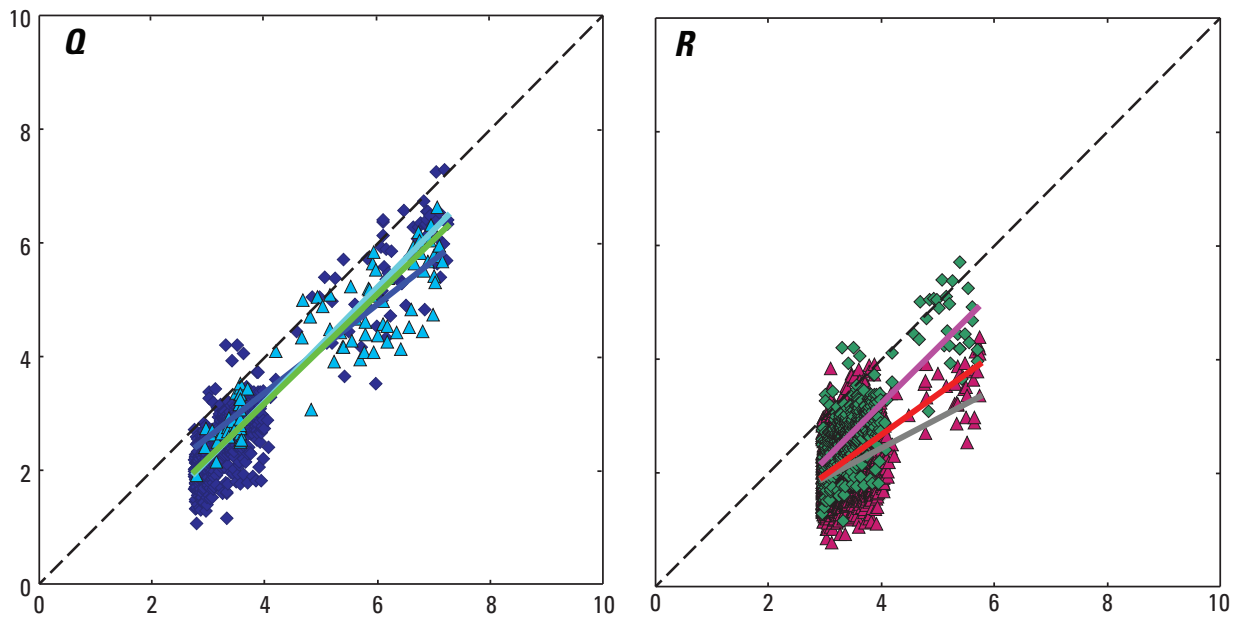

Time- and depth-averaged ambient stream velocity $(\bar{V})$, in feet per second

Figure 10.-Continued 
At typical ambient stream velocities, results indicate that over the average 0.8 -second interval a depth-integrating sampler typically transits a $1.2-\mathrm{ft}$ depth bin; the average difference in horizontal flow direction between successive depth bins typically ranges from 4 to 12 degrees (fig. 11). Measurements of nozzle-reorientation rates indicate that, at an ambient stream velocity of $\sim 3 \mathrm{ft} / \mathrm{s}$, the US D-96-A1 takes an average of 1.2 seconds to achieve nozzle reorientation into the upstream direction when the change in direction is 10 degrees. Combining these results with the effect of oblique flow angle on apparent nozzle entrance area calculated by FISP (1941a) and Winterstein and Stefan (1983), it was determined that average changes in flow direction of 11.4 and 7.8 degrees will only cause minimal reductions in apparent nozzle area, 2 and 1 percent, respectively, during the course of collecting a sample at a vertical (fig. 12). Therefore, even though a lag frequently exists between flow direction and nozzle orientation, the effect of this lag on the field intake efficiencies plotted in figures 8 and 9 is inconsequential.

\section{Effect of Transit Rate on Intake Efficiency}

Because of the potentially large ranges in depth and velocity in a river cross-section, it is sometimes impossible to make an EWI measurement that does not include a vertical in lower-velocity zones that violates the maximum transit-rate limitation of 40 percent of the depth-averaged ambient stream velocity. This problem may arise in an EWI measurement because (1) the transit rate must be held constant among all verticals, (2) the minimum transit rate is limited by the slowest transit rate in the deepest, highest-velocity vertical that will not overfill the sampler, and (3) this minimum transit rate may exceed the maximum FISP-allowed transit rate of 40 percent of the depth-averaged velocity at shallow, low-velocity verticals. Reducing the diameter of the nozzle (3/16-inch minimum diameter) used in the EWI measurement may reduce the occurrence of this problem but will not prevent it from occurring in all cases. Although the influence of this transit-rate problem on the velocity-weighted

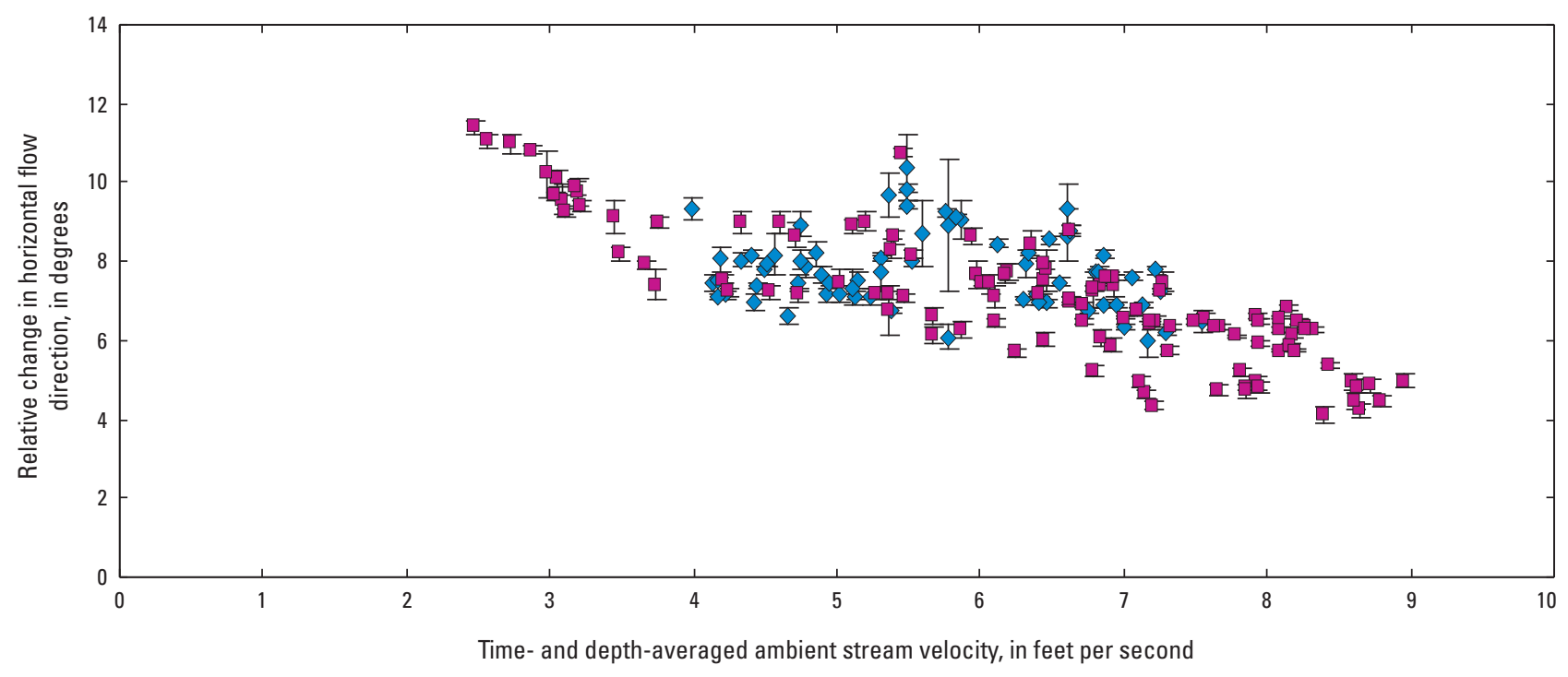

EXPLANATION

Numerical simulation for
30 -mile tagline b
61 -mile tagline $c$

Figure 11. Plots showing relative change in horizontal flow direction between different 1.2-foot depth bins along simulated upward and downward transits of depth-integrating suspended-sediment samplers plotted as a function of depth-and time-averaged ambient stream velocity. Numerical sampler-transit simulations were conducted within the range of Federal Interagency Sedimentation Project accepted transit rates at the 30-mile tagline B and 61-mile tagline C cross-sections. Error bars are one standard error. 


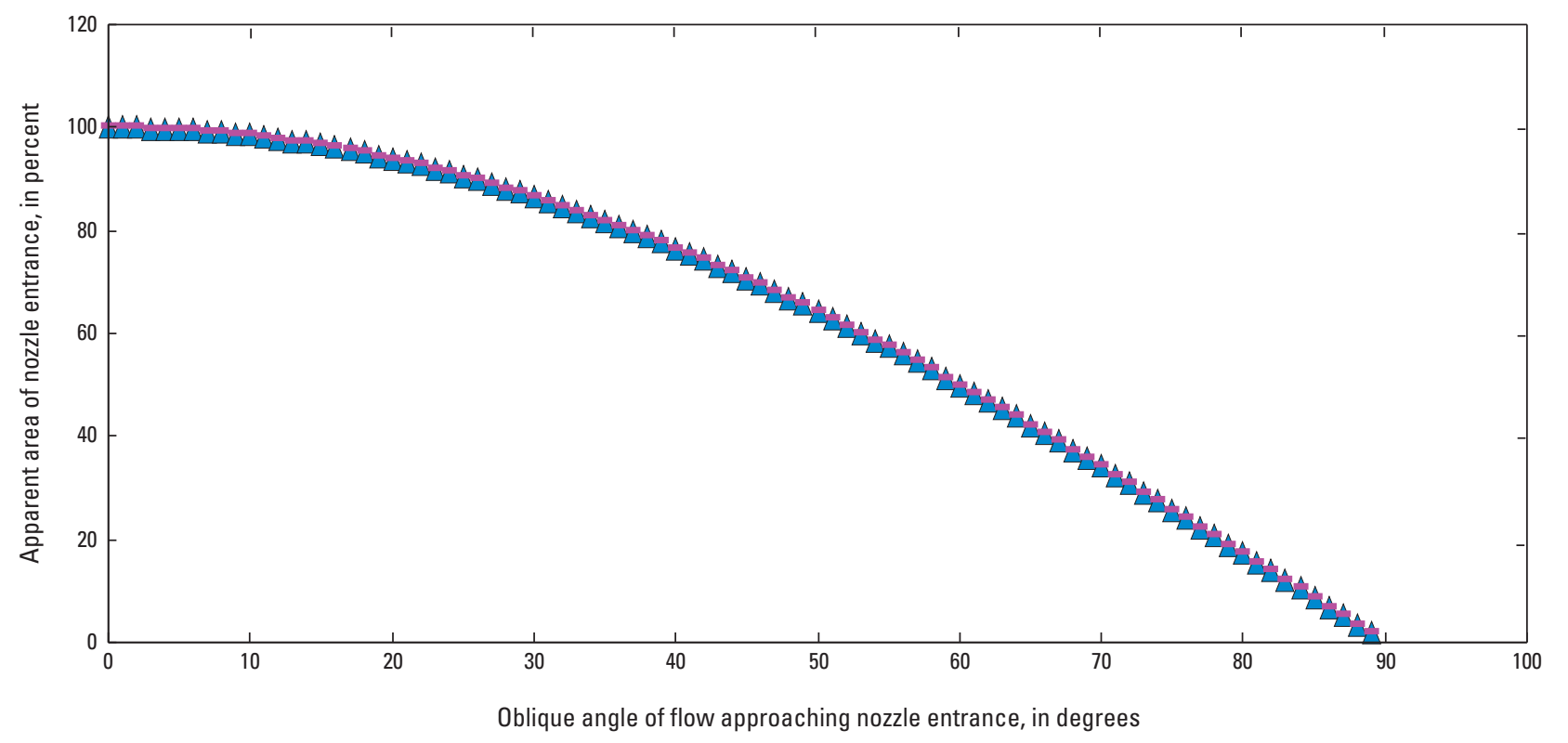

EXPLANATION

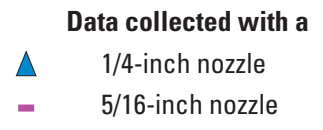

Figure 12. Plots showing relation between the oblique angle of flow approaching the nozzle entrance and the apparent area of the nozzle entrance for the US D-96-A1 depth-integrating suspended-sediment sampler. When the nozzle is pointed directly into the flow, the apparent area of the nozzle entrance is equal to the area of the nozzle entrance; when the nozzle is oriented perpendicular to the flow direction, the apparent area of the nozzle entrance is 0 percent of the area of the nozzle entrance.

suspended-sediment concentration in a full EWI measurement may be small because shallow, low-velocity verticals contribute relatively little to the velocity-weighted suspendedsediment concentration in a river cross-section, it is important to understand the effects of higher-than-maximum-allowed transit rates on field intake efficiencies because it is sometimes unavoidable to make EWI measurements without some verticals in violation of transit-rate limitations. Furthermore, because all previous investigations of the effects of higherthan-maximum-allowed transit rates were conducted using rigid-container depth-integrating samplers (FISP, 1952, 1954; Edwards and Glysson, 1999), it was deemed important to evaluate the effect of higher-than-maximum-allowed transit rates on the field intake efficiency of collapsible-bag depth-integrating samplers.

This analysis of the effect of transit rate on intake efficiency was conducted using the US D-96-A1 sampler at the 30-mile and 61-mile study sites. The previous plots of field intake efficiency (figs. 8, 9) only included data from sampling verticals in EWI measurements that were collected at transit rates less than the maximum FISP-allowed transit rate of $0.4 \bar{V}$. However, during the course of the EWI measurements from which these $\mathrm{IE}_{\text {field }}$-data were obtained, some data, not included in figures 8 and 9 , were collected in low-velocity verticals near the banks at transit rates exceeding $0.4 \bar{V}$. To evaluate the effect of transit rate on $\mathrm{IE}_{\text {field }}$ of the US D-96-type sampler, the $\mathrm{IE}_{\text {field }}$ data from all sampling verticals along the 30-mile tagline $\mathrm{B}$ and 61-mile tagline $\mathrm{C}$ cross-sections were binned relative to $\bar{V}$ and plotted in figure 13. At the 30-mile tagline $\mathrm{B}$ cross-section, measurements of $\mathrm{IE}_{\text {field }}$ were obtained for the US D-96-A1 sampler at 328 verticals, covering a transit-rate range of 0.14 to $0.66 \bar{V}$. At the 61 -mile tagline $\mathrm{C}$ cross-section, measurements of $\mathrm{IE}_{\text {field }}$ were obtained for the US D-96-A1 sampler at 274 verticals, covering a transit-rate range of 0.12 to $0.71 \bar{V}$. Because of the channel geometry and spatial distribution of velocity at these cross-sections, data at 71 of the 328 verticals along the 30 -mile tagline B cross-section and only 37 of the 274 verticals along the 61-mile tagline $\mathrm{C}$ cross-section were collected at transit rates exceeding $0.4 \bar{V}$. 


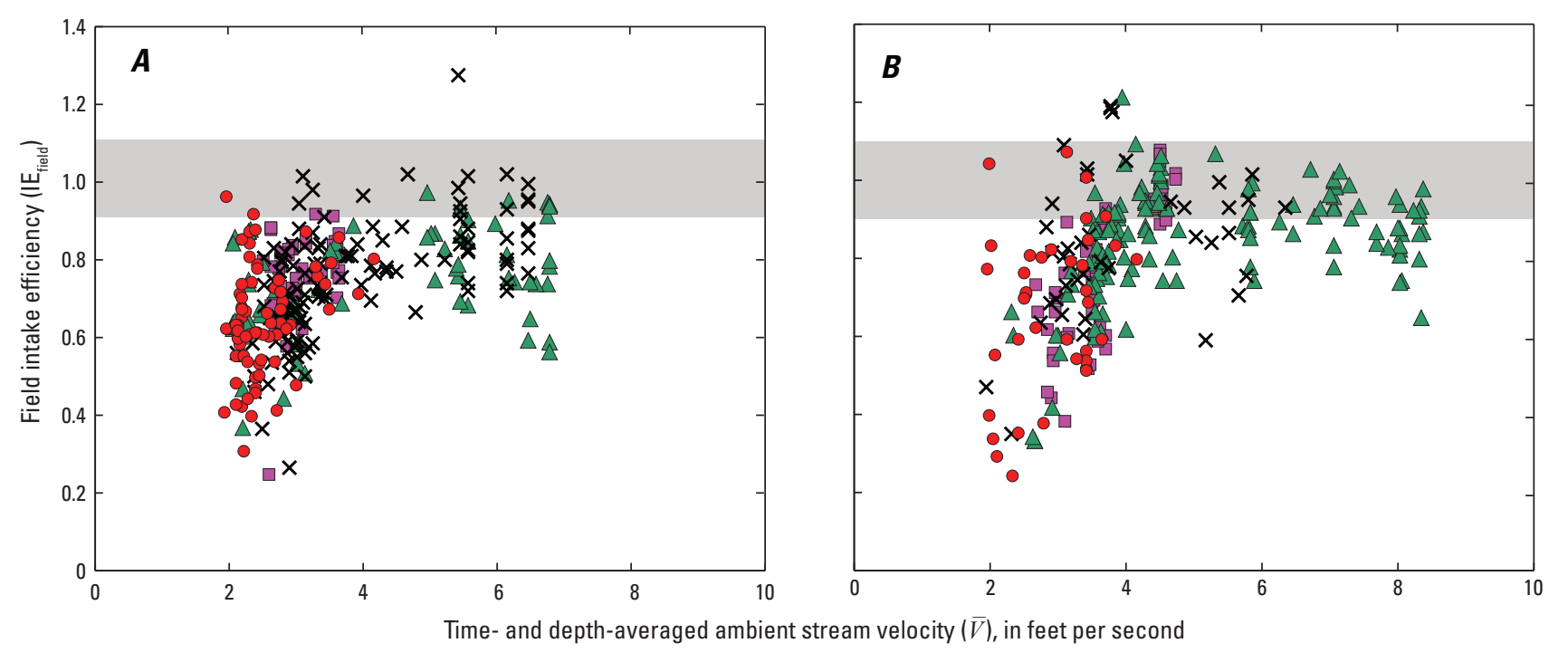

EXPLANATION

$\begin{array}{ll} & \text { Transit rate } \\ \square & <0.2 \bar{V} \\ \Delta \quad>0.2 \bar{V} & \text { to }<0.3 \bar{V} \\ \times \quad>0.3 \bar{V} \quad \text { to }<0.4 \bar{V} \\ ->0.4 \bar{V} \quad \text { to } 0.7 \bar{V}\end{array}$

Figure 13. Plots showing effect of transit rate on the field intake efficiency of the US D-96-A1 sampler at sampling verticals along the cross-sections at $(A)$ 30-mile tagline $B$ and $(B)$ 61-mile tagline $C$. Shaded area represents range in intake efficiency $(1.0 \pm 0.10)$ considered to be isokinetic.

Results from this analysis (fig. 13) indicate that transit rate does not greatly affect the field intake efficiency of the US D-96-A1 sampler, at least over the range in relative transit rate of 0.1 to $0.7 \bar{V}$ investigated. The clouds of data (red bullets in fig. 13) collected at transit rates in excess of $0.4 \bar{V}$ fall well within the regions defined by the data collected at FISP-allowed transit rates $(\leq 0.2 \bar{V}),(>0.2$ to $\leq 0.3 \bar{V})$, and $(>0.3$ to $\leq 0.4 \bar{V})$. In fact, some of the data collected at transit rates exceeding $0.4 \bar{V}$ in very low ambient stream velocities of $\sim 2 \mathrm{ft} / \mathrm{s}$ have higher and better field intake efficiencies (closer to 1.0) than those collected at lower transit rates. This observation suggests that the US D-96-type sampler may be more isokinetic when sampling durations are shorter (further physical support for this suggested outcome is provided below). As expected, because pressure-driven inrush does not affect the intake efficiency of collapsible-bag depth-integrating samplers (Szalona, 1982; Davis, 2001), we did not observe the superefficient intake efficiencies (much greater than 1.0) measured by FISP (1954) for the rigid-container US D-43 depth-integrating sampler at higher transit rates. Our analysis suggests that despite potential errors in sediment concentration arising from large entrance angles between the streamlines and the nozzle (FISP, 1952; Edwards and Glysson, 1999), transit rate does not greatly affect the behavior of the field intake efficiency of the US D-96-type sampler. In any case, the overall error in the velocity-weighted suspended-sediment concentration in a full EWI measurement arising from exceeding the maximum FISP-allowed transit rate of $0.4 \bar{V}$ at a few low-velocity verticals is deemed to be small because shallow, low-velocity verticals contribute relatively little to the velocity-weighted suspended-sediment concentration in a river cross-section, especially for sand-sized sediment. 


\section{Review of Fluid Mechanics Pertinent for Flow Through a Sampler Nozzle, with an Emphasis on Water Temperature}

Previous authors have concluded that intake efficiency is temperature dependent through temperature-driven changes in viscosity (FISP, 1952; Beverage and Futrell, 1986). Laboratory-based testing of the US D-43 and US D-96 samplers detected similar effects of water temperature on intake efficiency, with decreases in water temperature resulting in measurable decreases in intake efficiency (FISP, 1952; Davis, 2001). On the basis of the similarity between these US D-43 and US D-96 tests, Davis (2001) concluded that the decrease in the intake efficiency of the US D-96 sampler at lower water temperatures resulted from changes in viscosity affecting the flow through the nozzle, rather than through changes in the stiffness of the bag (as suggested by Szalona, 1982). As shown in figures 40 and 41 in FISP (1952), the temperature effect on intake efficiency is not inconsequential. For example, a 20-degree Celsius decrease in temperature will lead to a $\sim 12$ to 17 percent decrease ${ }^{7}$ in intake efficiency at an ambient stream velocity of $\sim 3.5 \mathrm{ft} / \mathrm{s}$ (fig. 14).

To further illustrate the effect of water temperature on the velocity of water in a sampler nozzle, the data in figure 40 in FISP (1952) were replotted to remove the intercorrelation of the dependent and independent variables through ambient stream velocity ${ }^{8}$ (fig. 15). Figure 15 shows the resultant relations between ambient stream velocity and nozzle velocity for both (1) all data collected with 1/8-, 3/16-, and 1/4-inchentrance-diameter nozzles in cold $\left(0^{\circ} \mathrm{C}\right)$ and warm $\left(19.4^{\circ} \mathrm{C}\right)$ water, and (2) data collected using all three nozzle diameters segregated into two groups on the basis of water temperature. Analysis of variance using a standard $F$-test results in $F_{1,28}=1,012$, indicating that the relation between stream and nozzle velocity for all data in all temperatures is significant at the 0.05 critical level. Furthermore, analysis of variance using the Griffiths (1967, p. 453-455) method indicates that the temperature-segregated relations between stream and nozzle velocity are significantly different at the 0.05 critical level (Griffiths $F_{1,26}=6.9, p=0.014$ ). Across the 1 to $7 \mathrm{ft} / \mathrm{s}$-range in ambient stream velocity in fig. 15 , the nozzle velocities in $19.4^{\circ} \mathrm{C}$ water are $\sim 0.3 \mathrm{ft} / \mathrm{s}$ higher than they are in $0^{\circ} \mathrm{C}$ water. This difference corresponds to a $\sim 15$ percent increase in nozzle velocity in warmer water at lower stream velocities but only a $\sim 5$ percent increase in nozzle velocity in warmer water at higher stream velocities. Thus, as observed by FISP (1952) and reiterated by Davis (2001), the effect of water temperature on intake efficiency "shows up markedly at lower velocities,

\footnotetext{
${ }^{7}$ As shown in FISP (1952, fig. 41), the decrease in intake efficiency gets slightly larger as nozzle diameter decreases from $1 / 4$ to $1 / 8 \mathrm{inch}$.

${ }^{8}$ Ambient stream velocity is the dependent variable and also appears in the denominator of the independent variable in figure 40 in FISP (1952).
}

but seems to decrease rapidly as velocities increase." Additional analysis of the data in figure 15 segregated by nozzle diameter using the Griffiths (1967, p. 453-455) method indicates that the effects of water temperature on the relations between stream and nozzle velocities are slightly but significantly different between the data collected with the three different nozzle diameters $\left(F_{2,24}=25.75, p<0.0001\right)$. Results from these analyses and from the physically based model described below therefore indicate that water temperature (1) affects the intake efficiency of sampler nozzles differently at different ambient stream velocities and (2) affects the intake efficiency of different-diameter sampler nozzles differently.

To fully understand how changes in water temperature affect the intake efficiency of suspended-sediment samplers, an understanding of the energy balance between the flow upstream from a sampler nozzle and the water and air in the container (rigid container or collapsible bag) inside the sampler is required, along with a basic knowledge of the fluid mechanics of flow evolution and resistance in pipe entrances. Solution of an appropriate physically based model can then be used to evaluate the effects of differences in water temperature on intake efficiency. Because the physical sampling characteristics of any given depth-integrating sampler depend on the interactions of sampler geometry (for example, the locations of air exhausts or vent holes), nozzle geometry (nozzle length, internal diameter, and internal taper), ambient stream velocity, and water temperature, it is exceedingly difficult to empirically deduce the effect of changing any one of these physical parameters on the intake efficiency without such a model. The following section describes the derivation, testing, and application of such a physically based model for a generalized depth-integrating suspended-sediment sampler.

At a given flow depth, the energy balance between the flow upstream from a nozzle and the flow inside a rigid-container (that is, bottle) sampler nozzle is:

$$
\begin{aligned}
& \mathrm{H}_{\mathrm{V} \text {-stream }}+\mathrm{H}_{\mathrm{P} \text {-difference }}-\mathrm{HL}_{\text {friction }}, \\
& -\mathrm{HL}_{\text {nozzle-geometry }}=\mathrm{H}_{\mathrm{V} \text {-nozzle }}
\end{aligned}
$$

after Rouse (1946). The first two terms in equation 4 are the terms responsible for "driving" water through the sampler nozzle, the second two terms are the terms responsible for "resisting" the flow of this water through the nozzle, and the final term is the velocity head of the water flowing through the nozzle into the sampler container. The energy balance for operation of a collapsible-bag sampler is slightly different; inclusion of an additional "resistance" term, $\mathrm{HL}_{\text {bag-dispacement }}$, accounting for the head loss arising from it becoming progressively more difficult for a filling bag to displace the water in a sampler cavity and purge this displaced water through the vent holes as the bag progressively occupies more of the sampler cavity. 

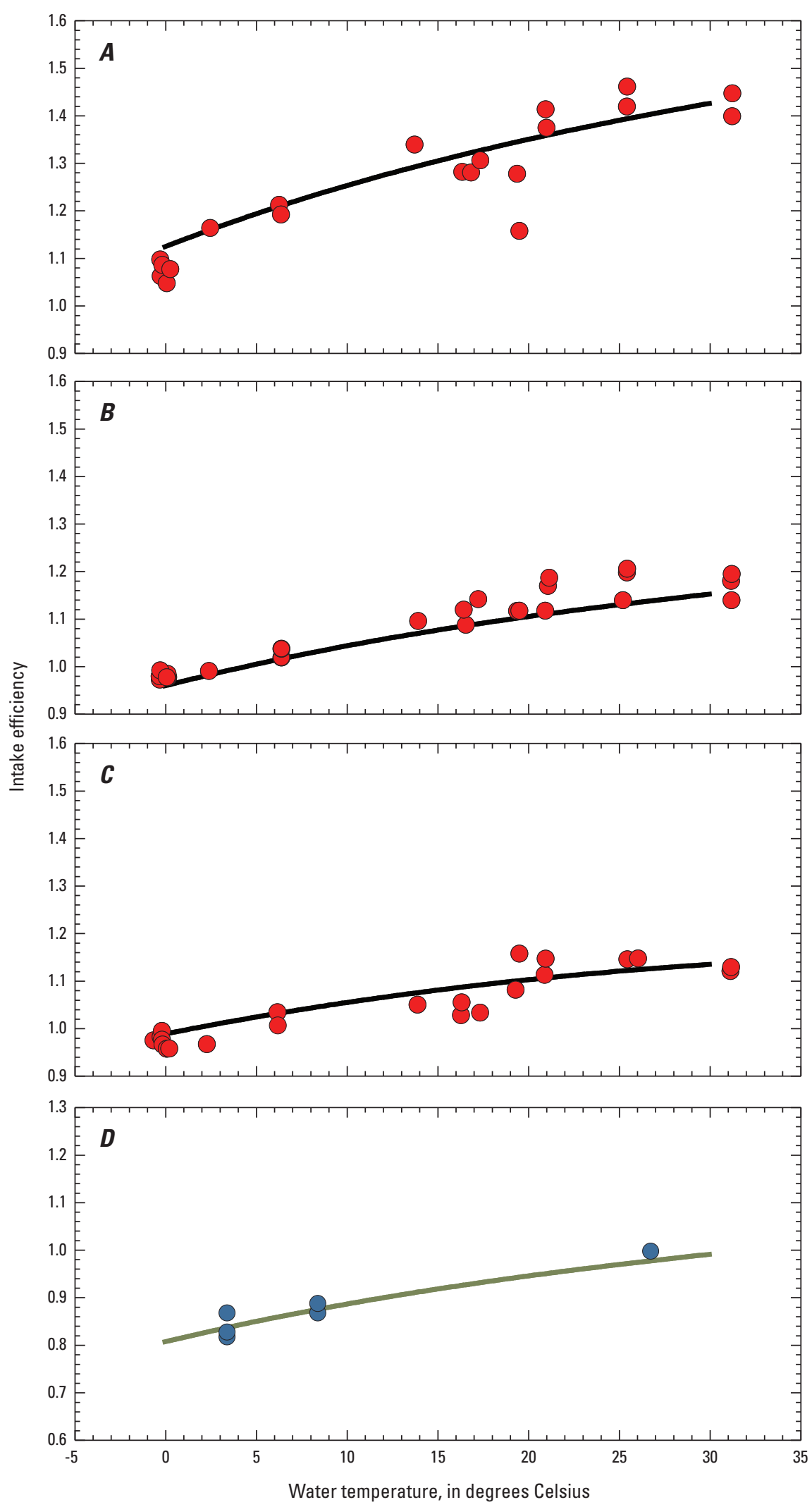

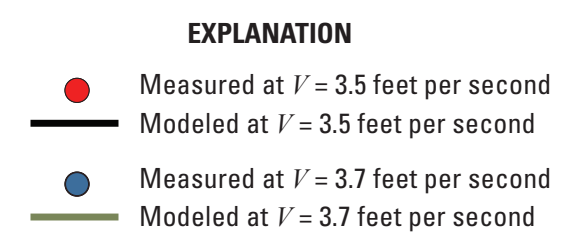

Figure 14. Graphs showing measured and modeled intake efficiencies of a US D-43 sampler (Federal Interagency Sedimentation Project (FISP), 1952) with nozzles that have entrance diameters of $(A)$ 1/8 inch, $(B) 3 / 16$ inch, and $(C)$ 1/4 inch at an ambient stream velocity of $3.5 \mathrm{ft} / \mathrm{s}$ (feet per second; measurements from FISP, 1952, figs. 40, 41), and measured and modeled intake efficiencies of a US D-96 sampler with a nozzle with an entrance diameter of $3 / 16$ inch $(D)$ at an ambient stream velocity of $3.7 \mathrm{ft} / \mathrm{s}$ (measurements from Davis, 2001). Taper depths were 3 inches for the $1 / 8$-inch nozzle, $1-7 / 8$ inches for the $3 / 16$-inch nozzle, $1-3 / 8$ inches for the $1 / 4$-inch nozzle on the US D-43 sampler, and 1-11/16 inches for the $3 / 16$-inch nozzle on the US D-96 sampler. Modeled intake efficiencies are from the physically based model described below in this section of this report. Because its use requires extremely low transit rates to avoid pressure-driven inrush during the descending transit, the $1 / 8$-inch nozzle is no longer recommended for use on depthintegrating samplers (J.R. Gray, USGS, written commun., 2011). 


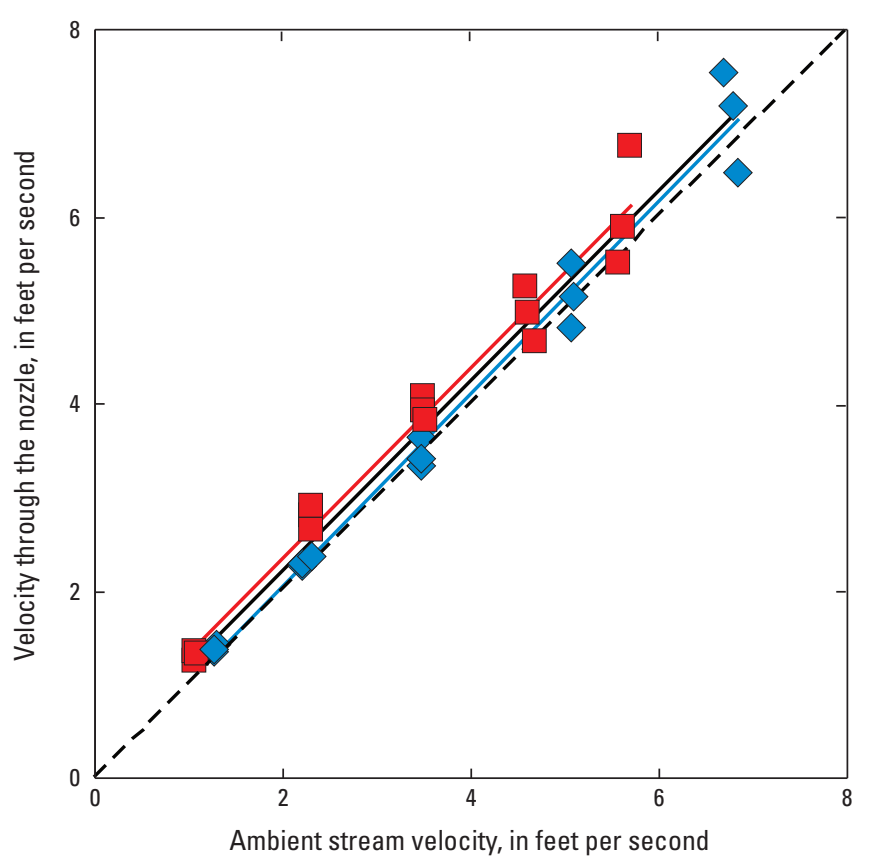

EXPLANATION

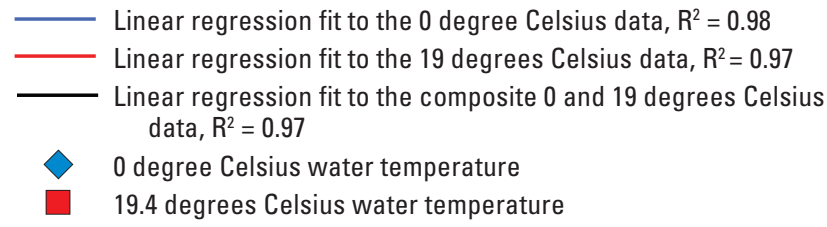

Figure 15. Graph showing relations between ambient stream velocity and the velocity of water through nozzles on US D-43 samplers at water temperatures of 0 and 19.4 Celsius $\left({ }^{\circ} \mathrm{C}\right.$ ) (after Federal Interagency Sedimentation Project (FISP), 1952, fig. 40). Shown are data for sampler nozzles with $1 / 8-, 3 / 16-$, and $1 / 4-$ inch entrance diameters; taper depths for these sampler nozzles were set so that these nozzles would be isokinetic at an ambient stream velocity of $3.5 \mathrm{ft} / \mathrm{s}$ (feet per second) and a water temperature of approximately 0 to $5^{\circ} \mathrm{C}$ (see fig. 14). The $1 / 8$-inch nozzle is no longer used.

This additional head loss dictates equation 4 to be rewritten as,

$$
\begin{aligned}
\mathrm{H}_{\mathrm{V} \text {-stream }} & +\mathrm{H}_{\mathrm{P} \text {-difference }}-\mathrm{HL}_{\text {friction }}-\mathrm{HL}_{\text {nozzle-geometry }} \\
& -\mathrm{HL}_{\text {bag-displacement }}=\mathrm{H}_{\mathrm{V} \text {-nozzle }}
\end{aligned}
$$

for a collapsible-bag depth-integrating suspended-sediment sampler. The first of the two driving terms in equations 4 and 5 ,

$$
\mathrm{H}_{\mathrm{V}-\text { stream }}=\frac{V^{2}}{2 g},
$$

is the velocity head of the undisturbed flow immediately upstream from the nozzle entrance. As before, $V$ is the instantaneous ambient stream velocity at the locus of the sampler-nozzle intake unaffected by the presence of the sampler; $g$ is the gravitational acceleration. The second of the two driving terms in equations 4 and 5 is the pressure head resulting from both (1) the difference between the hydrostatic pressures in the sample container and the nozzle entrance (this difference is zero in a collapsible-bag sampler) and (2) the difference between the dynamic pressure at the positions of either the air-exhaust exit (in a rigid-container sampler) or the sampler-cavity vent holes (in collapsible-bag samplers) and the dynamic pressure in the undisturbed flow immediately upstream from the nozzle entrance.

All depth-integrating samplers use the pressure head to compensate for the effect of friction inside the sampler nozzle. Without the pressure head, nozzle friction would result in nozzle velocities that are always lower than the ambient stream velocity and isokinetic sampling would be impossible. To help facilitate higher intake efficiencies at lower ambient stream velocities, rigid-container samplers are designed such that the hydrostatic pressure inside the sample container is slightly lower than that in the undisturbed flow immediately upstream from the nozzle entrance. As the ambient stream velocity increases, this hydrostatic pressure difference has progressively less of an effect on offsetting nozzle friction. Therefore, at higher ambient stream velocities, all depth-integrating samplers (rigid-container and collapsible-bag) are designed such that the dynamic pressure difference associated with the acceleration of flow around the sampler body is used to compensate for the effects of nozzle friction. Figure A9 in the appendix illustrates the relative importance of the hydrostatic and dynamic components of the pressure head at different ambient stream velocities.

The hydrostatic pressure difference between the nozzle entrance and the sample container in a rigid-container sampler results from the elevation difference between the nozzle entrance and the air-exhaust exit. As long as some air is present in the sample container, the hydrostatic pressure inside the sample container is equal to the hydrostatic pressure at the elevation of the air-exhaust exit. Unlike rigid-container samplers, collapsible-bag samplers are designed so that only minimal (in the perfect case, zero) air will be trapped in the sample container upon submergence. Ideally, this trapped air will be located only in the nozzle and nozzle holder and not in the bag. Because the volume of this trapped air is much smaller than that trapped in the bottle of a rigid-container sampler, there is no mechanism in a collapsible-bag sampler for creating a sustained difference between the hydrostatic pressures at the nozzle entrance and inside the sample container. However, because the volume of trapped air in a collapsible-bag sampler is typically slightly greater than zero, this air must be evacuated from the sample container or it will interfere with the filling of the bag with water through the nozzle, especially at lower ambient stream velocities. 
To provide an avenue by which any air trapped in the nozzle, nozzle holder, and bag can escape, a pressure-equalization hole is drilled into the top of the nozzle holder in the US D-96-type, US D-99, and US DH-02 samplers. While air is passing from the inside of the nozzle holder through this pressure-equalization hole in the collapsible-bag sampler, the pressure equalization hole serves a similar purpose as the air exhaust in a rigid-container sampler. Because the top of the pressure-equalization hole is higher than the elevation of the nozzle entrance, the presence of the pressure-equalization hole creates a slight hydrostatic pressure difference between the nozzle entrance and the sample container. However, because the volume of air trapped in a collapsible-bag sampler's sample container is much smaller than that trapped in a rigid-container sampler (and ideally no larger than the volume of the inside of the nozzle holder), the hydrostatic pressure difference caused by the pressure-equalization hole decreases rapidly over time as the trapped volume of air in the sample container approaches zero. Thus, unlike in a rigid-container sampler, where the effect of the hydrostatic pressure difference between the nozzle entrance and the air-exhaust exit is sustained throughout the collection of a sample, the effect of the hydrostatic pressure difference between the nozzle entrance and the top of the pressure-equalization hole decreases rapidly over time to zero during sample collection.

Among all rigid-container depth-integrating samplers, the hydrostatic component of the pressure head, $\Delta z$, ranges from $\sim 0.4$ to 0.8 inch $^{9}$. In the collapsible-bag samplers with a pressure-equalization hole, $\Delta z$ decreases rapidly during sample collection when air can pass through the hole; thus, over typical longer durations of sample collection $\Delta z$ is approximately zero in these samplers. Because of the differences between $\Delta z$ among the various depth-integratingsampler models, nozzle designs are unique ${ }^{10}$ for each sampler model to allow isokinetic sampling (Guy and Norman, 1970; Edwards and Glysson, 1999). The positive elevation difference between the nozzle entrance and the air-exhaust

\footnotetext{
${ }^{9}$ For the samplers that use the US D-77 nozzle holder, $\Delta z \approx 0.8$ inch; for the US D-43 sampler and its successors, the US D-49 and US D-74 samplers, $\Delta z \approx 0.5 \mathrm{inch}$; for the US DH-48, US DH-59 and US DH-76 samplers, $\Delta z \approx 0.7$ inch; and for the US DH-75 sampler, $\Delta z \approx 0.4$ inch (FISP, 1952, 1965, 1979; 1986; [n.d.]d, e; Webb and Radtke, 1998; McGregor, 2000a, 2000b, 2006). For all samplers with an air exhaust, we calculate $\Delta z$ as the change in elevation between the midpoint elevation of the nozzle entrance and the elevation of the air-exhaust exit. Because the volume of air trapped in the bag of a collapsible-bag sampler is minimal, the hydrostatic pressure difference between the nozzle entrance and the top of the pressure-equalization hole decreases rapidly during sample collection, thus $\Delta z \approx 0$ over typical longer sampling durations for the US D-96-type, US D-99, and US DH-2 collapsible-bag samplers (Davis, 2001, 2005; McGregor, 2006).

${ }^{10}$ In this usage, a unique nozzle design refers to a unique combination of nozzle entrance diameter, nozzle length, and an internal taper applied to the rear part of the nozzle.

${ }^{11}$ Depth-integrating samplers that use the US D-77 nozzle holder are the US D-77 rigid-container and bag-type samplers, and the US DH-81, US D-95, and US DH-95 samplers.
}

exit or top of the pressure-equalization hole is required to ensure that the sample will be collected in the sampler container rather than immediately exit the sampler through the air exhaust or pressure-equalization hole. In addition, as a result of the slightly positive pressure head arising from this elevation difference, the hydrostatic pressure inside the sampler container is slightly lower than the hydrostatic pressure in the river at the nozzle entrance. This slight hydrostatic pressure difference is used in rigid-container depth-integrating samplers to partially offset the frictional head losses in the nozzle and allow the isokinetic collection of a sample. This difference in hydrostatic pressure is especially important at low ambient stream velocities where $\mathrm{HL}_{\text {friction }}$ approaches or exceeds the combined velocity head plus dynamic pressure head, as illustrated by the following two examples. First, the first three FISP prototypes of a depth-integrating sampler had air exhausts that were located substantially higher above the nozzle entrance than in the final design of the US D-43 sampler (FISP, 1952). As a result, these earlier three designs had intake efficiencies that were too high, with nozzle velocities generally exceeding the ambient stream velocity, especially at lower ambient stream velocities. As a result, during the development of the US D-43, the midpoint-elevation of the air exhaust was lowered to a position 0.5 inch above the elevation of the nozzle entrance, at an elevation head that was empirically found to result in acceptable intake efficiencies over a wider range in ambient stream velocity, especially when an internal taper was applied to the rear part of the nozzle (FISP, 1952). Second, placement of the air-exhaust exit $\sim 0.8$ inch above the nozzle elevation in the US D-77 sampler results in sample being collected even when the ambient stream velocity is zero; in tests of this sampler in $0.6^{\circ} \mathrm{C}$ water, $V_{n}$ was observed to be $\sim 1 \mathrm{ft} / \mathrm{s}$ when $V$ was zero (FISP, 1979).

The dynamic pressure difference between the nozzle entrance and the positions of either the air-exhaust-exit or sampler-cavity vent holes arises from the acceleration of the flow around the sampler body. This dynamic pressure difference aids in the evacuation of the air from a rigid-container sampler or the water from the sampler cavity in a collapsible-bag sampler, thereby helping to offset the effect of nozzle friction on the velocity inside the sampler nozzle. In all depth-integrating samplers except those using the US D-77 nozzle holder ${ }^{11}$, the air exhaust or vent holes are typically located near the widest part of the sampler body. Because the flow accelerates around the body of a submerged depth-integrating sampler, the dynamic pressure at the typical locations of either the air exhaust or vent holes is lower than that immediately upstream from the nozzle entrance. In addition, because the bodies of depth-integrating samplers are streamlined to prevent flow separation, the dynamic pressure field around the body of a depth-integrating sampler can be estimated using irrotational flow. On the basis of the irrotational flow approximation for unseparated flow around a streamlined object with a shape similar to 
that of a depth-integrating sampler (for example, fig. 118 in Rouse, 1946), the dynamic pressure in the undisturbed flow immediately upstream from the nozzle entrance is likely $\sim 0.4 \rho V^{2} / 2$ higher than that in the accelerated flow at the typical locations of either the air exhaust or vent holes (where $\rho$ is the density of water). Furthermore, as long as flow separation does not occur around the body of the depth-integrating sampler, this difference in dynamic pressure should be constant regardless of the magnitude of the Reynolds number associated with the flow around the sampler (Pinkerton, 1938) (the Reynolds number is a dimensionless measure of the ratio of the inertial forces on an element to the viscous forces on an element). For all depth-integrating samplers except those using the US D-77 nozzle holder, the difference in dynamic pressure can be expressed as a dynamic pressure head as $\sim 0.4 V^{2} /(2 g)$. Thus, for rigid-container samplers the second term in equation 4 can be written as a combination of its hydrostatic and dynamic components as,

$$
\mathrm{H}_{\text {P-difference }}=\Delta z+0.4 \frac{V^{2}}{2 g} \text {. }
$$

For collapsible-bag-type depth-integrating samplers, the second term in equation 5 is written (that is, equation $7 \mathrm{a}$ is rewritten) as,

$$
\mathrm{H}_{\text {P-difference }}=0.4 \frac{V^{2}}{2 g},
$$

to remove the effect of $\Delta z$, which is approximately zero over the duration of sample collection in collapsible-bag samplers. On depth-integrating samplers that use the US D-77 nozzle holder, the air exhaust is located on the nozzle holder immediately behind the nozzle, a position upstream from most of the acceleration of the flow around the sampler body. Therefore, on these samplers, the dynamic pressure at the location of the air-exhaust exit is only slightly less than that in the undisturbed flow immediately upstream from the nozzle entrance. Thus, for the rigid-container-type samplers that use the US D-77 nozzle holder, the second term in equation 4 is written as,

$$
\mathrm{H}_{\text {P-difference }}=\Delta z+0.1 \frac{V^{2}}{2 g} \text {. }
$$

Just as equation 7a was rewritten for collapsible-bag-type samplers as equation $7 \mathrm{~b}$ to remove the effect of $\Delta z$, equation $7 \mathrm{c}$ is therefore rewritten as,

$$
\mathrm{H}_{\text {P-difference }}=0.1 \frac{V^{2}}{2 g},
$$

to remove the effect of $\Delta z$ in collapsible-bag samplers that use the US D-77 nozzle holder (that is, the US D-77 bag-type sampler).

The first of the resisting terms in equations 4 and 5 , $\mathrm{HL}_{\text {friction, }}$, includes the major head losses resulting from the friction between the water flowing through the nozzle and the inside walls of the nozzle, and is described in detail below. To allow different diameter nozzles to be used with the same model depth-integrating sampler (with a fixed value of $\Delta z$ ), the rear portions of most sampler nozzles are internally tapered with a 1.19-degree expansion. Nozzles are calibrated to be isokinetic at a given ambient stream velocity and water temperature by adjusting the depth of this internal taper (FISP, 1952; Guy and Norman, 1970; Davis, 2001, 2005). This expanding internal taper diameter of $1 / 4$ inch per foot (FISP, 1952, 1979; Guy and Norman, 1970, table 1) is the key aspect of a depth-integrating sampler nozzle that allows nozzles with identical lengths but different entrance diameters to be calibrated for a given model sampler to allow isokinetic sampling over specific ranges of water temperature and ambient stream velocity. The internal taper achieves this result by effectively reducing the magnitude of $\mathrm{HL}_{\text {friction, }}$, as shown in the appendix.

The second of the resisting terms, $\mathrm{HL}_{\text {nozzle-geometry }}$, in equations 4 and 5 includes the minor head losses resulting from changes in the geometry of the flow as it passes into and through a sampler nozzle. In contrast to the more-standard cases in the pipe-flow literature where water either enters a pipe from a tank (in which the water in the tank has zero velocity) or undergoes a constriction in flow (in which streamlines converge into a pipe entrance), (1) the velocity in a river immediately upstream from an isokinetic sampler nozzle is approximately equal to the velocity of the water in the nozzle entrance and (2) streamlines do not converge into a nozzle entrance because the water in streamlines adjacent to those upstream from a nozzle entrance can freely travel downstream around the outside of the nozzle and sampler body. Therefore, the minor head loss associated with water entering a sampler nozzle is negligible. Furthermore, because the expansion in the tapered rear parts of nozzles is only 1.19 degrees, the minor head loss associated with this minor flow expansion in the nozzle is also negligible. Because $\mathrm{HL}_{\text {nozzle-geometry }}$ is much smaller than the other terms in equation 5, it is excluded from our analysis, and the influence of the small internal taper angle on head loss is included only with respect to its effect on the mean inside nozzle diameter and associated velocity in the $\mathrm{HL}_{\text {friction }}$ term (defined below). By this approach, $\langle D\rangle$ is the mean inside diameter of the internally tapered sampler nozzle and $\left\langle V_{\mathrm{n}}\right\rangle$ is the nozzle velocity associated with $\langle D\rangle^{12}$. This approach greatly simplifies the analysis below.

\footnotetext{
${ }^{12}$ Relations between $\left\langle V_{n}\right\rangle$ and $V_{\mathrm{n}}$, and between $\langle D\rangle$ and $D$ are provided in the appendix.
} 
Because $\mathrm{HL}_{\text {friction }}$ is calculated on the basis of $\left\langle V_{\mathrm{n}}\right\rangle$, the final term in equations 4 and 5 , the velocity head of the water flowing through the nozzle into the sampler container, is expressed as:

$$
\mathrm{H}_{\text {V-nozzle }}=\frac{\left\langle V_{\mathrm{n}}\right\rangle^{2}}{2 g} .
$$

The first resisting term in equations 4 and $5, \mathrm{HL}_{\text {friction }}$ varies as a function of nozzle geometry, velocity in the nozzle, and water temperature. Water temperature influences $\mathrm{HL}_{\text {friction }}$ mainly through its effect on viscosity, and to a much lesser degree through its effect on density. Calculation of $\mathrm{HL}_{\text {friction }}$ for sampler nozzles is much more complicated than calculation of $\mathrm{HL}_{\text {friction }}$ in long horizontal pipes because sampler nozzles can be either shorter or longer than the distance required for flow to become fully developed in a pipe entrance. In this usage, "fully developed flow" refers to the condition where the boundary layer has grown from the pipe wall to the pipe center, resulting in a stable velocity profile that does not change with distance along the pipe. In this discussion, distance $x$ inside the entrance of a horizontal pipe increases from $x=0$ at the pipe entrance. As first observed by Reynolds (1883), flow entering a small-diameter pipe is initially uniform and may remain laminar or undergo a transition to turbulence as a function of the pipe diameter, velocity, and temperature. At $x=0$, the initial velocity profile of water entering a small-diameter pipe from a larger body of water is approximately uniform (Rouse, 1946) and can best be described as "plug flow." As the water enters the pipe, the velocity of the water along the pipe walls goes to zero by the "no-slip" condition and a laminar boundary layer starts to develop (Rouse, 1946; Schlichting, 1968). By conservation of mass and momentum, growth of this boundary layer results in deceleration of flow near the pipe walls and acceleration of the slowly shrinking inviscid "plug flow" in the center of the pipe (Rouse, 1946; Bender, 1969; Shimomukai and Kanda, 2008). Over some distance from the pipe entrance, the boundary layer will either remain laminar or undergo a transition to turbulence. Regardless of whether this transition to turbulence occurs within the pipe, the boundary layer will grow to the center of the pipe. The distance $x$ at which the boundary layer grows to the center of the pipe is known as the "entrance length," $L_{\mathrm{ent}}$, and the region of the pipe where $x<L_{\mathrm{ent}}$ is known as the "entrance region." After growth of the boundary layer to the center of the pipe, no plug flow will remain and the flow in the pipe will be "fully developed" laminar or turbulent flow, with velocities increasing from zero at the pipe wall to a maximum ${ }^{13}$ in the center of the pipe.

\footnotetext{
${ }^{13}$ For fully developed turbulent flow, the maximum velocity is a timeaveraged maximum velocity.
}

As reviewed in Munson and others (2009), for developing laminar flow,

$$
L_{\text {ent-lam }} \approx 0.06 \operatorname{Re} D,
$$

and for developing turbulent flow,

$$
L_{\text {ent-turb }} \approx 4.4 \mathbf{R e}^{1 / 6} D \text {, }
$$

where
$\mathbf{R e}$ is the Reynolds number defined below in equation 11 , and
$D$ is the inside diamer of the pipe.

These equations are only approximations because the exact value of $L_{\text {ent }}$ and whether the flow in the pipe entrance undergoes a transition to turbulence depend strongly on the smoothness of the pipe walls, the geometry of the pipe entrance, and the nature of the flow upstream from the pipe entrance (Pfenniger, 1961; Schlichting, 1968; Kanda, 1988; Hof and others, 2003; Ichimiya, 2004). Kanda (1988) provides a relatively thorough review of the experiments that form the basis for the equation 10 approximations. Over a wide range of flow conditions (ambient stream velocities ranging from less than 1 to $\sim 16 \mathrm{ft} / \mathrm{s}$ and water temperatures ranging from 0 to $30^{\circ} \mathrm{C}$ ), the length, $L$, of a sampler nozzle is much shorter than the value of $L_{\text {ent-lam }}$ required for fully developed laminar flow, but is typically comparable to the value of $L_{\text {ent-turb }}$ required for fully developed turbulent flow. For example, for the 3-1/8-inch-long, 1/8-, 3/16-, and 1/4-inch-diameter nozzles used in the US D-43 sampler, $L$ is about a factor of $\sim 2$ to 60 less than $L_{\text {ent-lam }}$, but only a factor of $\sim 0.6$ to 1.6 less than $L_{\text {ent-turb }}$. Similarly, for the 4-3/8-inch-long, 3/16-, 1/4-, and $5 / 16$-inch-diameter nozzles used in the US D-96 sampler, $L$ is about a factor of $\sim 3$ to 160 less than $L_{\text {ent-lam, }}$, but only a factor of $\sim 0.6$ to 1.8 less than $L_{\text {ent-turb }}$. Therefore, the flow within a sampler nozzle may be developing laminar flow, developing turbulent flow, or fully developed turbulent flow, depending on the value of the nozzle Reynolds number defined below. Because of the relative shortness of sampler nozzles, it is unlikely that the flow within a sampler nozzle is ever fully developed laminar flow.

Because flow in sampler nozzles can be either developing laminar or turbulent flow or fully developed turbulent flow, the friction experienced by the flow in a sampler nozzle will be greater than or equal to the friction associated with fully developed turbulent flows. In developing flow, the longitudinal drop in pressure is nonlinear and arises from both wall shear and the acceleration of the shrinking plug flow in the center of the pipe; in fully developed flow, the longitudinal drop in pressure is linear and arises purely from wall shear (Rouse, 1946; Bender, 1969; Shah, 1978; Bejan, 1984; Kanda, 1988; Yilmaz, 1990; Shimomukai and Kanda, 2008; Muzychka and Yovanovich, 1998, 2009; Munson and others, 2009). 
Therefore, in the entrance region of a pipe, the pressure decreases nonlinearly at a progressively decreasing rate until the flow becomes fully developed at a distance of $x=L_{\text {ent }}$, after which the pressure continues to decrease linearly with distance. In the region of fully developed flow and linear pressure drop beyond the entrance region,

$$
\mathrm{HL}_{\text {friction }}=f \frac{L}{D} \frac{V^{2}}{2 g}
$$

where

$f$ is the Darcy-Weisbach friction factor estimated on the basis of Moody (1944),

$L$ is the pipe length over which $f$ is calculated, and

$V$ is the cross-sectionally averaged velocity inside the pipe.

Associated with the rapid nonlinear drop in pressure in the entrance region of a pipe are values of the friction factor, commonly referred to as the apparent friction factor (denoted as $\left.f_{\text {app }}\right)$, that will be much larger than the value of $f_{\text {lam }}$, the friction factor estimated on the basis of Moody (1944) for fully developed laminar flow, and typically larger than the value of $f_{\text {turb }}$, the friction factor estimated on the basis of Moody (1944) for fully developed turbulent flow in smooth pipes $^{14}$ (Shah and London, 1978; Bejan, 1984; Muzychka and Yovanovich, 1998, 2009; Kandlikar and Campbell, 2002). Because $f_{\text {app }}$ can be much larger than $f$ for fully developed flows, empirical measurements of pipe friction will be dominated by $f_{\text {app }}$ until $x>L_{e n t}$.

The nozzle Reynolds number,

$$
\boldsymbol{R e}=\frac{\rho V D}{\mu}
$$

is the nondimensional physical balance between inertial forces (in the numerator) and viscous forces (in the denominator) and determines whether fully developed flow in a nozzle is ultimately turbulent or laminar (reviewed by Rouse, 1946). In equation $11, \mu$ is the viscosity, which varies nonlinearly with the inverse of water temperature. In addition, both $f$ (Moody, 1944) and $L_{e n t}$ scale with the Reynolds number (Reynolds, 1883; Boussinesq, reviewed in Prandtl and others, 1934; Langhaar, 1942; Kanda, 1988; Munson and others, 2009). Unlike the values of $f_{\text {lam }}$ and $f_{\text {turb }}$, which depend only on $\mathbf{R e}, f_{\text {app }}$ depends on the $\mathbf{R e}, D$, and $x$ because $L_{\text {ent }}$ varies as a function of both $\mathbf{R e}$ and $D_{\text {ent }}$ (Bender, 1969; Shah, 1978; Bejan, 1984; Yilmaz, 1990; Muzychka and Yovanovich, 1998,

\footnotetext{
${ }^{14}$ Sampler nozzles are made of machined brass, plastic, or Teflon ${ }^{\circledR}$; pipe materials that are all considered "smooth" in the fluid mechanics literature.
}

2009). On the basis of the analysis in the appendix, the best equation describing the major head losses arising from friction in an internally tapered sampler nozzle is,

$$
\mathrm{HL}_{\text {friction }}=f_{n} \frac{L}{\langle D\rangle} \frac{\left\langle V_{\mathrm{n}}\right\rangle^{2}}{2 g},
$$

where

$$
\begin{gathered}
f_{n} \text { is the nozzle friction factor and depending on } \\
\text { the value of } \operatorname{Re} \text { for a given } L \text { and }\langle D\rangle, \\
f_{n} \text { is either equal to } f_{\text {app }}, f_{\text {turb }} \text {, or smoothly varies } \\
\text { between } f_{\text {aap }} \text { and } f_{\text {turb }} \text { (see appendix). }
\end{gathered}
$$

The additional, third, resisting term for collapsible-bag samplers in equation $5, \mathrm{HL}_{\text {bag-displacement, }}$, arises because of "backpressure" on the filling bag in the flooded sampler cavity. Isokinetic sampling in a collapsible-bag sampler requires that the filling bag be able to displace the water in the flooded sampler cavity and purge this displaced water through the vent holes at exactly the rate at which the water-sediment mixture enters the sampler nozzle isokinetically. As discussed previously, the laboratory experiments of both Szalona (1982) and Davis (2001) show that the intake efficiency of collapsible-bag samplers decreases over time as the filling bag occupies more of the sampler cavity. The reason for this time-dependent decrease in intake efficiency becomes obvious upon derivation of the equation for $\mathrm{HL}_{\text {bag-displacement* }}$. As a bag fills within a sampler cavity, the region around the filling bag becomes progressively smaller, whereas the vent holes (assuming they do not become blocked by the filling bag) remain constant in diameter. Thus, the dominant source of the progressive increase in the resistance to the filling bag's displacement and purging of water from the sampler cavity is likely the progressive decrease in the cross-sectional area of flow in the sampler cavity around the filling bag. Assuming that the mathematical form of $\mathrm{HL}_{\text {bag-displacement }}$ must be similar to that of $\mathrm{HL}_{\text {friction }}$ allows $\mathrm{HL}_{\text {bag-displacement }}$ to be written as,

$$
\mathrm{HL}_{\text {bag-displacement }} \infty \frac{L_{\text {cavity }}}{D_{\text {cavity-flow }}} \frac{V_{\text {cavity-flow }}^{2}}{2 g} \text {, }
$$

where

$L_{\text {cavity }}$ is the length of the sampler cavity and is assumed to be constant,

$D_{\text {cavity-flow }}$ is the decreasing diameter of the water, in the samples cavity around the filling bag, and

$V_{\text {cavity-flow }}$ is the velocity of the water in the sampler cavity being displaced by the filling bag. 
By conservation of mass, as $D_{\text {cavity-flow }}$ decreases over time, $V_{\text {cavity-flow }}$ must increase to remain in balance with the isokinetic rate of flow into the sampler nozzle. Because $D_{\text {cavity-flow }}$ decreases over time and $V_{\text {cavity-flow }}$ increases over time, $\mathrm{HL}_{\text {bag-displacement }}$ must increase over time, leading to the physical requirement that intake efficiency must decrease over time in collapsible-bag samplers. In addition, because it is likely that a filling bag will also at least partially block some of the vent holes, $\mathrm{HL}_{\text {bag- }}$ displacement likely increases over time at a rate higher than that predicted by equation 13 . Therefore, although it is physically impossible to design a collapsible-bag sampler in which intake efficiencies do not decrease over time, it may be possible to minimize this effect by increasing the venting of the sampler cavity, an idea that is tested in a subsequent section of this report.

Rearrangement of equation 4 or rearrangement of equation 5 for the ideal case of $\mathrm{HL}_{\text {bag-displacement }}$ $\sim 0$, after making the appropriate substitutions on the basis of the analysis in the appendix, yields the following simplest relation between $\left\langle V_{\mathrm{n}}\right\rangle$ and the ambient stream velocity, $V$ :

$$
V=\sqrt{\left(\left\langle\mathrm{V}_{\mathrm{n}}\right\rangle^{2}\left(1+f_{\mathrm{n}}\left(\frac{L}{\langle D\rangle}\right)\right)-2 g \Delta z\right) / k_{\mathrm{P}}}
$$

where

$k_{\mathrm{P}}$ is a constant arising from the dynamic pressure head between the nozzle entrance and airexhaust exit or vent hole and, on the basis of equation 7 , is set to 1.1 for the samplers that use the US D-77 nozzle holder and is set to 1.4 for all other depth-integrating samplers.

Further substitution of equations A1 and A2 into equation 14 and rearrangement yields the following relation between the nozzle entrance velocity, $V_{\mathrm{n}}$, and the ambient stream velocity,

$V=\sqrt{\left(V_{\mathrm{n}}^{2}\left(\frac{D L}{D\left(L-L_{\mathrm{T}}\right)+L_{\mathrm{T}}\left(D+L_{\mathrm{T}} / 96\right)}\right)^{4}\left(1+f_{\mathrm{n}}\left(\frac{L^{2}}{D\left(L-L_{\mathrm{T}}\right)+L_{\mathrm{T}}\left(D+L_{\mathrm{T}} / 96\right)}\right)\right)-2 g \Delta z\right) / k_{\mathrm{P}}}$,

where

$L_{\mathrm{T}}$ is the nozzle taper depth.

\section{Correction of Water-Temperature Effects on the Field Intake Efficiencies of US D-96-Type Samplers}

Equation 15 describes the physically based model that can be used to evaluate the intake efficiency of any depth-integrating suspended-sampler under a wide range of nozzle geometries, ambient stream velocities, and water temperatures. The model performed well in comparisons with data collected using depth-integrating samplers with very different sampler designs; tests of this model (equation 15) against US D-43 rigid-container, US D-77 rigid-container, US D-96 collapsible-bag, and US DH-02 collapsible-bag samplers yield an in-sample RMAE of \pm 4.3 percent $(n=400)$ and an out of sample RMAE of \pm 5.0 percent $(n=882)$; see appendix. The excellent performance of this model provided justification for using it as a tool to investigate the effects of water temperature on intake efficiency over a relatively wide range of conditions. The model was therefore used to evaluate whether the differences between the $\sim 26.7^{\circ} \mathrm{C}$ water temperature used in FISP US D-96 nozzle calibrations and the typically much colder water temperatures in the Colorado River experiments could help explain the generally sub-isokinetic sampling of the US D-96-type samplers at the six cross-sections among the three study sites on the Colorado River. After completing this evaluation, equation 15 was used to determine whether application of a deeper taper depth to the sampler nozzles could improve the field intake efficiencies of the US D-96-type samplers at colder water temperatures over a wide range of ambient stream velocities. 
Intake efficiencies calculated using the model are in excellent agreement with those measured for the US D-96 sampler using the development nozzles (a set of nozzles used in the US D-96 development testing) in the flume and tow tests, and transit tests conducted at water temperatures of 23.9-29. $4^{\circ} \mathrm{C}$; also they are in generally excellent agreement with those measured in the flume tests for the US D-96 sampler using the standard calibrated nozzles conducted at water temperatures ranging from 2.8 to $29.4^{\circ} \mathrm{C}$ (fig. 16). For comparison with the measurements, the modeled intake efficiencies in figure 16 are plotted at increments of $5^{\circ} \mathrm{C}$ over the range in water temperature from 0 to $30^{\circ} \mathrm{C}$. The local maximum in these curves (most obvious in the modelpredicted intake efficiencies for the 3/16- and 1/4-inch nozzles in fig. $16 A-D$ ) owes to the transition in the nozzle friction factor, $f_{n}$, from one associated with developing flow to one associated with fully developed turbulent flow (see appendix). As discussed in the appendix, unlike the transit tests conducted on either the US D-96 sampler with the development nozzles or the DH-2 sampler, the transit-test data for the US D-96 sampler with the standard nozzles is not internally consistent with the flume-test data for the US D-96 sampler with the standard nozzles, and it is likely that the ambient stream velocities in these transit tests were measured $\sim 10$ percent low (on the basis of Davis' [2001] statement on the "difficulty of precise boat velocity control, coordination of personnel operating the crane, timing the sample, and measuring the sample volume on a moving boat"). Thus, the model-predicted intake efficiencies tend to be $\sim 10$ percent less than the intake efficiencies measured in these transit tests for the US D-96 sampler using the standard calibrated nozzles. The model-predicted intake efficiencies are in excellent agreement with those measured for the US D-96 sampler using the standard 5/16-inch plastic and Teflon ${ }^{\circledR}$ nozzles in flume tests conducted at all ambient stream velocities investigated by the FISP (ranging from 2 to $3.7 \mathrm{ft} / \mathrm{s}$ ) and water temperatures ranging from 2.8 to $29.4^{\circ} \mathrm{C}$ (fig. $16 F$ ). For the standard 3/16- and 1/4-inch plastic and Teflon ${ }^{\circledR}$ nozzles, the modelpredicted intake efficiencies for the US D-96 sampler are also generally in excellent agreement with the measurements. The only measurements not in excellent agreement with the model predictions are the intake efficiencies measured in the five flume tests conducted at an ambient stream velocity of $2 \mathrm{ft} / \mathrm{s}$ and a water temperature of $8.3^{\circ} \mathrm{C}$, where the modeled values tend to be slightly lower than the measured values (fig. 16B, D). Thus, among all 24 cases, the model predictions of intake efficiency for the US D-96 sampler with the standard nozzles are deemed to be in generally excellent agreement with the measured intake efficiencies because the modelpredicted values are in excellent agreement with the measured values in all but the five cases (where the agreement is not as good). Because the US D-96 sampler development-nozzle flume- and tow-test dataset was used in part to constrain $f_{\mathrm{n}}$ in the appendix, it is not surprising that the model-predicted and measured intake efficiencies in this dataset are in excellent agreement (fig. 16A, $C, E$ ). However, because the US D-96 sampler standard-nozzle flume tests were not in any way used to constrain $f_{\mathrm{n}}$, and are, therefore, part of the "out-ofsample" model evaluations in the appendix, this result means that the model predictions of intake efficiency at different ambient stream velocities and different water temperatures are sufficiently accurate to use to develop temperature corrections for the cold-water Colorado River data.

Temperature corrections were developed for the Colorado River data by first dividing the model-predicted intake efficiency associated with the ambient stream velocity and water temperature for each measurement by the model-predicted intake efficiency associated with the same ambient stream velocity but a water temperature of $26.7^{\circ} \mathrm{C}$ (the average of the water temperature range of Davis' (2001) data. This correction factor was then applied to each measurement by multiplying the measured intake efficiency by this factor. After applying this correction, the temperature-corrected intake efficiencies in the cold-water Colorado River US D-96-type data could be directly compared to the intake efficiencies in Davis' (2001) warm-water data; any remaining discrepancies in intake efficiency would then arise from physical processes other than from the effects of the differences in water temperature between the two datasets on nozzle friction. Comparisons of the temperature-corrected field intake efficiencies with the intake efficiencies measured by Davis (2001) in the Mississippi River are provided in figure 17.

As shown in figure 17, applying the temperature corrections to the US D-96-type Colorado River data reduces but does not fully remove the discrepancies in intake efficiency between this dataset and Davis' (2001) dataset. The average increase in intake efficiency of the Colorado River data after applying this temperature correction is only 0.035 over the entire range of ambient stream velocity in the dataset. Because of the convergent nature of the model-predicted intake-efficiency curves for large nozzle diameters, above an ambient stream velocity $\sim 5 \mathrm{ft} / \mathrm{s}$, in figure 16 , this temperature correction has less of an effect at higher ambient stream velocities than it does at lower ambient stream velocities. At ambient stream velocities $<3 \mathrm{ft} / \mathrm{s}$, the average increase in intake efficiency arising from application of the temperature correction is 0.047 ; at ambient stream velocities $>5 \mathrm{ft} / \mathrm{s}$, the average increase in intake efficiency arising from application of the temperature correction is only 0.016 . In any case, because application of the temperature correction only partially shifts the Colorado River data into the FISPaccepted isokinetic intake-efficiency range of $1.0 \pm 0.1$, some additional physical process must explain the differences in intake efficiency between this US D-96-type data and Davis' (2001) data. 

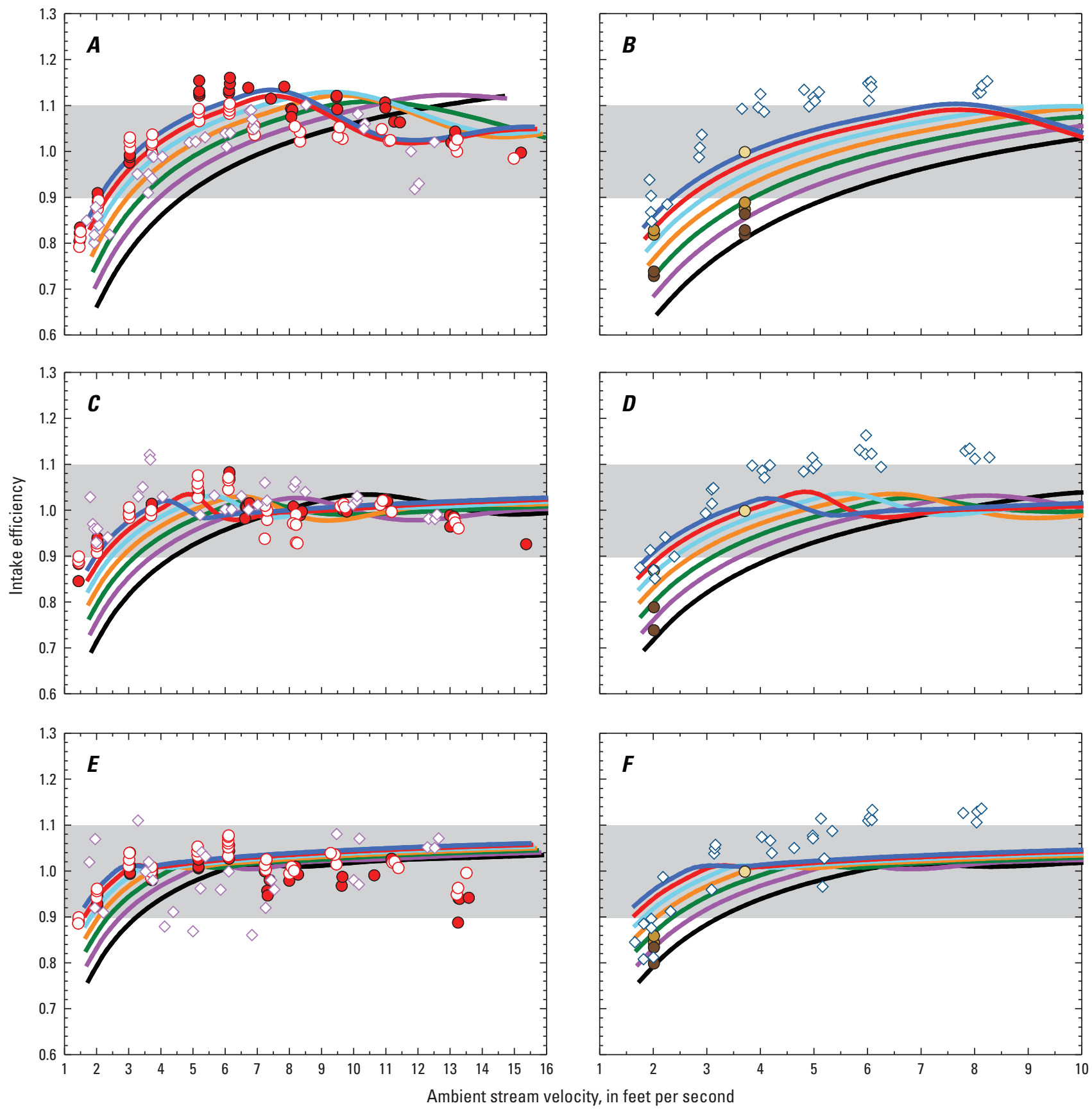

EXPLANATION
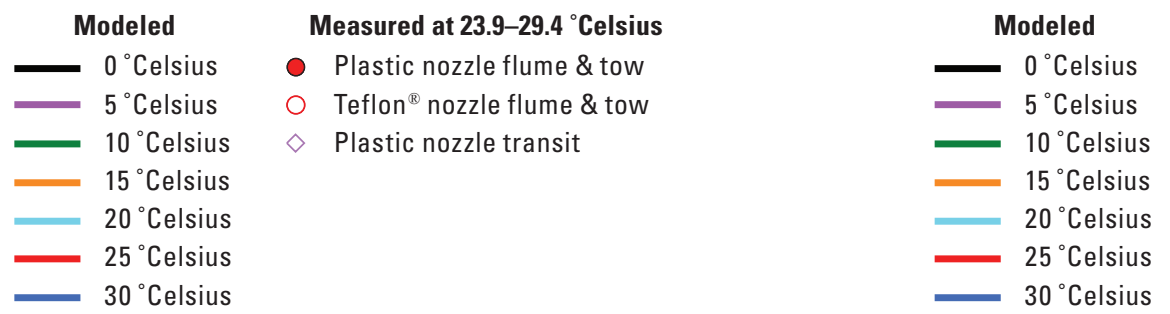

Figure 16. Graphs showing modeled and measured intake efficiencies plotted as a function of ambient stream velocity for the US D-96 sampler using $(A)$ the 3/16-inch development nozzle, $(B)$ the 3/16-inch standard nozzle, $(C)$ the $1 / 4$-inch development nozzle, $(D)$ the $1 / 4$-inch standard nozzle, $(E)$ the 5/16-inch development nozzle, and $(F)$ the 5/16-inch standard nozzle. Temperature ranges of the measured values are indicated; modeled intake efficiencies are plotted at increments of $5^{\circ} \mathrm{C}$ for comparison with the measurements. Shaded area represents range in intake efficiency $(1.0 \pm 0.10)$ considered to be isokinetic Taper depths and other aspects of nozzle geometry are listed in table $A 1$ in the appendix. For simplicity, because the Federal Interagency Sedimentation Project (FISP) taper depths for the plastic and Teflon ${ }^{\circledR}$ standard calibrated nozzles are almost identical, nozzle type is not indicated for the flume-measured intake efficiencies for the standard plastic and Teflon ${ }^{\circledR}$ nozzles. 


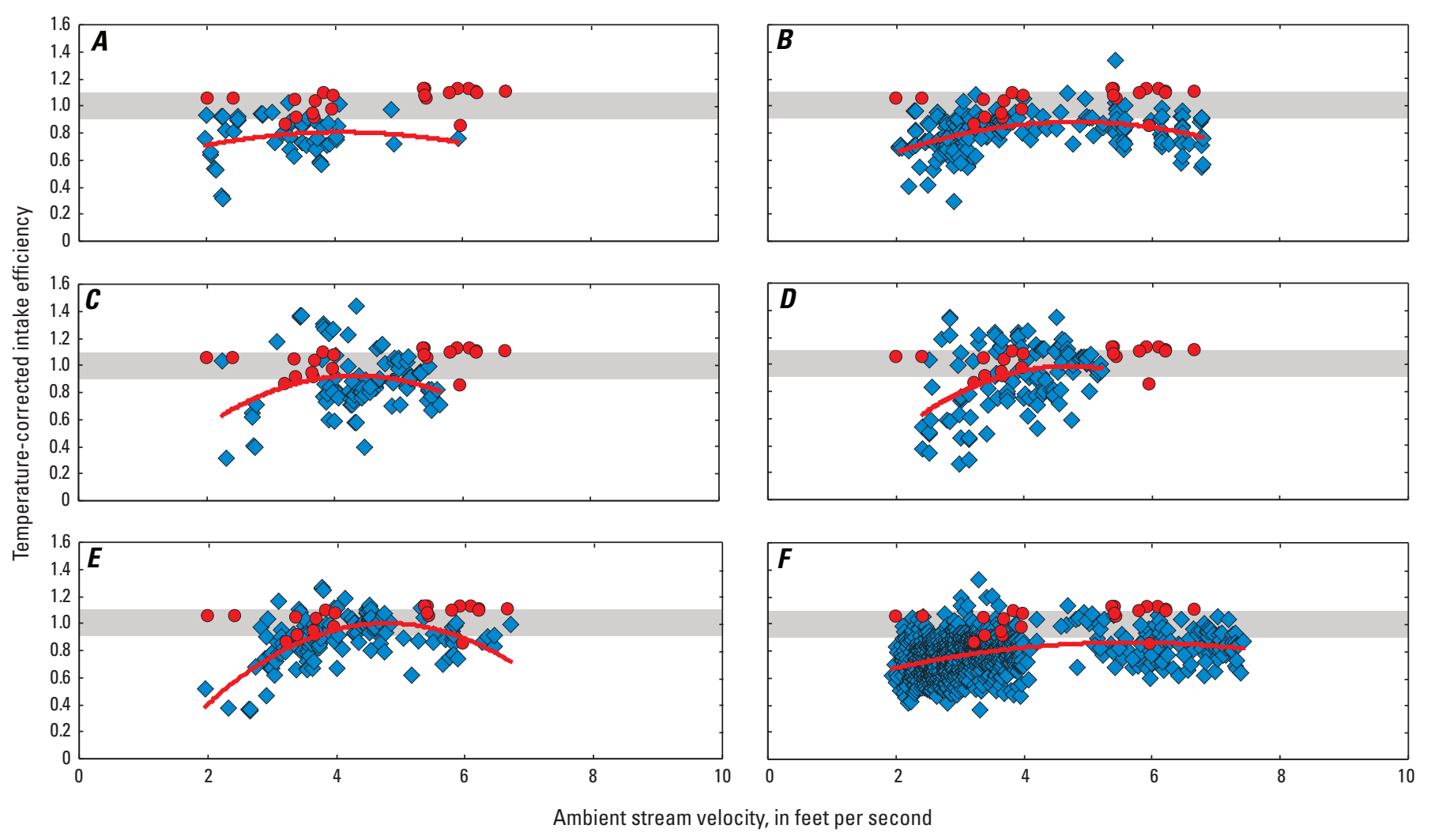

EXPLANATION

$\checkmark \quad$ US D-96-type sampler deployed on the Colorado River during this study

- US D-96-type sampler field test on the Mississippi River

$2^{\text {nd }}$ polynominal regression fit to the Colorado River US D-96-type sampler data

Figure 17. Plots showing comparison of US D-96 intake efficiencies obtained during river tests in the Mississippi River near Vicksburg, Mississippi, from Davis (2001), and the temperature-corrected field-determined intake efficiencies for all samples collected within the operating range of the US D-96-type depth-integrating suspended-sediment samplers at $(A)$ 30-mile tagline $A,(B)$ 30-mile tagline $B,(C)$ 61-mile tagline $A,(D)$ 61-mile tagline $B,(E)$ 61-mile tagline $C$, and $(F)$ 87-mile cableway. Shaded area represents range in intake efficiency $(1.0 \pm 0.10)$ considered to be isokinetic.

Nozzles in older FISP-developed depth-integrating samplers, for example, the US D-43 and the US D-77 rigid-container samplers, were calibrated to be isokinetic at colder water temperatures than the modern depth-integrating samplers developed by the FISP (table A1 in appendix) after FISP moved its laboratory facilities from Saint Anthony Falls Hydraulic Laboratory in Minneapolis, Minnesota, to the Waterways Experimental Station in Vicksburg, Mississippi, in 1992 (FISP, 2011). This increase in the water temperature at which taper depths were empirically determined in flume experiments is likely because it is more difficult to achieve colder water temperature in flumes in Mississippi than it is in Minnesota. To evaluate the effect of an increase in the calibration temperature at which taper depths are determined, the model was used to determine the taper depths for nozzles in the US D-96 sampler that would result in isokinetic sampling at an ambient stream velocity of $3.7 \mathrm{ft} / \mathrm{s}$ and a water temperature of $10^{\circ} \mathrm{C}$ (fig. $\mathrm{A} 10 \mathrm{D}$ in appendix). The model-predicted intake efficiencies associated with these taper depths over a range of ambient stream velocities and water temperatures were then compared to those associated with the smaller taper depths determined by the FISP at an ambient stream velocity of $3.7 \mathrm{ft} / \mathrm{s}$ and water temperatures of $23.9-29.4^{\circ} \mathrm{C}$ (fig. 18). As expected on the basis of the analysis in the appendix, use of a cold-water isokinetic taper depth results in a much greater increase in intake efficiency in smaller diameter nozzles than it does in larger diameter nozzles. As shown in figure 18, use of such a cold-water isokinetic taper depth actually results in an improvement in isokinetic sampling at lower ambient stream velocities over the entire likely range in river water temperature of 0 to $30^{\circ} \mathrm{C}$. However, use of such a coldwater isokinetic taper depth instead of the FISP warm-water isokinetic taper depth does result in intake efficiencies that are generally unacceptably high in 3/16-inch nozzles at ambient stream velocities in excess of 4 or $5 \mathrm{ft} / \mathrm{s}$. 
To evaluate the effect of using an alternative cold-water isokinetic taper depth in nozzles for the US D-96 sampler instead of the FISP warm-water isokinetic taper depth on errors in suspended-sand concentration, we combined the results in figure 18 with the FISP (1941a) laboratory data in figure 4 (fig. 19). For this evaluation, the error curve in figure 4 for 0.15 -mm sediment was used because this grain size is a fairly common size for suspended sand in many rivers. As shown in figure 19, use of a cold-water isokinetic taper depth instead of the FISP warm-water isokinetic taper depth is predicted to reduce or remove positive biases in 0.15 -mm suspended-sand concentration at lower ambient stream velocities. Furthermore, only when using nozzles with 3/16-inch entrance diameters is this reduction expected to increase negative biases to unacceptable levels at higher ambient stream velocities (fig. 19A). When using 3/16-inch nozzles and a $10^{\circ} \mathrm{C}$ isokinetic taper depth (instead of the 23.9-29. $4^{\circ} \mathrm{C}$ FISP taper depth) with a US D-96 sampler between ambient stream velocities of 2 and $4 \mathrm{ft} / \mathrm{s}$, the biases in $0.15-\mathrm{mm}$ suspended-sand concentration are predicted to decrease on average from +6.5 to +3.6 percent at a water temperature of $0^{\circ} \mathrm{C}$, from +3.9 to +1.4 percent at a water temperature of $10^{\circ} \mathrm{C}$, from +2.2 to 0.0 percent at a water temperature of $20^{\circ} \mathrm{C}$, and from +1.1 to -1.0 percent at a water temperature of $30^{\circ} \mathrm{C}$. When using $1 / 4$-inch nozzles and a $10^{\circ} \mathrm{C}$ isokinetic taper depth (instead of the $23.9-29.4^{\circ} \mathrm{C}$ FISP taper depth) with a US D-96 sampler between ambient stream velocities of 2 and $4 \mathrm{ft} / \mathrm{s}$, the biases in $0.15-\mathrm{mm}$ suspended-sand concentration are predicted to decrease on average from +4.3 percent to +2.7 percent at a water temperature of $0^{\circ} \mathrm{C}$, from +2.5 percent to +1.0 percent at a water temperature of $10^{\circ} \mathrm{C}$, from +1.3 percent to -0.1 percent at a water temperature of $20^{\circ} \mathrm{C}$, and from +0.4 percent to -0.8 percent at a water temperature of $30^{\circ} \mathrm{C}$. Finally, when using 5/16-inch nozzles and a $10^{\circ} \mathrm{C}$ isokinetic taper depth (instead of the $23.9-29.4^{\circ} \mathrm{C}$ FISP taper depth) with a US D-96 sampler between ambient stream velocities of 2 and $4 \mathrm{ft} / \mathrm{s}$, the biases in $0.15-\mathrm{mm}$ suspended-sand concentration are predicted to decrease on average from +2.8 percent to +2.1 percent at a water temperature of $0^{\circ} \mathrm{C}$, from +1.4 percent to +0.8 percent at a water temperature of $10^{\circ} \mathrm{C}$, from +0.5 percent to 0.0 percent at a water temperature of $20^{\circ} \mathrm{C}$, and from +0.1 percent to -0.5 percent at a water temperature of $30^{\circ} \mathrm{C}$. Therefore, especially at lower ambient stream velocities, suspended-sand data are slightly more accurate at all water temperatures when using a larger cold-water isokinetic taper depth instead of the smaller FISP warm-water isokinetic taper depth. Conversely, at higher ambient stream velocities (that is, $V>>4 \mathrm{ft} / \mathrm{s}$ ), suspended-sand data are likely to be slightly more accurate at all water temperatures when using the FISP warm-water isokinetic taper depth, especially when using smaller diameter nozzles.

\section{Effect of Sampling Duration on Intake Efficiency in Collapsible-Bag Samplers}

As described previously, intake efficiency is time dependent in collapsible-bag samplers and decreases as sampling duration increases (Szalona,1982; Davis, 2001). This effect arises in collapsible-bag samplers because as the volume of the filling bag occupies more of the sampler cavity, it becomes progressively more difficult for the filling bag to displace the water in the sampler cavity and purge this displaced water out through the vent holes. Analysis of the data Szalona (1982, figs. 4-6) collected with a US D-77 bag-type sampler held stationary in a flume indicates that, as sampling duration increased from $<5$ seconds to $\sim 60$ seconds, intake efficiency decreased from $\sim 1.03-1.08$ to $\sim 0.71-0.89$, regardless of whether a flow deflector was present or absent from the upper sampler-cavity vent hole. These measurements covered a range in ambient stream velocity of 2.8 to $5.7 \mathrm{ft} / \mathrm{s}$ and a range in water temperature from 0.9 to $26.2^{\circ} \mathrm{C}$ (Szalona, 1982). Results from this analysis of Szalona's (1982) data are plotted in figures $20 A-B$. No major difference in the time-dependent behavior of intake efficiency is obvious in figure $20 \mathrm{~A}$ on the basis of differences in ambient stream velocity. In contrast to the conclusion of Szalona (1982), the data plotted in figure $20 \mathrm{~A}$ also suggest that inclusion of the flow deflector on the upper vent hole did not reduce the rate at which intake efficiency decreased over time. Interestingly, US D-77-bag-type sampler intake efficiencies were highest for a given sampling duration for the cases of warm water temperature $\left(T>20^{\circ} \mathrm{C}\right)$ and without a vent-hole flow deflector (fig. 20B). On the basis of the analyses in the preceding sections of this report, these slightly increased intake efficiencies were likely a result of lower nozzle friction at these warmer water temperatures and not a result of the absence of the flow deflector; unfortunately, Szalona (1982) did not make similar measurements of intake efficiency at warm water temperatures with a vent-hole flow deflector present for comparison. Analysis of the data Davis (2001, figs. 6, 7) collected with a US D-96 sampler held stationary in a flume indicates that, as sampling duration increased from 20 to 175 seconds at an ambient stream velocity of $2 \mathrm{ft} / \mathrm{s}$ and water temperatures of $23.9-29.4^{\circ} \mathrm{C}$, intake efficiency decreased from 1.21 to 0.91 ; and as sampling duration increased from 13 to 71 seconds at an ambient stream velocity of $5 \mathrm{ft} / \mathrm{s}$ and water temperatures of 23.9-29. $4^{\circ} \mathrm{C}$, intake efficiency decreased only from 0.99 to 0.92 . At the lower ambient stream velocity of $2 \mathrm{ft} / \mathrm{s}$, exclusion of the pressure-equalization hole in the top of the US D-96 nozzle holder resulted in a decrease in intake efficiency from 0.94 to 0.65 as sampling duration increased from 29 to 183 seconds; at the higher ambient stream velocity of $5 \mathrm{ft} / \mathrm{s}$, plugging of the sampler-cavity vent holes in the US D-96 sampler resulted in a decrease in intake efficiency from 0.99 to 0.64 as sampling duration increased from 14 to 84 seconds. 

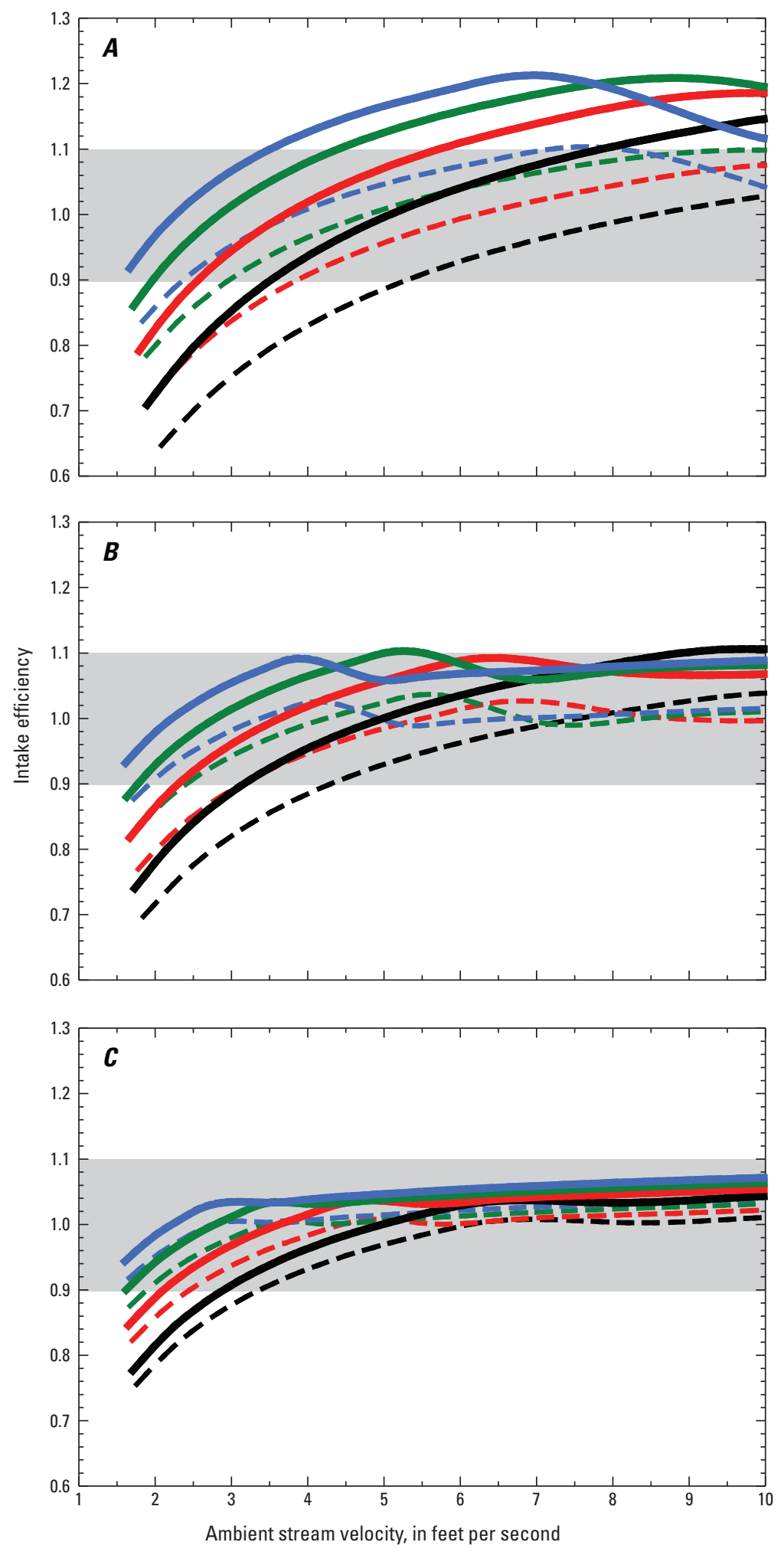

\section{EXPLANATION}

FISP 1.688-inch taper depth

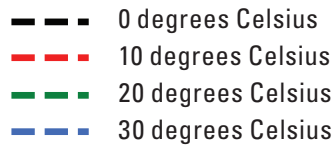

Model-determined 2.651-inch taper depth

0 degrees Celsius

10 degrees Celsius

20 degrees Celsius

30 degrees Celsius

\section{FISP 1.188-inch taper depth}

$\begin{array}{ll}-\boldsymbol{Z} & 0 \text { degrees Celsius } \\ -\boldsymbol{-}= & 10 \text { degrees Celsius } \\ -\boldsymbol{E}= & 20 \text { degrees Celsius } \\ \boldsymbol{E}= & 30 \text { degrees Celsius }\end{array}$

Model-determined 2.192-inch taper depth

0 degrees Celsius

10 degrees Celsius

20 degrees Celsius

30 degrees Celsius

FISP 0.875-inch taper depth

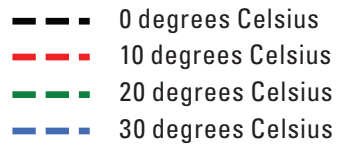

Model-determined 1.607-inch taper depth

0 degrees Celsius

10 degrees Celsius

20 degrees Celsius

30 degrees Celsius

Figure 18. Graphs showing comparisons of modeled intake efficiencies for the US D-96 sampler using different diameter nozzles with two different taper depths $(A-C)$. The two taper depths used in these comparisons are (1) the FISP-determined taper depth that resulted in isokinetic sampling in flume tests at $V=3.7 \mathrm{ft} / \mathrm{s}$ at water temperatures of $23.9-29.4^{\circ} \mathrm{C}$ and (2) a model-determined larger taper depth that results in isokinetic sampling at $V=3.7 \mathrm{ft} / \mathrm{s}$ at a water temperature of $10^{\circ} \mathrm{C}$. Intake efficiencies are plotted as a function of ambient stream velocity at water-temperature increments of $10^{\circ} \mathrm{C}$. Shaded area represents range in intake efficiency $(1.0 \pm 0.10)$ considered to be isokinetic. $(A)$ intake-efficiency comparison for a nozzle with a 3/16-inch entrance diameter; $(B)$ intake-efficiency comparison for a nozzle with a 1/4-inch entrance diameter; $(C)$ intake-efficiency comparison for a nozzle with a $5 / 16$-inch entrance diameter. 


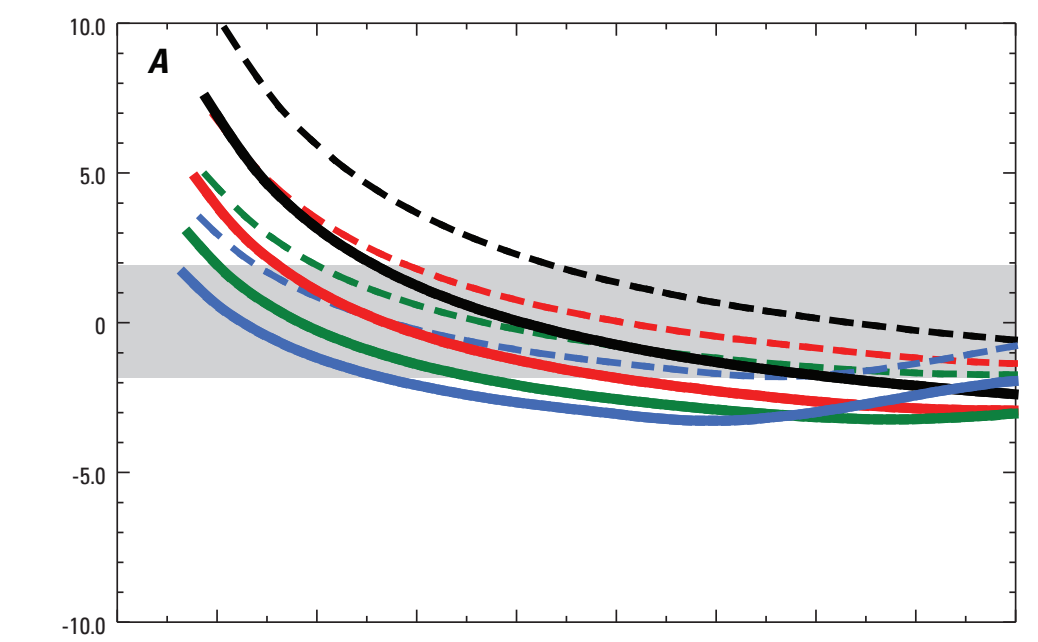

\author{
EXPLANATION \\ FISP 1.688-inch taper depth

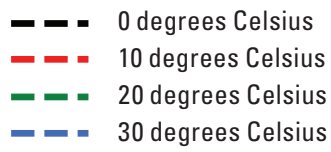

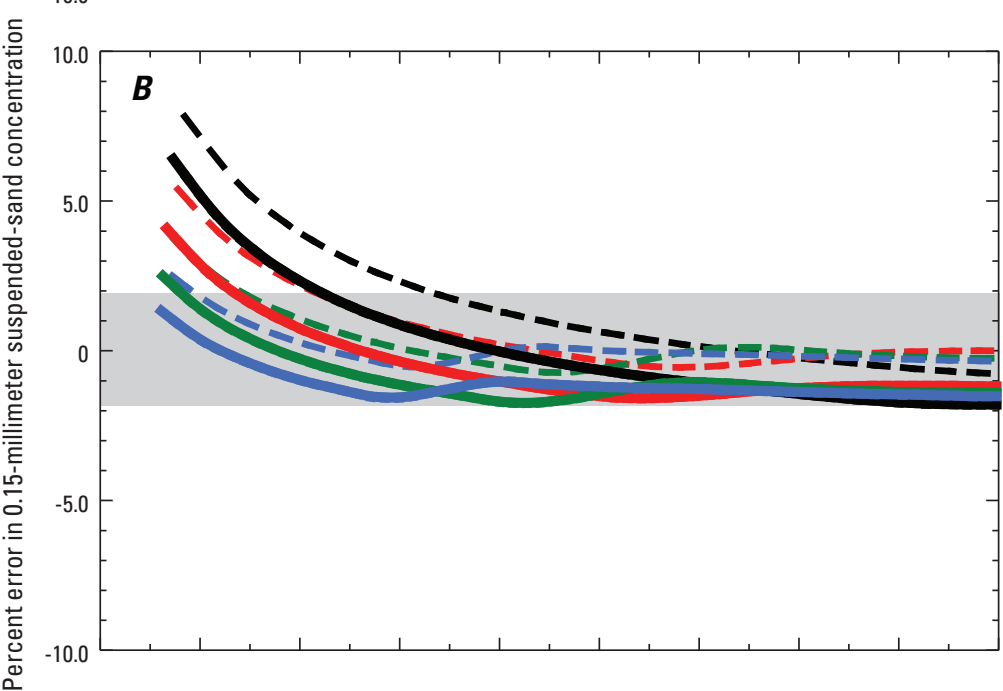

FISP 1.188-inch taper depth

- - 0 degrees Celsius

-20 degrees Celsius

- -20 degrees Celsius

- - 30 degrees Celsius

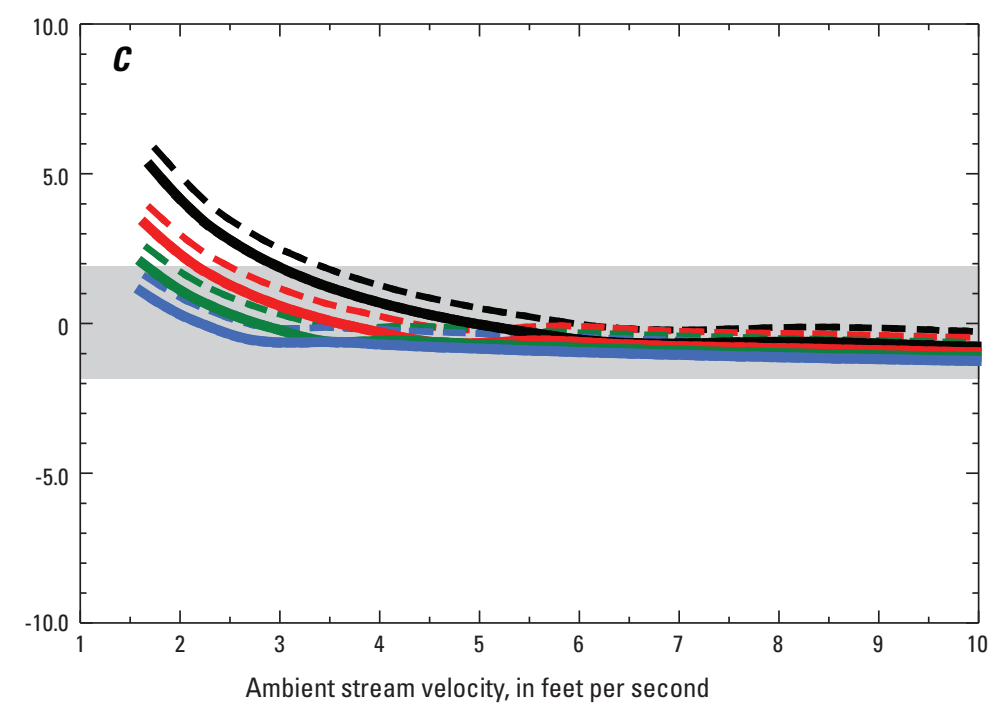

FISP 0.875-inch taper depth

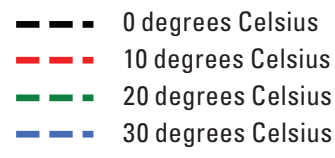

Model-determined 1.607-inch taper depth

0 degrees Celsius

10 degrees Celsius

20 degrees Celsius

30 degrees Celsius

Figure 19. Graphs showing comparisons of the predicted errors in 0.15-millimeter $(\mathrm{mm})$ suspended-sand concentration associated with the modeled intake efficiencies in figure 18 for the US D-96 sampler using nozzles with three different entrance diameters and two taper depths $(A-C)$. Errors are calculated on the basis of the laboratory data in figure 4 from FISP (1941a). Shaded area represents range in intake efficiency $(1.0 \pm 0.10)$ considered to be isokinetic. $(A)$ error comparison for a nozzle with a 3/16-inch entrance diameter; $(B)$ error comparison for a nozzle with a 1/4-inch entrance diameter; $(C)$ error comparison for a nozzle with a 5/16-inch entrance diameter. 


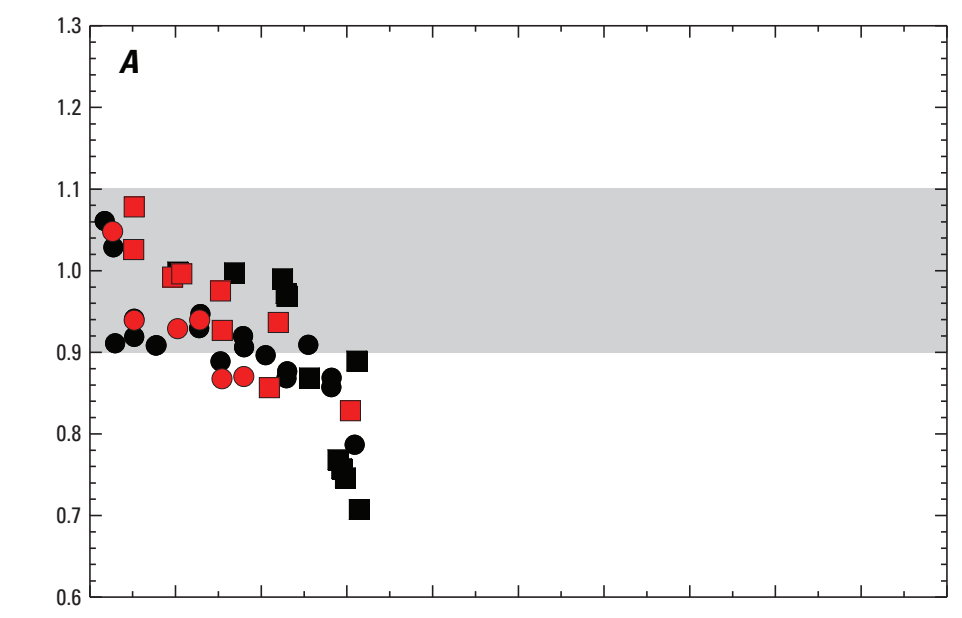

\section{EXPLANATION}

Vent-hole flow deflector present; velocity from 2.8 to 3.5 feet per second

- Vent-hole flow deflector present; velocity from 3.8 to 5.7 feet per second

- No vent-hole flow deflector; velocity from 2.8 to 3.5 feet per second

No vent-hole flow deflector; velocity from 3.8 to 5.7 feet per second

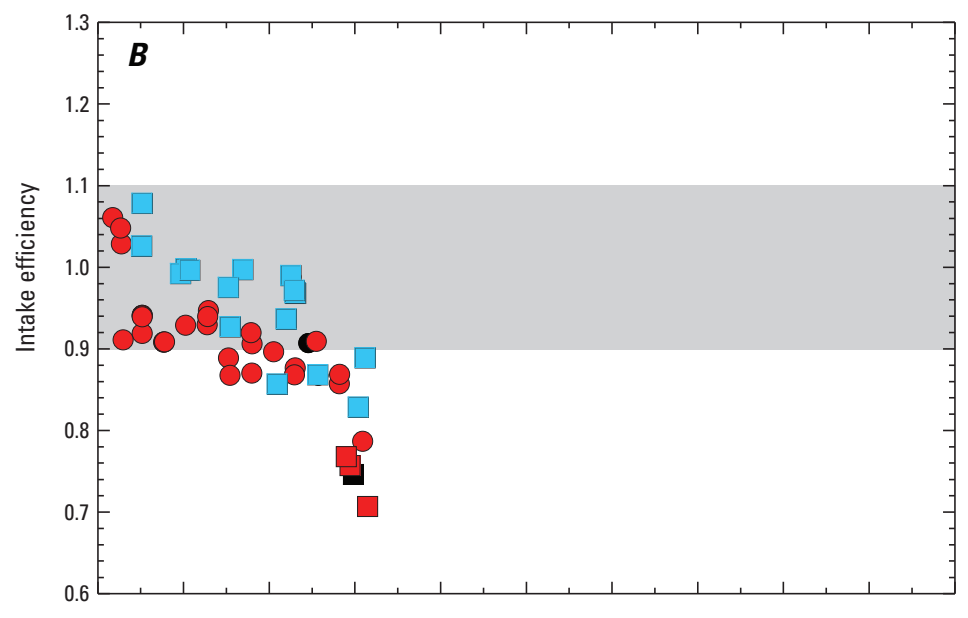

- Vent-hole flow deflector present; temperature less than $10^{\circ} \mathrm{Celsius}$

- Vent-hole flow deflector present; temperature from 10 to $20^{\circ} \mathrm{Celsius}$

- No vent-hole flow deflector; temperature less than $10^{\circ} \mathrm{Celsius}$

$\square \quad$ No vent-hole flow deflector; temperature from 10 to $20^{\circ} \mathrm{Celsius}$

No vent-hole flow deflector; temperature greater than $20^{\circ} \mathrm{Celsius}$

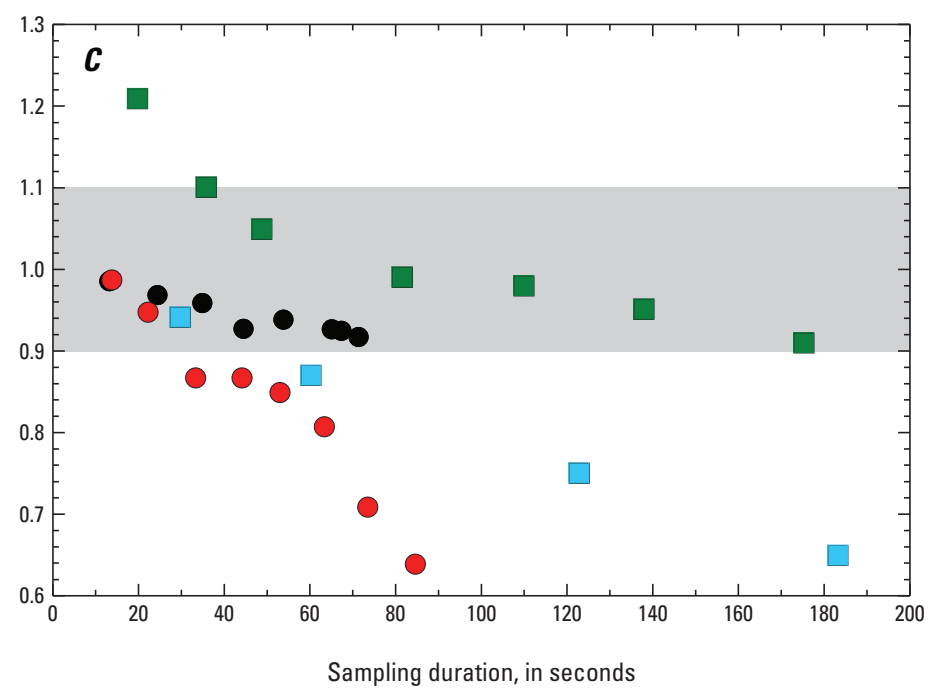

- Cavity vented; velocity equal to 5 feet per second

- Cavity not vented; velocity equal to 5 feet per second

- Pressure-equalization hole present; velocity equal to 2 feet per second

- No pressure-equalization hole; velocity equal to 2 feet per second

Figure 20. Plots showing effect of sampling duration on intake efficiency measured in flume tests of collapsible-bag samplers (after Szalona, 1982; Davis, 2001). Shaded area represents range in intake efficiency $(1.0 \pm 0.10)$ considered to be isokinetic. $(A)$ Intake efficiency plotted as a function of sampling duration for the US D-77 bag-type sampler segregated into two ranges of ambient stream velocity $(V)$ and with or without an upper vent-hole flow deflector. $(B)$ Intake efficiency plotted as a function of sampling duration for the US D-77 bag-type sampler segregated into three ranges of water temperature and with or without an upper vent-hole flow deflector. $(C)$ Intake efficiency plotted as a function of sampling duration for the US D-96 sampler for two ranges in $V$; shown for the high- $V$ case are results with and without the three sampler-cavity vent holes included in the final sampler design; shown for the low- $V$ case are results with the sampler cavity vent holes but with and without the pressure-equalization hole in the nozzle holder. 
Therefore, both (1) the ability of the air trapped in the sampler nozzle upon submergence to be able to escape through the pressure-equalization hole and (2) the ability of water to be able to be displaced from the flooded sampler cavity through the vent holes at the rate at which water enters the bag through the nozzle are crucial to reducing the rate at which the intake efficiency of a US D-96 sampler decreases over time. Results from this analysis of Davis' (2001) data are plotted in figure $20 C$.

Analysis of the time-dependent behavior of the intake efficiency of the US D-77 bag-type and US D-96-type samplers transiting verticals in the Colorado River indicates that in both samplers, after sampling for about 20-30 seconds and after about 0.5 to 1 liter of sample has been collected, intake efficiency decreases much more rapidly with increasing sampling duration in the river than in the stationary flume experiments of Szalona (1982) and Davis (2001). These Colorado River observations were made over a range in water temperature from 7 to $17^{\circ} \mathrm{C}$ with no apparent dependence on water temperature within this range. Figures 21 and 22 show the time-dependent decrease in intake efficiency in both samplers binned by ambient stream velocity at all six cross-sections at all three study sites. As indicated by the presence of regression lines significant at the 0.05 critical level in these figures, the relations between sampling duration and intake efficiency are significant over most ranges in ambient stream velocity for both the US D-77 bag-type and US D-96-type samplers using both 1/4- and 5/16-inch nozzles. As shown in figure 22, the intake efficiency of the US D-96-type sampler can be within the FISP-accepted range of $1 \pm 0.10$ when the sampling duration is less than about 30 seconds. However, as shown in figure 21, although the intake efficiency of the US D-77 bag-type sampler is greatest at sampling durations less than about 30 seconds, it is typically still $<<1$. In both sampler designs, as sampling duration increases and the filling bag occupies progressively more of the volume of the sampler cavity, it apparently becomes more difficult for the filling bag to displace the remaining water in the sampler cavity and purge it through the vent holes at the rate required for isokinetic sampling. As discussed previously, the likely causes of this problem in both sampler designs are the increased importance of wall friction on the water in the sampler cavity being displaced by the filling bag and the potential of the filling bag to block one or more vent holes. With respect to the design of the US D-77 bag-type sampler and unlike in the design of the US D-96-type sampler, it is important to note that there are no vent holes located on the rear of the US D-77 bag-type sampler; thus, the absence of rear vent holes could help explain the much lower intake efficiencies of the US D-77 bag-type sampler. It is important to note that Davis $(2001,2005 \mathrm{a})$ did not observe such substantial decreases in intake efficiency when sampling durations greatly exceeded 30 seconds in the towed-transit tests in the lake of the US D-96 or DH-2 samplers. Furthermore, Davis (2001) did not observe major decreases in intake efficiency in most of his 22 transit tests of the US D-96 sampler in the Mississippi River, although he did not report sampling duration for these river tests.

On the basis of the measurements plotted in figure 22, the temperature-corrected US D-96-type data in figure 17 were filtered to remove all data collected with sampling durations exceeding 30 seconds. These data were then re-plotted in figure 23 as a function of ambient stream velocity. After application of the temperature correction to make our colder-water US D-96-type data consistent with the warmer-water data of Davis (2001) and after removing all data with sampling durations in excess of 30 seconds, the average intake efficiency of the US D-96-type sampler in our river tests is 0.93 , a value well within the FISP-accepted range for isokinetic sampling. Therefore, it seems reasonable to conclude that a combination of differences in water temperature and sampler venting could explain the observed differences in the intake efficiency of the US D-96-type sampler between the Colorado River and Mississippi River tests.

To determine if progressive blocking of sampler-cavity vent holes (from front to back) was a cause of the large time-dependent reductions in intake efficiency observed with the US D-96-type sampler in the Colorado River, a set of experiments were conducted using a US D-96-A1 sampler submerged in a tank. As water was pumped into the nozzle of the submerged sampler, observations showed that as the bag fills with water through the nozzle, the bag fills mostly from front to back within the sampler cavity and not from bottom to top. As the bag initially begins to fill, the water displaced by the expanding bag in the sampler cavity can exit the sampler cavity through any of the three vent holes. However, as the bag continues to fill with the water (with volumes of water in the bag exceeding $\sim 0.5$ to 1 liter), the front two holes become partially blocked and water displaced by the expanding bag from the sampler cavity must exit the sampler cavity largely through the bottom rear vent hole. Further examination of the bottom rear vent hole revealed that in all of the US D-96-type samplers used in this study, the clear molded plastic sampler tray (on which the bag rests) extends all of the way to the back of the sampler cavity, partially blocking the bottom rear vent hole. Thus, tests were conducted to evaluate whether shortening the tray and thereby increasing the effective area of the rear vent hole could improve the intake efficiency of US D-96-type samplers in the Colorado River. 


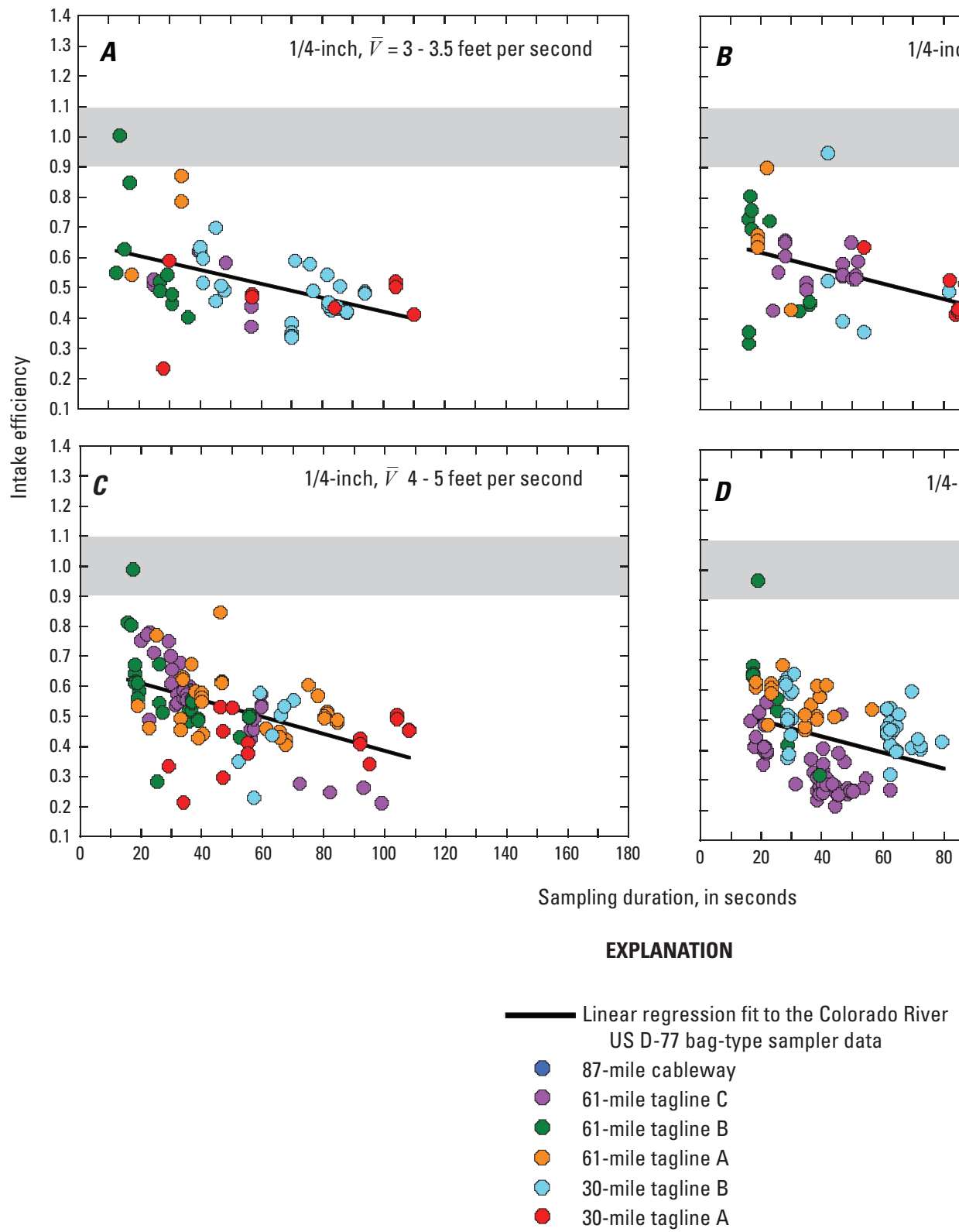

Figure 21. Plots showing velocity-binned intake efficiency plotted as a function of sampling duration for the US D-77 bag-type sampler using $1 / 4$-inch nozzles $(A-F)$ and using a $5 / 16$-inch nozzles $(G-K)$ at all six cross-sections at all three study sites. Nozzle entrance diameter and range in time- and depth-averaged ambient stream velocity, $\bar{V}$, are indicated on each plot. Linear regressions fit to the data in each velocity bin (black lines) are shown when these regressions are significant at the 0.05 critical level, thus indicating significant time-dependent decrease in intake efficiency. Gray shaded regions indicate 1.0 \pm 0.1 Federal Interagency Sedimentation Project (FISP) accepted range of isokinetic sampling. 

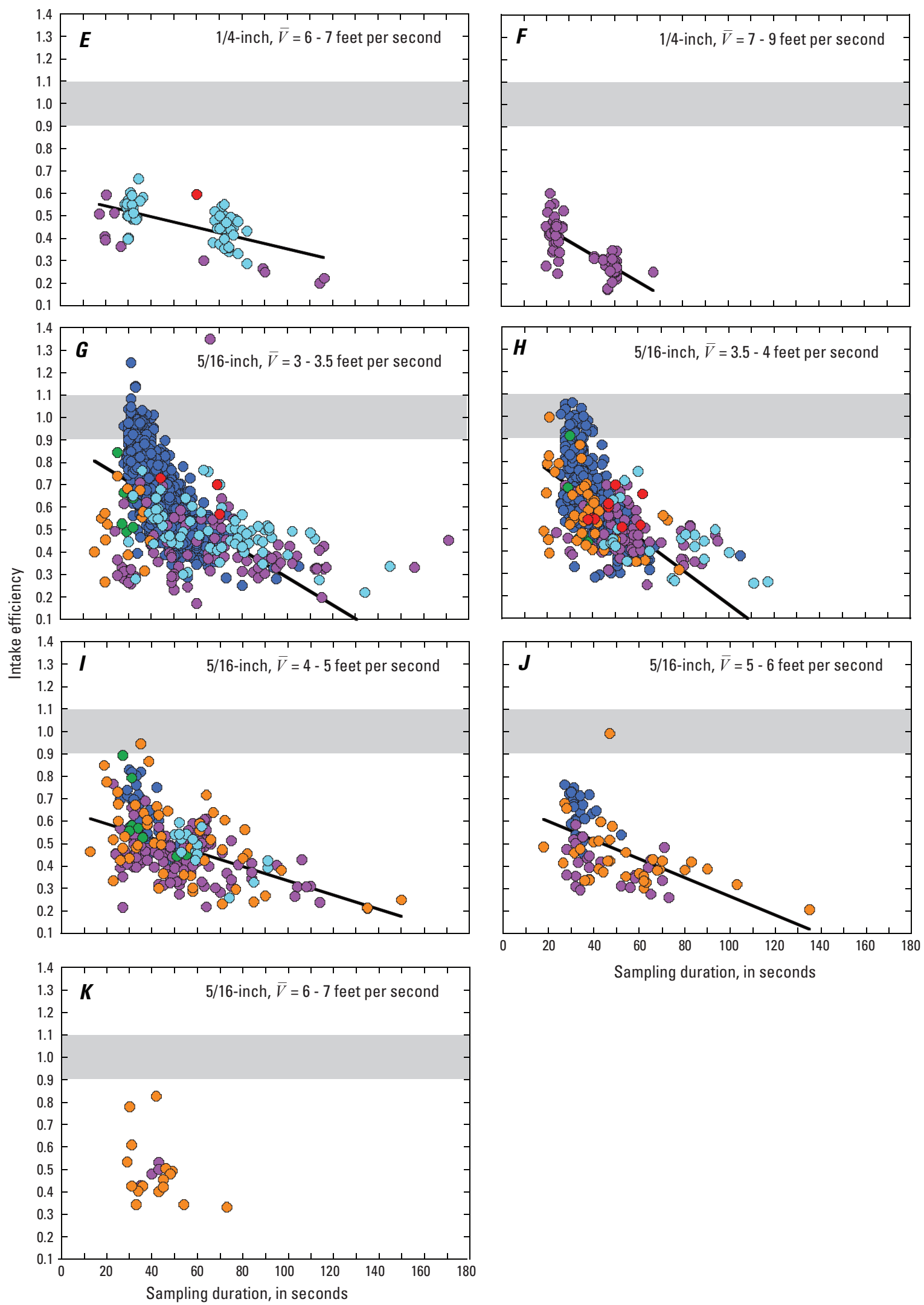

Figure 21.-Continued 

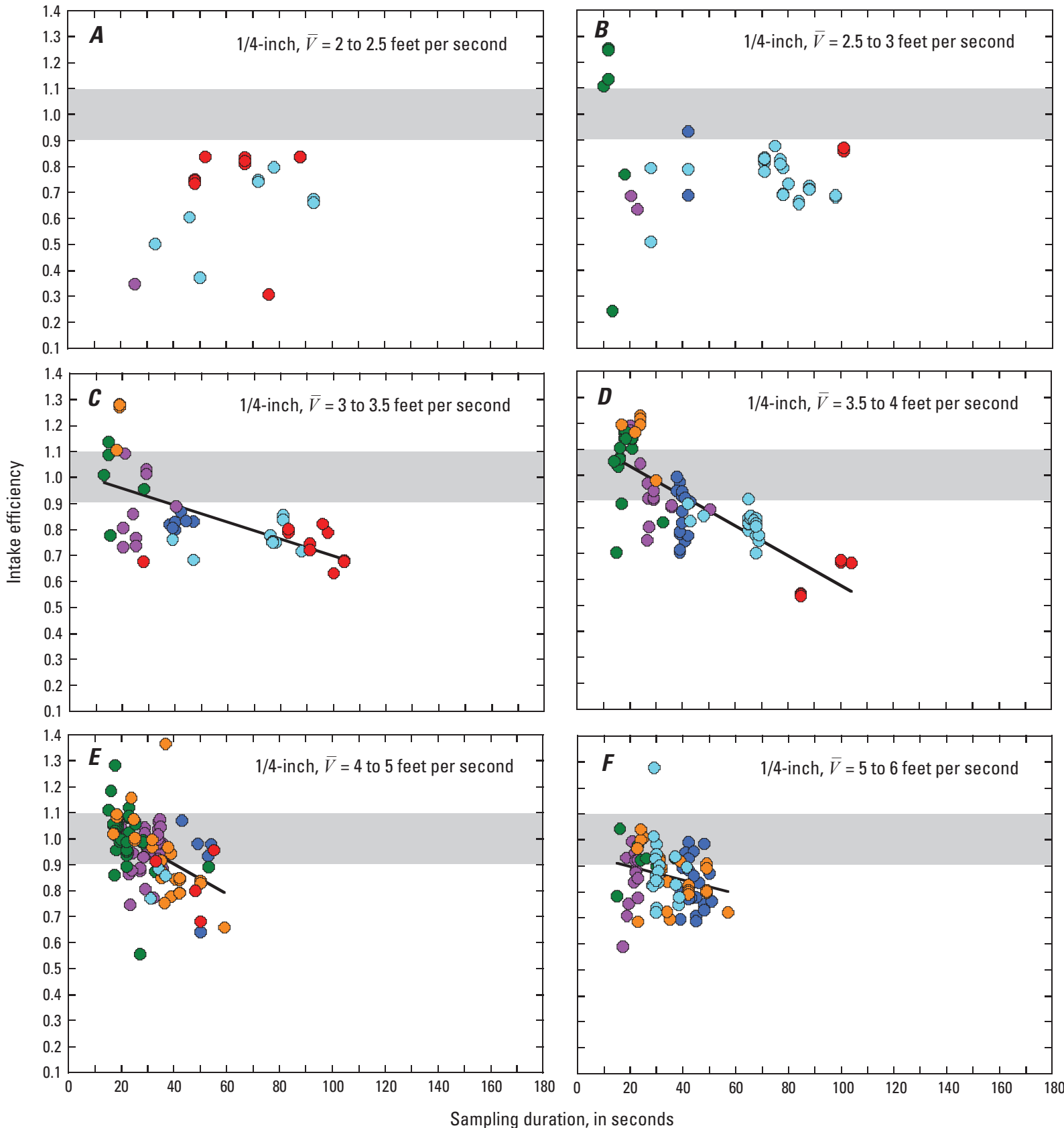

EXPLANATION

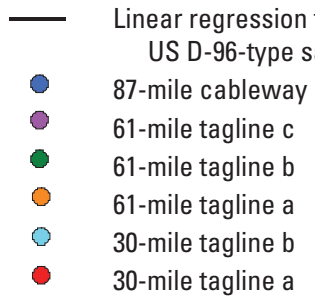

Figure 22. Plots showing velocity-binned intake efficiency plotted as a function of sampling duration for the US D-96-type sampler using $1 / 4$-inch nozzles $(A-H)$ and using $5 / 16$-inch nozzles $(I-P)$ at all six cross-sections at all three study sites. Nozzle entrance diameter and range in time- and depth-averaged ambient stream velocity, $\bar{V}$, are indicated on each plot. Linear regressions fit to the data in each velocity bin (black lines) are shown when these regressions are significant at the 0.05 critical level, thus indicating significant timedependent decrease in intake efficiency. Shaded area represents range in intake efficiency $(1.0 \pm 0.10)$ considered to be isokinetic. 

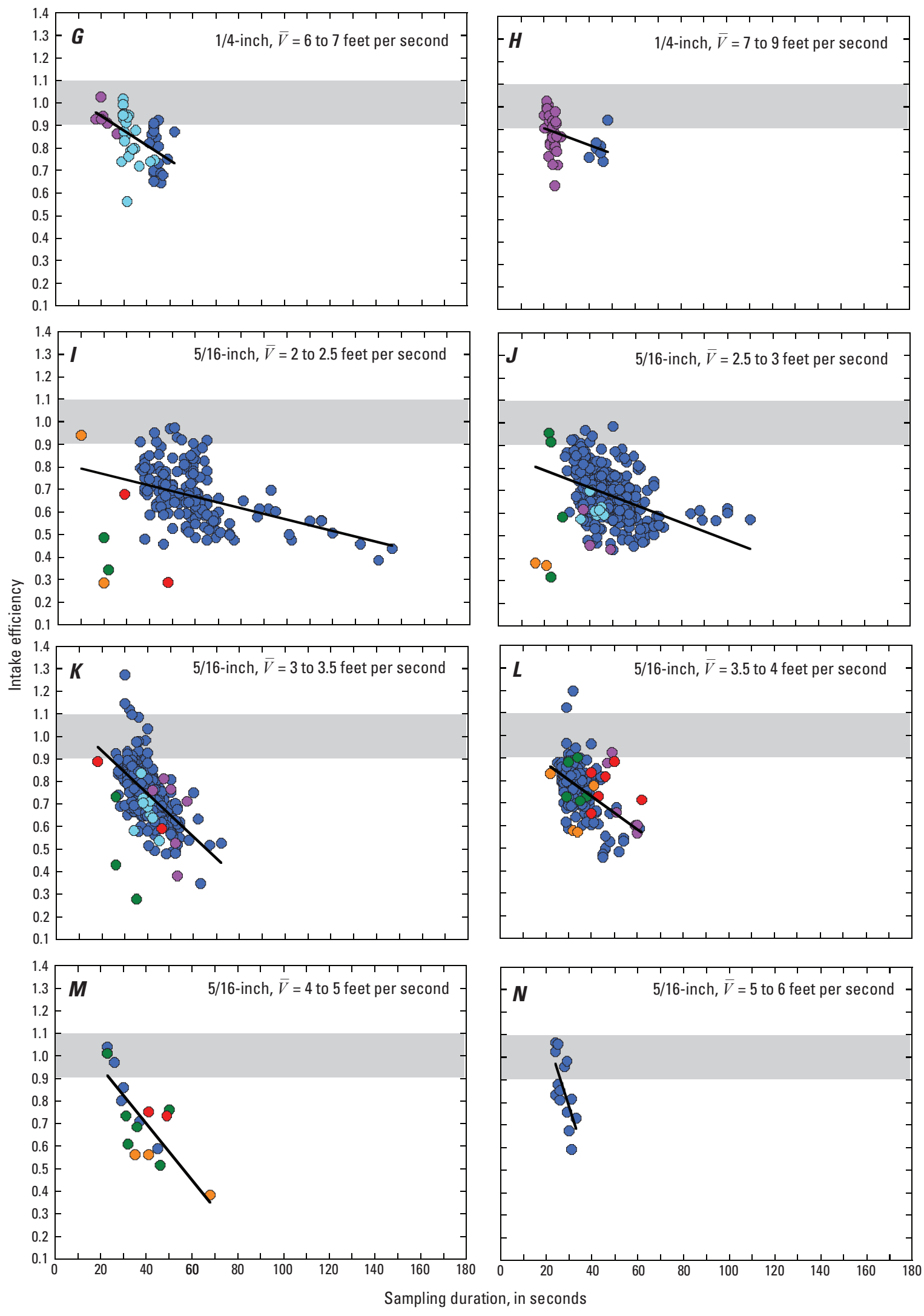

Figure 22.-Continued 


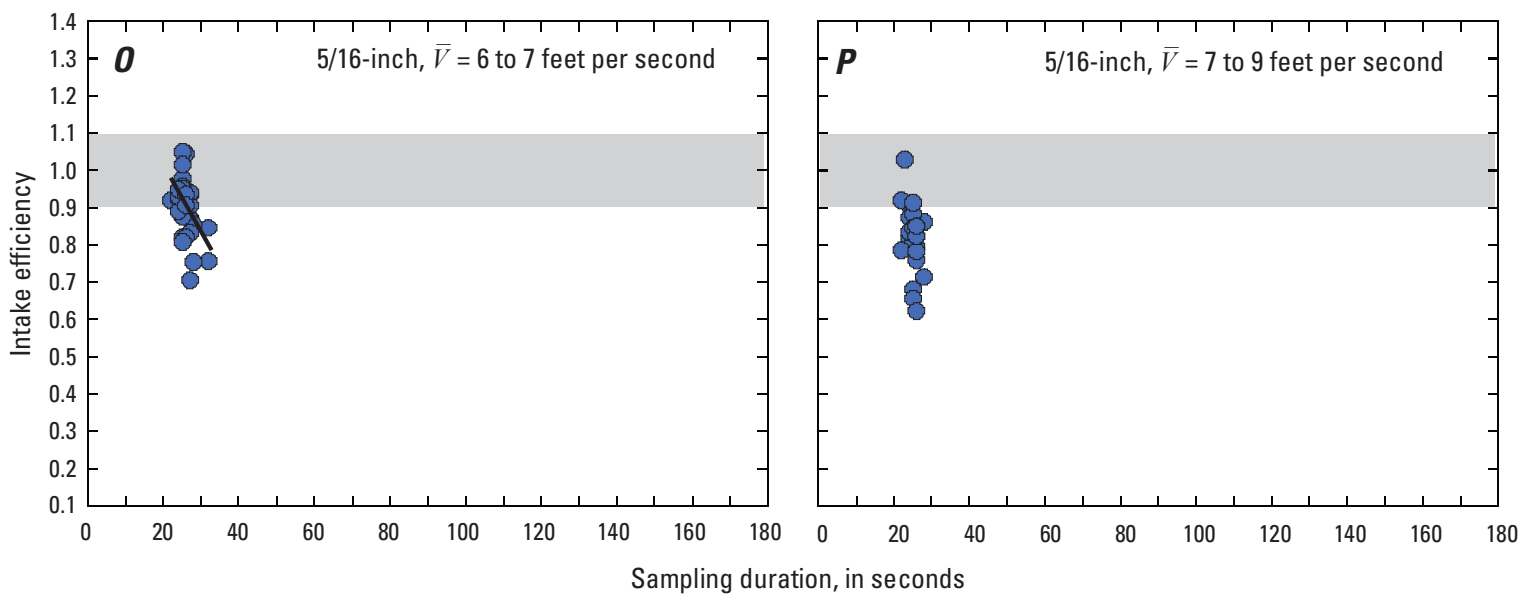

Figure 22.-Continued
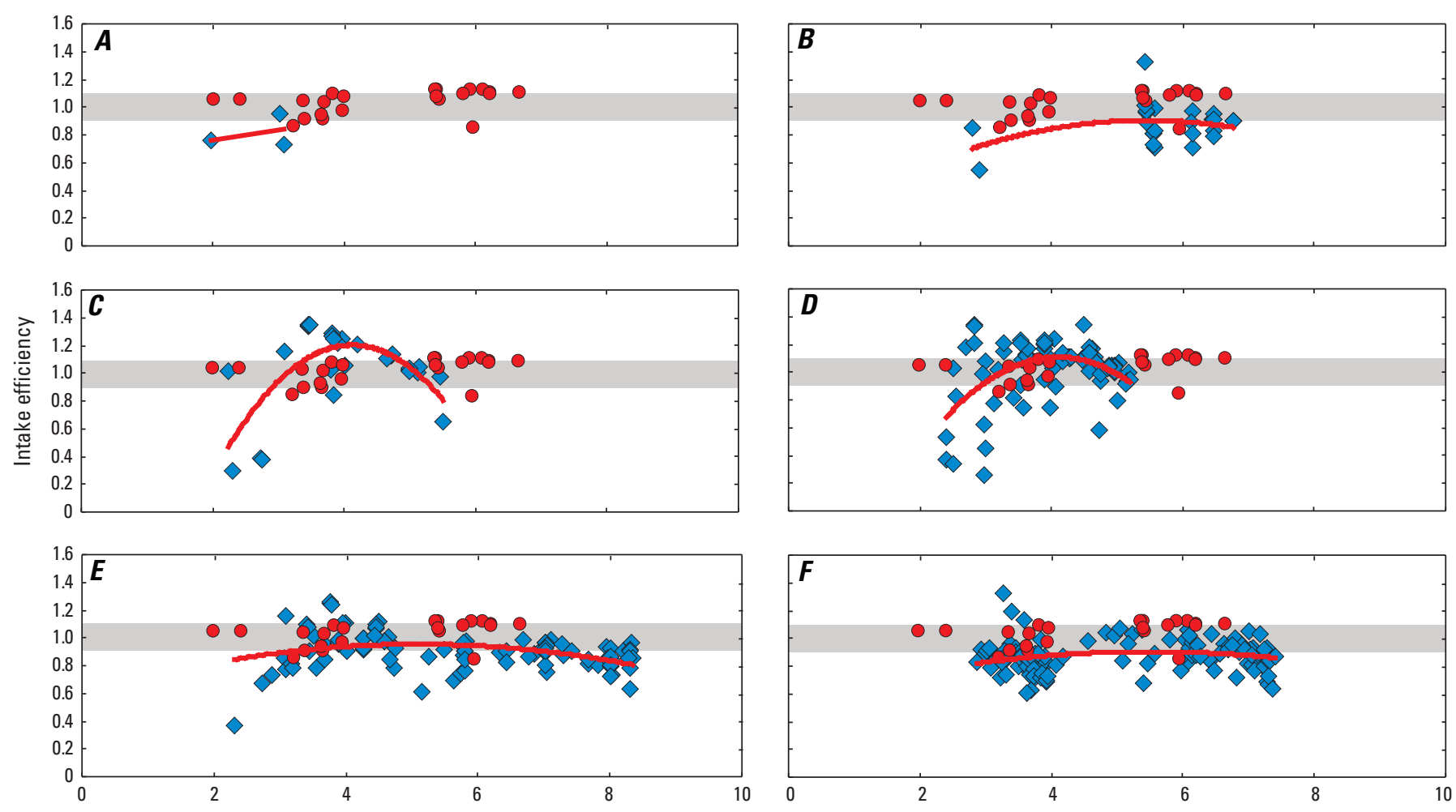

Ambient stream velocity, in feet per second

\section{EXPLANATION}

$\checkmark \quad$ US D-96-type sampler deployed on the Colorado River during this study, temperature corrected

- US D-96-type sampler field test on the Mississippi River

- $\quad 2^{\text {nd }}$ polynominal regression fit to the Colorado River US D-96-type sampler data, temperature corrected

Figure 23. Plots showing comparison of US D-96 intake efficiencies in river tests on the Mississippi River near Vicksburg, Mississippi (from Davis, 2001), with the temperature-corrected US D-96 intake efficiencies in the Colorado River for sampling durations of $\leq 30$ seconds at $(A)$ 30-mile tagline $A,(B)$ 30-mile tagline $B,(C)$ 61-mile tagline $A,(D)$ 61-mile tagline $B,(E)$ 61-mile tagline $C$, and $(F)$ 87-mile cableway. All plotted data were collected within the operating range of the US D-96-type sampler. Shaded area represents range in intake efficiency $(1.0 \pm 0.10)$ considered to be isokinetic. 
Comparison of the US D-96-type sampler trays used in the Colorado River with the sampler tray from the likely FISP prototype US D-96 sampler photographed in figures 12, 14, and 15 in FISP ([n.d.]c) suggests that the sampler trays used in this study are $\sim 4 \mathrm{~cm}$ longer than the sampler tray likely used by Davis (2001) in his tests of the US D-96 sampler. Thus, it is possible that the reason Davis (2001) did not observe substantial decreases in intake efficiency when sampling durations greatly exceeded 30 seconds is that the bottom rear vent hole in his US D-96 sampler was not obstructed, whereas it was in all three of the US D-96-type samplers purchased from the FISP by the USGS-GCMRC and used in this study, beginning in 2002. In support of this likelihood, the one set of experiments that Davis (2001) conducted showing time-dependent decreases in intake efficiency as large and rapid as those observed in the tests in this study was the series of tests conducted on a US D-96 sampler without any sampler-cavity vent holes, at an ambient stream velocity of $5 \mathrm{ft} / \mathrm{s}$ and with a 1/4-inch nozzle (fig. 20C). These "cavity not vented" data plotted in figure $20 \mathrm{C}$ closely track with the data collected in the Colorado River using a D-96-type sampler with a 1/4-inch nozzle at ambient stream velocities of $4-5 \mathrm{ft} / \mathrm{s}$ depicted in figure $22 E$.

In summary, intake efficiencies of collapsible-bag samplers with two very different designs, the US D-77 bag-type and the US D-96-type samplers, decrease much more quickly when these samplers are transiting verticals in the Colorado River than (1) when these samplers are held stationary in a flume, (2) when these samplers are towed (either stationary or transiting) behind a boat in a lake under nonturbulent, nonshear-flow ${ }^{15}$ conditions, or (3) likely when these samplers transit verticals in a relatively deep river (in this case, the lower Mississippi River). With respect to the US D-96-type sampler, the two possible explanations for this difference in sampling behavior are (1) a key difference between the physical environment in the Colorado River and in the laboratory and field tests conducted by Davis (2001), or (2) a difference in the design of the prototype US D-96 sampler tested by Davis (2001) and the design of the US D-96-type samplers purchased by the USGS-GCMRC from FISP beginning in 2002.

The only major differences between the Colorado River study sites in this paper and the Mississippi River study site in Davis (2001) are the shallower water depths and higher velocity gradients that are present in the Colorado River. Even though the range in sampled ambient stream velocity in the Colorado and Mississippi Rivers is virtually identical and the locations of verticals sampled in both rivers are typically sand bedded with dunes (and, as a result, have similar bed roughness), the water depths are very different in these two rivers. The depths of the sampled verticals in the Colorado River range from $\sim 5$ to $\sim 30$ feet, whereas the depths of Davis' (2001) sampled verticals in the Mississippi River range from $\sim 30$ to $\sim 70$ feet. Therefore, because only the depths differ between the two rivers (that is, ambient stream velocities and bed roughness are similar), the gradient in the velocity profiles in the Colorado River is likely much greater than the gradient in the velocity profiles in the Mississippi River. As a result of this steeper velocity gradient, the Colorado River in Grand Canyon is subject to much greater shear and turbulence. Thus, it is fair to conclude that the Mississippi River is much more similar to a flume or towing tank than the Colorado River, which can also have a very irregular shoreline. This greater gradient in velocity will, by Bournoulli-principlebased shear-lift effects (for example, Rouse, 1946; Wiberg and Smith, 1985; Auton and others, 1988; Schmeeckle and others, 2007), result in a greater differential in the dynamic pressures between the bottom and top vent holes of the US D-96-type sampler in the Colorado River than in the Mississippi River. Although this effect is predicted to be small, it could possibly make it relatively more difficult for water to exit a flooded sampler cavity through the lower vent holes in shallower rivers than in deeper rivers with comparable ambient stream velocities. Because the above effect is predicted to be small, however, the more likely explanation, discussed in subsequent sections, seems to be that the longer sampler trays in the US D-96-type samplers used in this study made it more difficult for water to exit the sampler cavity through the bottom rear vent hole than did the likely shorter tray in the prototype US D-96 sampler used by Davis (2001). In theory, shortening the sampler tray in a US D-96-type sampler could better allow water to exit the flooded sampler cavity through the bottom rear vent hole and therefore result in higher intake efficiencies at longer sampling durations. Additionally, increasing the number and area of the sampler-cavity vent holes could make it less difficult for the water in the cavity, trapped between the sampler cavity walls and the actively filling collapsible-bag container, to exit the sampler cavity at the rate required for isokinetic sampling.

\footnotetext{
${ }^{15}$ All flows in rivers and flumes are turbulent "shear flows," whereas some of the "flows" in which depth-integrating samplers have been tested have zero shear and no turbulence, specifically the tests in which depth-integrating samplers are towed behind boats in lakes (Davis, 2001, 2005a; McGregor, 2006). In shear flows, that is, any boundary-layer flow with a nonzero gradient in the velocity parallel to the boundary, the dynamic pressure will be different between the bottom and top of a depth-integrating sampler because the velocity at the top of the sampler body is slightly higher than the velocity at the bottom of the sampler body.
} 
Therefore, (1) until the large time-dependent decrease in intake efficiency in the US D-96-type samplers is reduced (as informed by future research, perhaps by shortening the sampler tray or increasing the number of vent holes) and (2) because both the US D-96-type and the phased-out US D-77 bag-type samplers show evidence of similar and substantial time-dependent decreases in intake efficiencies when deployed for sampling durations of more than $\sim 30$ seconds under actual-river conditions, users should be aware of equipment limitations. We recommend that sampling durations be kept as short as possible and isokinetic sampling be confirmed by independent velocity measurements when any collapsible-bag sampler is used in a river (as recommended previously by Pickering, 1983; Webb and Radtke, 1998; Yorke and Ward, 1998; Sorenson, 2002), especially when velocity gradients are relatively large and when the accuracy of suspended-sand data is important. In addition, if the situation permits, we recommend that rigid-container depth-integrating samplers be used instead of collapsible-bag depth-integrating samplers because rigid-container samplers do not have time-dependent intake efficiencies when these samplers are used within their operational limits. When the purpose of a data-collection program is to measure either suspended-siltand-clay concentrations or dissolved constituents that are less affected by non-isokinetic sampling, it may not matter as much if the intake efficiency decreases rapidly over time, and therefore this independent check may not be needed.

\section{Likely Biases in Suspended-Sediment Concentration in EDI and EWI Measurements Arising from Observed Field Intake Efficiencies}

The above-evaluated field intake efficiencies at the six cross-sections can be combined with the results from FISP laboratory experiments (fig. 4; FISP, 1941a) to estimate the likely biases in velocity-weighted suspended-sediment concentrations, in three size classes, when full EDI or EWI measurements are made using either the US D-77 bag-type or US D-96-type sampler. These bias estimations were made on the basis of a two-step process. First, composite field intake efficiency was computed for each EDI or EWI measurement by weighting the field intake efficiency at each vertical (fig. 8) by the proportion of the total volume of sample in the EDI or EWI measurement collected at that vertical. Second, these composite field intake efficiencies were combined with the FISP experimental results in figure 4 to estimate how these intake efficiencies correspond to biases in the measured velocity-weighted concentration of suspended sediment in a cross-section, in three size classes (table 2). As shown in table 2, because of the US D-77 bag-type sampler's inferior isokinetic behavior $(\mathrm{IE}<<1)$, the predicted likely biases in 0.15 -mm suspended-sand concentration associated with the US D-77 bag-type sampler are on average much larger and cover a much broader range than those associated with the US D-96-type sampler.

Table 2. Composite field intake efficiencies and associated predicted likely biases in suspended-sediment concentration in three size classes.

[Study site and cross-section: RM30A, tagline cross-section A at the 30-mile study site; RM30B, tagline cross-section B at the 30-mile study site; RM61A, tagline cross-section A at the 61-mile study site; RM61B, tagline cross-section B at the 61-mile study site; RM61C, tagline cross-section C at the 61-mile study site; RM87, cableway cross-section at the 87-mile study site; $\mu$, mean; $\sigma, 1$ standard deviation; $n$, number of EWI or EDI measurements. Sampler type: "D-77 bag" indicates US D-77 bag-type sampler; "D-96-A1" indicates US D-96-A1 sampler; "D-96-type" indicates both US D-96 and US D-96-A1 samplers used. The EWI method was used for all measurements at the 30-mile and 61-mile study sites and the EDI method was used for all measurements at the 87-mile study site. Abbreviations: EDI, equal-discharge instrument; EWI, equal-width instrument; IE, intake efficiency; mm, millimeter]

\begin{tabular}{|c|c|c|c|c|c|c|c|c|c|c|c|c|c|}
\hline \multirow{2}{*}{$\begin{array}{l}\text { Study } \\
\text { site } \\
\text { and cross- } \\
\text { section }\end{array}$} & \multirow{2}{*}{$\begin{array}{l}\text { Sampler } \\
\text { type }\end{array}$} & \multicolumn{3}{|c|}{$\begin{array}{l}\text { Composite field intake } \\
\text { efficiency (IE) }\end{array}$} & \multicolumn{3}{|c|}{$\begin{array}{l}\text { Percent error in } 0.06-\mathrm{mm}- \\
\text { sediment concentration } \\
\text { corresponding to }\end{array}$} & \multicolumn{3}{|c|}{$\begin{array}{l}\text { Percent error in } 0.15-\mathrm{mm} \text { - } \\
\text { sediment concentration } \\
\text { corresponding to }\end{array}$} & \multicolumn{3}{|c|}{$\begin{array}{l}\text { Percent error in } 0.45-\mathrm{mm}- \\
\text { sediment concentration } \\
\text { corresponding to }\end{array}$} \\
\hline & & $\begin{array}{c}\text { Mean } \\
(\mu)\end{array}$ & $\sigma$ & $n$ & $\begin{array}{l}\mu \\
\text { IE }\end{array}$ & $\begin{array}{l}\mu-1 \sigma \\
\text { IE }\end{array}$ & $\begin{array}{c}\mu+1 \sigma \\
\text { IE }\end{array}$ & $\begin{array}{l}\mu \\
\text { IE }\end{array}$ & $\begin{array}{c}\mu-1 \sigma \\
\text { IE }\end{array}$ & $\begin{array}{c}\mu+1 \sigma \\
\text { IE }\end{array}$ & $\begin{array}{l}\mu \\
\text { IE }\end{array}$ & $\begin{array}{c}\mu-1 \sigma \\
\text { IE }\end{array}$ & $\begin{array}{c}\mu+1 \sigma \\
\text { IE }\end{array}$ \\
\hline RM30A & D-77 bag & 0.56 & 0.08 & 19 & +3 & +4 & +2 & +16 & +22 & +12 & +23 & +31 & +16 \\
\hline RM30A & D-96-A1 & 0.80 & 0.11 & 20 & +1 & +2 & 0 & +5 & +9 & +2 & +7 & +13 & +2 \\
\hline RM30B & D-77 bag & 0.50 & 0.09 & 193 & +4 & +5 & +3 & +21 & +29 & +15 & +29 & +43 & +20 \\
\hline RM30B & D-96-A1 & 0.74 & 0.10 & 56 & +2 & +2 & +1 & +7 & +12 & +4 & +10 & +16 & +5 \\
\hline RM61A & D-77 bag & 0.55 & 0.12 & 110 & +3 & +4 & +2 & +17 & +27 & +10 & +23 & +39 & +14 \\
\hline RM61A & D-96-A1 & 0.85 & 0.11 & 16 & 0 & +2 & 0 & +4 & +7 & +1 & +5 & +10 & 0 \\
\hline RM61B & D-77 bag & 0.60 & 0.09 & 18 & +3 & +4 & +2 & +14 & +20 & +9 & +19 & +28 & +13 \\
\hline RM61B & D-96-A1 & 0.89 & 0.13 & 17 & 0 & +2 & 0 & +3 & +7 & -2 & +3 & +9 & -2 \\
\hline RM61C & D-77 bag & 0.44 & 0.12 & 278 & +4 & +6 & +3 & +26 & +42 & +16 & +38 & +68 & +23 \\
\hline RM61C & D-96-A1 & 0.82 & 0.10 & 57 & +1 & +2 & 0 & +4 & +8 & +2 & +6 & +12 & +2 \\
\hline RM87 & D-77 bag & 0.64 & 0.16 & 1,027 & +2 & +4 & +1 & +12 & +23 & +5 & +16 & +33 & +7 \\
\hline RM87 & D-96 type & 0.75 & 0.11 & 247 & +2 & +3 & 0 & +7 & +13 & +3 & +9 & +18 & +4 \\
\hline
\end{tabular}


The intake efficiencies of each sampler model vary among different cross-sections (table 2), as a function of the different deployment depths, velocities, and the possibly different levels of turbulence encountered. These differences in intake efficiencies between different sampler models at different cross-sections may result in substantial relative biases in measured suspended-sand concentrations when different sampler models are used to sample the same cross-section or possibly even when the same sampler model is used to sample different cross-sections. Therefore, to avoid introduction of biases when (1) changing between different models of suspended-sediment samplers at the same cross-section or (2) changing the cross-section at which data are collected with the same model of suspended-sediment sampler, intake efficiencies should be evaluated at each river cross-section where collapsible-bag-type suspended-sediment samplers are used.

\section{Relative Biases in Suspended-Sediment Concentration Arising from Use of the US D-77 Bag-Type Sampler}

Intake efficiencies in both the US D-96-type and the US D-77 bag type sampler models were typically $<1$ in our field tests. However, because intake efficiencies were much closer to isokinetic in the US D-96-type sampler, there should be a measurable bias in the suspended-sand data collected using the US D-77 bag-type sampler relative to that collected using the US D-96-type sampler. To investigate this likely bias, we collected a total of 160-paired US D-96-A1 and US D-77 bag-type suspended-sediment samples, from all six cross-sections under a wide range of flow and sediment conditions. These paired samples allowed us to evaluate the size-class by size-class biases in suspended-sediment concentrations measured using the US D-77 bagtype samplers relative to those measured using the US D-96-type samplers. Each paired sample consists of either sequential EWI cross-section data from the 30-mile and 61-mile study sites or sequential EDI cross-section data from the Grand Canyon gaging station. At each study site, data collected using both the 1/4-inch and 5/16inch nozzles were combined to construct crosssection specific curves of the relative intake

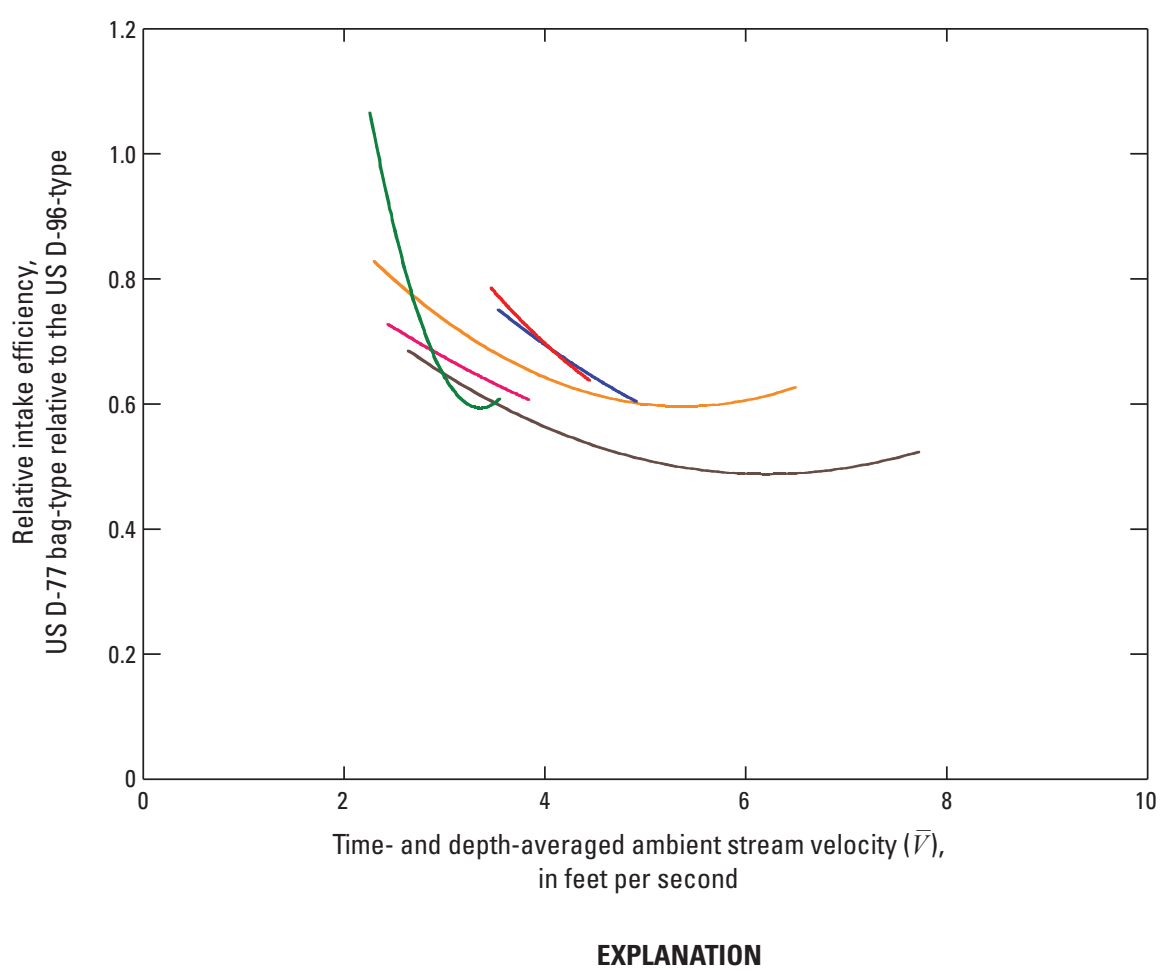

- 30-mile tagline $A$, curve is best fit $2^{\text {nd }}$ order polynominal regression
30-mile tagline $B$, curve is best fit $2^{\text {nd }}$ order polynominal regression
- 61 -mile tagline $A$, curve is best fit $2^{\text {nd }}$ order polynominal regression
61-mile tagline $B$, curve is best fit $2^{\text {nd }}$ order polynominal regression
61-mile tagline $C$, curve is best fit $2^{\text {nd }}$ order polynominal regression
87-mile cableway, curve is best fit $2^{\text {nd }}$ order polynominal regression

Figure 24. Plot of relative intake efficiencies between US D-77 bag-type and US D-96-type depth-integrating suspended-sediment samplers deployed at all cross-sections at all study sites.

efficiency between these two sampler models. Relative intake efficiencies were calculated by dividing the field intake efficiencies of the US D-77 bagtype sampler by those of the US D-96-type sampler over the full range of flow conditions in which the paired samples were collected (fig. 24).

The relative intake efficiencies plotted in figure 24 allow the results from laboratory experiments in FISP (1941a) to be used to estimate the likely bias in the suspended-sediment concentration measured using the US D-77 bag-type sampler relative to the suspended-sediment concentration measured using the US D-96-type sampler, for the three size classes of sediment in table $2(0.06,0.15$, and $0.45 \mathrm{~mm})$. Among all paired suspendedsediment samples, with the exception of some low velocity data at the 87-mile cableway, observed intake efficiencies for the US D-77 bag-type sampler are much lower than those for the US D-96-type sampler (fig. 24). As expected, this lower relative intake efficiency leads to large biases in suspended-sand concentration, which are positively correlated with grain size. With the exception of cross-section B at the 61-mile study site, both laboratory data and field-based intake-efficiency estimates of error in concentration (fig. 25) show the same positive correlation between grain size and sediment-concentration bias, with the field-measured biases in suspended-sediment concentration generally exceeding the laboratorymeasured biases in suspended-sediment concentration, especially for the sand size classes. 

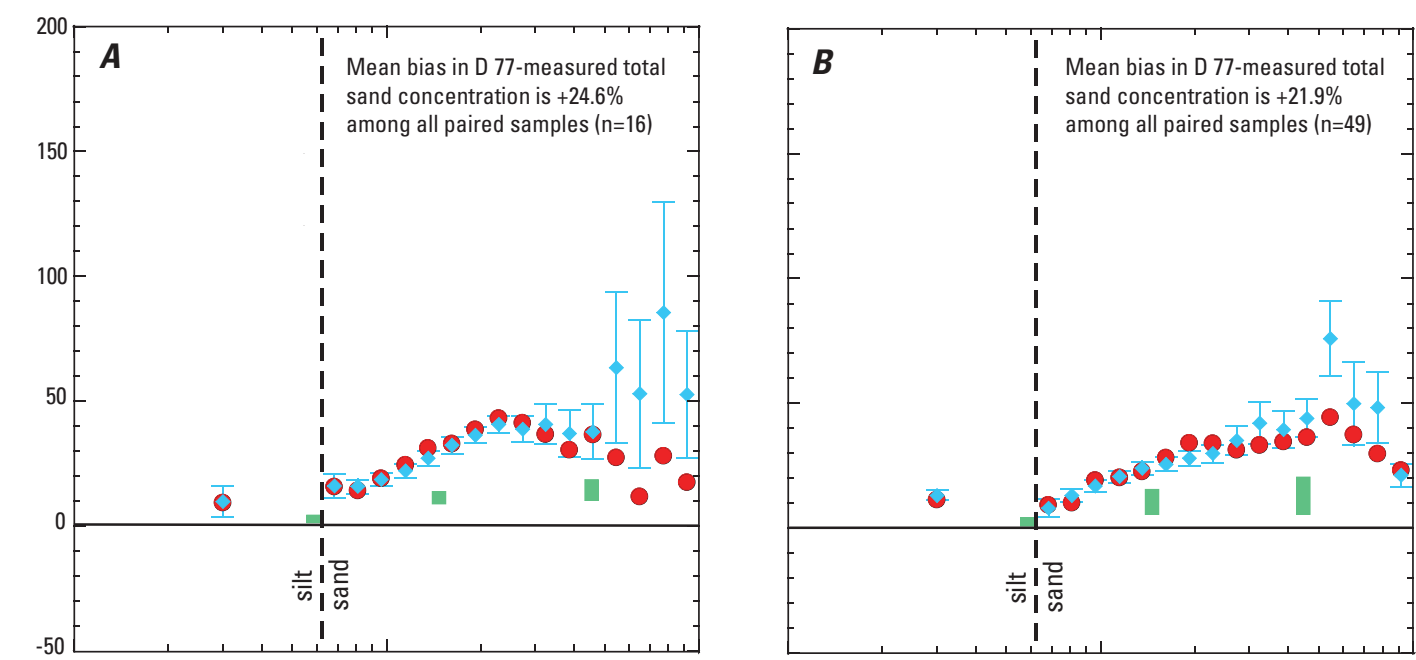

\section{EXPLANATION}

Median bias

- Mean bias

Laboratory-predicted range in error
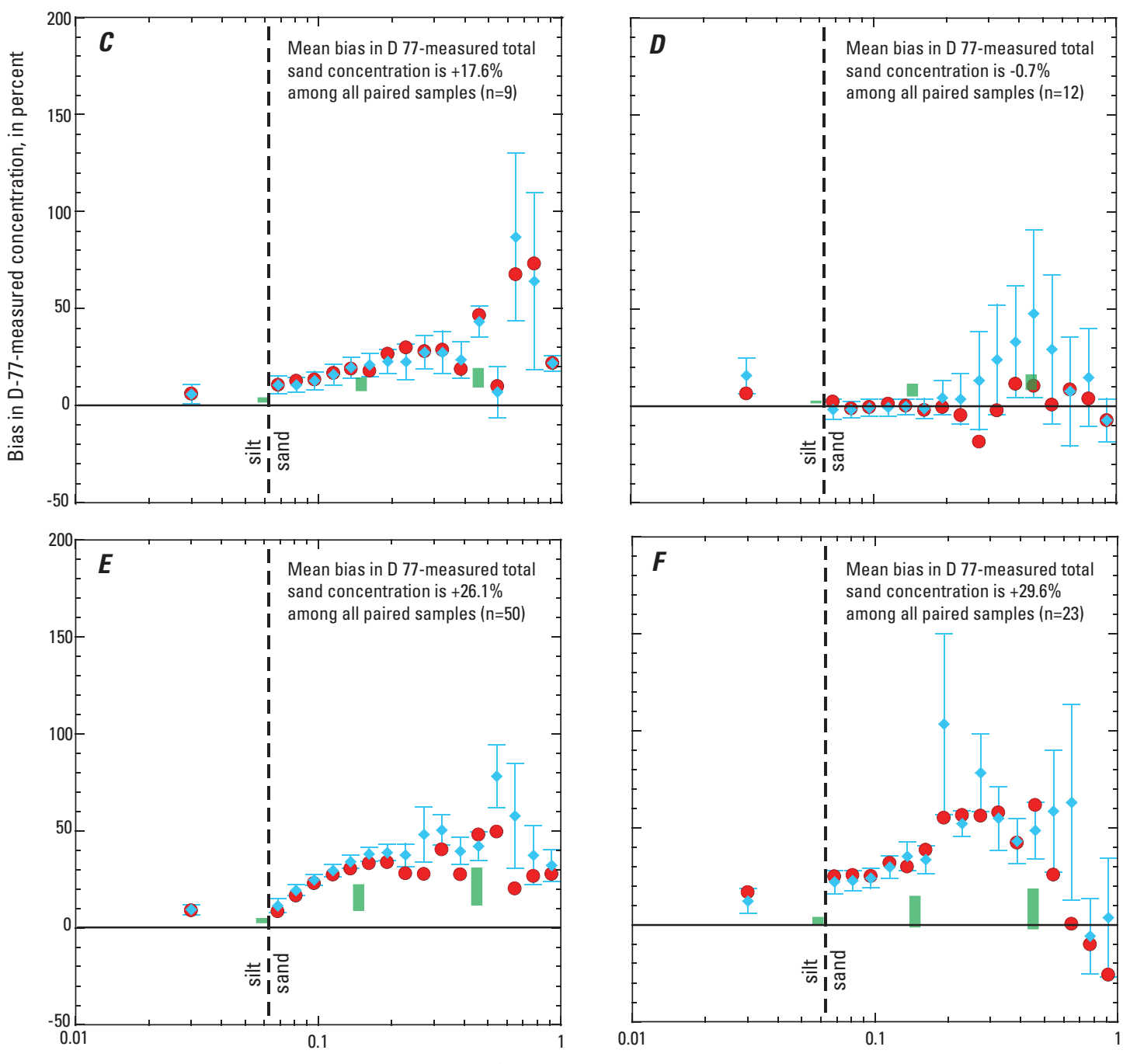

Grain size, in millimeter

Figure 25. Graphs showing US D-77 bag-type to US D-96-type sampler relative bias in measured suspended-sediment concentration at $(A)$ 30-mile tagline $A,(B)$ 30-mile tagline $B,(C)$ 61-mile tagline $A,(D)$ 61-mile tagline $B,(E)$ 61-mile tagline $C$, and $(F)$ the 87-mile cableway; error bars are one standard error. All silt-and-clay-sized sediment are treated as though they are one 0.03-millimeter $(\mathrm{mm})$ size class; sand-size sediment is segregated into $1 / 4-\phi$ increments. Green boxes display the predicted range in the bias in sediment concentration at this site- for $0.06-\mathrm{mm}, 0.15-\mathrm{mm}$, and $0.45-\mathrm{mm}$ sediment—based on the results from laboratory experiments in FISP (1941a). With the exception of (D) 61-mile tagline B, the paired sampler comparisons at these locations indicate greater bias in the concentration of each size class of sediment than that expected on the basis of the laboratory experiments conducted under morecontrolled and more-uniform flow conditions in flumes. \%, percent. 


\section{Biases in Suspended-Sediment Concentration Arising from Use of the US D-96-Type Sampler}

As previously discussed, super- and sub-isokinetic sampling typically leads to biases in suspended-sediment concentration that can be estimated on the basis of laboratory experiments in FISP Report 5 (fig. 4; FISP, 1941a). On the basis of the published effects of non-isokinetic sampling on errors in suspended-sediment concentration (figs. 3, 4), and the field intake efficiency data collected in this study (fig. 8), it is predicted that the US D-77 bag-type sampler oversamples sand (by about +18 percent) and that the US D-96-type sampler slightly oversamples sand (by about +5 percent) at the six cross-secitons at the study sites on the Colorado River (table 2). In addition, back-to-back comparisons of suspended-sand data collected with the US D-77 bag-type and US D-96-type samplers indicate that the US D-77 bag-type sampler oversamples sand by about 20 percent relative to the US D-96-type sampler, on average, at the six cross-sections at the study sites on the Colorado River (fig. 25). This 20 percent oversampling of sand relative to the US D-96-type sampler suggests that the true oversampling of sand by the US D-77 bag-type sampler might be closer to about +26 percent $^{16}$, not the +18 percent suggested by the results from the laboratory experiments in figures 3 and 4 . Thus, it seems possible that the results from the 1940s FISP laboratory experiments might underpredict the amount of oversampling of sand produced by sub-isokinetic sampling in actual rivers. Therefore, to evaluate whether the predicted errors in suspended-sand concentrations measured with the US D-96-type sampler are consistent with those expected on the basis of the 1940s FISP laboratory experiments, a series of single-vertical sampling tests were conducted at the 61-mile and 87-mile study sites with the US D-96-A1 sampler and the known isokinetic rigid-container US D-74 and US D-77 (bottle not bag) samplers. In these tests, intake efficiencies were measured and suspended-sediment data were analyzed to determine the relative concentration biases in different size classes of sediment between the different sampler models. In addition, samples were collected with the US D-96-A1 sampler over different sampling durations with two different tray-length configurations to evaluate whether increasing the cavity venting through the rear vent hole improved the intake efficiency of this sampler, and whether any improvement in intake efficiency resulted in a reduction in any biases in the suspended-sand concentrations measured with the US D-96-A1 sampler. The two different trays used in these tests were the standard US D-96-type tray sold with this sampler since 2002 (this tray extends to the back of the sampler cavity and partially blocks the rear vent hole) and a tray $\sim 4 \mathrm{~cm}$ shorter than the standard tray. The shorter length of this second tray may correspond to the length of the

\footnotetext{
${ }^{16}$ This +26 percent value was estimated by multiplying the observed +20 percent average oversampling of sand for the US D-77 bag-type sampler by the predicted +5 percent average oversampling of 0.15 - $\mathrm{mm}$ sand for the US D-96-type sampler presented in table 2.
}

tray used in Davis' (2001) tests of the US D-96 sampler and was based on analyses of photographs in figures 12,14 , and 15 in FISP ([n.d.]c). In this study, these two trays are referred to as the "standard tray" and the "short tray."

The single-vertical sampling tests at the 61-mile and 87 -mile study sites were conducted by collecting a sequential series of depth-integrated suspended-sediment samples with the three sampler models, rotating through each sampler model, under constant flow and suspended-sediment conditions. Depth-averaged velocity was measured concurrently with sample collection using a boat-mounted ADCP (fig. 6), to allow accurate calculations of the field intake efficiency associated with each sample. For the US D-74 and US D-77 rigid-container samplers, sampling duration was held approximately constant at each study site; for the US D-96-A1 sampler, sequential back-to-back samples were collected with each tray length (standard and short) with progressively longer sampling durations until overfill of the bag occurred. At the 61-mile study site, samples were collected while ADCP velocity measurements were made from the boat (depicted in fig. 6) at cross-section $\mathrm{C}$ tagline station $318 \mathrm{ft}$; at the 87-mile study site, samples were collected from the cableway at station $158 \mathrm{ft}$ while ADCP velocity measurements were made from the boat deployed under the cableway at this station. At each study site, samples were collected such that groups of samples collected with the US D-74 and US D-77 rigid-container samplers bracketed those collected with the US D-96-A1 collapsible bag sampler. The sequence of samples collected at the 61-mile study site was as follows: (1) five US D-74 samples, (2) five US D-77 rigid-container samples, (3) seven US D-96-A1 "short tray" samples with progressively longer sampling durations (increasing from 21 to 85 seconds), (4) five US D-77 rigid-container samples, (5) five US D-74 samples, (6) seven US D-96-A1 "standard tray" samples with progressively longer sampling durations (increasing from 21 to 80 seconds), (7) five US D-74 samples, and (8) five US D-77 rigid-container samples. The sequence of samples collected at the 87-mile study site was as follows: (1) three US D-74 samples, (2) three US D-77 rigid-container samples, (3) six US D-96-A1 "short tray" samples with progressively longer sampling durations (increasing from 20 to 70 seconds), (4) eight US D-96-A1 "standard tray" samples with progressively longer sampling durations (increasing from 20 to 84 seconds), (5) three US D-77 rigid-container samples, and (6) three US D-74 samples. At the 87-mile study site, overfill of the bag in the US D-96-A1 "short tray" sampler occurred at a much shorter sampling duration than in the US D-96-A1 "standard tray" sampler.

For these single-vertical sampling tests, all samples were collected within the operational limits of each model depth-integrating sampler (FISP, 1979, [n.d.]c, d) except for the US D-77 rigid-container sampler at the 61-mile study site and the US D-74 sampler at the 87-mile study site, where the the maximum allowable transits rates were exceeded. 
Because flow depth at each sampling vertical was slightly deeper than the $15-\mathrm{ft}$ maximum depth of the US D-74 sampler, each sample was integrated to depths of only $15 \mathrm{ft}$ so that all samples would be collected over the same part of the water column (to allow direct comparison of the data collected with each sampler) and at depths within the operational limits of all three depth-integrated suspended-sediment samplers (FISP, 1979, [n.d.]c, d). Nozzles were selected for the rigid-container samplers to prevent overfill and to minimize the possibility of pressure-driven inrush during the descending transits. Because depth-averaged velocity was 25 percent larger at the sampling vertical at the 61-mile study site than at the 87-mile study site, 1/4-inch nozzles were used on both the US D-77 rigid-container sampler and the US D-96-A1 sampler at the 61-mile study site and 5/16-inch nozzles were used on both these samplers at the 87-mile study site. The 3/16-inch nozzle was used on the US D-74 rigid-container sampler at both study sites. Transit rates for each sampler were much less than $0.4 \bar{V}$, and attempts were made to keep transit rates within the operational limits of each sampler (FISP, 1979, [n.d.] c, d) such that the rigid-container samplers did not overfill. This proved difficult, however, and although transit rates at the 61-mile study site were approximately equal to the maximum allowable transit rate ${ }^{17}$ for the $3 / 16$-inch nozzle on the US D-74 sampler, the transits rates at the 87-mile study site slightly exceeded the maximum allowable transit rate for the 3/16-inch nozzle on this sampler. Thus, it is likely that some small amount of pressure-driven inrush occurred during the descending transit for the samples collected with the US D-74 rigid-container sampler at the 87-mile study site. Likewise, although transit rates at the 87-mile study site were less than the maximum allowable transit rate for the 5/16-inch nozzle on the US D-77 rigid-container sampler, the transits rates at the 61-mile study site exceeded the maximum allowable transit rate for the $1 / 4$-inch nozzle on this sampler. Thus, it is likely that pressure-driven inrush occurred during the descending transit for the samples collected with the US D-77 rigid-container sampler at the 61-mile study site. Given the relative transit rates, the amount of pressure-driven inrush experienced by the US D-77 rigid-container sampler at the 61-mile study site likely exceeded the amount of pressure-driven inrush experienced by the US D-74 sampler at the 87-mile study site.

\footnotetext{
${ }^{17}$ In this study, the maximum allowable transit rates were calculated using a logarithmic velocity profile, not using the depth-averaged constant velocity approach of FISP (1979, [n.d.]c, d). Because velocity profiles in rivers are approximately logarithmic and are not constant, our approach provides a more accurate estimate of the maximum transit rate that avoids pressure-driven inrush during the descending transit. The maximum allowable transit rate calculated using a logarithmic velocity profile is slightly greater than that using a constant depth-averaged velocity because, under a logarithmic velocity profile, more water enters the sampler nozzle isokinetically in the upper part of the water column than is predicted under a constant depth-averaged velocity.

${ }^{18}$ Although intake efficiency decreases with increasing sampling duration in the US D-96-A1 "standard tray" test at the 87-mile study site, this decrease is only significant at the 0.074 level.
}

Shortening the tray in the US D-96-A1 sampler, and thereby increasing the effective area of the rear sampler-cavity vent hole, appears to improve the intake efficiency of this sampler at both study sites, with perhaps greater improvement in $\mathrm{IE}_{\text {field }}$ at shorter sampling durations (fig. 26). At the 61-mile study site, $\mathrm{IE}_{\text {field }}=0.85 \pm 0.06(\mu \pm 1 \sigma)$ among the 7 samples collected with the US D-96-A1 "standard tray" sampler and $\mathrm{IE}_{\text {field }}=0.89 \pm 0.05$ among the 7 samples collected with the US D-96-A1 "short tray" sampler. At sampling durations less than 45 seconds, this improvement in intake efficiency is more pronounced, with $\mathrm{IE}_{\text {field }}$ increasing from $0.84 \pm 0.03(n=3)$ for the US D-96-A1 "standard tray" sampler to $0.94 \pm 0.03$ $(n=3)$ for the US D-96-A1 "short tray" sampler at the 61-mile study site. At the 87-mile study site, $\mathrm{IE}_{\text {field }}=0.65 \pm 0.07$ among the 8 samples collected with the US D-96-A1 "standard tray" sampler and $\mathrm{IE}_{\text {field }}=0.74 \pm 0.08$ among the 6 samples collected with the US D-96-A1 "short tray" sampler. Unlike at the 61-mile study site, the improvement in $\mathrm{IE}_{\text {field }}$ obtained by shortening the tray was not restricted to shorter sampling durations at the 87-mile study site. In general, however, shortening the tray did result in a 12 to 14 percent increase in the intake efficiency of the US D-96-A1 sampler. As expected on the basis of the discussion in the previous paragraph, the US D-74 rigid-container was isokinetic at the 61-mile study site, with $\mathrm{IE}_{\text {field }}=1.05 \pm 0.04$ among the 15 samples collected with this sampler, whereas the US D-77 rigidcontainer was super-isokinetic at the 61-mile study site, with $\mathrm{IE}_{\text {field }}=1.27 \pm 0.07$ among the 15 samples collected with this sampler (fig. 26). Likewise, the US D-77 rigid-container was isokinetic at the 87-mile study site, with $\mathrm{IE}_{\text {field }}=0.98 \pm 0.04$ among the 6 samples collected with this sampler, whereas the US D-74 rigid-container was slightly super-isokinetic at the 61-mile study site, with $\mathrm{IE}_{\text {field }}=1.13 \pm 0.03$ among the 6 samples collected with this sampler (fig. 26).

Results from the single-vertical tests indicate that, although the intake efficiency of the US D-96-type sampler generally decreases as sampling duration increases (fig. 22), the intake effciency of the US D-96-type sampler may not always decrease as sampling duration increases at any individual sampling vertical (fig. 26). Among the four tests of this sampler with progressively increasing sampling duration (standard and short tray tests at the two study sites), intake efficiency significantly decreased as sampling duration increased in only one, the US D-96-A1 "short tray" test at the 61 -mile study site $\left(F_{1,5}=12.1, p=0.018\right)$. In the other three tests, no significant relation between intake efficiency and sampling duration was detected at the 0.05 critical level $^{18}$. 

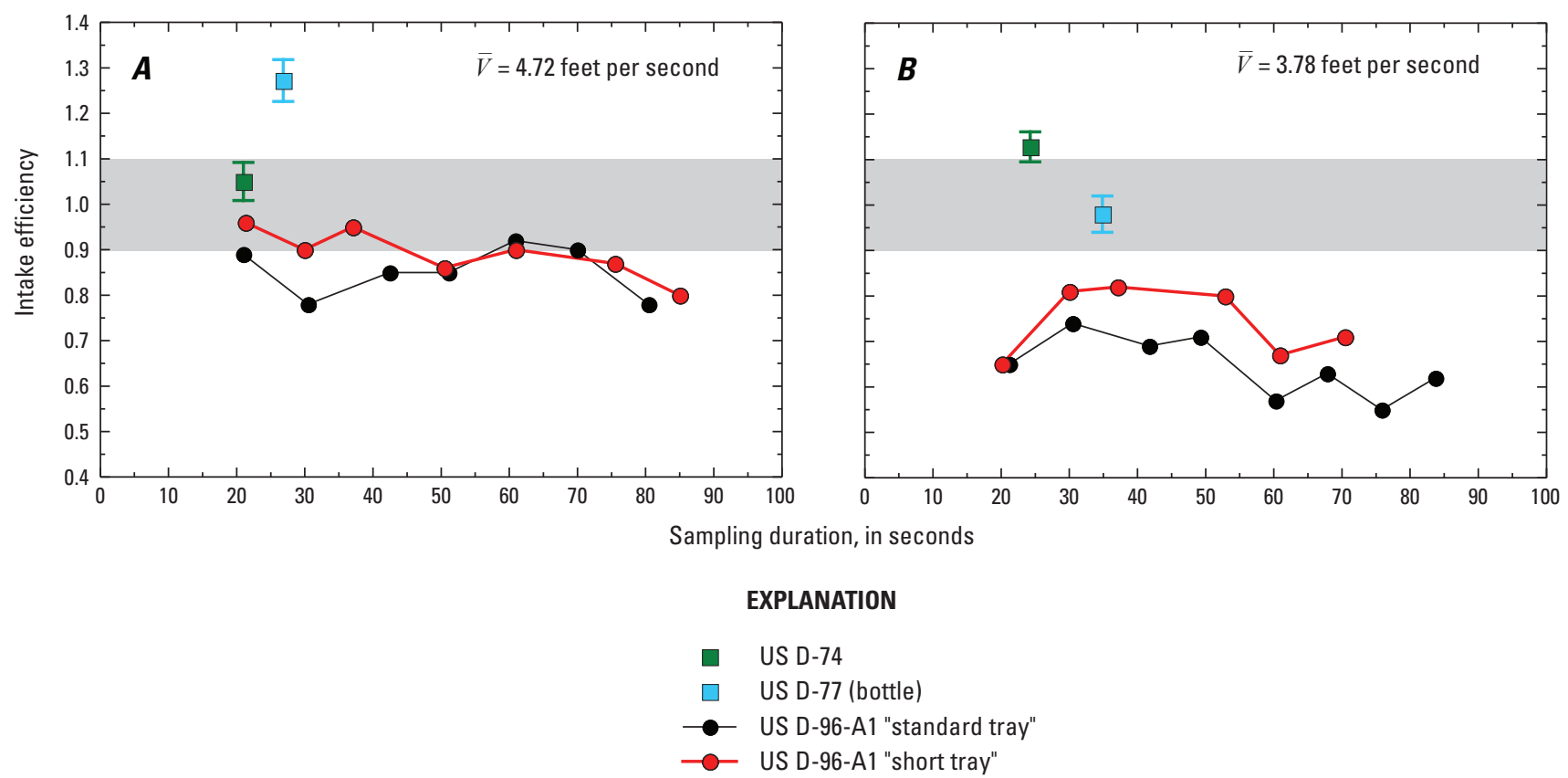

Figure 26. Plots showing relations between sampling duration and intake efficiency for paired comparisons among the US D-96-A1 collapsible-bag sampler, the US D-74 rigid-container sampler, and the US D-77 rigid-container (bottle) sampler along 61 -mile cross-section $C$ at tagline station 318 feet $(A)$ and along the 87-mile cross-section at cableway station 158 feet $(B)$. Error bars for the US D-74 and US D-77 intake efficiencies indicate one standard deviation (computed among all the samples collected with each of the samplers at each study site). Gray box indicates FISP-accepted $1.0 \pm 0.1$ range in intake efficiency deemed to be isokinetic. The US D-96-A1 sampler was deployed using sampler trays with two different lengths. Sampling duration for the US D-74 and US D-77 rigid-container samplers was held constant. Sampling duration for the US D-96-A1 sampler was increased until an overfill of the sampling container (bag) was achieved. $\bar{V}$, ambient stream velocity.

Regardless of whether significant relations exist between sampling duration and intake efficiency in these four tests, however, it is important to note that values of $\mathrm{IE}_{\text {field }}$ measured in these tests fall within the variability of the "clouds" of $\mathrm{IE}_{\text {field }}$ in figure 22, and that even with this large variability in $\mathrm{IE}_{\text {field, }}$, the relations between sampling duration and intake effficiency in figure 22 are significant. This result suggests that, even though there is a general statistically significant tendency for the intake efficency of the US D-96-type sampler to decrease with increasing sampling duration, the likely variability in how the bag actually fills and displaces the water in the sampler cavity (and perhaps even blocks vent holes) plays a major role in regulating the intake efficiency of this sampler during the collection of any individual sample.

Comparison of suspended-sand data collected with the US D-96-A1 sampler with suspended-sand data collected with the isokinetic rigid-container samplers indicates that the US D-96-A1 sampler oversamples sand as a function of intake efficiency in exactly the manner expected on the basis of the laboratory experiments in FISP (1941a). Biases in the US D-96-A1-measured concentration of suspended-sand in each size class (fig. 27) were calculated on the basis that rigid-container depth-integrating samplers shown to be isokinetic collect unbiased suspended-sediment data. Thus, because the US D-74 sampler was shown to be isokinetic at the 61-mile site and the US D-77 rigid-container sampler was shown to be isokinetic at the 87-mile study site, biases in the US D-96-A1-measured concentrations of suspended sediment in each size class were calculated relative to the US D-74-measured concentrations at the 61-mile study site and relative to the US D-77-rigid-container-measured concentrations at the 87-mile study site (fig. 27). The median, mean, and standard error of these biases in figure 27 were calculated on the basis of comparing the concentration of each size class of suspended sediment measured among the given set of US D-96-A1 samples to the mean concentrations of each size class of suspended sediment measured by the rigid-container sampler shown to be isokinetic in figure 26 . 


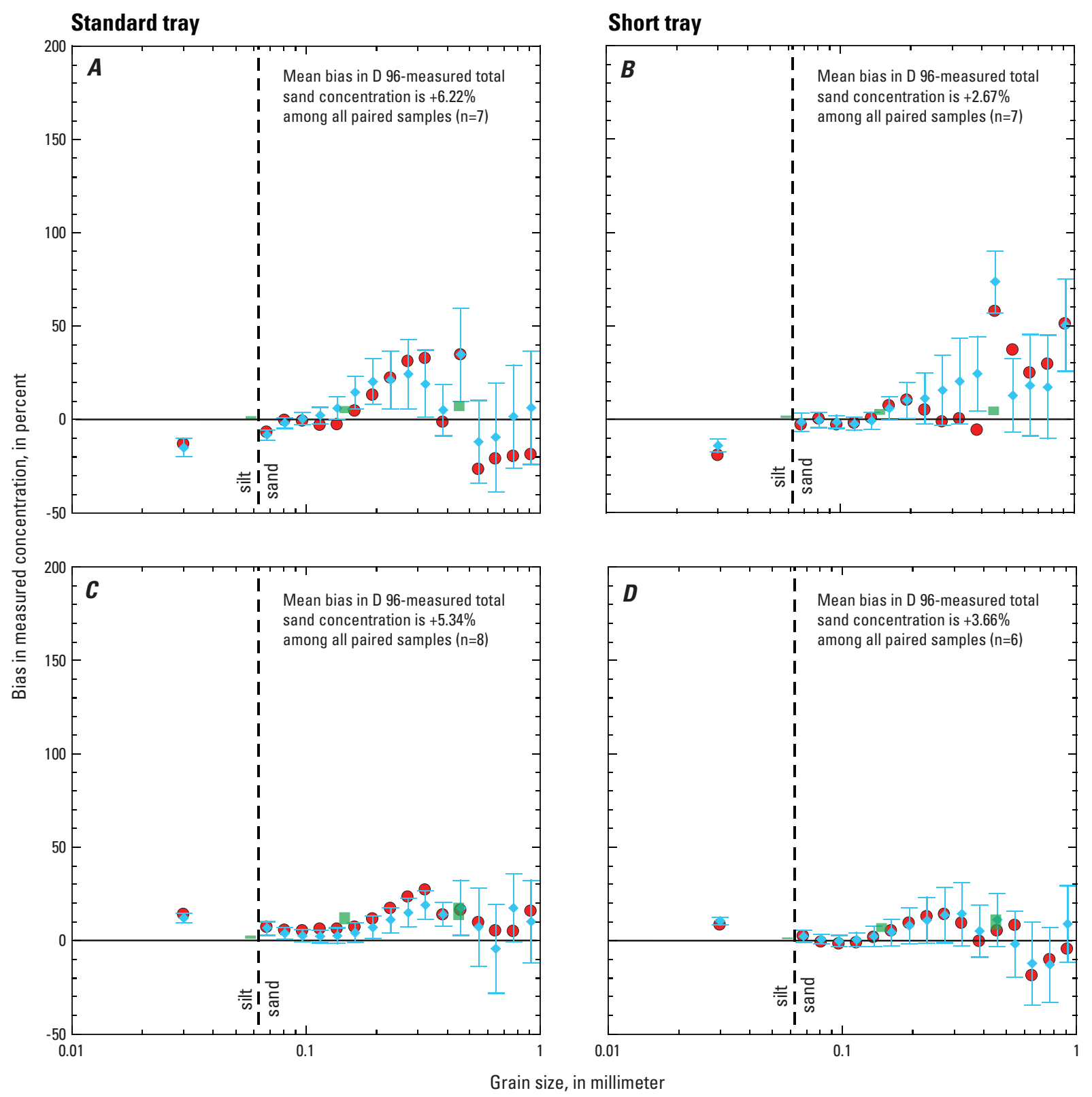

EXPLANATION

- Median bias

- Mean bias

Laboratory-predicted range in error

Sand $D_{50}=0.13 \mathrm{~mm}$

Sand $D_{84}=0.21 \mathrm{~mm}$

Figure 27. Graphs showing biases in the concentration of each size class of suspended sediment measured with the US D-96-A1 collapsible-bag sampler; measured biases are compared with those predicted on the basis of the 1940s Federal Interagency Sedimentation Project (FISP) laboratory experiments. Biases at the 61-mile study site $(A, B)$ are calculated relative to the assumed unbiased data collected with the isokinetic US D-74 rigid-container sampler. Biases at the 87-mile study site $(C, D)$ are calculated relative to the assumed unbiased data collected with the isokinetic US D-77 rigid-container sampler. Results from the "standard" tray tests are shown on the left half of this figure $(A-C)$ and results from the "short" tray tests are shown on the right half of this figure $(B-D)$. All silt-and-clay-sized sediments are treated as though they are one $0.03-\mathrm{mm}$ size class; sand-sized sediment is segregated into $1 / 4-\phi$ increments. Error bars are one standard error. Green boxes display the laboratory-predicted range in concentration bias-for 0.06-millimeter (mm), 0.15 -mm, and 0.45-mm sediment—on the basis of FISP (1941a). 
These biases were calculated separately for the "standard" and "short" tray tests of the US D-96-A1 sampler at each study site. Predicted ranges in the biases in the concentration of suspended sediment in the $0.06,0.15$, and $0.45-\mathrm{mm}$ size classes were calculated on the basis of the data in figure 4 from FISP (1941a) in combination with the mean plus and minus one standard error $\mathrm{IE}_{\text {field }}$ measured among each of the four US D-96-A1 sampler tests with different sampling durations. As shown in figure 27, the laboratory-predicted biases in suspended-sediment concentration are in good to excellent agreement with the biases in suspended-sediment concentration measured with the US D-96-A1 sampler at both the 61-mile and 87-mile study sites for both the "standard" and "short" tray sets of samples. Because these biases arise as a result of sub-isokinetic sampling, and as in the case of the relative biases in the suspended-sediment concentration measured by the US D-77 bag-type sampler, the biases in the suspended-sediment concentration measured by the US D-96-A1 sampler are also positively correlated with grain size. For the grain-size distributions of sand in suspension during the tests at the sampling verticals, the US D-96-A1 sampler with the standard tray oversampled sand by +6.2 percent at the 61 -mile study site and by +5.3 percent at the 87-mile study site, and the US D-96-A1 sampler with the short tray oversampled sand by +2.7 percent at the 61 -mile study site and by +3.7 percent at the 87 -mile study site. Therefore, the 12-14 percent improvement in $\mathrm{IE}_{\text {field }}$ resulting from shortening the tray corresponds to a $\sim 50$ percent decrease in the bias (from about +6 to +3 percent) in suspended-sand concentration measured with the US D-96-A1 sampler. These results indicate that improving the venting of the sampler cavity could markedly improve the intake efficiency of the US D-96-type sampler and greatly reduce the tendency for the US D-96-type sampler to oversample suspended sand. In addition, these results, in combination with the previously discussed water-temperature results, suggest that improving the venting of the sampler cavity and increasing the nozzle taper depth could result in the US D-96-type sampler being isokinetic, and therefore could result in the US D-96-type sampler collecting unbiased suspended-sand data in cold water rivers like the Colorado River downstream from Glen Canyon Dam in Grand Canyon National Park.

\section{Conclusions}

Any time new suspended-sediment samplers are designed that function in a physically different manner from previous model samplers, it is prudent to conduct extensive testing both in the laboratory and at various sites in different rivers. In addition, it is beneficial if these tests include not only analyses of intake efficiency, but also analyses of suspended-sediment data collected using intercomparisons with previous model isokinetic suspended-sediment samplers that are known to collect accurate suspended-sediment data. This was the approach used by the FISP when it developed and tested the fundamentally new (at that time) isokinetic rigid-container depth- and point-integrating suspended-sediment samplers in the 1940s and 1950s (Benedict, 1944; FISP, 1944, 1951, 1952, 1957). Because of the quality and importance of the measurement cross-section, some of these FISP river tests were conducted at one of the same cross-sections used in this study, the 87-mile cableway cross-section at the Colorado River near Grand Canyon, Arizona, gaging station.

Since the development of the US D-43 rigid-container depth-integrating sampler in the early 1940s, the first fundamental change in the physics underlying the operation of depth-integrating samplers came with the development of the US D-77 bag-type sampler (Szalona, 1982) and the subsequent development of the US D-96, US D-99, and US DH-2 collapsible-bag depth-integrating samplers (Davis, 2001, 2005a; McGregor, 2006). These samplers are much more physically complex than the older rigid-container samplers. In addition to the physics governing the isokinetic operation of rigid-container samplers, isokinetic operation of collapsible-bag samplers also requires that a filling bag be able to displace water from a sampler cavity through vent holes at exactly the rate at which the water enters the nozzle isokinetically. This is a much more difficult physics problem and, even with proper vent-hole design, it is likely not possible to design a collapsible-bag sampler that has intake efficiencies that do not decrease over time as sampling duration increases.

Because the development of the collapsible-bag samplers represented the largest increase in the physical complexity of depth-integrating samplers since the early 1940s, it would have been prudent if extensive river tests with the collection of suspended-sediment data were conducted to confirm that these samplers (with radically new designs) sampled isokinetically under a reasonable range of actual-river conditions. Unfortunately, these tests were never conducted; thus, the study described in this report was undertaken beginning in 2002-03. As indicated in Topping and others (2011), the sampling conditions at these study sites on the Colorado River are typical of those found at many USGS gaging stations where suspended-sediment data are collected, and perhaps more so than the sampling conditions found at Davis' (2001) site on the deep lower Mississippi River. Therefore, the conclusions reached in this study should be generally applicable to the use of collapsible-bag samplers on other rivers. 
The major conclusions from this study are as follows:

- Although both the US D-77 bag-type and US D-96-type samplers have been shown to sample isokinetically in flumes, typically neither of these samplers sampled isokinetically in field tests on the Colorado River. The sub-isokinetic sampling behavior of both sampler designs is similar regardless of whether the samplers were deployed from cableways or boats.

- Even though both samplers typically sampled with intake efficiencies $<1$ in the Colorado River tests, the intake efficiencies of the US D-96-type sampler were generally closer to unity at all ambient stream velocities than were the intake efficiencies of the US D-77 bag-type sampler.

- Transit rate does not greatly affect the intake efficiency of the US D-96-type sampler over the relative transit rate range of 0.1 to $0.7 \bar{V}$ investigated in this study.

- Despite the fact that the nozzles for the US D-96-type sampler were calibrated by the FISP to be isokinetic at water temperatures much warmer than those in the Colorado River in this study, and this warm-water nozzle calibration contributed to the intake efficiencies of the US D-96-type sampler being generally $<1$ in the Colorado River, water temperature was not the dominant physical factor in causing the sub-isokinetic sampling of the US D-96-type sampler in the Colorado River tests.

- Although water temperature was not the dominant physical factor causing the sub-isokinetic sampling of the US D-96-type sampler in the Colorado River tests, model results indicate that the calibration of nozzles with greater taper depths for colder water would measurably improve the intake efficiencies of the US D-96-type sampler at lower ambient stream velocities, regardless of water temperature. Use of a nozzle calibrated with a cold-water isokinetic taper depth is predicted to result in more accurate suspended-sand data at ambient stream velocities below $\sim 4 \mathrm{ft} / \mathrm{s}$ over the entire likely range in river water temperature of 0 to $30^{\circ} \mathrm{C}$. Conversely, at ambient stream velocities much greater than $4 \mathrm{ft} / \mathrm{s}$, suspended-sand data are likely to be slightly more accurate at all water temperatures when using the FISP warm-water isokinetic taper depth standard for US D-96-type nozzles, especially when using smaller diameter nozzles.
- Intake efficiencies of all bag-type samplers in this study are time dependent and decrease over time as sampling duration increases. Conversely, intake efficiencies in all rigid-container samplers are constant so long as some air remains in the sampling container and no pressure-driven inrush occurs during the descending transit. This difference in the behavior of intake efficiency arises because collapsible-bag samplers are much more physically complex than rigid-container samplers. Isokinetic sampling in a bag sampler requires that, as the bag fills with water through the nozzle, the expanding bag must displace the water in the flooded sampler cavity and purge this displaced water through the vent holes at exactly the rate required for isokinetic sampling through the nozzle. This is an extremely difficult physics problem that requires the proper design of vent holes for the sampler cavity. In reality (as shown by the flume data of previous investigations and by our data), regardless of vent-hole design, as the filling bag progressively occupies more of the volume of the sampler cavity, it becomes increasingly more difficult for the expanding bag to purge the displaced water through the vent holes. Proper design of the vent holes and ensuring that the vent holes remain unobstructed may reduce the time-dependent decrease in intake efficiency, as observed by Davis (2001, 2005a), but it will not likely remove this effect.

- The most likely physical mechanism responsible for the large time-dependent decreases in intake efficiency observed in the Colorado River tests of both the US D-77 bag-type and US D-96-type samplers is the improper venting of the rear of the sampler cavity. During the initial stages of bag filling, the expanding bag can easily displace the water in the sampler cavity and purge this water from the cavity through any of the vent holes, thus resulting in near isokinetic sampling. However, because bags generally fill from front to back within a sampler cavity, as the volume of the bag occupies progressively more of the volume of the sampler cavity, the ability of the expanding bag to purge the remaining water in the sampler cavity out through the rear vent hole(s) becomes more important as the influence of wall friction on the flow of water outside the bag in the sampler cavity grows. In both the US D-77 bag-type and the US D-96-type samplers, as sampling duration exceeds $\sim 20$ to 30 seconds and sample volume exceeds $\sim 0.5$ to 1 liter, intake efficiencies decrease rapidly to approach values of $\sim 0.5$ to 0.6 over much longer sampling durations. 
- The physical environments of the Mississippi River test sites of Davis (2001) and the Colorado River test sites are slightly different. Although this (physical environmental differences) could result in small differences in the venting behavior of the sampler cavity in the US D-96-type sampler, the most likely explanation for the differences in venting observed by Davis (2001) and observed in this study is a probable design difference between Davis' (2001) prototype of the US D-96 sampler and all of the US D-96-type samplers purchased by the USGS-GCMRC from the FISP since 2002 that were used in this study. The prototype sampler tested by Davis likely had a much shorter sampler tray than any of the US D-96type samplers used in this study. As depicted in FISP ([n.d.]c), the sampler tray in the prototype sampler was shorter than the length of the bag; in all of the USGS-GCMRC's US D-96-type samplers, the sampler tray is as long as the bag and extends completely to the back of the sampler cavity, largely blocking the bottom rear vent hole. Because Davis' (2001) tests were likely conducted using a sampler with a shorter sampler tray, the bottom rear vent hole in the prototype US D-96 sampler was most likely unobstructed, allowing relatively easy venting of water through the bottom rear vent hole as the bag filled within the sampler cavity. In the USGS-GCMRC's US D-96-type samplers with standard trays, it would be very difficult for the expanding bag to adequately purge water through the obstructed lower vent hole. Tests with different tray lengths show that shortening the tray results in substantially improved intake efficiencies in the US D-96-type sampler, as a likely result of the improved venting of the cavity through the lower rear vent hole. In addition, shortening sampling durations to $<60$ seconds at any given sampling vertical also helps alleviate the problem of large time-dependent decreases in the intake efficiency of the US D-96type sampler.

- The large variance in the intake-efficiency datasets of both the US D-77 bag-type and US D-96-type samplers results from time-dependent decreases in intake efficiency that arise from improper venting of the sampler cavity and backpressure on the bag.

- Because the intake efficiencies of the US D-77 bag-type samplers were generally lower than those of the US D-96-type samplers, suspended-sand concentrations measured by the US D-77 bag-type samplers were higher than those measured by the US D-96-type samplers. On average, among the six cross sections at the three study sites on the Colorado River, suspended-sand concentrations measured by the US D-77 bag-type sampler were $\sim 20$ percent higher than those measured by the US D-96-A1 sampler.
- As expected on the basis of the laboratory experiments in FISP (1941a), any positive bias in suspended-sand concentration measured using the US D-77 bag-type sampler and the US D-96-type sampler in the Colorado River tests was positively correlated with grain size.

- Although the US D-96-type sampler is generally sub-isokinetic in the Colorado River, paired sampler comparison between the US D-96-type sampler and the isokinetic and nonbiased US D-74 and US D-77 rigid-container samplers indicate that the US D-96 type sampler slightly oversamples sand $(+3$ to +6 percent depending on tray length) and in a manner consistent with the FISP (1941a) laboratory experiments in figure 4.

- Shortening the tray in the US D-96-type sampler to increase the effective area of the rear sampler-cavity vent hole results in a measurable ( $\sim 12$ to 14 percent) increase the intake efficiency of the US D-96-type sampler. This improvement in the venting of the rear part of the sampler cavity resulted in an approximate 50 percent decrease in the small positive bias in the suspended-sand concentration measured by the US D-96-type sampler under the conditions in the river tests. The positive bias in suspended-sand concentration decreased from about +6 percent with the standard tray to about +3 percent with the shorter tray.

- This study shows that isokinetic sampling behavior in laboratory and tow tests does not generally equate with isokinetic sampling behavior in rivers. Furthermore, sub-isokinetic sampling behavior does not always result in substantial oversampling of sand. Thus, river tests that include hydraulic and sediment data should be conducted when fundamentally new sampler designs are introduced.

Because it remains somewhat unclear as to why the time dependent decrease in intake efficiency for both the US D-77 bag-type sampler and the US D-96-type sampler is larger and more rapid in our river tests than was observed in flume experiments by Szalona (1982) or Davis (2001), and because collapsible-bag samplers are much more physically complex than standard rigid-container samplers, it would be prudent for others using collapsible-bag samplers to confirm that these samplers are functioning isokinetically at the river sites where they are being used, as originally recommended by Pickering (1983), Webb and Radtke (1998), and Yorke and Ward (1998). This additional fieldwork only requires independent measurement of the time- and depth-averaged ambient stream velocity at each sampling vertical (data that are already collected to rate USGS gaging stations) and measurements of water temperature, sampling duration, and sample volume. Although this additional work would add some amount of time and effort in the field, it has great importance in that it would allow for the evaluation of whether the suspended-sediment data collected with a collapsible-bag sampler on any specific river are of acceptable accuracy. 


\section{Acknowledgments}

Funding for this research was provided by the U.S. Department of the Interior's Glen Canyon Dam Adaptive Management Program through the USGS Grand Canyon Monitoring and Research Center. Over the course of nearly a decade, so many people have helped with the collection of suspended-sediment data that it is impossible to list them all. Ron Griffiths deserves special thanks for his help in collecting data and providing advice on analyses. Krissy Killoy, Nick Voichick, Robert Tusso, and Karen Vanaman were also integral in the recent high-intensity suspended-sediment data collection efforts required to make this report possible. Acoustic Doppler current profiler (ADCP) data were collected during multiple field efforts with the help of Jeff Gartner, Neil Ganju, Chris Magirl, Greg Schellenbarger, Scott Wright, Ron Griffiths, Nick Voichick, Jim Parent, and Frank Schaffner. Logistical and expert technical boating support during data collection on the Colorado River in Grand Canyon was provided by Humphrey Summit Support. Insightful reviews of earlier versions of this paper were provided by John Gray, Roger Kuhnle, Mark Landers, and Scott Wright.

\section{References Cited}

Allen, P.B., and Petersen, D.V., 1981, A study of the variability of suspended sediment measurements, in Erosion and Sediment Transport Measurement, Proceedings of the Florence Symposium, June 1981: IAHS Publ. no. 133, p. 203-211. (Also available at http://www.itia.ntua.gr/hsj/ redbooks/133/iahs_133_0203.pdf.)

Auton, T.R., Hunt, J.C.R., and Prud'homme, M., 1988, The force exerted on a body in inviscid unsteady non-uniform rotational flow: Journal of Fluid Mechanics, v. 197, p. 241-257. (Also available at http://www.cpom.org/people/ jcrh/jfm-197.pdf.)

Bender, E., 1969, Druckverlust bei Laminarer Stromung im Rohreinlauf: Chemie Ingenieur Technik, v. 41, p. 682-686, doi: 10.1002/cite.330411108.

Benedict, P.C., 1944, Preliminary field tests of the US sediment-sampling equipment in the Colorado River Basin: FISP Report A: Iowa City, Iowa, University of Iowa Hydraulic Laboratory, 10 p.

Bejan, Adrian, 1984, Convection heat transfer, 1st edition: New York, John Wiley and Sons, 477 p.

Bejan, Adrian, 1995, Convection heat transfer, 2nd edition: New York, John Wiley and Sons, 652 p.
Beverage, J.P., and Futrell, J.C., II, 1986, Comparison of flume and towing methods for verifying the calibration of a suspended-sediment sampler: U.S. Geological Survey Water-Resources Investigation Report 86-4193, 12 p. (Also available at http://pubs.usgs.gov/wri/1986/4193/report.pdf.)

Boning, C.W., 1992, Summary of documentation that describes instrumentation and field methods for collecting sediment data: U.S. Geological Survey Office of Surface Water Technical Memorandum No. 93.01. (Also available at http://water.usgs.gov/admin/memo/SW/sw93.01.html.)

Davis, B.E., 2001, The US D-96: An isokinetic suspendedsediment/water-quality collapsible-bag sampler; Report PP: Vicksburg, Mississippi, Federal Interagency Sedimentation Project, Waterways Experiment Station, 37 p. (Also available at http://water.usgs.gov/fisp/docs/Report_PP, US_D-96_011114_.pdf.)

Davis, B.E., 2005a, The US DH-2: A one-liter hand-line isokinetic suspended-sediment/water-quality collapsible-bag sampler; Report SS: Vicksburg, Miss., Federal Interagency Sedimentation Project, Waterways Experiment Station, 19 p. (Also available at http://water.usgs.gov/fisp/docs/Report SS_050720_DH-2_.pdf.)

Davis, B.E., 2005b, A guide to the proper selection and use of federally approved sediment and water-quality samplers; Report QQ: Vicksburg, Miss., Federal Interagency Sedimentation Project, Waterways Experiment Station, 35 p. (Also available at http://water.usgs.gov/fisp/docs/ Report_QQ-Users_Guide.pdf.)

Davis, B.E., 2006, FISP's suite of federally approved suspended-sediment/water quality collapsible-bag samplers: Proceedings of the 8th Federal Inter-Agency Sedimentation Conference, April 2-6, 2006: Reno, Nev., p. 296-303, CD-ROM, ISBV 0-9779007-1-1. (Also available at http:// pubs.usgs.gov/misc/FISC_1947-2006/pdf/1st-7thFISCsCD/8thFISC/Session\%202C-2_Davis.pdf.)

Edwards, T.K., and Glysson, G.D., 1999, Field methods for measurement of fluvial sediment: Techniques of WaterResources Investigations of the U.S. Geological Survey, book 3, chap. C2, 89 p. (Also available at http://pubs.usgs. gov/twri/twri3-c2/pdf/TWRI_3-C2.pdf.)

Federal Interagency Sedimentation Project, [n.d.]a, Using the US VTP-99 vertical transit rate pacer: Operator's Manual: Vicksburg, Miss., Waterways Experiment Station, 6 p. (Also available at http://water.usgs.gov/fisp/docs/Instructions US_VTP-99_990722.pdf.) 
Federal Interagency Sedimentation Project, [n.d.]b, Operating instructions for the US D-96 depth-integrating collapsible bag suspended-sediment sampler: Vicksburg, Miss., Waterways Experiment Station, 13 p. (Also available at http://water.usgs.gov/fisp/docs/Instructions_US_D-96_ Instructions_020709.pdf.)

Federal Interagency Sedimentation Project, [n.d.]c, Operating instructions for the US D-96-A1 depth-integrating collapsible bag suspended-sediment sampler: Vicksburg, Miss., Waterways Experiment Station, 13 p. (Also available at http://water.usgs.gov/fisp/docs/Instructions_US_D96-A1_030507.pdf.)

Federal Interagency Sedimentation Project, [n.d.] d, Instructions for sampling with depth-integrating, suspended-sediment samplers D-74, D-74AL, D-74TM, and D-74AL-TM: Minneapolis, Minn., St. Anthony Falls Hydraulic Laboratory, 12 p. (Also available at http://water. usgs.gov/fisp/docs/D-74_Instruction_Manual.pdf.)

Federal Interagency Sedimentation Project, [n.d.]e, Operator's manual for the DH-81 depth-integrating suspendedsediment sampler: Vicksburg, Miss., Waterways Experiment Station, 23 p. (Also available at http://water.usgs.gov/fisp/ docs/Instructions_US_DH-81_010612.pdf.)

Federal Interagency Sedimentation Project, 1940a, Field practice and equipment used in sampling suspended sediment; Report 1: Iowa City, Iowa, University of Iowa Hydraulic Laboratory, 175 p. (Also available at http://water. usgs.gov/fisp/docs/Report_1.pdf.)

Federal Interagency Sedimentation Project, 1940b, Equipment used for sampling bed-load and bed material; Report 2: Iowa City, Iowa, University of Iowa Hydraulic Laboratory, 56 p. (Also available at http://water.usgs.gov/fisp/docs/ Report_2.pdf.)

Federal Interagency Sedimentation Project, 1941a, Laboratory investigation of suspended-sediment samplers; Report 5: Iowa City, Iowa, University of Iowa Hydraulic Laboratory, 99 p. (Also available at http://water.usgs.gov/fisp/docs/ Report_5.pdf.)

Federal Interagency Sedimentation Project, 1941b, Analytical study of methods of sampling suspended sediment; Report 3: Iowa City, Iowa, University of Iowa Hydraulic Laboratory, 82 p. (Also available at http://water.usgs.gov/ fisp/docs/Report_3.pdf.)

Federal Interagency Sedimentation Project, 1941c, Methods of analyzing sediment samples; Report 4: Iowa City, Iowa, University of Iowa Hydraulic Laboratory, 203 p. (Also available at http://water.usgs.gov/fisp/docs/Report_4.pdf.)
Federal Interagency Sedimentation Project, 1944, Progress report-Comparative field tests on suspended-sediment samplers; Report C: Iowa City, Iowa, University of Iowa Hydraulic Laboratory, 58 p. plus Appendices A-H. (Also available at http://water.usgs.gov/fisp/docs/Report_C.pdf.)

Federal Interagency Sedimentation Project, 1951, Progress report-Field tests on suspended-sediment samplers Colorado River at Bright Angel Creek near Grand Canyon, Arizona; Report F: Minneapolis, Minn., St. Anthony Falls Hydraulic Laboratory, 119 p. (Also available at http://water. usgs.gov/fisp/docs/Report_F.pdf.)

Federal Interagency Sedimentation Project, 1952, The design of improved types of suspended-sediment samplers; Report 6: Minneapolis, Minn., St. Anthony Falls Hydraulics Laboratory, 103 p. (Also available at http://water.usgs.gov/ fisp/docs/Report_6.pdf.)

Federal Interagency Sedimentation Project, 1954, Investigation of intake characteristics of depth-integrating suspended-sediment samplers at the David Taylor model basin; Report H: Minneapolis, Minn., St. Anthony Falls Hydraulic Laboratory, 59 p. (Also available at http://water. usgs.gov/fisp/docs/Report_H.pdf.)

Federal Interagency Sedimentation Project, 1957, Progress report-Comparative field tests on suspended-sediment samplers as of January 1946; Report D: Minneapolis, Minn., St. Anthony Falls Hydraulic Laboratory, 55 p. (Also available at http://water.usgs.gov/fisp/docs/Report_D.pdf.)

Federal Interagency Sedimentation Project, 1965, Instructions for sampling with depth-integrating suspended-sediment samplers US D-49 and DH-59; Report O: Minneapolis, Minn., St. Anthony Falls Hydraulic Laboratory, 6 p. (Also available at http://water.usgs.gov/fisp/docs/Report_O_ US_D-49_and_US_DH-59_Instructions.pdf.)

Federal Interagency Sedimentation Project, 1979, Operating instructions D-77 suspended sediment sampler: Minneapolis, Minn., St. Anthony Falls Hydraulic Laboratory, $5 \mathrm{p}$.

Federal Interagency Sedimentation Project, 1986, Catalog, Instruments and reports for fluvial sediment investigations: Minneapolis, Minn., St. Anthony Falls Hydraulics

Laboratory: 138 p. (Also available at http://water.usgs.gov/ fisp/docs/1986_catalog.pdf.)

Federal Interagency Sedimentation Project, 2003, The US D-96: An isokinetic suspended-sediment/water-quality collapsible-bag sampler, the US D-96-A1: A lightweight version of the US D-96; Report PP, Addendum II: Vicksburg, Miss., Waterways Experiment Station, 4 p. (Also available at http://water.usgs.gov/fisp/docs/Report_ PP-Addendum_II,_US_D-96_030507_.pdf.) 
Federal Interagency Sedimentation Project, 2011, Federal Interagency Sedimentation Project - Background and history, accessed April 1, 2012, at http://water.usgs.gov/fisp/ background.html.

Gartner, J.W., and Ganju, N.K., 2007, Correcting acoustic Doppler current profiler discharge measurement bias from moving-bed conditions without global positioning during the 2004 Glen Canyon Dam controlled flood on the Colorado River: Limnology and Oceanography-Methods, v. 5, p. 156-162. (Also available at http://www.aslo.org/ lomethods/locked/2007/0156.pdf.)

Gray, J., Glysson, J.D., and Edwards, D.T., 2008, Suspendedsediment samplers and sampling methods, in Garcia, M., ed., Sedimentation engineering, processes, measurements, modeling, and practice: ASCE Manuals and Reports on Engineering Practice No. 110, p. 320-339.

Griffiths, J.C., 1967, Scientific method in analysis of sediments: New York, McGraw-Hill, 508 p.

Griffiths, R.E., Topping, D.J., Andrews, Timothy, Bennett, G.E., Sabol, T.A., and Melis, T.S., 2012, Design and maintenance of a network for collecting high-resolution suspended-sediment data at remote locations on rivers, with examples from the Colorado River: U.S. Geological Survey Techniques and Methods, book 8, chapter C2, 44 p. (Available at http://pubs.usgs.gov/tm/tm8c2/.)

Guy, H.P., 1969, Laboratory theory and methods for sediment analysis: Techniques of Water-Resources Investigations of the U.S. Geological Survey, book 5, chap. C1, 58 p. (Also available at http://pubs.er.usgs.gov/usgspubs/twri/ twri05C1.)

Guy, H.P., and Norman, V.W., 1970, Field methods for measurement of fluvial sediment: U.S. Geological Survey Techniques of Water-Resources Investigations, book 3 , chap. C2, 59 p.

Hof, B., Juel, A., and Mullin, T., 2003, Scaling of the turbulence transition threshold in a pipe: Physical Review Letters, v. 91, n. 24, p. 244502-1 through 244502-4, doi: 10.1103/PhysRevLett.91.244502.

Ichimiya, M., 2004, Laminar-turbulent transition of a boundary layer by a single roughness element in an inlet region of a circular pipe, in Proceedings of the 15th Australasian Fluid Mechanics Conference, December 13-17, 2004: Sydney, Australia, The University of Sydney, 4 p. (Also available at http://sydney.edu.au/engineering/ aeromech/15afmc/proceedings/papers/AFMC00121.pdf.)
Kanda, Hidesada, 1988, Numerical study of the entrance flow and its transition in a circular pipe: Japan Aerospace Exploration Agency, The Institute of Space and Astronautical Science Report No. 626, 60 p. (Also available at http://airex.tksc.jaxa.jp/dr/prc/japan/contents/ IS0035040000/IS0035040.pdf.)

Kandlikar, S.G., and Campbell, L.A., 2002, Effect of entrance condition on frictional losses and transition to turbulence: Proceedings of IMECE2002 American Society of Mechanical Engineering International Mechanical Engineering Congress and Exposition, November 17-22, 2002, New Orleans, La., paper IMECE2002-39573, 6 p., accessed December 1, 2010, at http://www.rit.edu/kgcoe/ mechanical/taleme/Papers/Conference\%20Papers/C058.pdf.

Knott, J.M., Sholar, C.J., and Matthes, W.J., 1992, Quality assurance guidelines for the analysis of sediment concentration by U.S. Geological Survey sediment laboratories: U.S. Geological Survey Open-File Report 92-33, 22 p. (Also available at http://pubs.usgs.gov/ of/1992/0033/report.pdf.)

Knott, J.M., Glysson, G.D., Malo, B.A., and Shroder, L.J., 1993, Quality assurance plan for the collection an processing of sediment data by the U.S. Geological Survey, Water Resources Division: U.S. Geological Survey OpenFile Report 92-499, 18 p. (Also available at http://pubs. usgs.gov/of/1992/0499/report.pdf.)

Langhaar, H.L., 1942, Steady flow in the transition length of a straight tube: Journal of Applied Mechanics, v. 9, p. A55-A58.

Lane, S.L., Flanagan, S., Gibs, J., Radtke, D.B., Webb, W.E., and Wilde, F.D., 2003, Sample collection, in Wilde, F.D., Radtke, D.B., Gibs, J., and Iwatsubo, R.T., eds., Selection of equipment for water sampling: Techniques of WaterResources Investigations of the U.S. Geological Survey, book 9, chap. A2, p. 21-56. (Also available at http:// water.usgs.gov/owq/FieldManual/Chapter2/Chapter2_ V2uncompressed.pdf.)

McGregor, Johnny, 2000a, Development of the US D-95 suspended-sediment sampler; Report LL: Vicksburg, Miss., Federal Interagency Sedimentation Project, Waterways Experiment Station, 24 p. (Also available at http://water. usgs.gov/fisp/docs/Report_LL_US_D-95_000619.pdf.)

McGregor, Johnny, 2000b, Development of the US DH-95 suspended-sediment sampler; Report MM: Vicksburg, Miss., Federal Interagency Sedimentation Project, Waterways Experiment Station, 27 p. (Also available at http://water.usgs.gov/fisp/docs/Report_MM_US_ DH-95_000619.pdf.) 
McGregor, Johnny, 2006, The US D-99: An isokinetic depth-integrating collapsible-bag suspended-sediment sampler: Report RR: Vicksburg, Miss., Federal Interagency Sedimentation Project, Waterways Experiment Station, 19 p. (Also available at http://water.usgs.gov/fisp/docs/ Report_RR.pdf.)

Melis, T.S., Topping, D.J., and Rubin D.M., 2003, Testing laser-based sensors for continuous in situ monitoring of suspended sediment in the Colorado River, Arizona, in Bogen, J., Fergus, T., and Walling, D.E., eds., Erosion and sediment transport measurement in rivers; technological and methodological advances: Wallingford, Oxfordshire, United Kingdom, IAHS Press, IAHS Publication 283, p. 21-27. (Also available at http://www.gcmrc.gov/library/reports/ physical/Fine_Sed/Melis2003.pdf.)

Moody, L.F., 1944, Friction factors for pipe flow: Transactions of the American Society of Mechanical Engineers, v. 66, no. 8 , p. 671-684.

Mueller, D.S., 2002, Field assessment of acoustic Doppler based discharge measurements: Proceedings, Hydraulic Measurements \& Experimental Methods 2002 (CD-ROM), ASCE (American Society of Civil Engineers), Reston, Va., 9 p. (Also available at http://hydroacoustics.usgs.gov/ publications/DSM-Test.pdf.)

Mueller, D.S., 2003, Field evaluation of boat-mounted acoustic Doppler instruments used to measure streamflow: Proceedings, IEEE $7^{\text {th }}$ Working Conference on Current Measurement, Institute of Electrical and Electronics Engineers, Piscataway, N.J., 5 p. (Also available at http:// hydroacoustics.usgs.gov/publications/CMTC_Paper_ David_S_Mueller.pdf.)

Mueller, D.S., and Wagner, C.R., 2009, Measuring discharge with acoustic Doppler profilers from a moving boat: U.S. Geological Survey Techniques and Methods 3-A22, 86 p. (Also available at http://pubs.usgs.gov/tm/3a22/.)

Munson, B.R., Young, D.F., Okiishi, T.H., and Huebsch, W.W., 2009, Fundamentals of fluid mechanics, Sixth edition (first printed in 1990): Hoboken, N.J., John Wiley and Sons, Inc., $725 \mathrm{p}$.

Muzychka, Y.S., and Yovanovich, M.M., 1998, Modeling friction factors in non-circular ducts for developing laminar flow: Proceedings of the 2nd American Institute of Aeronautics and Astronautics Theoretical Fluid Mechanics Meeting, June 15-18, 1998, Albuquerque, N. Mex., Paper AIAA 98-2492, 12 p. (Accessed December 1, 2010, at http://www.mhtlab.uwaterloo.ca/pdf_papers/mht198-7.pdf.)
Muzychka, Y.S., and Yovanovich, M.M., 2009, Pressure drop in laminar developing flow in noncircular ducts-A scaling and modeling approach: Journal of Fluids Engineering, v. 131, p. 111105-1 through 111105-11, doi: 10.1115/1.4000377. (Also available at http://dx.doi. org/10.1115/1.4000377.)

Nolan, K.M., Gray, J.G., and Glysson, G.D., 2005, Introduction to suspended-sediment sampling: U.S. Geological Survey Scientific Investigations Report 20055077 [CD-ROM]. (Also available at http://pubs.er.usgs.gov/ pubs/sir/sir20055077.)

Oberg, K.A., and Mueller, D.S., 2007, Validation of streamflow measurements made with acoustic Doppler current profilers: Journal of Hydraulic Engineering, v. 133, no. 12, p. 1421-1432. (Also available at http:// hydroacoustics.usgs.gov/publications/14-Oberg-Mueller. pdf.)

Pickering, R.J., 1983, Equipment and supplies-Bag-type suspended-sediment sampler: U.S. Geological Survey Quality of Water Branch Technical Memorandum No. 83.08. (Also available at http://water.usgs.gov/admin/ memo/historical/qw83.08Historical.txt.)

Pinkerton, R.M., 1938, The variation with Reynolds number of pressure distribution over an airfoil section: National Advisory Committee for Aeronautics (NACA) Report No. 613, 20 p. (Also available at http://ntrs.nasa.gov/archive/ nasa/casi.ntrs.nasa.gov/19930091689_1993091689.pdf.)

Pfenniger, W., 1961, Transition in the inlet length of tubes at high Reynolds numbers, in Lachman, G.V., ed., Boundary layer and flow control: New York, Pergamon Press, p. 970.

Prandtl, L., Tietjens, O.G., and Hartjog, J., 1934, Applied hydro and aeromechanics: London, McGraw-Hill Book Company, Inc.

Rantz, S.E., and others, 1982, Measurement and computation of streamflow: Volume 1. Measurement of stage and discharge: U.S. Geological Survey Water-Supply Paper 2175, 284 p. (Also available at http://www.engr.scu. edu/ emaurer/classes/ceng140_watres/handouts/usgs_ streamflow_measurement_dilution.pdf.)

Reynolds, Osborne, 1883, An experimental investigation of the circumstances which determine whether the motion of water shall be direct or sinuous, and of the law of resistance in parallel channels: Transactions of the Royal Society of London, v. 174, p. 932-982.

Rouse, Hunter, 1946, Elementary mechanics of fluids: New York, John Wiley and Sons. 
Rubin, D.M., Topping, D.J., Schmidt, J.C., Hazel, J., Kaplinski, K., and Melis, T.S., 2002, Recent sediment studies refute Glen Canyon Dam hypothesis: EOS (American Geophysical Union Transactions), v. 83, no. 25, p. 273, 277-278.

Schlichting, H., 1968, Boundary-layer theory: New York, McGraw-Hill, 817 p.

Schmeeckle, M.W., Nelson, J.M., and Shreve, R.L., 2007, Forces on stationary particles in near-bed turbulent flows: Journal of Geophysical Research, v. 112, F02003, 21 p., doi:1.1029/2006JF000536. (Also available at http://www. agu.org/journals/jf/jf0702/2006JF000536/2006JF000536. pdf.)

Shah, R.K., 1978, A correlation for laminar hydrodynamic entry length solutions for circular and non circular ducts: Journal of Fluids Engineering, v. 100, p. 177-179.

Shah, R.K., and London, A.L., 1978, Laminar flow forced convection in ducts-A source book for compact heat exchanger analytical data: New York, Academic Press, 477 p., ISBN 0120200511.

Shapiro, A.H., Siegel, R., and Kline, S.J., 1954, Friction factor in the laminar entry region of a smooth tube: Proceedings of the American Society of Mechanical Engineers 2nd National Congress on Applied Mechanics, p. 733-741.

Shimomukai, K., and Kanda, H., 2008, Numerical study of normal pressure distribution in entrance pipe flow: Electronic Transactions on Numerical Analysis, v. 30, p. 10-25, ISSN 1068-9613. (Also available at http://etna.math. kent.edu/vol.30.2008/pp10-25.dir/pp10-25.pdf.)

Skinner, J.V., 1989, History of the Federal Interagency Sedimentation Project, in Wang, S.S.Y., ed., Sediment Transport Modeling - Proceedings of the International Symposium: Reston, Va.: Hydraulics Division, American Society of Civil Engineers, p. 266-271. (Also available at http://water.usgs.gov/fisp/docs/FISP_history_1989.pdf.)

Sorenson, S.K., 2002, Water-quality field methods phaseout of US D-77 and frame-type samplers: U.S. Geological Survey Office of Water Quality Technical Memorandum No. 2002.09. (Also available at http://water.usgs.gov/admin/ memo/QW/qw02.09.html.)

Szalona, J.J., 1982, Development of a bag-type suspendedsediment sampler, A study of methods used in measurement and analysis of sediment loads in streams; Report Y: Minneapolis, Minn., Federal Interagency Sedimentation Project, St. Anthony Falls Hydraulic Laboratory, 32 p. (Also available at http://water.usgs.gov/fisp/docs/Report_Y.pdf.)
Topping, D.J., Melis, T.S., Rubin, D.M., and Wright, S.A., 2004, High-resolution monitoring of suspended-sediment concentration and grain size in the Colorado River in Grand Canyon using a laser-acoustic system, in $\mathrm{Hu}, \mathrm{C}$., and Tan, Y, eds., Proceedings of the Ninth International Symposium on River Sedimentation, October 18-21, 2004, Yichang, China: People's Republic of China, Tsinghua University Press, p. 2507-2514. (Also available at http://www.gcmrc.gov/ library/reports/Physical/Fine_Sed/Topping2004.pdf.)

Topping, D.J., Wright, S.A., Melis, T.S., and Rubin, D.M., 2006, High-resolution monitoring of suspended-sediment concentration and grain size in the Colorado River using laser-diffraction instruments and a three-frequency acoustic system: Proceedings of the 8th Federal Inter-Agency Sedimentation Conference, Reno, Nevada, April 2-6, 2006 (CD-ROM), ISBN 0-9779007-1-1. (Also available at http:// pubs.usgs.gov/misc_reports/FISC_1947-2006/pdf/1st7thFISCs-CD/8thFISC/Session\%206C-3_Topping.pdf.)

Topping, D.J., Wright, S.A., Melis, T.S., and Rubin, D.M., 2007, High-resolution measurements of suspendedsediment concentration and grain size in the Colorado River in Grand Canyon using a multi-frequency acoustic system: Proceedings of the Tenth International Symposium on River Sedimentation, August 1-4, 2007, Moscow, Russia, v. 3, p. 330-339. ISBN 978-5-89575-124-4, 978-5-89575-127-5. (Also available at http:/www.gcmrc.gov/library/reports/ physical/Fine_Sed/Topping2007b.pdf.)

Topping, D.J., Rubin, D.M., Grams, P.E., Griffiths, R.E., Sabol, T.A., Voichick, N., Tusso, R.B., Vanaman, K.M., and McDonald, R.R., 2010, Sediment transport during three controlled-flood experiments on the Colorado River downstream from Glen Canyon Dam, with implications for eddy-sandbar deposition in Grand Canyon National Park: U.S. Geological Survey Open-File Report 20101128, 111 p. (Also available at http://pubs.usgs.gov/ of/2010/1128/.)

Topping, D.J., Rubin, D.M., Wright, S.A., and Melis, T.S., 2011, Field evaluation of the error arising from inadequate time averaging in the standard use of depth-integrating suspended-sediment samplers: U.S. Geological Survey Professional Paper 1774, 95 p. (Also available at http:// pubs.usgs.gov/pp/1774/.)

Voichick, N., and Wright, S.A., 2007, Water-temperature data for the Colorado River and tributaries between Glen Canyon Dan and Spencer Canyon, northern Arizona, 1988-2005: U.S. Geological Survey Data Series 251, 24 p. (Also available at http://pubs.usgs.gov/ds/2007/251/.) 
Webb, W.E., and Radtke, D.B., 1998, Surface-water sampling equipment, in Wilde, F.D., Radtke, D.B., Gibs, J., and Iwatsubo, R.T., eds., Selection of equipment for water sampling: Techniques of Water-Resources Investigations of the U.S. Geological Survey, book 9, chap. A2, p. 17-32.

Wiberg, P.L., and Smith, J.D., 1985, A theoretical model for saltating grains in water: Journal of Geophysical Research, v. 90(C4), p. 7341-7354, doi:10.1029/JC090iC04p07341. (Also available at http://www.agu.org/journals/jc/v090/ iC04/JC090iC04p07341/JC090iC04p07341.pdf.)

Winterstein, T.A., and Stefan, H.G., 1983, Suspended sediment sampling in flowing water: laboratory study of effects of nozzle orientation, withdrawal rate and particle size: Minneapolis, Minn., University of Minnesota, St. Anthony Falls Hydraulic Laboratory, External Memorandum M-168, 97 p. (Also available at http://water.usgs.gov/fisp/docs/ SAFL_Report_M-168.pdf.)
Yilmaz, T., 1990, General equations for pressure drop for laminar flow in ducts of arbitrary cross sections, Journal of Energy Resources Technology, v. 112, p. 220-223.

Yorke, T.H., 1998, A national quality assurance program for sediment laboratories operated or used by the Water Resources Division: U.S. Geological Survey, Office of Surface Water Technical Memorandum No. 98.05. (Also available at http://water.usgs.gov/admin/memo/SW/ sw98.05.html.)

Yorke, T.H., Jr., and Ward, J.R., 1998, Guidance for collecting discharge-weighted samples in surface water using an isokinetic sampler: U.S. Geological Survey, Office of Surface Water Technical Memorandum No. 99.01. (Also available at http://water.usgs.gov/admin/memo/SW/ sw99.01.html.) 


\section{Appendix-Development and Testing of a Generalized Physically Based Model for Depth-Integrating Samplers}

The most difficult part of solving the energy balance between the flow upstream from a nozzle and the flow inside a sampler nozzle is the parameterization of the friction factor, $f_{\mathrm{n}}$, for the flow inside the nozzle. As stated in this report, this difficulty arises because the length of sampler nozzles are much shorter than the entrance length required for fully developed laminar flow and may be shorter or longer than the entrance length required for fully developed turbulent flow. Because of the relative shortness of sampler nozzles, $f_{\mathrm{n}}$ will be much greater than the value of $f$, the Darcy-Weisbach friction factor, estimated on the basis of Moody (1944) for fully developed laminar flow in a pipe and may even be greater than that for fully developed turbulent flow in a smooth pipe. This greater apparent friction arises for those cases where over most or all of a sampler nozzle's length, the boundary layer is growing from the nozzle wall to the nozzle center. Depending on the ambient stream velocity, water temperature, and nozzle geometry, this growing boundary layer may remain laminar or undergo a transition to turbulence in the rear part of the nozzle.

The key physical balance that determines whether the flow inside a sampler nozzle will remain as either developing or fully developed laminar flow is the Reynolds number (Re), which is the nondimensional physical balance between inertial forces and viscous forces that determines whether fully developed flow in a nozzle is ultimately turbulent or laminar. When $\mathbf{R e}$ is less than 2,000 to 2,300 for pipe flow, disturbances to the flow are damped by viscous forces and turbulence is impossible to maintain (for example, Reynolds, 1883; Rouse, 1946; Schlichting, 1968). Thus, when Re is $<2,300$, the flow inside a sampler nozzle will be either developing laminar flow or become fully developed laminar flow depending on whether the length, $L$, of the sampler nozzle is greater or less than $L_{\text {ent-lam }}$ (the distance from the nozzle entrance at which the flow in the nozzle will be fully developed laminar flow). However, when $\mathbf{R e} \geq 2,300$, the flow in a pipe does not necessarily become turbulent, but will likely become turbulent as a result of disturbance to the flow, with the likelihood of a transition to turbulence increasing with Re (Rouse, 1946; Schlichting, 1968; Hof and others, 2003). In fact, laminar flow has been maintained for $\mathbf{R e}$ numbers as large as 100,000 in a case where the pipe was extremely smooth and the flow was free of all disturbances (Pfenniger, 1961). In general, however, fully developed pipe flow is assumed to usually be turbulent when $\mathbf{R e}$ is greater than $\sim 4,000$ (Munson and others, 2009). Because in the case of sampler nozzles, $L$ is always comparable in magnitude to $L_{\text {ent-turb }}$ (the distance from the nozzle entrance at which the flow in the nozzle will be fully developed turbulent flow), we assume that the developing flow in sampler nozzles will undergo the transition to turbulence somewhere within a sampler nozzle when $2,300<<\mathbf{R e}<<20,000$. The standard technique for referencing the longitudinal position within a developing flow in a pipe or duct entrance is by calculating the dimensionless duct entrance length (for example, Bender, 1969; Shah, 1978; Bejan, 1984; Kanda, 1988; Yilmaz, 1990; Muzychka and Yovanovich, 1998, 2009; Kandlikar and Campbell, 2002; Shimomukai and Kanda, 2008), which in the case of an internally tapered sampler nozzle can be written as, $L /(\langle D\rangle \mathbf{R e})$, where $D$ is the diameter of the nozzle entrance. Because it is likely that any transition to turbulence within the developing flow inside a sampler nozzle occurs at an approximately constant value of the dimensionless duct entrance length, we assume that this transition occurs at a fixed value of $L /(\langle D\rangle \mathbf{R e})$ when $L \approx L_{\text {ent-turb }}$. The chief implication from this approximation is that for a given nozzle length, the transition to turbulence occurs at slightly greater Reynolds numbers for smaller diameter nozzles; as shown below, there is some evidence for this inverse relation between nozzle diameter and the transition Reynolds number in the data of Davis (2001). Therefore, when $\mathbf{R e}>2,300$, the flow in a sampler nozzle may be either developing laminar flow, developing turbulent flow, or fully developed turbulent flow, depending on $L /(\langle D\rangle \mathbf{R e})$ and the relation between $L$ and $L_{\text {ent-turb}}$.

Development and testing of the physically based model for a generalized depth-integrating sampler (including evaluation of the parameterization of $f_{\mathrm{n}}$ ) requires datasets that include nozzle velocity measurements made using different depth-integrating samplers with a range of nozzle geometries (nozzle lengths, diameters, and taper depths) over a range of ambient stream velocities and water temperatures. The only datasets that were found to be sufficiently complete and accurate for this undertaking were the US D-43-sampler flume dataset presented in figures 40 and 41 in FISP (1952); the US D-77-rigid-container-sampler flume dataset presented in figure 1 in FISP (1979); the warm-water flume and tow tests conducted using the US D-96 sampler with both the development and flume-calibrated nozzles in Davis (2001); the cold-water flume tests of the US D-96 sampler with flumecalibrated nozzles in Davis (2001); and, the warm-water flume and tow tests conducted using the DH-2 sampler with flumecalibrated nozzles in Davis (2005a). Other sampler datasets were too incomplete, with typically insufficient information provided for the nozzle taper depths or water temperatures. The geometric properties of the sampler nozzles used in the analyses in this study are provided in table A1. For a given taper depth, $L_{\mathrm{T}}$, the mean inside diameter of an internally tapered sampler nozzle by trigonometry is, 
Table A1. Geometric properties of sampler nozzles.

[Taper depths for these nozzles were determined empirically in flume tests at the indicated calibration ambient stream velocity and water temperature. Abbreviations: FISP, Federal Interagency Sedimentation Project; $\mathrm{ft} / \mathrm{s}$, feet per second; ${ }^{\circ} \mathrm{C}$, degrees Celsius]

\begin{tabular}{|c|c|c|c|c|c|c|c|}
\hline $\begin{array}{l}\text { Sampler } \\
\text { model }\end{array}$ & Nozzle type & $\begin{array}{l}\text { Nozzle } \\
\text { entrance } \\
\text { diameter } \\
\text { (inches) }\end{array}$ & $\begin{array}{l}\text { Nozzle } \\
\text { length } \\
\text { (inches) }\end{array}$ & $\begin{array}{c}\text { Taper } \\
\text { depth } \\
\text { (inches) }\end{array}$ & $\begin{array}{l}\text { Calibration } \\
\text { ambient stream } \\
\text { velocity } \\
\text { (ft/s) }\end{array}$ & $\begin{array}{c}\text { Calibration } \\
\text { water } \\
\text { temperature } \\
\left({ }^{\circ} \mathrm{C}\right)\end{array}$ & Taper-depth source \\
\hline \multirow[t]{3}{*}{ US D-43 } & Brass & $1 / 8$ & 3.375 & ${ }^{13} .000$ & 3.5 & $\mathrm{n} / \mathrm{a}$ & FISP (1952, fig. 40) \\
\hline & Brass & $3 / 16$ & 3.375 & ${ }^{1} 1.875$ & 3.5 & 0 to 5 & FISP (1952, fig. 40) \\
\hline & Brass & $1 / 4$ & 3.375 & ${ }^{1} 1.375$ & 3.5 & 0 to 5 & FISP (1952, fig. 40) \\
\hline US D-77 & Plastic & $5 / 16$ & 4.375 & 1.111 & 2.4 & 0.6 & FISP (1979, fig. 1) \\
\hline \multirow[t]{9}{*}{ US D-96 } & $\begin{array}{c}\text { Plastic or Teflon }^{\circledR} \\
\text { development }\end{array}$ & $3 / 16$ & 4.375 & 2.000 & 3.7 & 23.9 to 29.4 & $\begin{array}{l}\text { B.E. Davis (written } \\
\text { commun., 2010) }\end{array}$ \\
\hline & $\begin{array}{c}\text { Plastic or Teflon } \\
\text { development }^{\circledR}\end{array}$ & $1 / 4$ & 4.375 & 1.062 & 3.7 & 23.9 to 29.4 & $\begin{array}{l}\text { B.E. Davis (written } \\
\text { commun., 2010) }\end{array}$ \\
\hline & $\begin{array}{c}\text { Plastic or Teflon }{ }^{\circledR} \\
\text { development }^{2}\end{array}$ & $5 / 16$ & 4.375 & 1.094 & 3.7 & 23.9 to 29.4 & $\begin{array}{l}\text { B.E. Davis (written } \\
\text { commun., 2010) }\end{array}$ \\
\hline & Plastic & $3 / 16$ & 4.375 & 1.688 & 3.7 & 23.9 to 29.4 & $\begin{array}{l}\text { B.E. Davis (written } \\
\text { commun., 2010) }\end{array}$ \\
\hline & Teflon $^{\circledR}$ & $3 / 16$ & 4.375 & 1.875 & 3.7 & 23.9 to 29.4 & $\begin{array}{l}\text { B.E. Davis (written } \\
\text { commun., 2010) }\end{array}$ \\
\hline & Plastic & $1 / 4$ & 4.375 & 1.188 & 3.7 & 23.9 to 29.4 & $\begin{array}{l}\text { B.E. Davis (written } \\
\text { commun., 2010) }\end{array}$ \\
\hline & Teflon $^{\circledR}$ & $1 / 4$ & 4.375 & 1.156 & 3.7 & 23.9 to 29.4 & $\begin{array}{l}\text { B.E. Davis (written } \\
\text { commun., 2010) }\end{array}$ \\
\hline & Plastic & $5 / 16$ & 4.375 & 0.875 & 3.7 & 23.9 to 29.4 & $\begin{array}{l}\text { B.E. Davis (written } \\
\text { commun., 2010) }\end{array}$ \\
\hline & Teflon $^{\circledR}$ & $5 / 16$ & 4.375 & 0.937 & 3.7 & 23.9 to 29.4 & $\begin{array}{l}\text { B.E. Davis (written } \\
\text { commun., 2010) }\end{array}$ \\
\hline \multirow[t]{9}{*}{ US DH-2 } & Plastic & $3 / 16$ & 4.375 & 2.250 & 3.7 & 23.9 to 29.4 & Davis (2005a, table 3) \\
\hline & Teflon $^{\circledR}$ & $3 / 16$ & 4.375 & 1.920 & 3.7 & 23.9 to 29.4 & Davis (2005a, table 3 ) \\
\hline & Plastic nozzle 1 & $1 / 4$ & 4.125 & 2.250 & 3.7 & 23.9 to 29.4 & Davis (2005a, fig. 4) \\
\hline & Plastic nozzle 2 & $1 / 4$ & 4.375 & 2.250 & 3.7 & 23.9 to 29.4 & Davis (2005a, fig. 4) \\
\hline & ${ }^{3}$ Plastic nozzle 3 & $1 / 4$ & 4.375 & 1.556 & 3.7 & 23.9 to 29.4 & Davis (2005a, fig. 4 , table 3 ) \\
\hline & Plastic nozzle 4 & $1 / 4$ & 4.375 & 1.188 & 3.7 & 23.9 to 29.4 & Davis (2005a, fig. 4) \\
\hline & Teflon $^{\circledR}$ & $1 / 4$ & 4.375 & 1.670 & 3.7 & 23.9 to 29.4 & Davis (2005a, table 3) \\
\hline & Plastic & $5 / 16$ & 4.375 & 0.875 & 3.7 & 23.9 to 29.4 & Davis (2005a, table 3 ) \\
\hline & Teflon ${ }^{\circledR}$ & $5 / 16$ & 4.375 & 0.937 & 3.7 & 23.9 to 29.4 & Davis (2005a, table 3 ) \\
\hline
\end{tabular}

\footnotetext{
${ }^{1}$ The taper depths for the US D-43 3/16-inch and 1/4-inch nozzles resulted in an intake efficiency of 1.0 at an ambient stream velocity of $3.5 \mathrm{ft} / \mathrm{s}$ and a water temperature of $\sim 0$ to $5^{\circ} \mathrm{C}$; the 3 -inch taper depth for the US D-43 $1 / 8$-inch nozzle was too large to permit isokinetic sampling at any water temperature at this ambient stream velocity (Federal Interagency Sedimentation Project, 1952, fig. 41).

${ }^{2}$ The taper depths for the plastic and Teflon ${ }^{\circledR}$ development nozzles for the US D-96 sampler were determined in a flume using a US D-77 nozzle holder mounted on the body of a rigid-container sampler (Davis, 2001); thus, $\Delta \mathrm{z}=0.8$ inches and $k P=1.1$ for the calibration of the development nozzles, whereas $\Delta z=0$ and $k P=1.4$ for the nozzles calibrated in a US D-96 sampler, hence the slightly different taper depths between the development nozzles and the standard US D-96 plastic and Teflon ${ }^{\circledR}$ nozzles.

${ }^{3}$ The taper depth associated with 1/4-inch plastic nozzle 3 was found by Davis (2005a) to give the best results and thus is the standard taper depth used for US DH-2 1/4-inch plastic nozzles.
} 


$$
\langle D\rangle=\frac{D\left(L-L_{\mathrm{T}}\right)+L_{\mathrm{T}}\left(D+L_{\mathrm{T}} / 96\right)}{L},
$$

where

$D$ is the diameter of the nozzle entrance, and, by conservation of mass, the nozzle velocity associated with $\langle D\rangle$ is,

$$
\left\langle V_{\mathrm{n}}\right\rangle=V_{\mathrm{n}}\left(\frac{D}{\langle D\rangle}\right)^{2},
$$

where

$V_{\mathrm{n}}$ is the cross-sectionally averaged velocity in the nozzle entrance.
The first step in the development of the physically based sampler model is an evaluation of the flow conditions that are likely to exist in a sampler nozzle. Because $f_{\mathrm{n}}$ depends on the type of flow present, this first step is required to know which relations to use to estimate $f_{\mathrm{n}}$. As shown in figure A1, on the basis of all the US D-43, US D-77, US D-96, and DH-2 flume and tow-test data in FISP (1952, figs. 40, 41), FISP (1979), and Davis (2001, 2005a) - data that cover the flow conditions expected in almost all river settings - the two most likely conditions for flow within a sampler nozzle are developing laminar and developing turbulent flow. Fully developed laminar flow is predicted to never occur (as already suggested in the main part of this report) and fully developed turbulent flow is predicted to only occur rarely.
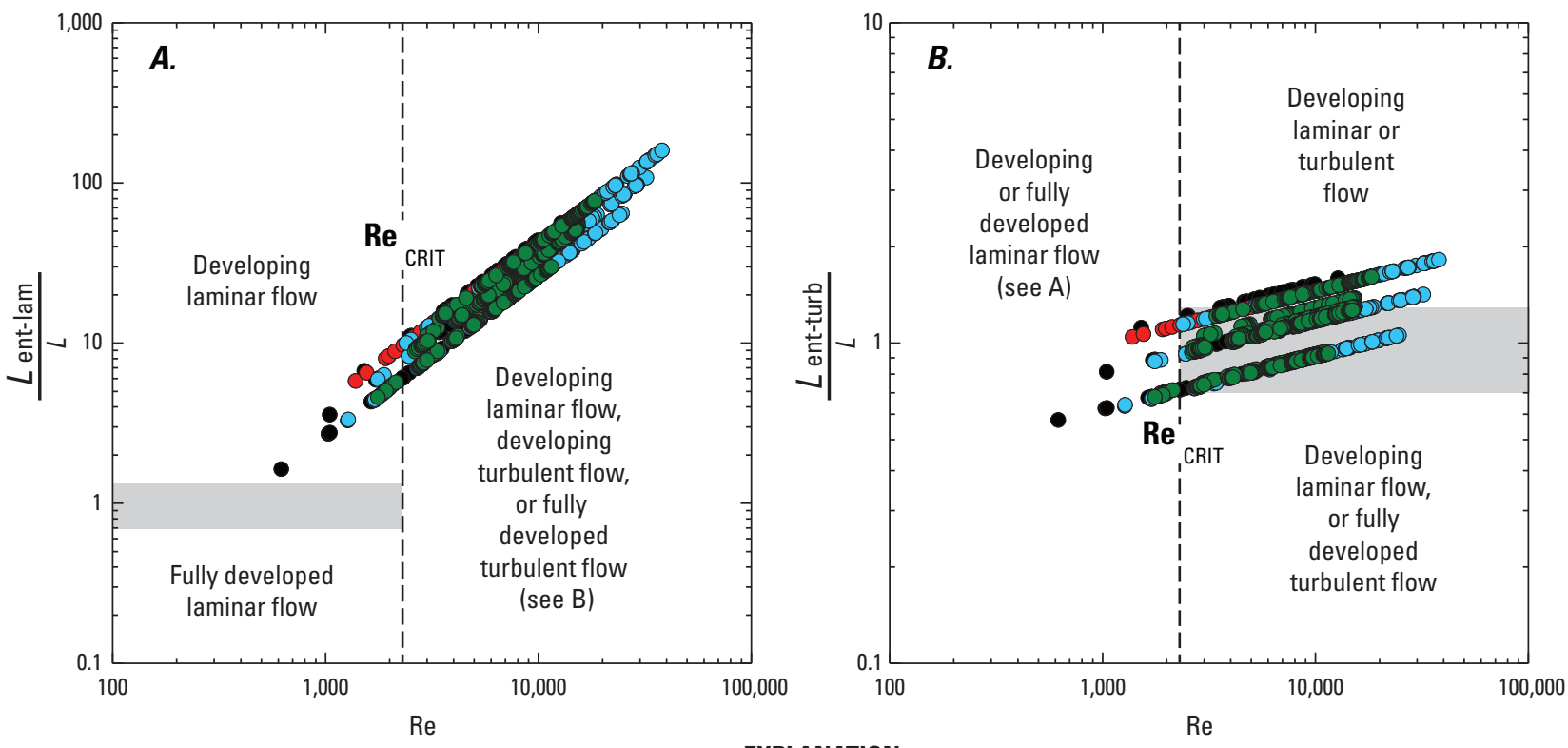

EXPLANATION

$\begin{array}{ll}\text { - } & \text { US D-43 } \\ \text { - US D-77 } \\ \text { US D-96 } \\ \text { - US DH-2 }\end{array}$

Figure A1. Predicted state of the flow in sampler nozzles for the US D-43, US D-77, US D-96, and DH-2 data in Federal Interagency Sedimentation Project (FISP) (1952, figs. 40, 41), FISP (1979), and Davis (2001, 2005a) that cover the flow conditions expected in most river settings. Gray shaded regions show the likely transitional regions between developing and fully developed flow on the basis of $L$ being within 30 percent of either $L_{\text {ent-lam }}$ or $L_{\text {ent-turb. }}$. In these plots, nozzle diameter increases from lower right to upper left. $(A)$ Ratio of the laminar-flow entrance length to nozzle length plotted as a function of the nozzle Reynolds number (Re). When $\mathbf{R e}<\mathbf{R e}_{\text {CRIT }}=2,300$, the flow in sampler nozzles is developing laminar flow; when $\mathbf{R e}>\mathbf{R e}_{\mathrm{CRIT}}$, the flow in sampler nozzles is either developing laminar flow, developing turbulent flow, or fully developed turbulent flow. $(B)$ Ratio of the turbulent-flow entrance length to nozzle length plotted as a function of the nozzle Reynolds number. As Re increases to be $>>2,300$, it becomes more likely that the developing flow in a sampler nozzle has undergone the transition to turbulence, depending on $L /(\langle D\rangle \mathbf{R e})$ and the relation between $L$ and $L_{\text {ent-turb }}$. Fully developed turbulent flow is not commonly predicted to occur in sampler nozzles. 
By the reasoning in the previous paragraphs, $f_{\mathrm{n}}$ can be estimated for the simplest cases when the flow emerging from a sampler nozzle is fully developed using the following common well-tested relations:

1. Although on the basis of figure A1, fully developed laminar flow is never likely to occur in sampler nozzles, when $\boldsymbol{R e}<2,300$ and $L>L_{\text {ent-lam }}, f_{\mathrm{n}}$ is calculated using the equation of Poiseuille (Moody, 1944; Rouse, 1946) as:

$$
f_{\mathrm{n}}=f_{\mathrm{lam}}=\frac{64}{\mathbf{R e}} .
$$

2. Whereas fully developed turbulent flow is predicted on the basis of figure A1 to only rarely occur in sampler nozzles, when $\boldsymbol{R e}>>2,300$ and $L>>L_{\text {ent-turb }}, f_{\mathrm{n}}$ is calculated for a smooth pipe using the equation of Blassius (Moody, 1944; Rouse, 1946) as:

$$
f_{\mathrm{n}}=f_{\text {turb }}=\frac{0.316}{\mathbf{R e}^{1 / 4}} .
$$

Because fully developed laminar flow is predicted to never occur and fully developed turbulent flow is predicted to only rarely occur in sampler nozzles, the ultimate accuracy of the physically based model for depth-integrating samplers depends largely on the extremely difficult problem of estimating $f_{\mathrm{n}}$ for the cases where the flow emerging from a sampler nozzle is developing laminar or developing turbulent flow.

Relatively few generalized relations exist in the literature for the estimation of the longitudinal pressure drop and associated apparent friction factor for regions of developing laminar flow in pipe entrances; no known generalized relations exist in the literature for the estimation of the longitudinal pressure drop and associated apparent friction factor for regions of developing turbulent flow in pipe entrances. For developing laminar flow, the only known relations are those in the heat-transfer literature for developing laminar flow in ducts; for example, the relations of Shah (1978), Yilmaz (1990), and Muzychka and Yovanovich (1998, 2009), developed on the basis of Shapiro and others (1954) and Bender (1969). These relations were developed for cases where the fully developed flow is laminar, therefore they cannot be used without modification when $\mathbf{R e}>2,300$. Because these relations produce similar results and the relation of Muzychka and Yovanovich (2009) is the simplest, the Muzychka and Yovanovich relation is used herein as a basis for modification of the apparent friction factor, $f_{\text {app}}$, relation we use for developing flow in sampler nozzles.

\footnotetext{
${ }^{19}$ For consistency, we have converted the original Muzychka and Yovanovich (2009) apparent friction factor relation from a Fanning-frictionfactor form to a Darcy-Weisbach-friction-factor form.
}

The Darcy-Weisbach-friction-factor form of the Muzychka and Yovanovich (2009) apparent-friction-factor relation, $f_{\mathrm{MY}},{ }^{19}$ written using our notation for sampler nozzles is:

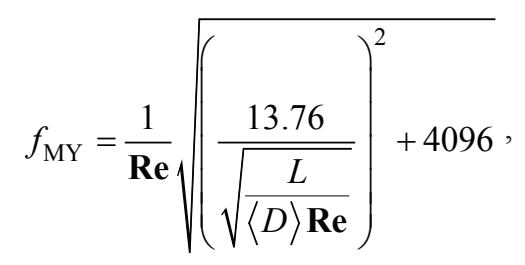

where the first term in quadrature is the square of the short-duct asymptote for the apparent friction factor for developing laminar flow, and the second term in quadrature, 4096, is the square of the long-duct asymptote of $f_{\text {lam }} \mathbf{R e}$ (the friction factor associated with fully developed laminar flow-Reynolds number product). The numerator in the first term in quadrature in equation A5 is determined on the basis of theory for the core velocity near the entrance of a circular duct; the denominator in this first term is the square root of the dimensionless duct entrance length. Muzychka and Yovanovich (2009) argue on the basis of Bejan (1995) that the square root of the dimensionless duct length is the appropriate scaling for this first term; we show that this approximation can be slightly improved for the case of developing flow in sampler nozzles.

Comparison of the developing-laminar-flow apparent friction factors, $f_{\mathrm{MY}}$, predicted by equation $\mathrm{A} 5$ with empirically determined apparent friction factors, $f_{\text {emp }}$, for the developing laminar and/or turbulent flow cases in the sampler-nozzle dataset indicates that the relation in equation $\mathrm{A} 5$ tends to slightly overpredict $f_{\text {emp }}$ when $\mathbf{R e}<2,000$, adequately predict $f_{\text {emp }}$ when $\sim 2,000<\mathbf{R e}<\sim 4,000$, and underpredict $f_{\text {emp }}$ when $\sim 4,000<\boldsymbol{R e}<\sim 10,000$ (fig. A2). In other words, although the mean magnitudes of $f_{\text {emp }}$ for each nozzle diameter are reasonably predicted by equation $\mathrm{A} 5, f_{\text {emp }}$ decreases more rapidly as a function of $\operatorname{Re}$ than do the values of $f_{\mathrm{MY}}$ for each nozzle diameter. The values of $f_{\text {emp }}$ used in this comparison were calculated on the basis of a rearranged version of equation 14 (where $f_{\text {emp }}$ is treated as the unknown). This rearranged version of equation 14 is written as:

$$
f_{\text {emp }}=\left(\frac{\langle D\rangle}{L}\right)\left(\frac{V^{2} k_{\mathrm{P}}+2 g \Delta z}{\left\langle\mathrm{~V}_{\mathrm{n}}\right\rangle^{2}}-1\right) .
$$

The data chosen for this comparison were the flume data for the US D-43 rigid-container sampler (FISP, 1952, figs. 40, 41) and the flume data for the US D-96 collapsible-bag sampler with the plastic and Teflon ${ }^{\circledR}$ development nozzles (Davis, 2001, figs. 9-14). These two datasets were chosen for this comparison because they have sufficient data that cover a wide range in $\mathbf{R e}$ and were collected using depth-integrating samplers with very different designs. 


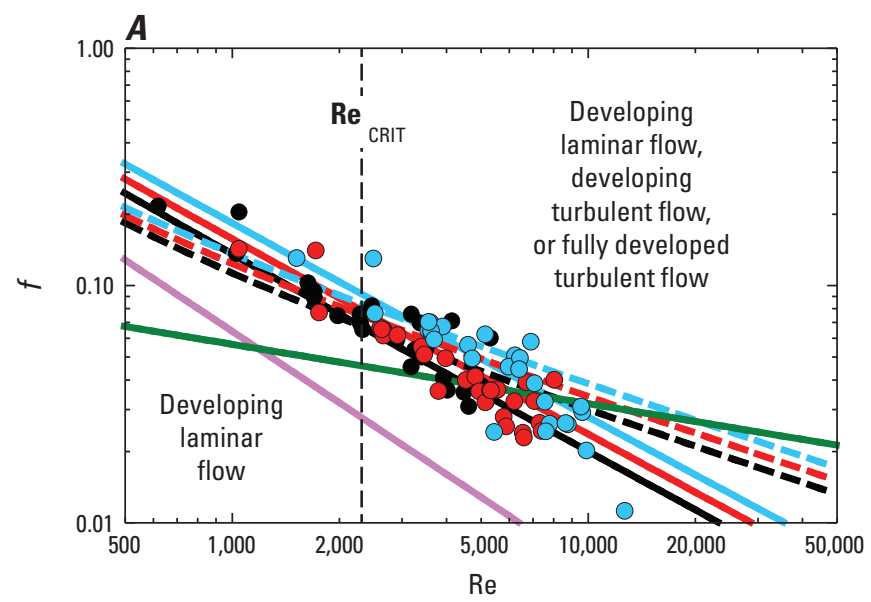

EXPLANATION
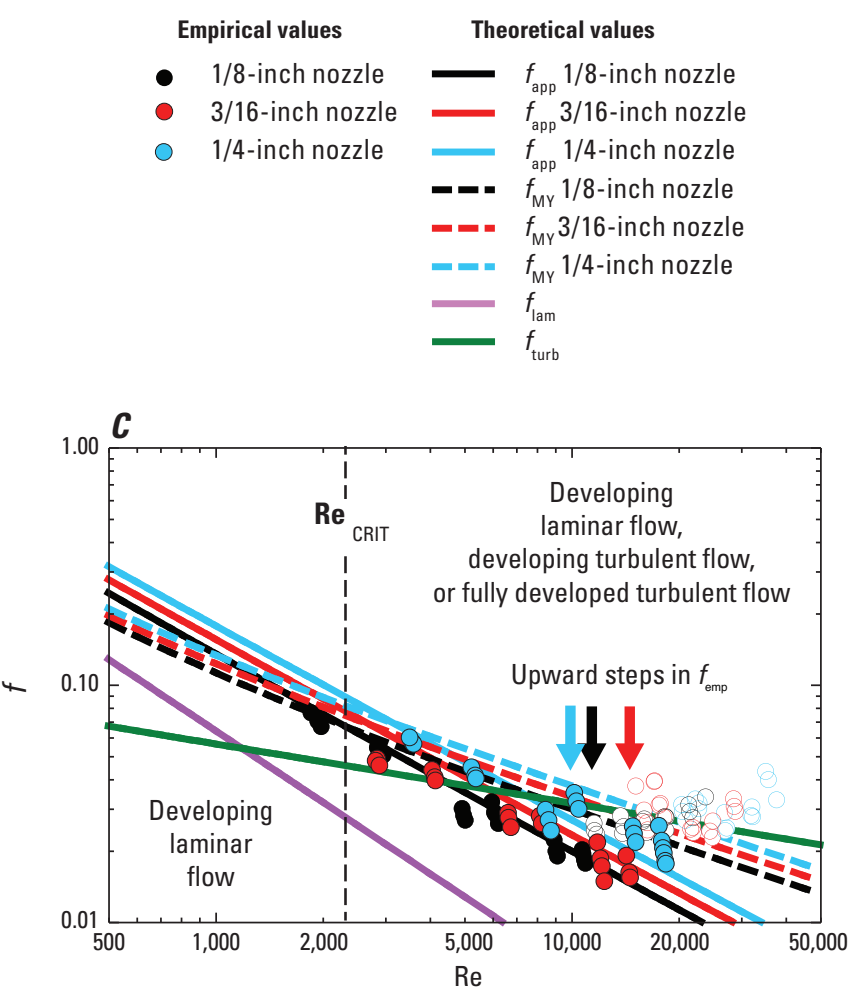

EXPLANATION

Empirical values

- Flume 3/16-inch nozzle

- Tow $3 / 16$-inch nozzle

- Flume $1 / 4$-inch nozzle Tow 1/4-inch nozzle

- Flume $5 / 16$-inch nozzle Tow 5/16-inch nozzle
Theoretical values

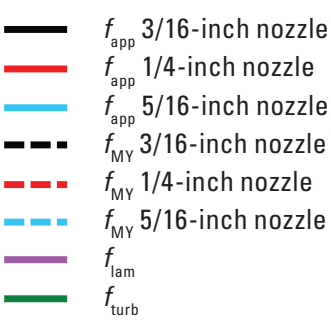

\section{$B$}

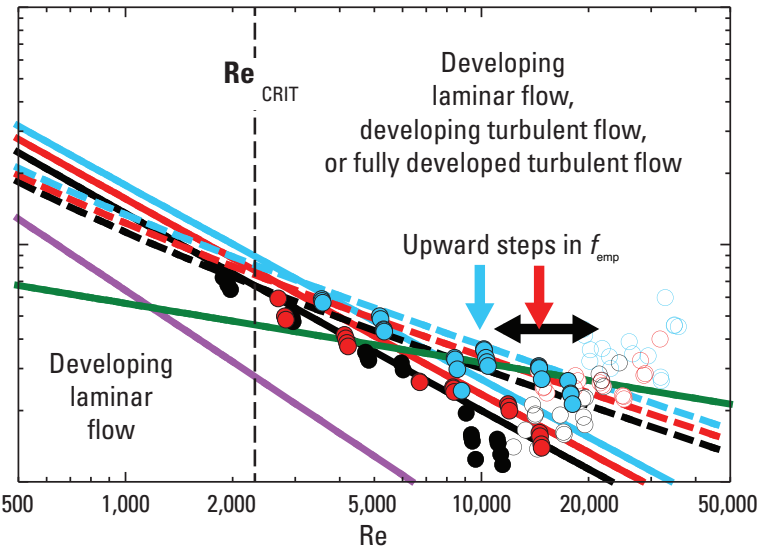

EXPLANATION
Empirical values

- Flume 3/16-inch nozzle Tow 3/16-inch nozzle

- Flume 1/4-inch nozzle Tow 1/4-inch nozzle

Flume $5 / 16$-inch nozzle Tow 5/16-inch nozzle

\section{Theoretical values}

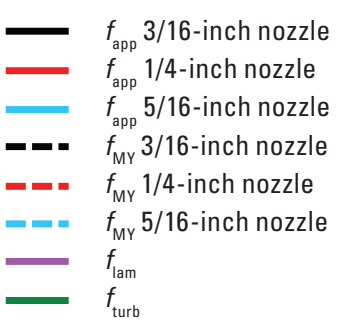

Figure A2. Comparison of empirical values, $f_{\text {emp }}$, with theoretical values of the friction factor for the flow inside a sampler nozzle plotted as a function of $\mathbf{R e}$. Theoretical values of $f$ shown are: $f_{\mathrm{MY}}$ for each nozzle diameter, $f_{\text {lam, }}$ and $f_{\text {turb }}$. Also shown are the values of $f_{\text {app }}$ modified from $f_{\mathrm{MY}}$ on the basis of the data in this figure. The value of $\mathbf{R e}_{\mathrm{CRIT}}$ separating the likely sampler-nozzle flow states is also indicated. (A) $f$-comparison for the US D-43 rigid-container-sampler dataset from $\operatorname{FISP}(1952$, figs. 40, 41) . (B) f-comparison for the US D-96 collapsible-bag-sampler flume- and tow-test plastic development-nozzle dataset from Davis (2001). (C) $f$-comparison for the US D-96 collapsible-bag-sampler flumeand tow-test Teflon development-nozzle dataset from Davis (2001). Bold arrows in $B$ and $C$ indicate approximate Re values at which upward steps in $f_{\text {emp }}$ occur in the 3/16-inch-nozzle dataset (black), 1/4-inch-nozzle dataset (red), and 5/16-inchnozzle dataset (blue). 
Because the results from this comparison indicate similar behavior in the discrepancies between $f_{\mathrm{MY}}$ and $f_{\text {emp }}$ for these two very different samplers, the data presented in figure A2 were used to modify equation A5 to provide a better fit with the observed behavior of $f_{\text {emp }}$. This best fit was obtained by modifying the short-duct asymptote (the first term in quadrature) in equation A5. This modification included (1) a dimensionless dependence on nozzle geometry in the numerator of this term, and (2) a reduction in the power of the exponent from $1 / 2$ to $1 / 5$ in the denominator of this term (the dimensionless duct entrance length). The dimensionless dependence on nozzle geometry in the numerator is included by multiplying 13.76 by a factor of $19 \sqrt{L /\langle D\rangle}$. The modified version of equation $\mathrm{A} 5$ is thus,

$$
f_{\text {app }}=\frac{1}{\operatorname{Re}} \sqrt{\left(\frac{\left.13.76\left(\sqrt[19]{\frac{L}{\langle D\rangle}}\right)\right)^{2}}{\left(\frac{L}{\langle D\rangle \mathbf{R e}}\right)^{1 / 5}}+4096\right.},
$$

which upon simplification becomes,

$$
f_{\text {app }}=\frac{1}{\operatorname{Re}} \sqrt{\left(261.44\left(\frac{\langle D\rangle}{L}\right)^{0.7} \mathbf{R e}^{1 / 5}\right)^{2}+4096}
$$

Predictions of $f_{\text {app }}$ calculated using equation A8 are shown in figure $\mathrm{A} 2$ for comparison with the predictions of $f_{\mathrm{MY}}$ calculated using equation A5.

As hypothesized above, the transition between developing laminar and turbulent flow inside a sampler nozzle appears to depend, for a given nozzle length, on nozzle diameter and Re. Evident in figures $\mathrm{A} 2 B-C$ are upward steps in the values of $f_{\text {emp }}$ occurring with increasing Re over the range in $\mathbf{R e}$ from $\sim 10,000$ to 21,500 , depending on nozzle diameter. The data in figure $\mathrm{A} 2 A$ do not extend to a large enough $\mathbf{R e}$ to show this effect. For each nozzle diameter, these upward steps in $f_{\text {emp }}$ roughly correspond to a shift from $f_{\mathrm{n}}$ being best characterized by the Darcy-Weisbach friction factor associated with developing flow, $f_{\text {app }}$, to $f_{\mathrm{n}}$ being best characterized by the Darcy-Weisbach friction factor associated with fully developed turbulent flow in smooth pipes, $f_{\text {turb }}$. The best constrained of these upward steps in $f_{\text {emp }}$ occurs at $\mathbf{R e} \approx 10,000$ in the US D-96 flume data for both the 5/16-inch plastic and Teflon ${ }^{\circledR}$ development nozzles. Unfortunately, the upward steps in $f_{\text {emp }}$ for the other diameter sampler nozzles typically coincide with changes in the laboratory method between flume and tow tests; therefore they are less well constrained because the tow-test data are less accurate than

\footnotetext{
${ }^{20}$ This value is weighted the least in the average below because the upward step in $f_{\text {emp }}$ is least well-defined for the 1/4-inch-nozzle dataset.
}

the flume-test data (after Davis, 2001) and these steps could merely reflect the change in laboratory method (as evidenced by the second upward step in the US D-96 flume data for both the 5/16-inch plastic and Teflon ${ }^{\circledR}$ nozzles coinciding with the change between flume and tow tests at $\mathbf{R e} \approx 20,000$ ). The style of the upward step in $f_{\text {emp }}$ in the US D-96 3/16-inch development-nozzle data is different depending on whether the nozzle is plastic or Teflon ${ }^{\circledR}$. For the plastic 3/16-inch development nozzle, the upward step in $f_{\text {emp }}$ occurs almost entirely within the tow-test part of the dataset and occurs gradually over the range in $\boldsymbol{R e}$ from $\sim 11,000$ to $\sim 21,000$. For the Teflon ${ }^{\circledR} 3 / 16$-inch development nozzle, the upward step in $f_{\text {emp }}$ coincides with the change between flume and tow tests and occurs abruptly at $\mathbf{R e} \approx 11,500$. On the basis of the assumption that the upward step in $f_{\text {emp }}$ is better defined by the plastic-nozzle data because it does not coincide with a change between laboratory methods, the upward step in $f_{\text {emp }}$ in the US D-96 3/16-inch development-nozzle data occurs therefore at an average value of $\mathbf{R e} \approx 16,000$. The upward step in $f_{\text {emp }}$ in the US D-96 1/4-inch development-nozzle data is the least constrained of the upward steps in $f_{\text {emp }}$ because, even though this upward step occurs at the same Re for both plastic and Teflon ${ }^{\circledR}$ nozzles, it is coincident with the change between flume and tow tests. This questionable upward step in $f_{\text {emp }}$ occurs at $\mathbf{R e} \approx 14,700$.

Evidence that these upward steps in $f_{\text {emp }}$ are associated with the transition between developing laminar and turbulent flow is provided in figure $\mathrm{A} 1 B$, where the Re values associated with these upward steps in $f_{\text {emp }}$ are relatively high and approximately correspond to values of $L_{\text {ent-turb }}$ that are either equal to or only slightly greater than $L$. For the 3/16-inch-nozzle dataset, the upward step in $f_{\text {emp }}$ at $\mathbf{R e} \approx 16,000$ occurs at a value of $L_{\text {ent-turb }} / L \approx 1.0$; for the $1 / 4$-inch-nozzle dataset, the upward step in $f_{\text {emp }}$ at $\mathbf{R e} \approx 14,700$ occurs at a value of $L_{\text {ent-turb }} / L \approx 1.3$; and for the 5/16-inchnozzle dataset, the upward step in $f_{\text {emp }}$ at $\mathbf{R e} \approx 10,000$ occurs at a value of $L_{\text {ent-turb }} / L \approx 1.5$. The approximate values of the dimensionless duct length, $L /(\langle D\rangle \mathbf{R e})$, associated with these upward steps in $f_{\text {emp }}$ is 0.0014 for the 3/16-inch-nozzle dataset, 0.0012 for the $1 / 4$-inch-nozzle dataset ${ }^{20}$, and 0.0014 for the 5/16-inch-nozzle dataset. Therefore, for the entire US D-96 development-nozzle dataset, the best approximation of the dimensionless duct length is $L /(\langle D\rangle \mathbf{R e}) \approx 0.0014$ at the transition from a friction factor best characterized by $f_{\text {app }}$ to a friction factor approximately equal to that for fully developed turbulent flow. In addition, because the dimensionless duct length theoretically should be constant at this transition, the transition to turbulence in the developing flow inside a sampler nozzle likely occurs at slightly higher $\mathbf{R e}$ for smaller diameter nozzles (as hypothesized above). Therefore, we impose a linear transition from $f_{\mathrm{n}}=f_{\text {app }}$ to $f_{\mathrm{n}}=f_{\text {turb }}$ over the range $0.0015>L /(\langle D\rangle \mathbf{R e})>0.0014$ in the physically based depth-integrated sampler model. 
On the basis of the analyses above, the following approach is used to estimate $f_{\mathrm{n}}$ across the entire range of flow conditions likely to occur inside a sampler nozzle: (1) equation $\mathrm{A} 8$ is used to estimate $f_{\mathrm{n}}$ at lower Re when $L /(\langle D\rangle \mathbf{R e}) \geq 0.0015$, (2) equation A4 is used to estimate $f_{\mathrm{n}}$ at higher $\mathbf{R e}$ when $L /(\langle D\rangle \mathbf{R e}) \leq 0.0014$ and the flow emerging from the sampler nozzle is likely to be either developing or barely fully developed turbulent flow, and (3) linear interpolation on the basis of $L /(\langle D\rangle \mathbf{R e})$ is used to smoothly match the values of $f_{\mathrm{n}}$ predicted by equations $\mathrm{A} 8$ and A4 when $0.0015>L /(\langle D\rangle \mathbf{R e})>0.0014$. The predicted behavior of $f_{\mathrm{n}}$ by this approach is similar to that observed by Moody (1944) for fully developed pipe flow, but with transitions in $f_{\mathrm{n}}$ occurring at different $\mathbf{R e}$ than the transitions in the Darcy-Weisbach friction factor for fully developed flow. As illustrated in figures A2 and A3, for a given nozzle geometry, as $\boldsymbol{R e}$ increases from $\sim 100$ to between $\sim 10,000$ and $16,000, f_{\mathrm{n}}$ decreases. Over this range in $\mathbf{R e}$, because the flow is developing, $f_{\mathrm{n}}$ is always much greater than $f_{\text {lam }}$ and, at lower $\mathbf{R e}$, is also much greater than $f_{\text {turb }}$. As $\mathbf{R e}$ continues to increase, $f_{\mathrm{n}}$ decreases to be slightly less than $f_{\text {turb }}$, and then over a narrow range in $\mathbf{R e}$ (between $\sim 10,000$ and 16,000 depending on nozzle geometry), a transition to turbulence in the developing flow likely occurs, and $f_{\mathrm{n}}$ abruptly increases to be equal to $f_{\text {turb }}$. Finally, as Re increases further, $f_{\mathrm{n}}$ remains equal to $f_{\text {turb }}$. This behavior is very similar to that in fully developed pipe flow, where as Re increases, a transition from laminar to turbulent flow occurs over the range in $\mathbf{R e}$ between $\sim 2,300$ and $\sim 4,000$, and the Darcy-Weisbach friction factor abruptly increases from $f_{\text {lam }}$ to $f_{\text {turb }}$.

Evaluations of this approach, through "in-sample" comparison of predicted $f_{\mathrm{n}}$ and measured $f_{\text {emp }}$, are provided in figure A3. Evaluations through independent "out-of-sample" comparisons of predicted $f_{\mathrm{n}}$ and measured $f_{\text {emp }}$ are provided in figure A4. The in-sample evaluation uses data used to help constrain $f_{\text {app }}$ in equations $\mathrm{A} 7$ and A8, that is, the US D-43 data and US D-96 development-nozzle data in FISP (1952, figs. 40, 41) and Davis (2001), and is therefore less independent than the out-of-sample evaluation that uses data not used to constrain $f_{\mathrm{n}}$. Data used in this out-of-sample evaluation are the US D-77 rigid-container-sampler data in FISP (1979), the US D-96 calibrated-nozzle warm and cold-water flume data in Davis (2001), and the US DH-2 collapsible-bag-sampler data in Davis (2005a).

The in-sample and out-of-sample evaluations of data presented in figures $\mathrm{A} 3$ and $\mathrm{A} 4$ indicate that our approach for estimating $f_{\mathrm{n}}$ produces reasonable results. Across the entire range of $\mathbf{R e}$ for all four depth-integrating samplers with all nozzles (a total of 1,050 cases among four depth-integrating samplers with very different designs), the geometric mean $f$ ratio of $f_{\mathrm{n}}$ to $f_{\text {emp }}$ is 1.04 (fig. A5). Furthermore, for each of the four depth-integrating samplers, the vast majority of all cases of the ratio of $f_{\mathrm{n}}$ to $f_{\mathrm{emp}}$ falls within a factor of $1.5 \times$ unity (where unity indicates perfect agreement between $f_{\mathrm{n}}$ and $f_{\text {emp }}$ ). This result suggests that our approach for estimating $f_{\mathrm{n}}$ works equally well for a wide range in depth-integrating-sampler design. By equation 12, because for a given nozzle geometry $f_{\mathrm{n}}$ changes as the square of $\left\langle V_{\mathrm{n}}\right\rangle$, the error in the ambient stream velocity, $V$, predicted by equation 15 , is typically much less than \pm 22 percent. In addition, the ratio of $f_{\mathrm{n}}$ to $f_{\text {emp }}$ is distributed symmetrically about unity suggesting that our approach to estimating $f_{\mathrm{n}}$ performs equally well across a broad range in Re. In any case, the agreement between $f_{\mathrm{n}}$ and $f_{\text {emp }}$ is deemed to be sufficiently good over a wide range in $\mathbf{R e}$ to proceed with using our generalized physically based model for depth-integrating samplers to model intake efficiency.

Evaluation of in-sample and out-of-sample comparisons between measured and model-predicted ambient stream velocities indicates that the model predictions are in good agreement with the measurements, and indicates that the model performs equally well for depth-integrating samplers with very different designs (figs. A6, A7). The modeled ambient stream velocities in figures A6 and A7 were calculated using equation 15 (in the main section of this report). In all cases, solution of equation 15 was accomplished after conversion of all units into centimeter, gram, and second units, with reconversion of $V$ into inch-pound-second units for consistency with the units used for velocity in this report. In addition to illustrating that the model performs well, analysis of the data plotted in figures A6 and A7 also indicates that the data collected in flume, tow, and transit tests are all internally consistent for each sampler with each nozzle (meaning that no systematic difference exists between the velocities in the different tests), with only one exception. Velocities measured in the transit tests conducted on the US D-96 sampler with standard nozzles differ from those measured in the flume tests conducted on the US D-96 sampler with standard nozzles by about 10 percent (figs. A7B-D). This discrepancy requires that either the nozzle-entrance velocities in these transit tests were measured $\sim 10$ percent high or that the ambient stream velocity (that is, boat velocity) in these transit tests were measured $\sim 10$ percent low. None of the other transit tests conducted on either the US D-96 sampler with the development nozzles or the DH-2 sampler show this discrepancy. Although Davis (2001) reported problems with "timing the sample and measuring the sample volume on a moving boat," it is unlikely that the nozzle-entrance velocities in these tests were measured with a consistent bias; because Davis (2001) also reported problems with maintaining "precise boat velocity control," it seems more likely that the boat velocities in these transit tests were measured $\sim 10$ percent low. This internal inconsistency in this dataset is more evident in figure 16 in the main section of this report. 


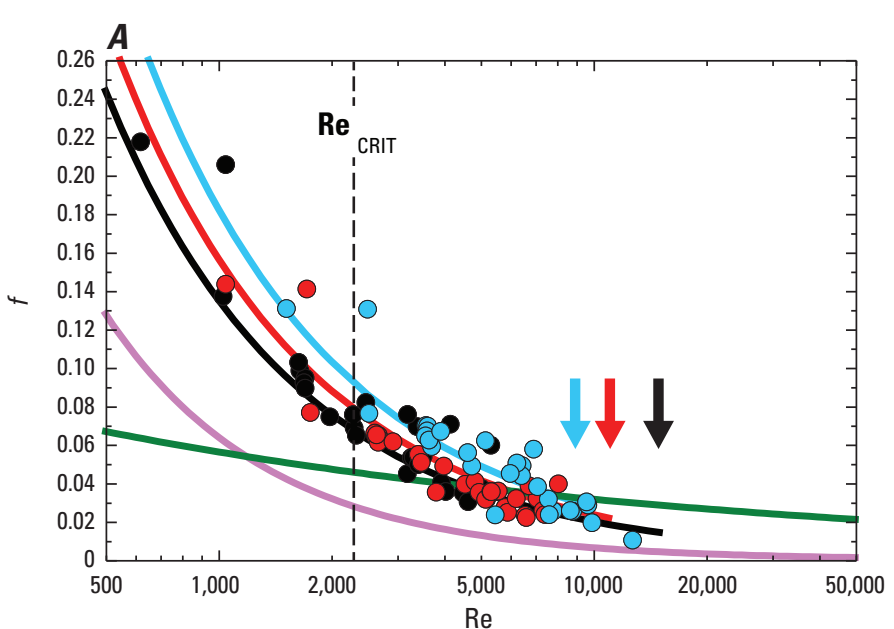

EXPLANATION

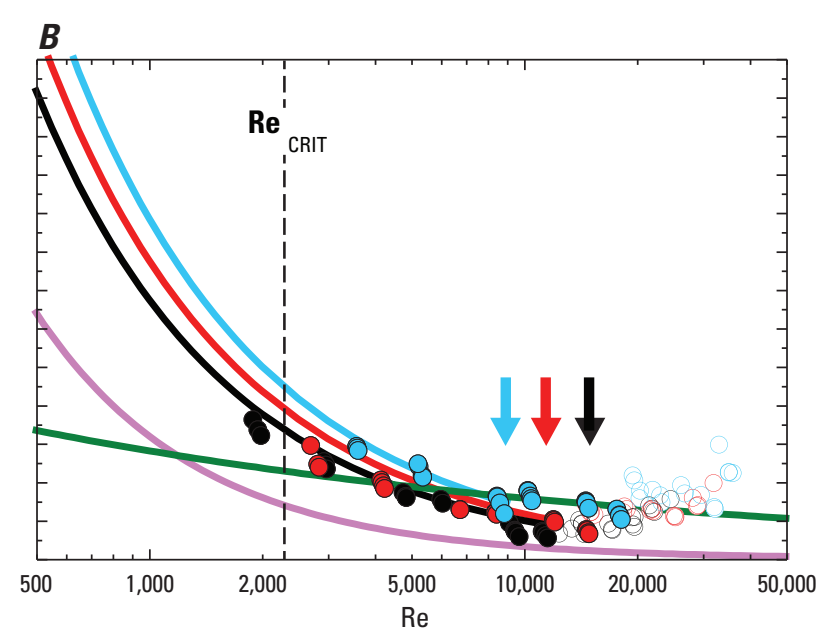

EXPLANATION

Empirical values Theoretical values

- Flume $3 / 16$-inch nozzle $f_{\text {app }} 3 / 16$-inch nozzle

Tow $3 / 16$-inch nozzle $\quad f_{\text {app }} 1 / 4$-inch nozzle

- Flume $1 / 4$-inch nozzle $\longrightarrow f_{\text {app }} 5 / 16$-inch nozzle

Tow $1 / 4$-inch nozzle $\quad f_{\text {lam }}$

- Flume $5 / 16$-inch nozzle $\longrightarrow f_{\text {turb }}$ Tow $5 / 16$-inch nozzle

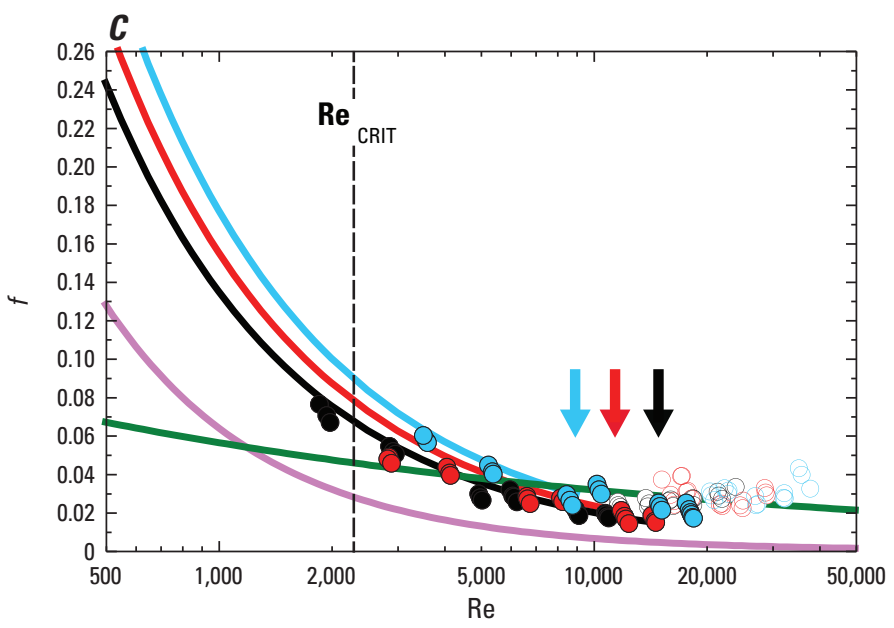

EXPLANATION
Empirical values

- Flume $3 / 16$-inch nozzle

Tow $3 / 16$-inch nozzle

- Flume $1 / 4$-inch nozzle Tow $1 / 4$-inch nozzle

- Flume $5 / 16$-inch nozzle Tow $5 / 16$-inch nozzle
Theoretical values

$f_{\text {app }} 3 / 16$-inch nozzle $f_{\text {app }} 1 / 4$-inch nozzle app $5 / 16$-inch nozzle $f^{\text {app }}$ turb
Figure A3. In-sample comparison of empirical and theoretical values of $f$ plotted as a function of Re. Values of $f_{\text {emp }}$ calculated using equation A6, values of $f_{\text {app }}$ calculated using equation $A 8$, values of $f_{\text {lam }}$ calculated using equation $A 1$, and values of $f_{\text {turb }}$ calculated using equation A2. Colored arrows indicate $\mathbf{R e}$ where $L /(D\rangle \mathbf{R e})=0.0015$ for each nozzle diameter; when $0.0015>L /(\langle D\rangle \mathbf{R e}\rangle>0.0014, f_{n}$ is estimated using linear interpolation between $f_{\text {app }}$ and $f_{\text {turb }}$ on the basis of $L(\langle D\rangle \mathbf{R e})$. Comparison of empirical and theoretical values of $f$ for the: $(A)$ US D-43 flume dataset from FISP [1952, figs. 40, 41]; (B) US D-96 plastic development-nozzle flume and tow-test dataset from Davis [2001]; and (C) US D-96 Teflon ${ }^{\circledR}$ development-nozzle flume and tow-test dataset from Davis [2001]. 


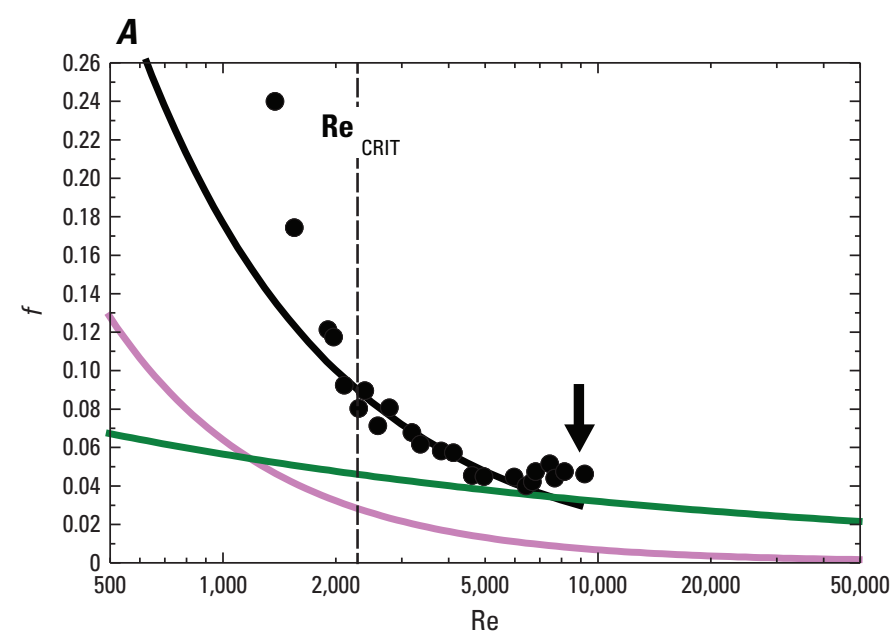

EXPLANATION
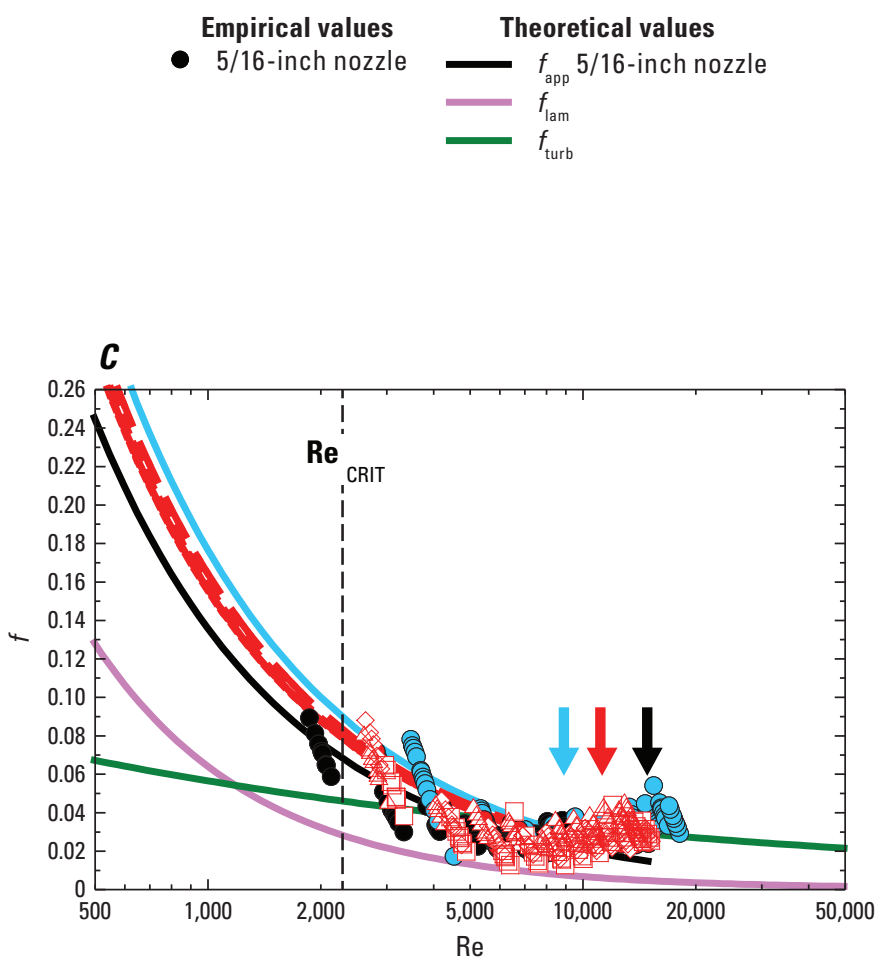

EXPLANATION

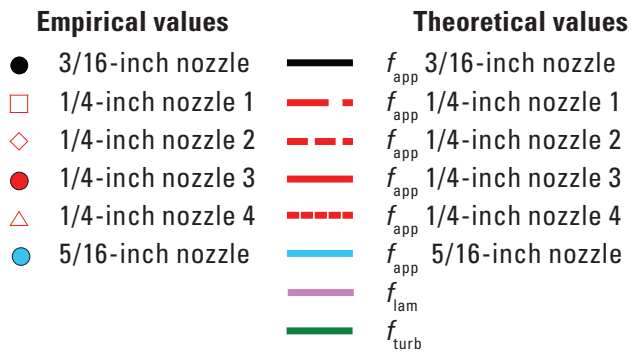

$B$

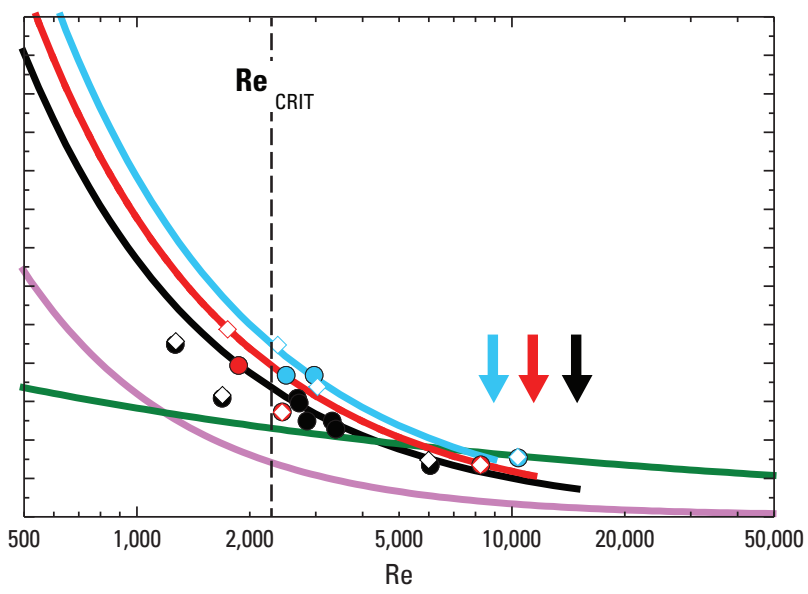

EXPLANATION

Empirical values Theoretical values

- 3/16-inch plastic nozzle $f_{\text {app }} 3 / 16$-inch nozzle

$\diamond 3 / 16$-inch Teflon nozzle $\longrightarrow \quad f_{\text {app }} 1 / 4$-inch nozzle

- 1/4-inch plastic nozzle $\quad f_{\text {app }} 5 / 16$-inch nozzle

$\diamond 1 / 4$-inch Teflon nozzle $\quad f_{\text {lam }}$

5/16-inch plastic nozzle $\quad f_{\text {turb }}$

5/16-inch Teflon nozzle

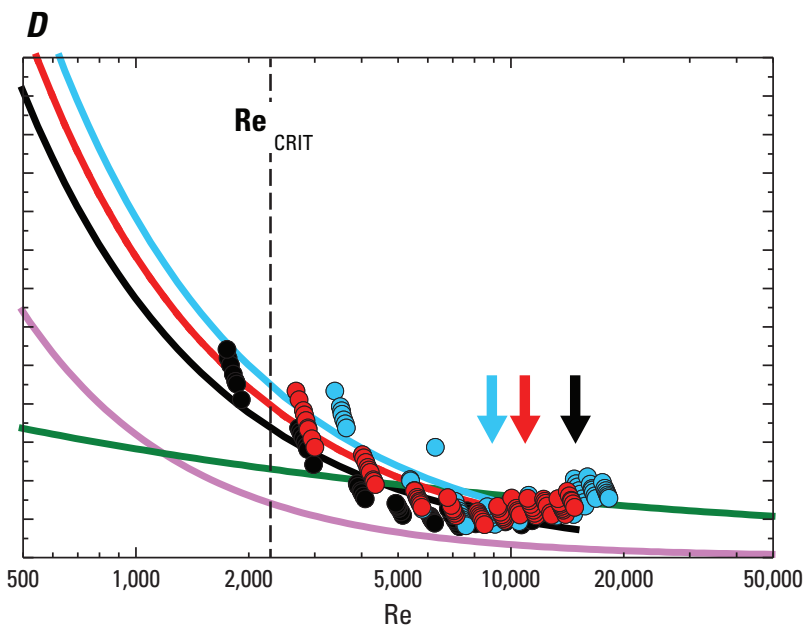

EXPLANATION

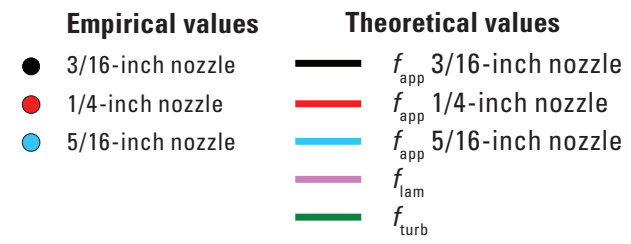

Figure A4. Out-of-sample comparison of empirical and theoretical values of $f$ plotted as a function of Re. Values of $f_{\text {emp }}$ calculated using equation $\mathrm{A} 6$, values of $f_{\text {app }}$ calculated using equation $\mathrm{A} 8$, values of $f_{\text {lam }}$ calculated using equation $\mathrm{A} 1$, and values of $f_{\text {turb }}$ calculated using equation A2. Colored arrows indicate $\mathbf{R e}$ where $L /(\langle D\rangle \mathbf{R e})=0.0015$ for each nozzle diameter; when $0.0015>L /(D\rangle \mathbf{R e})>0.0014, f_{\mathrm{n}}$ is estimated using linear interpolation between $f_{\text {app }}$ and $f_{\text {turb }}$ on the basis of $\left.L /\langle D\rangle \mathbf{R e}\right)$. Comparison of empirical and theoretical values of $f$ for the: (A) US D-77 flume dataset from FISP [1979]; (B) US D-96 plastic- and Teflon ${ }^{\circledR}$-calibrated-nozzle flume dataset from Davis [2001]; (C) US DH-2 plastic-nozzle flume dataset from Davis [2005a]; and (D) US DH-2 Teflon ${ }^{\circledR}$-nozzle flume dataset from Davis [2005a]. See table A1 for geometric details for US DH-2 1/4-inch nozzles 1-4. 


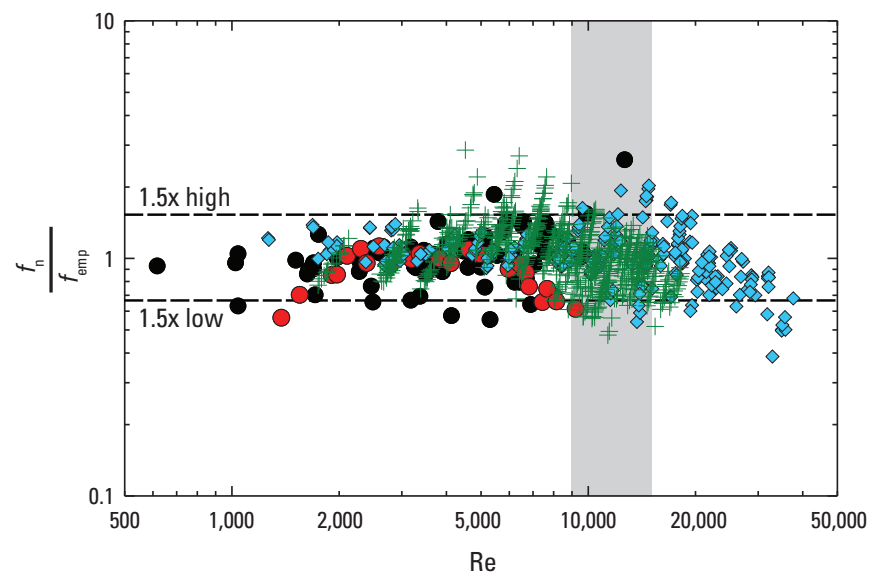

\section{EXPLANATION}

- US D-43: $n=90$, geometric mean $f$ ratio $=1.03$, $91 \%$ of cases within a factor of $1.5 \times$ of unity

- US D-77: $\mathrm{n}=23$, geometric mean $f$ ratio $=0.95$, $83 \%$ of cases within a factor of $1.5 \times$ of unity

$\diamond \quad$ US D-96: $\mathrm{n}=246$, geometric mean $f$ ratio $=1.04$, $89 \%$ of cases within a factor of $1.5 \times$ of unity

US DH-2: $\mathrm{n}=691$, geometric mean $f$ ratio $=1.05$ $87 \%$ of cases within a factor of $1.5 \times$ of unity

Figure A5. The $f$ ratio of $f_{\mathrm{n}}$ to $f_{\mathrm{emp}}$ plotted as a function of Re for all data shown in figures A3 and A4. Perfect agreement between $f_{\mathrm{n}}$ and $f_{\text {emp }}$ is indicated when this ratio is unity; threshold values of this ratio at factors of $1.5 \times$ above and below unity are indicated. Gray shaded region indicates $\mathbf{R e}$ region where $f_{n}$ is estimated using linear interpolation between $f_{\text {app }}$ and $f_{\text {turb }}$ on the basis of $\left.L /(D\rangle \mathbf{R e}\right)$. Predicted to observed ratios of any quantity are right-skewed distributions. To remove the right skew in the ratio of $f_{\mathrm{n}}$ to $f_{\text {emp }}$, the Y-axis in this figure is plotted in logarithmic space, and geometric means (not arithmetic means) are used to characterize the central tendencies of the $f_{n}$ to $f_{\text {emp }}$ ratios for each sampler.

Figure A6. (See opposite page.) In-sample comparison of measured and model-predicted values of the ambient stream velocity for the (A) US D-43 1/8-inch nozzle flume dataset; $(B)$ US D-43 3/16-inch nozzle flume dataset; (C) US D-43 1/4-inch nozzle flume dataset; $(D)$ US D-96 3/16-inch plastic and Teflon ${ }^{\circledR}$ development-nozzle flume, tow, and transit-test dataset; (E) US D-96 1/4-inch plastic and Teflon ${ }^{\circledR}$ development-nozzle flume, tow, and transit-test dataset; and (F) US D-96 1/4-inch plastic and Teflon ${ }^{\circledR}$ development-nozzle flume, tow, and transit-test dataset. US D-43 data are from FISP (1952, figs. 40-41); US D-96 data are from Davis (2001). For the US D-43 comparisons, watertemperature ranges for the various flume tests are indicated. All of the flume, tow, and transit tests of the US D-96 sampler were conducted at water temperatures ranging from 23.9 to 29.4 degree Celsius $\left({ }^{\circ} \mathrm{C}\right.$ ) (Davis, 2001); all model predictions of ambient stream velocity for these tests were made at the assumed average water temperature of $26.7^{\circ} \mathrm{C}$. For the US D-96 sampler, flume tests were conducted at ambient stream velocities $\leq 6 \mathrm{ft} / \mathrm{s}$ and tow tests were conducted at ambient stream velocities $>6 \mathrm{ft} / \mathrm{s}$ (Davis, 2001). 

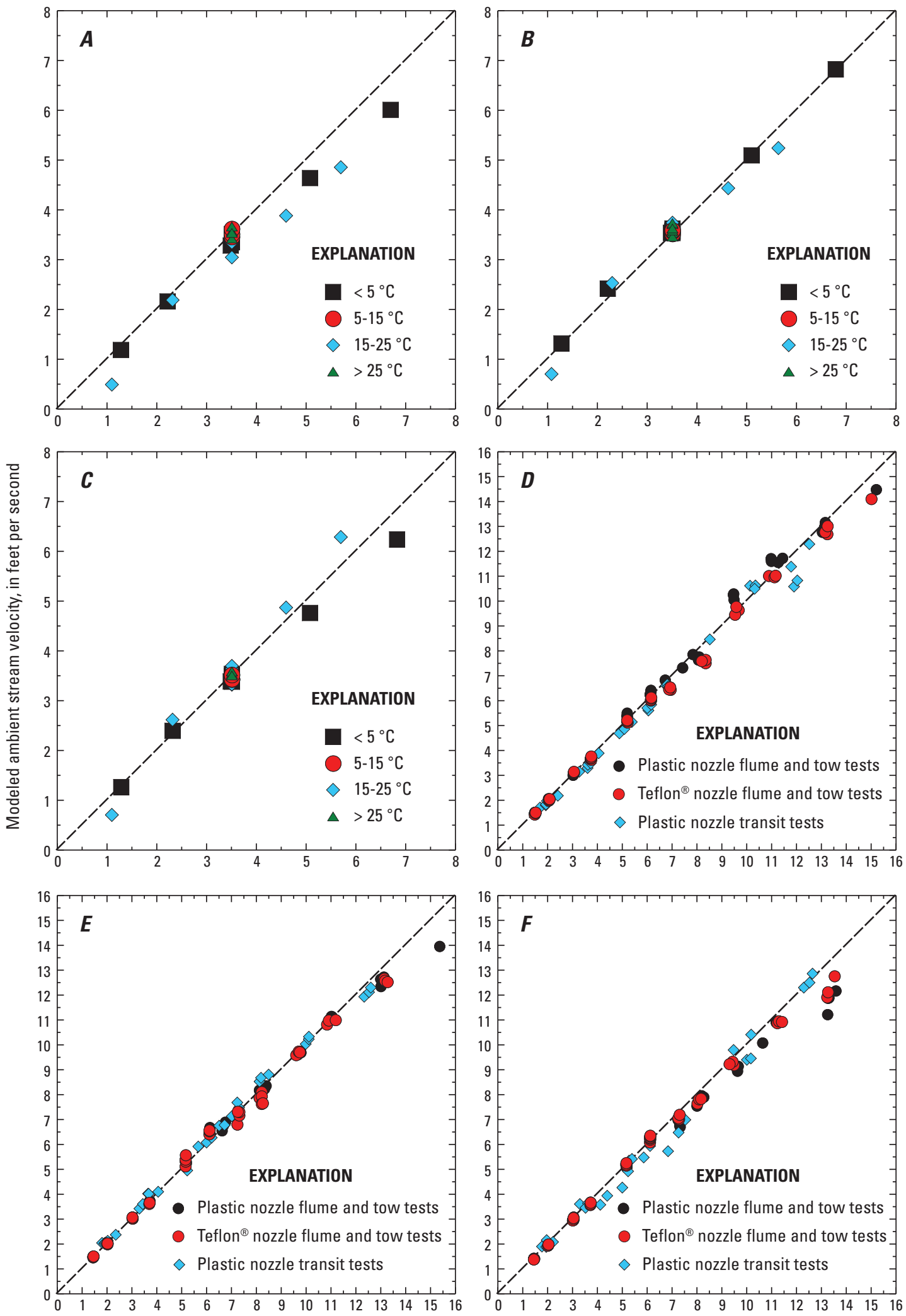

Measured ambient stream velocity, in feet per second

Figure A6. 


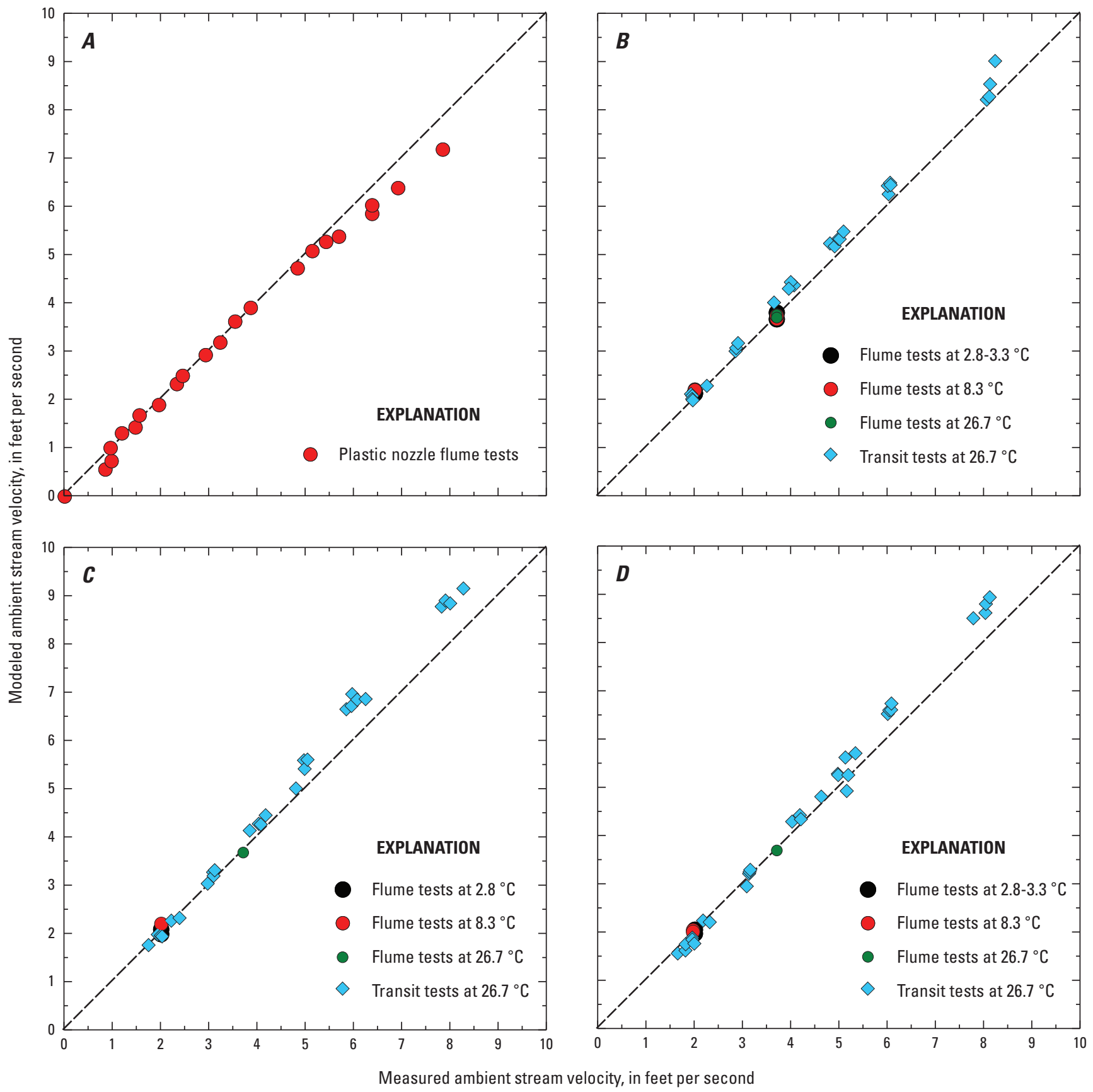

Figure A7. Out-of-sample comparison of measured and model-predicted values of the ambient stream velocity for the: (A) US D-77 5/16-inch nozzle flume dataset; (B) US D-96 3/16-inch nozzle flume and transit-test dataset; $(C)$ US D-96 1/4inch nozzle flume and transit-test dataset; (D) US D-96 5/16-inch nozzle flume and transit-test dataset; (E) US DH-2 3/16inch plastic and Teflon ${ }^{\circledR}$ nozzle flume and transit-test dataset; (F) US DH-2 1/4-inch plastic and Teflon ${ }^{\circledR}$ nozzle flume and transit-test dataset; $(G)$ US DH-2 1/4-inch plastic nozzles 1, 2, and 4 flume-test dataset; and $(H)$ US DH-2 5/16-inch plastic and Teflon ${ }^{\circledR}$ nozzle flume and transit-test dataset. US D-77 data are from Federal Interagency Sedimentation Project (FISP) (1979); US D-96 data are from Davis (2001); US DH-2 data are from Davis (2005a). The flume tests of the D-77 rigid-container sampler were conducted at a water temperature of 0.6 degree Celsius $\left({ }^{\circ} \mathrm{C}\right)(\mathrm{FISP}, 1979)$. All of the flume and transit tests of the US DH-2 sampler were conducted in water temperatures ranging from 23.9 to $29.4^{\circ} \mathrm{C}$ (Davis, 2005a); all model predictions of ambient stream velocity for these tests were made at the assumed average water temperature of $26.7^{\circ} \mathrm{C}$. 


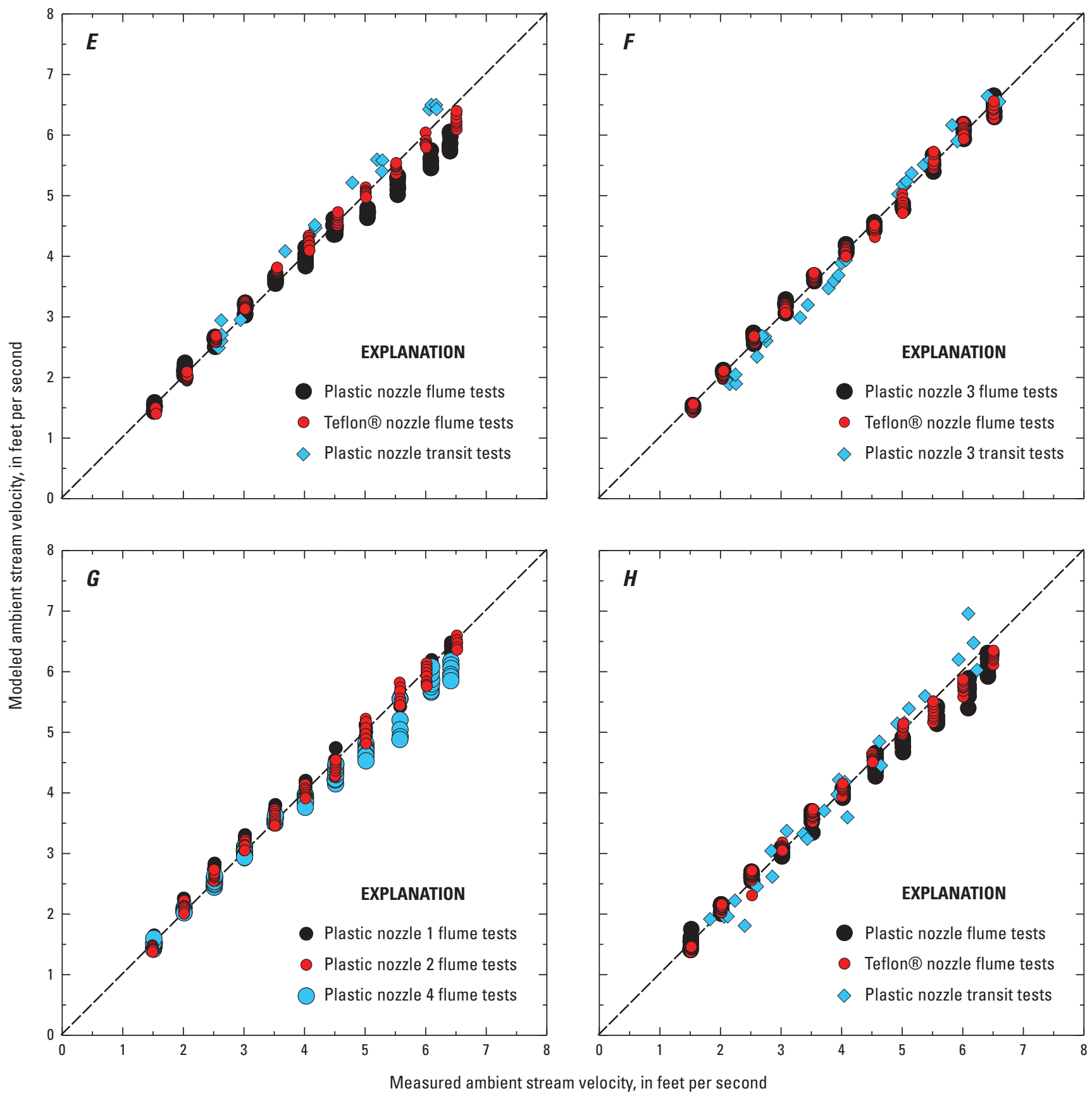

Figure A7.-Continued 
Following the in-sample and out-of-sample evaluations of the model, the model was used to evaluate, at different ambient stream velocities, the relative importance of the hydrostatic and dynamic pressure heads, between the nozzle entrance and air exhaust, on offsetting the effects of nozzle friction. The agreement between the model predictions and measurements in this first part of the analysis was excellent. This analysis was conducted by first using the data from FISP (fig. 1, 1979) collected using a US D-77 rigid-container sampler in a flume at a water temperature of $0.6^{\circ} \mathrm{C}$ to model and evaluate changes in intake efficiency arising from either changing the elevation of the air exhaust or changing the position of the air exhaust relative to the position of maximum flow acceleration around the body of the sampler. Because the FISP (1979) US D-77 dataset was not used in any way to constrain $f_{n}$ and is part of the out-of-sample evaluation in figure A7, this application of the model is robust and provides an accurate measure of the relative importance of the hydrostatic and dynamic pressure heads on offsetting the effects of nozzle friction. Comparisons of the measured and modeled velocities and intake efficiencies for the FISP (1979)

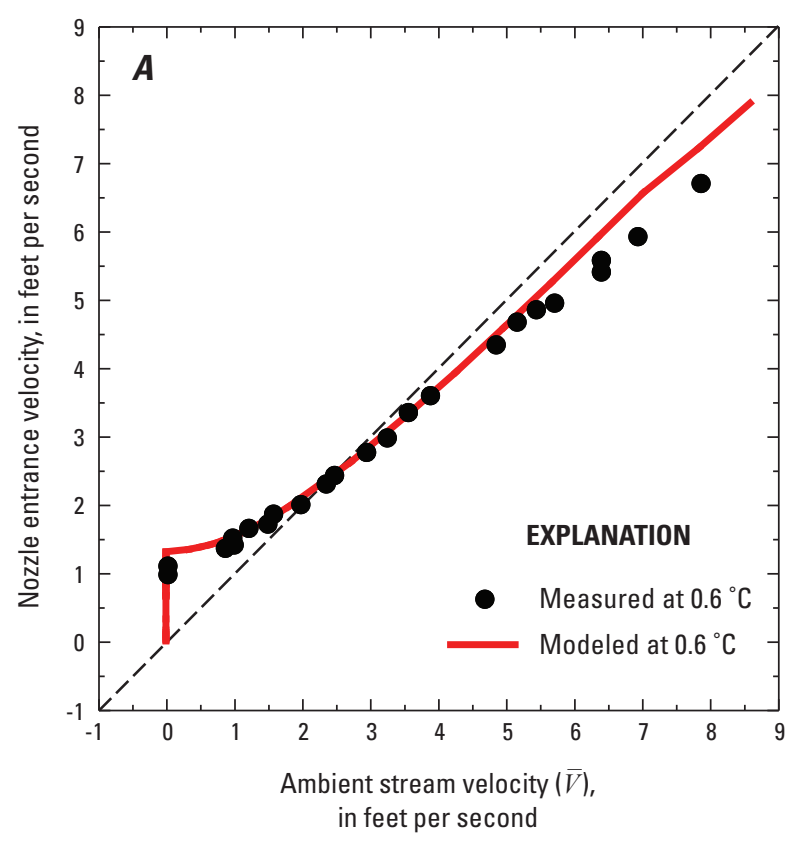

US D-77 dataset, provided in figure A8, illustrate the excellent performance of the model; the effects on intake efficiency of changing either the hydrostatic pressure head or the dynamic pressure head are illustrated in figure A9.

As shown in figure A9, changes in the hydrostatic pressure head have a greater effect on intake efficiency at lower ambient stream velocities than do changes in the dynamic pressure head, and changes in the dynamic pressure head have a greater effect on intake efficiency at higher ambient stream velocities than do changes in the hydrostatic pressure head. Therefore, at lower ambient stream velocities, the elevation difference between the nozzle entrance and either the air exhaust in a rigid-container sampler or the pressure-equalization hole in a collapsible-bag sampler provides the dominant mechanism for offsetting nozzle friction and allowing for isokinetic sampling. At higher ambient stream velocities, the position of the air exhaust in a rigid-container sampler or the vent holes in a collapsible-bag sampler, relative to the position of the flow acceleration around a sampler body, provides the dominant mechanism for offsetting nozzle friction and allowing for isokinetic sampling.

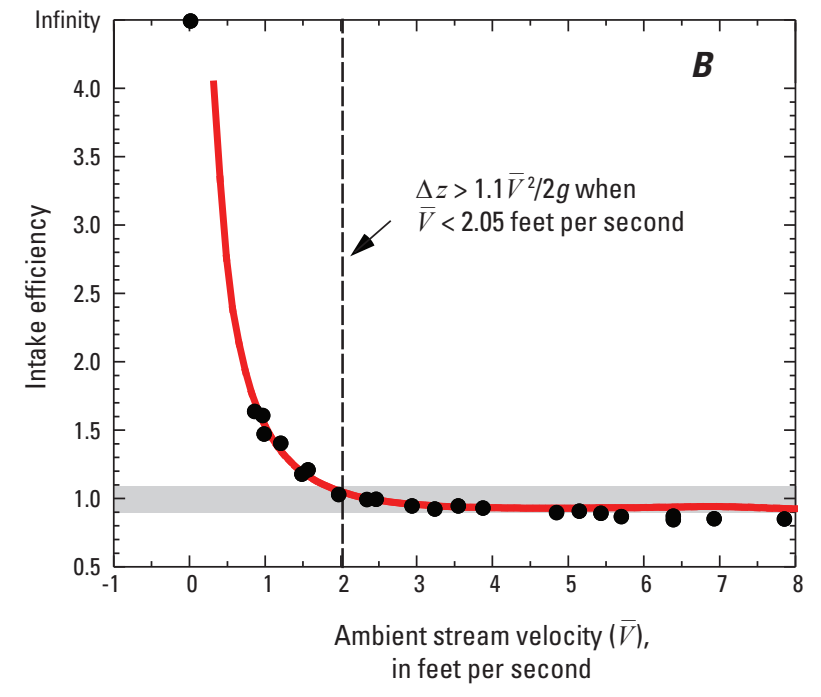

Figure A8. Comparison of measured and model-predicted velocities and intake efficiencies for the US D-77 rigid-container sampler. $(A)$ Nozzle velocity plotted as a function of ambient stream velocity. $(B)$ Intake efficiency plotted as a function of ambient stream velocity. Because of the relatively large value of the hydrostatic pressure head ( $\Delta z=0.8$ inch) associated with use of the US D-77 nozzle holder, the measured and modeled nozzle velocity for this sampler is not zero when the ambient stream velocity is zero, leading to the infinite intake efficiencies in $B$. Dashed line in $A$ indicates perfect isokinetic sampling; gray shaded region in $B$ indicates $1.0 \pm 0.1$ Federal Interagency Sedimentation Project (FISP) accepted range of isokinetic sampling. Dashed vertical line in $B$ indicates ambient stream velocity at which the hydrostatic pressure head equals the dynamic pressure head. To the left of this line, the hydrostatic pressure head dominates over the dynamic pressure head in offsetting the effects of nozzle friction, and, to the right of this line, the dynamic pressure head dominates over the hydrostatic pressure head in offsetting the effects of nozzle friction. 


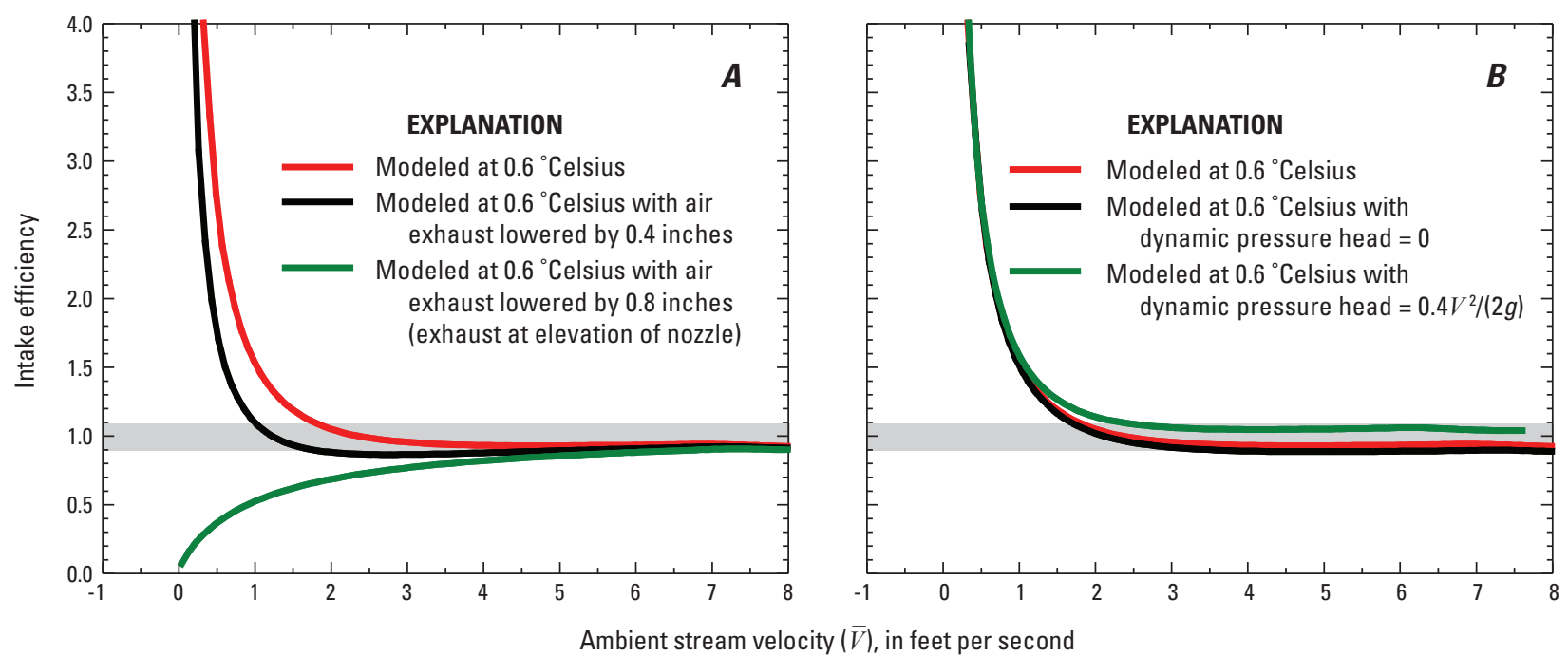

Figure A9. Plots showing the intake-efficiency effects of different elevations of the air exhaust above the nozzle entrance $(A)$ and different positions of the air exhaust relative to the position of flow acceleration around the outside of the sampler body $(B)$. Gray shaded regions indicate 1.0 \pm 0.1 Federal Interagency Sedimentation Project (FISP) accepted range of isokinetic sampling. In $A$, the red curve indicates the modeled intake efficiency at a water temperature of 0.6 degree Celsius $\left({ }^{\circ} \mathrm{C}\right)$ of samplers using the US D-77 nozzle holder, in which the air exhaust is located 0.8 inch above the nozzle entrance (this is the same red curve as in figure $A 8 B$ ). The other two curves in $A$ indicate the modeled intake efficiencies when the air exhaust is 0.4 inch (black) and 0 inch (green) above the nozzle entrance. In $B$, the red curve indicates the modeled intake efficiency at a water temperature of $0.6^{\circ} \mathrm{C}$ of samplers using the US D-77 nozzle holder, in which the air exhaust is located immediately behind the nozzle and upstream from most of the flow acceleration around the sampler body [that is, modeled with a dynamic pressure head of $0.1 \mathrm{~V}^{2} /(2 \mathrm{~g})$ ]. The other two curves in $B$ indicate the modeled intake efficiencies when the elevation of the air exhaust remains unchanged but the dynamic pressure head is either 0 (black) or equal to that associated with the maximum acceleration of flow around a streamlined submerged object (green). The green curve thus indicates the intake efficiencies that would exist at a water temperature of $0.6^{\circ} \mathrm{C}$ if the air exhaust on a US D-77 rigid-container sampler were located 0.8 inch above the nozzle entrance on the outside of the widest part of the sampler body (not immediately behind the nozzle).

To quantify the effect of water temperature on the nozzle taper depth required for isokinetic sampling, we used the model to calculate the taper depths required for isokinetic sampling at FISP-chosen ambient stream velocities for nozzles in US D-43, US D-77, US D-96, and US DH-2 samplers. Nozzles included in this evaluation were (1) for the US D-43 sampler, the 3-3/8-inch long brass nozzles with 1/8-, 3/16-, and 1/4-inch entrance diameters, (2) for the US D-77 rigid-container sampler, the 4-3/8-inch long plastic nozzle with a 5/16-inch entrance diameter ${ }^{21}$, (3) for the US D-77 nozzle holder mounted on a rigid-container sampler, the 4-3/8-inch long plastic and Teflon ${ }^{\circledR}$ US D-96 development nozzles with 3/16-, 1/4-, and 5/16-inch entrance diameters, (4) for the US D-96 sampler, the 4-3/8-inch long plastic and Teflon ${ }^{\circledR}$ nozzles with 3/16-, 1/4-, and 5/16-inch entrance diameters, and (5) for the US DH-2 sampler, the 4-3/8-inch long standard plastic and Teflon ${ }^{\circledR}$ nozzles with 3/16-, 1/4-, and 5/16-inch entrance diameters (see table A1 for detailed descriptions of nozzle geometry). This evaluation of taper depths was conducted by iteratively solving equation 15 for $L_{\mathrm{T}}$ for the condition where $V=V_{\mathrm{n}}$ over the range in water temperature from 0 to $30^{\circ} \mathrm{C}$. For each sampler, $V$ was held constant at the value of $V$ chosen by the FISP in the original flume calibration (3.5 ft/s for the US D-43 sampler, $2.4 \mathrm{ft} / \mathrm{s}$ for the US D-77 rigid-container sampler, $3.7 \mathrm{ft} / \mathrm{s}$ for the calibration of the US D-96 development nozzles inserted into a US D-77 nozzle holder mounted on a rigid-container sampler, and $3.7 \mathrm{ft} / \mathrm{s}$ for the US D-96 and DH-2 samplers). Results from this evaluation are plotted in figure A10. Plotted in figure A10 are (1) the modeled taper depths over the full 0 to $30^{\circ} \mathrm{C}$-range in water temperature that result in an intake efficiency of 1 at the FISP-chosen value of the ambient stream velocity, (2) the FISP empirically determined, that is, "measured," taper depths that result in an intake efficiency of 1 in a flume at a chosen water temperature and ambient stream velocity, and (3) the modeled intake efficiencies associated with the FISP-measured "isokinetic" taper depths.

\footnotetext{
${ }^{21}$ Because the taper depth for only the US D-77 5/16-inch nozzle is presented in FISP (1979), only this nozzle is included in this analysis.
} 

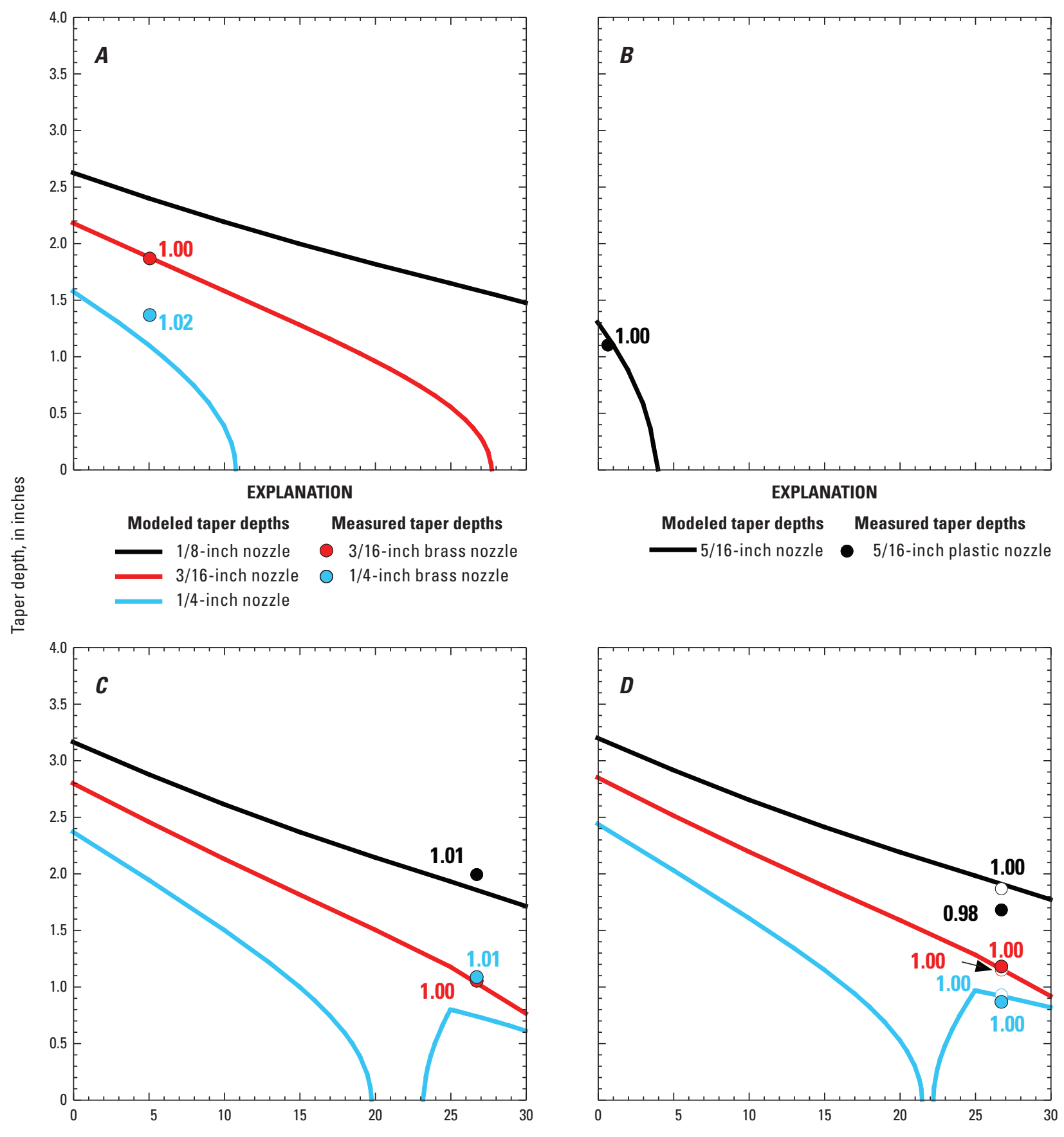

EXPLANATION

Modeled taper depths

3/16-inch nozzle

1/4-inch nozzle

5/16-inch nozzle
Measured taper depths

3/16-inch plastic and Teflon ${ }^{\circledR}$ nozzles

- 1/4-inch plastic and Teflon ${ }^{\circledR}$ nozzles

5/16-inch plastic and Teflon ${ }^{\circledR}$ nozzles

EXPLANATION

Modeled taper depths

3/16-inch nozzle

1/4-inch nozzle

5/16-inch nozzle
Measured taper depths

3/16-inch plastic nozzle

○ 3/16-inch Teflon® nozzle

- $1 / 4$-inch plastic nozzle

1/4-inch Teflon $\circledast$ nozzle

- 5/16-inch plastic nozzle 5/16-inch Teflon® nozzle

Figure A10. 


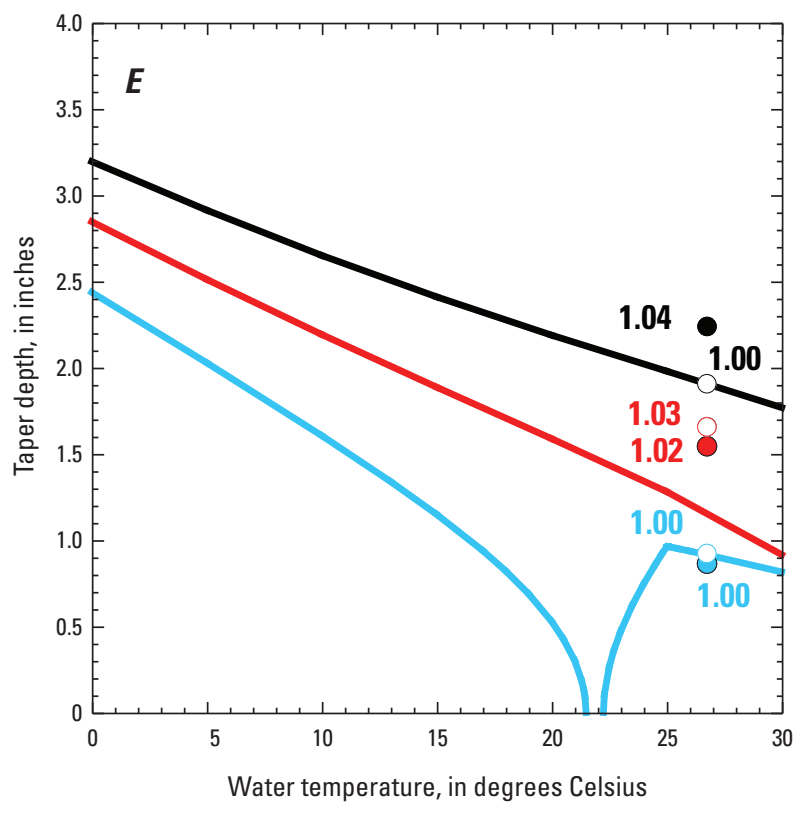

EXPLANATION

\begin{tabular}{ccc} 
Modeled taper depths & \multicolumn{2}{c}{ Measured taper depths } \\
3/16-inch nozzle & $\bullet$ & $3 / 16$-inch plastic nozzle \\
1/4-inch nozzle & $\bigcirc$ & $3 / 16$-inch Teflon ${ }^{\circledR}$ nozzle \\
5/16-inch nozzle & 0 & $1 / 4$-inch plastic nozzle \\
& $\bigcirc$ & $1 / 4$-inch Teflon ${ }^{\circledR}$ nozzle \\
& $\bigcirc$ & $5 / 16$-inch plastic nozzle \\
& & $5 / 16$-inch Teflon ${ }^{\circledR}$ nozzle
\end{tabular}

Figure A10. (See opposite page.) Comparisons of the modeled and Federal Interagency

Sedimentation Project (FISP) measured taper depths associated with an intake efficiency of 1 plotted as a function of water temperature at a fixed FISP-chosen ambient stream velocity. FISP-measured taper depths are listed in table A1. The bold number in the same color scheme as each discrete nozzle diameter, adjacent to a corresponding measured taper depth symbol on the plots, indicates the model-predicted intake efficiency associated with that taper depth. (A) US D-43 sampler modeled and measured brass-nozzle taper depths associated with an intake efficiency of 1 at $V=3.5 \mathrm{ft} / \mathrm{s}$ (feet per second). Measured taper depths are associated with intake efficiencies of 1 for 3/16- and $1 / 4$-inch nozzles at water temperatures of $\sim 2$ to $\sim 5$ degrees Celsius $\left({ }^{\circ} \mathrm{C}\right.$ ) (FISP, 1952, fig. 41 ); the 3 -inch taper depth for the 1/8-inch nozzle was too large to permit isokinetic sampling at any water temperature at this ambient stream velocity; modeled taper depths are calculated at a water temperature of $5^{\circ} \mathrm{C} .(B)$ US D-77 rigid-container sampler modeled and measured plastic-nozzle taper depths associated with an intake efficiency of 1 at $V=2.4 \mathrm{ft} / \mathrm{s}$ (feet per second). Measured taper depth is associated with an intake efficiency of 1 at a water temperature of $0.6^{\circ} \mathrm{C}$ (FISP, 1979). (C) Modeled and measured taper depths associated with an intake efficiency of 1 at $V=3.7 \mathrm{ft} / \mathrm{s}$ for the US D-96 plastic and Teflon ${ }^{\circledR}$ development nozzles mounted on a US D-77 rigid-container sampler. Measured taper depths are associated with an intake efficiency of 1 at a water temperature of 23.9-29.4 ${ }^{\circ} \mathrm{C}$ (Davis, 2001); modeled taper depths are calculated at a water temperature of $26.7^{\circ} \mathrm{C}$. (D) US D-96 sampler modeled and measured plastic- and Teflon ${ }^{\circledR}$-nozzle taper depths associated with an intake efficiency of 1 at $V=$ $3.7 \mathrm{ft} / \mathrm{s}$. Measured taper depths are associated with an intake efficiency of 1 at a water temperature of $23.9-29.4^{\circ} \mathrm{C}$ (Davis, 2001); modeled taper depths are calculated at a water temperature of $26.7^{\circ} \mathrm{C}$. (E) US DH-2 sampler modeled and measured plastic- and Teflon ${ }^{\circledR}$-nozzle taper depths associated with an intake efficiency of 1 at $V=3.7 \mathrm{ft} / \mathrm{s}$. Measured taper depths are associated with an intake efficiency of 1 at a water temperature of $23.9^{2}-29.4^{\circ} \mathrm{C}$ (Davis, 2005a); modeled taper depths are calculated at a water temperature of $26.7^{\circ} \mathrm{C}$. 
Results from this evaluation indicate excellent agreement between the modeled and FISP-measured nozzle taper depths that result in isokinetic sampling at the FISP-chosen ambient stream velocity and water temperature (fig. A10). This agreement is deemed excellent because, in the cases where the differences between the modeled and FISP-measured isokinetic taper depths are relatively large, the difference between the modeled and measured intake efficiency associated with the FISP-measured taper depth is extremely small. For example, the discrepancy between the modeled and FISP-measured isokinetic taper depth for the US DH-2 $1 / 4$-inch Teflon ${ }^{\circledR}$ nozzle is $1 / 2$ inch, whereas the discrepancy between the modeled and measured intake efficiency associated with the FISP-measured taper depth for this nozzle is only 3 percent, a value well within the error of either the measurements of $V$ or $V_{\mathrm{n}}$ in the FISP flume tests. As illustrated in figure A10, the taper depth required for isokinetic sampling at a given water temperature and ambient stream velocity is inversely proportional to the nozzle entrance diameter and, because the values of the hydrostatic and dynamic pressure heads are different for each sampler, these taper depths differ slightly between the different sampler models. Furthermore, at a given ambient stream velocity and nozzle entrance diameter, the taper depth required for isokinetic sampling is also inversely proportional to water temperature. In some cases, a nozzle may be too short to result in sufficient frictional losses for isokinetic sampling at a given water temperature and ambient stream velocity (indicated by the cases in figs. A10 $C-E$ where the model-predicted taper depth is $<0$ ). Upward steps in the modeled taper depths for the 5/16-inch nozzles in figs. A $10 C-E$ arise from the $f_{\mathrm{n}}$ transition from $f_{\text {app }}$ to $f_{\text {turb }}$ when $\left.0.0015>L /(D D\rangle \mathbf{R e}\right)>0.0014$. Smaller diameter nozzles do not exhibit this upward step in taper depth because flow conditions in these nozzles do not undergo this transition in $f_{\mathrm{n}}$ within the 0 to $30^{\circ} \mathrm{C}$ range in water temperature at the relatively low ambient stream velocities in figure A10. 
Publishing support provided by the U.S. Geological Survey Science Publishing, Menlo Park and Tacoma Publishing Service Centers

For more information concerning the research in this report, contact the Grand Canyon Monitoring and Research Center

U.S. Geological Survey

2255 N. Gemini Drive

Flagstaff, AZ 86001

http://www.gcmrc.gov 


\section{ख़्र}

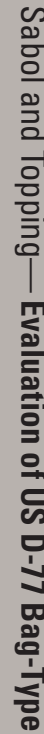

를

क

कू

동

옹 